Prepared for the U.S. Department of Energy under Contract DE-AC05-76RL01830

\title{
Modeling of GE Appliances in GridLAB-D: Peak Demand Reduction
}

JC Fuller

B Vyakaranam

N Prakash Kumar

SM Leistritz

GB Parker

April 2012

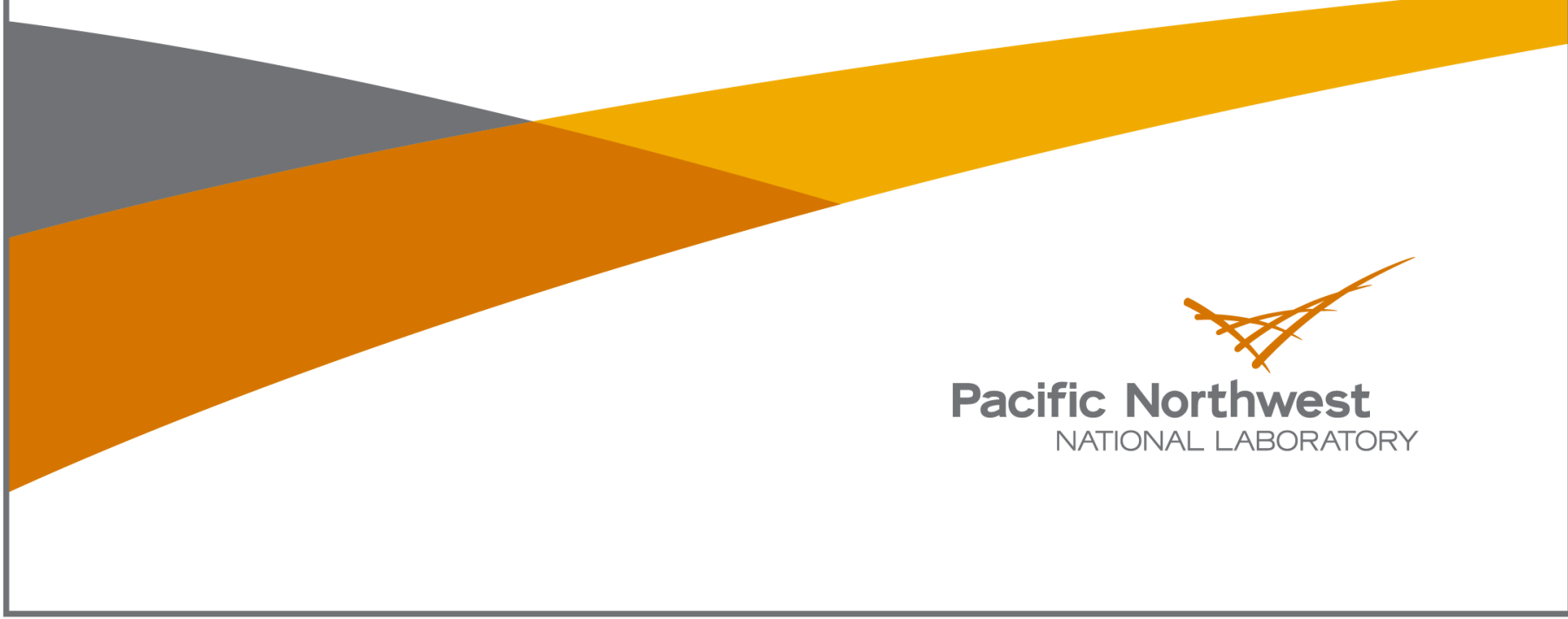





\title{
DISCLAIMER
}

This report was prepared as an account of work sponsored by an agency of the United States Government. Neither the United States Government nor any agency thereof, nor Battelle Memorial Institute, nor any of their employees, makes any warranty, express or implied, or assumes any legal liability or responsibility for the accuracy, completeness, or usefulness of any information, apparatus, product, or process disclosed, or represents that its use would not infringe privately owned rights. Reference herein to any specific commercial product, process, or service by trade name, trademark, manufacturer, or otherwise does not necessarily constitute or imply its endorsement, recommendation, or favoring by the United States Government or any agency thereof, or Battelle Memorial Institute. The views and opinions of authors expressed herein do not necessarily state or reflect those of the United States Government or any agency thereof.

\author{
PACIFIC NORTHWEST NATIONAL LABORATORY \\ operated by \\ BATTELLE \\ for the \\ UNITED STATES DEPARTMENT OF ENERGY \\ under Contract DE-AC05-76RL01830
}

Printed in the United States of America
Available to DOE and DOE contractors from the Office of Scientific and Technical Information,
P.O. Box 62, Oak Ridge, TN 37831-0062;
ph: (865) 576-8401
fax: $(865)$ 576-5728
email: reports@adonis.osti.gov

\begin{abstract}
Available to the public from the National Technical Information Service, U.S. Department of Commerce, 5285 Port Royal Rd., Springfield, VA 22161 ph: (800) 553-6847 fax: $(703) 605-6900$ email: orders@ntis.fedworld.gov online ordering: http://www.ntis.gov/ordering.htm
\end{abstract}

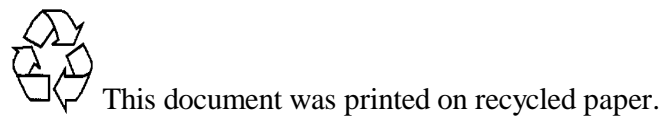




\section{Modeling of GE Appliances in GridLAB-D: Peak Demand Reduction}

JC Fuller

B Vyakaranam

N Prakash Kumar

SM Leistritz

GB Parker

February 2012

Prepared for

the U.S. Department of Energy

under Contract DE-AC05-76RL01830

Pacific Northwest National Laboratory

Richland, Washington 99352 


\section{Summary}

The widespread adoption of demand response (DR) enabled appliances and thermostats can result in a significant reduction to peak electrical demand and provide potential grid stabilization benefits. GE Appliances has developed a line of appliances that will have the capability of offering several levels of demand reduction actions based on information received from the utility grid, often in the form of price or grid status. However due to a number of factors, including the number of DR-enabled appliances available at any given time, the reduction of diversity factor due to the synchronizing control signal, and the percentage of consumers who may override the utility signal, it can be difficult to predict the aggregate response of a large number of residences. The effects of these behaviors can be modeled and simulated in the Pacific Northwest National Laboratory (PNNL) developed open-source software, GridLAB-D ${ }^{\mathrm{TM}}$, including evaluation of the appliance controls, improvement to current algorithms, and development of aggregate control methodologies.

This report is the first in a series of three reports describing the potential of GE Appliances' DR-enabled appliances to provide benefits to the utility grid. The first report will describe the modeling methodology used to represent the appliances in the GridLAB-D simulation environment and the estimated potential for peak demand reduction at various deployment levels. The second and third reports will explore the potential of aggregated group actions to positively impact grid stability, including frequency and voltage regulation and spinning reserves, and the impacts on distribution feeder voltage regulation, including mitigation of fluctuations caused by high penetration of photovoltaic distributed generation and the effects on volt-var control schemes.

In Section 2, the effects and potential benefits of appliances on the power system were studied by modeling GE Appliances' DR-enabled appliances in GridLAB-D. GridLAB-D is an open-source, state-of-the-art software designed at PNNL for the Department of Energy's Office of Electricity Delivery and Energy Reliability to simulate the complexities of the smart grid from the substation down to the end-use load. Multi-state appliance models were used to represent not only the baseline instantaneous power demand and energy consumption, but the control systems developed by GE Appliances. This enabled the modeled appliances to respond to load reduction signals, as well as the change in behavior of the appliance in response to the signal. This included the power and energy consumption and the time horizon over which they operate for the various operational modes, and how changes in the DR control signal affect load behavior. This gives insight into the potential for short term versus longer term reduction in power consumption, and allows for exploration of different DR control signals without developing a new model for each case. Additionally, it gives insight into how to improve the effectiveness of the DR-enabled appliances across various time horizons. 
The GE Appliances are designed to automatically respond to a control signal (analogous to price), while engaging the customer through a visual interface and various override actions. This is a key to acceptability with customers, operating under the principle of automating as many response actions as possible without circumventing the customer's freedom to choose to override the response strategy and operate normally. Currently, each of the appliances respond to Normal, High, and Critical control signals, analogous to a two-rate Time-of-Use (TOU) program with a Critical Peak Price (CPP) overlay. In general, when the price of electricity increases, the customer is presented with three choices: delay operation to a later time when prices are cheaper; enter an Energy Savings mode (ES-mode), but continue operation; or override the load reduction and operate normally. When the customer is not present, the appliance defaults to either energy savings or delay of operation, depending upon the control signal and particular appliance settings. Again, this blends the advantages of automated responses with customer choice.

This adds a layer of complexity to the simulation of the appliance response; how many customers override the DR operation versus delay operation? These were designed as inputs into the model. Survey data from GE Appliances' field studies were used to approximate the responsiveness of customers. However for some appliances, a number of scenarios were tested to observe the effects of human interaction.

It was also apparent through the simulation of the appliance models that the methods for releasing appliances back to normal operation after a high or critical event was just as important as the methods for creating the reduction in the first place. Reduction of appliance load over extended time periods (two to six hours) led to a significant decrease in the diversity factor of the population of appliances. This led to an increase in load immediately following a reduction in the price of electricity, often to a level higher than the original peak. This is commonly referred to as a rebound, as all of the appliances which deferred processes attempt to turn back on at the same time. Effectively, the price signal acts a synchronizing control signal activating all of the appliances at the same time. To mitigate this effect, GE Appliances developed a number of "release options" which were explored in the simulation environment. In general, this included randomization of restart times across the population (e.g., dryer 1 restarts 5 minutes after the price reduction while dryer 2 restarts 10 minutes after) or a transition into an energy savings mode, depending upon the type of appliance and the customer's previous choice.

To test the response of the appliances to a DR signal, prototypical test feeders available with GridLAB-D were used that contained a population of residential building models (single-family home). Each home contained a dryer model (and of each of the other appliances), each with their own subset of parameters and usage patterns. To create a base case which represented a realistic scenario, load shapes from the End-Use Load and Consumer Assessment Program (ELCAP) load study are used to estimate the usage pattern of the appliances at different times, during the course of an average day. While the confidence in this data source has waned since the end-use metering study was performed in the 1980s, most other studies are either unavailable or too small 
for generalization. As an example, Figure S-1 shows the ELCAP electric dryer load shapes for an average winter and summer weekday and weekend. The load shapes are used to "schedule" the dryer usage throughout the population of devices, so that the average energy consumed during each hour of the simulation approximately equals the average hourly energy consumption of the ELCAP load shapes for each season and day type. This means that annual energy consumption of the simulated dryers matched annual energy consumption data from the ELCAP load study. However, since appliances have generally become more efficient since the ELCAP load study was performed, where appropriate, adjustments were made so that annual energy consumption matched current information. This resulted in the simulated dryer population matching the relative pattern of the ELCAP load shapes for each season (summer vs. winter), day type (weekday vs. weekend), and hourly (noon vs. six p.m.) while matching the annual energy consumption to available updated information. A more detailed description of the methodology to calibrate the simulations to ELCAP load shapes is presented in Appendix B.

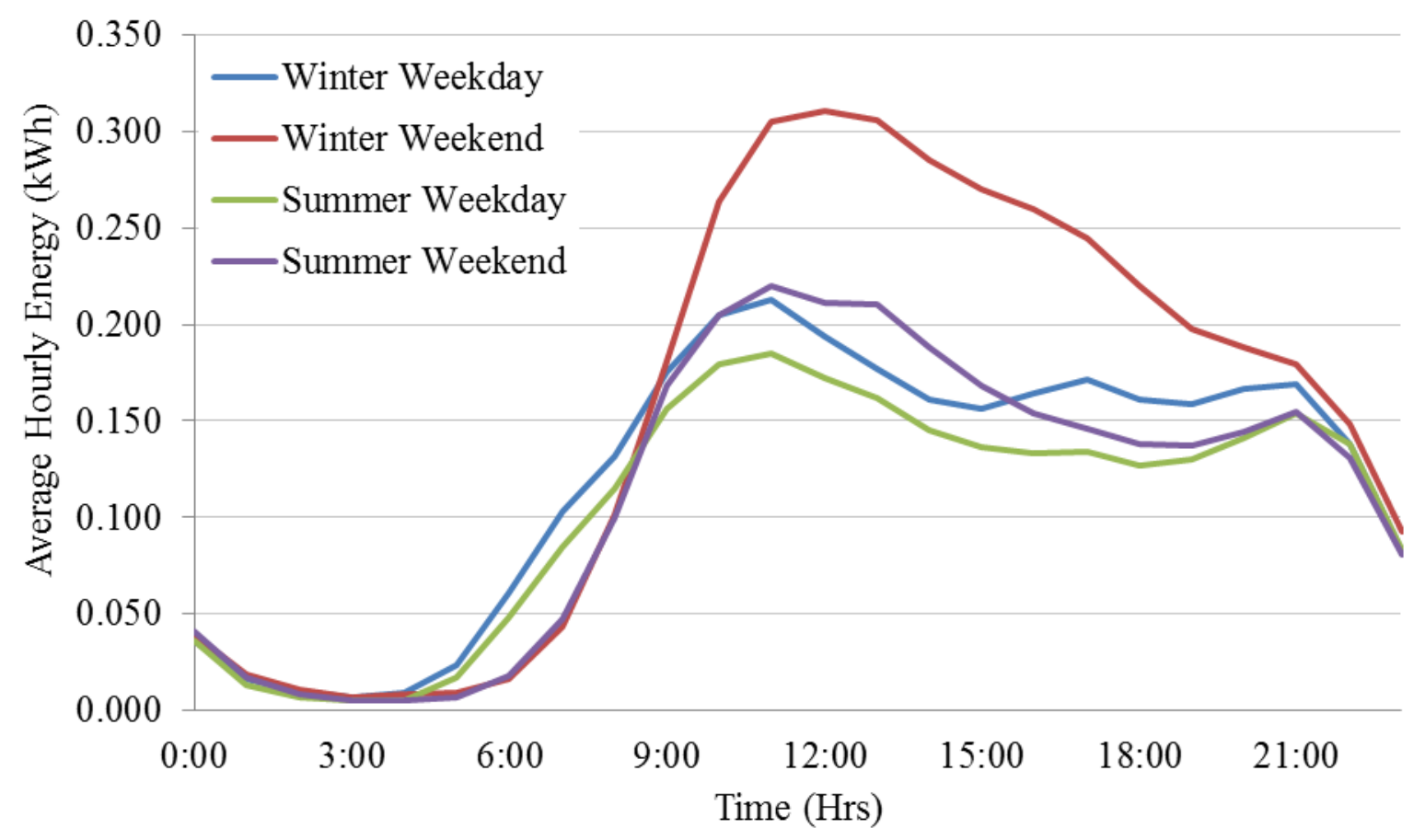

Figure S-1: ELCAP load shapes for the electric clothes dryer.

As an example, the first model explored was the dryer model. As this was both GE Appliances' introduction to GridLAB-D and its modeling capabilities and PNNL's introduction to GE Appliances' DR strategies, a number of simulations were performed using a variety of inputs and parameters. Figure S-2 shows an example simulation of 544 dryers, where the Normal 
(or base) case is calibrated to the ELCAP load studies via the previously described method. A TOU plus CPP signal is then applied to subsequent cases. In this case, it is assumed that $25 \%$ of customers delay operation, $70 \%$ choose the ES-mode, and 5\% choose to override the DR operation. Release Option 1 represents the case where all deferred dryer cycles immediately start when the price signal returns to Normal. Release Options 2 and 3 show the effects of a uniformly randomize restart ( 0 to 48 minutes and 0 to 72 minutes, respectively). First, notice that the peak demand within the High/Critical period has been reduced by approximately $45 \%$. Second, notice that without randomization, the rebound peak is over $200 \%$ of the original peak, while randomization reduces this to less than $135 \%$. This indicates that the release option greatly affects the rebound.

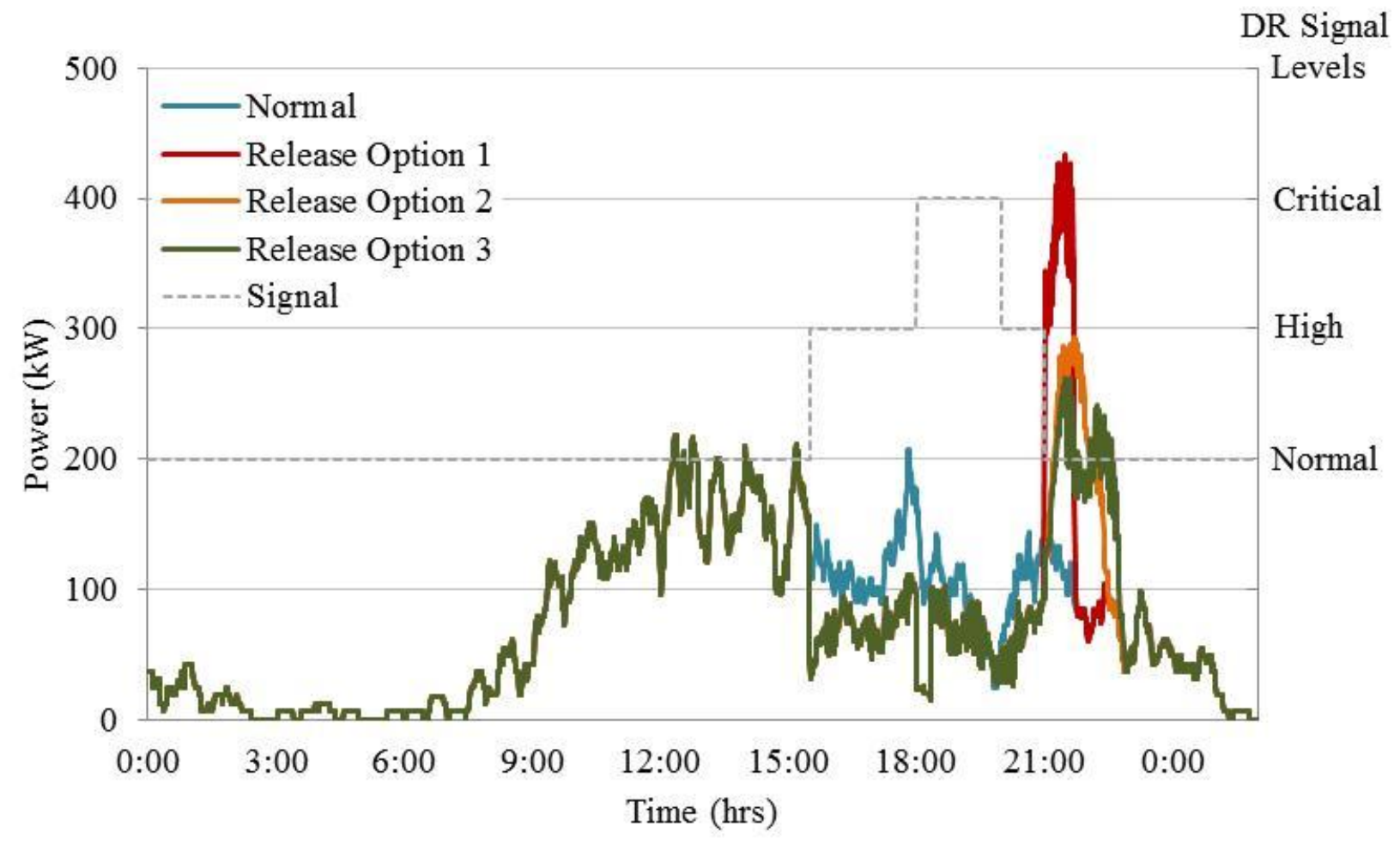

Figure S-2: Time series of clothes dryer load, example case 1.

To study the effects of customer interaction, the same case was simulated, except the customer behavior is modified. In this case, more customers choose delay (75\%), fewer choose ES-mode (20\%), and the same number override (5\%); all other options are held constant. Figure S-3 demonstrates the time series results. 


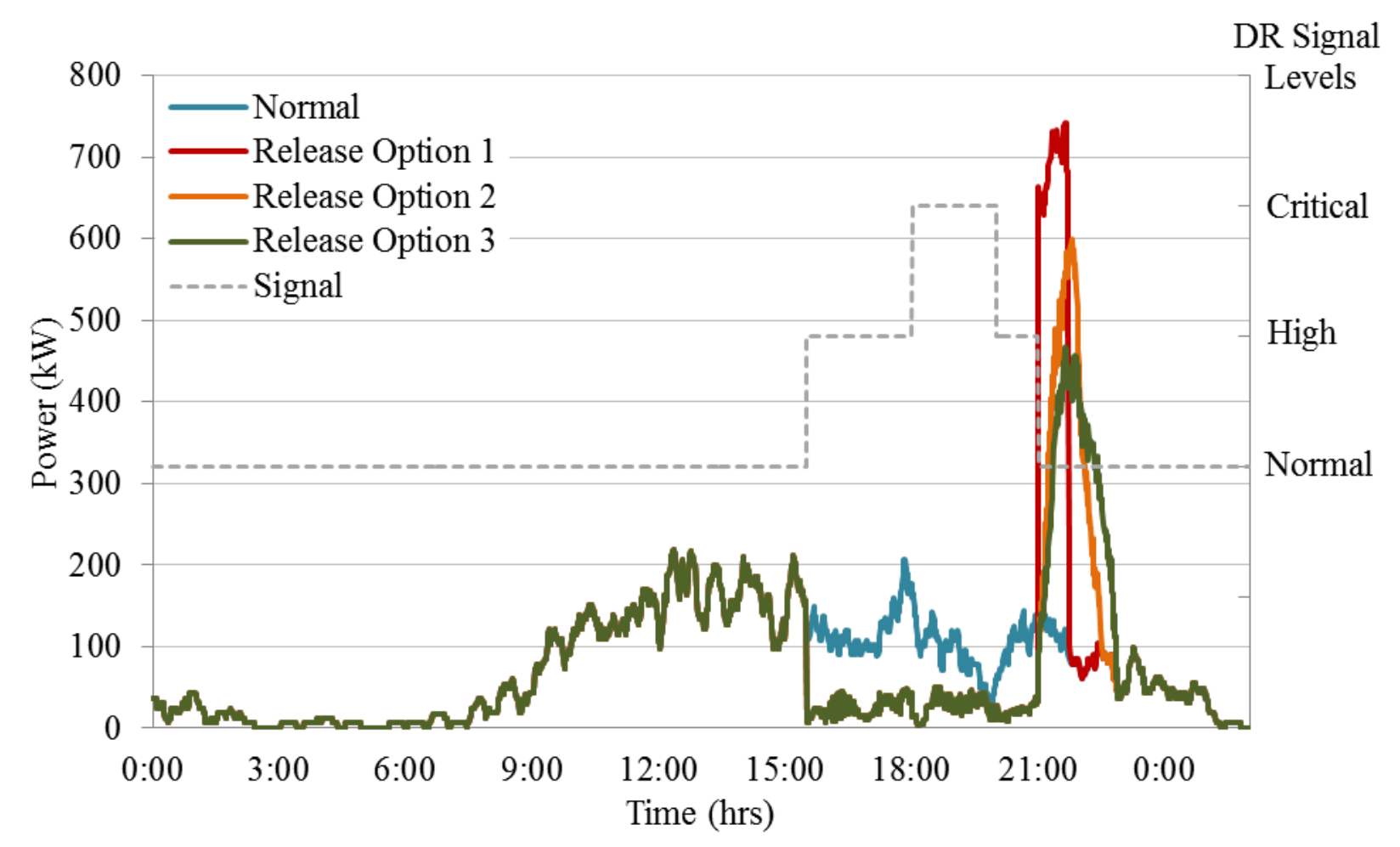

Figure S-3: Time series of clothes dryer load, increased customer participation.

In this case, since customers have effectively increased their participation in the load reduction during the High and Critical price periods, the peak demand during that period has been reduced by nearly $75 \%$ (as compared to $45 \%$ previously). However, the secondary effect is that the peak rebound is significantly greater than before, nearly 4 times that of the base case. This is due to the greater number of customers who deferred operation during the High and Critical price periods. Again, notice that by using randomized release options (Release Option 2 $\& 3)$, the peak rebound can be significantly reduced.

For each of the appliance models developed, a number of such scenarios were developed. These cases are shown in more detail in Section 2, including more detailed descriptions of the deferred appliance processes and cases used to test the performance of the appliances using various control signals (e.g., TOU versus TOU+CPP). From these tests, conclusions about the performance of each appliance were drawn, including possible algorithmic improvements. These conclusions are discussed in detail within Sections 2 and 4; a brief discussion is included at the end of this summary.

Section 3 expands the approach in Section 2, and creates a simulation with a more holistic and realistic approach. Again, a prototypical distribution circuit is developed. The circuit is populated with approximately 600 residential home models, including Heating, Ventilation, and 
Air Conditioning (HVAC) systems, appliances, and various other parameters. Penetration levels of appliances reflect national averages for appliance saturation (e.g., 50\% of homes have electric water heaters). A series of scenarios were designed to test the response of the appliances to a variety of control signals (e.g., two-hour peak prices versus six-hour TOU versus 15 -minute critical periods), various DR-enabled appliance penetration levels, and the relative effects when adding HVAC to the modeled load. Other miscellaneous loads, such as lights and plug loads are also included.

The first set of scenarios are designed to investigate the potential peak load reduction, and the resultant rebound, when the penetration levels of DR-enabled GE appliances vary from $0 \%$ to $100 \%$. This looks at the relative effects of the DR-enabled appliances when all of the appliances, including HVAC systems, are simulated simultaneously, i.e., does the addition of HVAC systems dwarf the load reduction of the appliances. The second scenario studied the addition of DR-enabled HVAC systems to the DR-enabled appliances. The third set of scenarios looked at similar situations to scenarios 1 and 2, except the weather was that of a more humid climate with a higher penetration of electric HVAC systems (Houston, TX versus Los Angeles, CA). Scenarios 4 and 5 addressed "worst case" scenarios or the potential rebound when every user tries to recover as soon as the critical signal is released, synchronizing all of the delayed loads (Release Option 1).

For example, Section 3.2 studies the appliance response only case (HVACs are present, but not responsive to price changes). A six-hour critical signal is applied, and the effects of different penetration levels of DR-enabled appliances are observed. Figure S-4 shows an example of a 24hour time series of the feeder load on a relatively warm summer day (not hot), with each case representing a different penetration level of DR-enabled appliances $(0 \%, 5 \%, 25 \%$, and $100 \%)$. The peak reduction within the peak period is approximately $2 \%, 5 \%, 15 \%$, respectively, while the rebound is only significant in the $100 \%$ penetration case. 


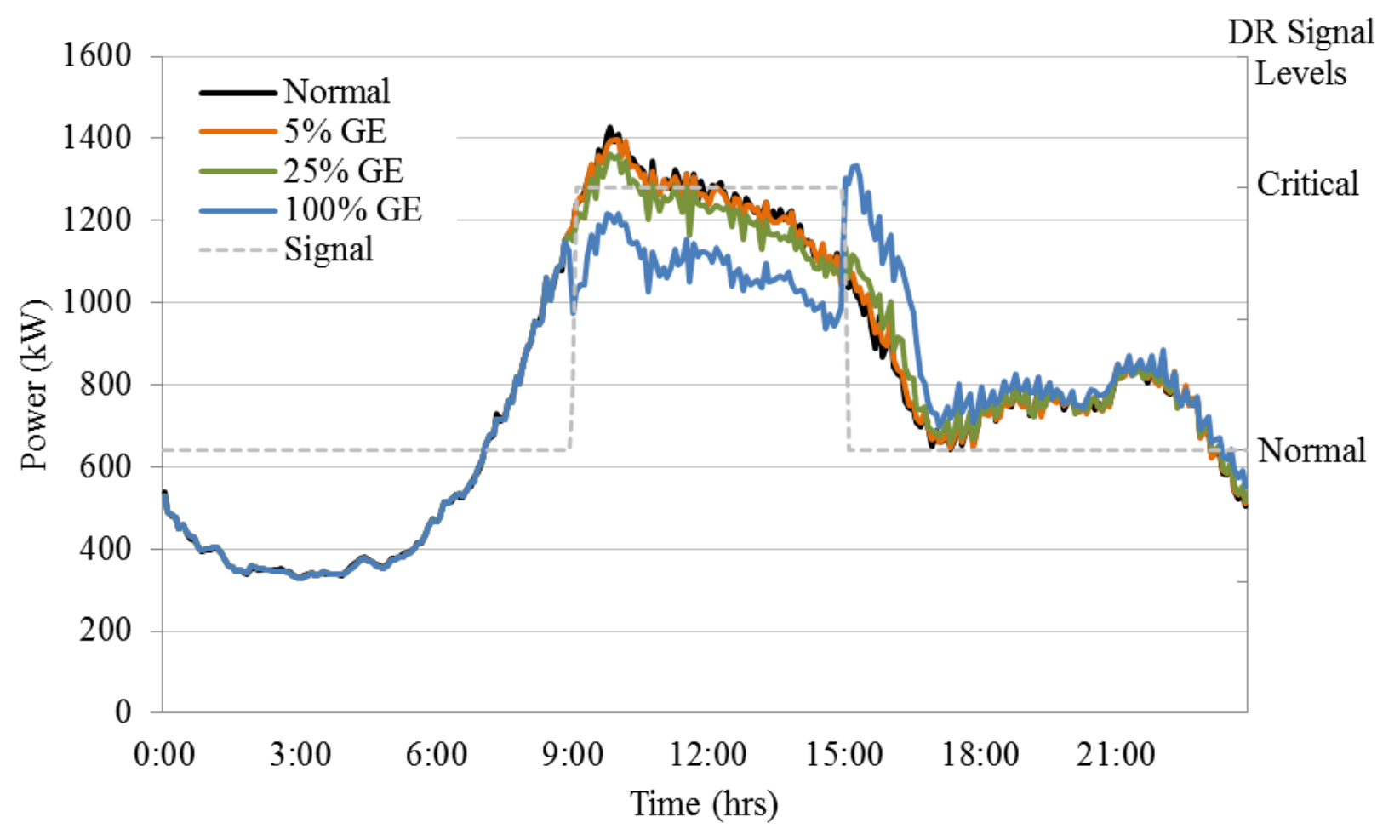

Figure S-4: Time series of total feeder demand, with various DR-enabled appliance penetration levels.

In Sections 3.3 through 3.5, the same cases are used, but different DR signal patterns are applied (four hour critical signal, three 15-minute critical signals, and a TOU + CPP signal, respectively). As expected, results showed that by shortening the required response period progressively from six hours to fifteen minutes, the rebound could be effectively reduced, while the peak reduction within the required window held steady.

Sections 3.6 and 3.7 simulate similar cases, except the HVAC systems are also responsive to the price signal. For example, Figure S-5 compares four cases: Normal (base case no response), Responsive Appliances (100\% of the appliances are DR-enabled, but the HVACs are not), Responsive HVAC (100\% of the HVACs are responsive, but the appliances are not), and Both Responsive (100\% of HVACs and appliances respond). Notice that the peak rebound is significant immediately following the return to Normal, but that the appliances contribute very little to the rebound. Also notice that the amount of peak reduction supplied by the suite of appliances is on the same order of peak reduction as the HVAC systems, and that the appliance reduction is more evenly sustained throughout the period. The HVAC systems, on the other hand, have a very large initial reduction which slowly decays as the internal air temperature of the participating homes begins to return to equilibrium and the HVACs run nearly as much as they were before. Again, it should be noted that this is relatively warm summer day, but not the 
hottest of the year. These two sections explore various control signals and HVAC penetration levels. As expected, as HVAC penetration levels increase the relative effectiveness of the appliances in providing peak reduction is reduced.

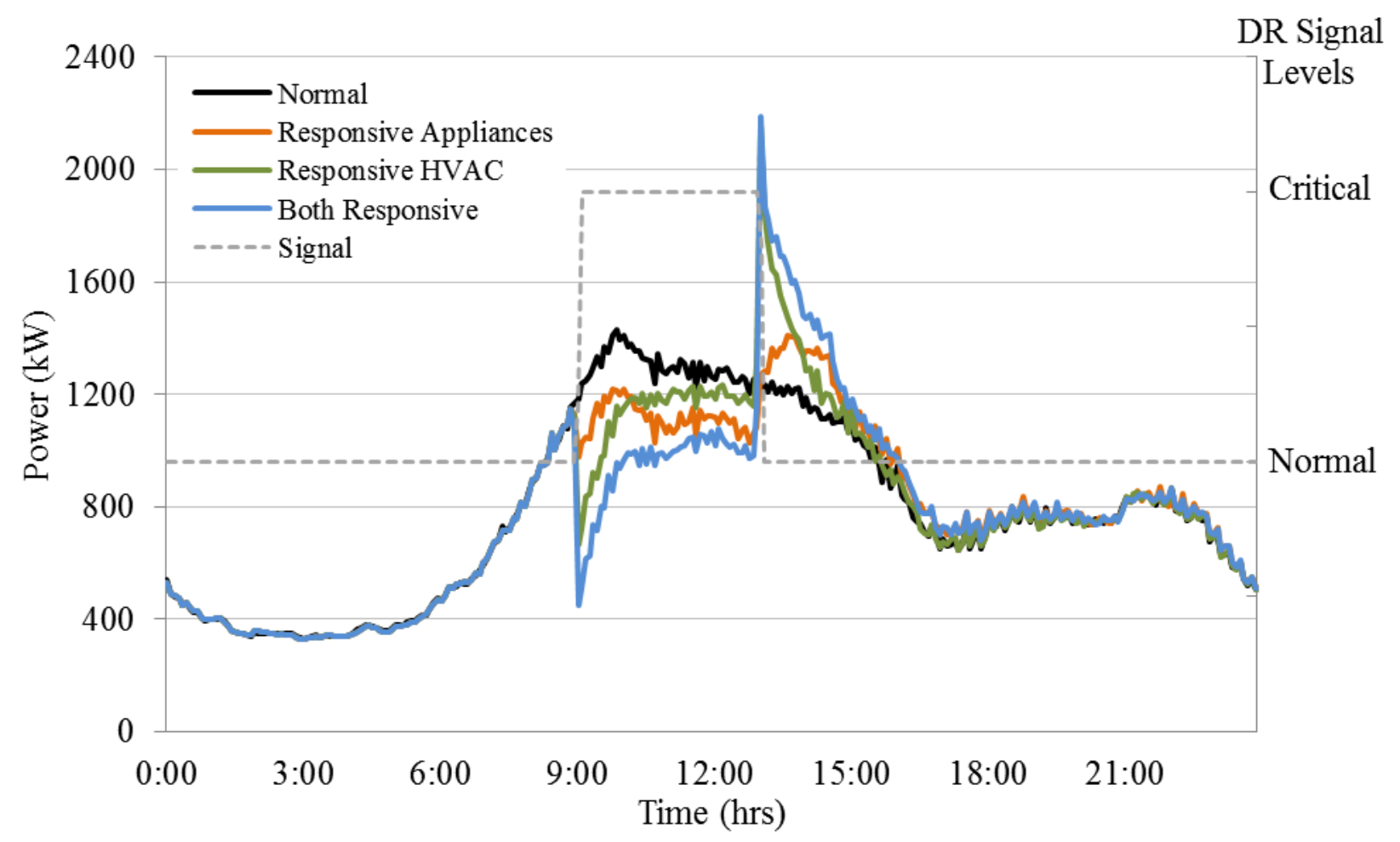

Figure S-5: Time series of total feeder demand, including responsive HVAC systems.

Finally, Section 3.8 investigates a "worst" case rebound scenario, with $95 \%$ penetration of responsive HVACs, $100 \%$ penetration of DR-enabled appliances, and all of the appliances accept a delay and immediately restart at the end of the Critical period. This is used to explore the bounds of the absolute worst case rebound scenario. Figure S-6 demonstrates one of these cases, where a six-hour critical price signal is applied. Notice that while the peak reduction is approximately $25 \%$, the rebound is nearly two times the original feeder peak. Obviously, this is an exaggerated case, but shows the potential for negative affects when not considering the release of the controlled appliances. 


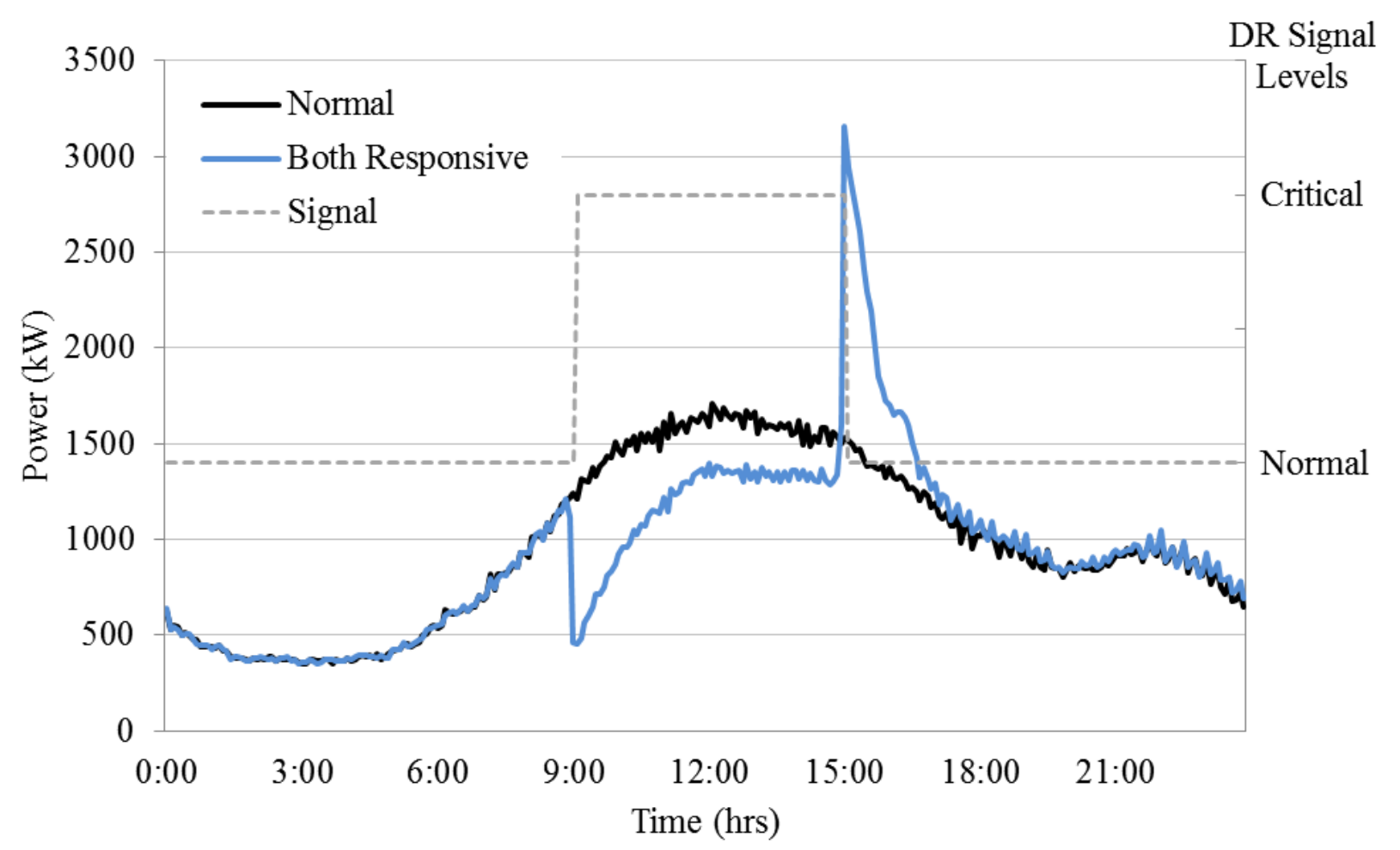

Figure S-6: Time series of total feeder demand, "worst" case scenario.

From the individual appliance simulations presented in Section 2 and the aggregate simulations presented in Section 3, conclusions about the effectiveness of the DR control strategies can be drawn for each of the appliances.

Electric clothes dryers:

- Can provide significant reduction in demand during both high and critical pricing periods due to the fact that they have a greater instantaneous demand than other appliances (on the order $40-70 \%$ of appliance load, or 10s - 100s of $\mathrm{kW}$ ).

- Provide very significant short term reductions (on the order of 100s of $\mathrm{kW}$ for 15 minutes or less) due to the critical signal operational strategy.

- Because of the ES-mode of operation, energy consumption can be reduced by nearly $10 \%$ during a high or critical period, while extending the amount of time it takes the clothes to dry.

- Are significantly affected by the addition of a randomization function during the rebound period, reducing the peak rebound significantly when applied. Without a control method during the rebound period, appliance load can increase by as much as 8.5 times the original appliance peak demand, while with built-in mitigation methods this can be reduced to three to four times the original appliance peak. 
- Typically peak in demand during the late morning or early afternoon, which does not coincide with typical CPP and TOU time periods, when system demand is greatest.

Clothes washers:

- Can provide peak reductions during critical pricing periods (on the order of 50\% of the appliance load, or a few $\mathrm{kW}$ ), in addition to the secondary effects of reduced water heater load. Secondary effects of reduced water heater load were not explicitly modeled in this analysis.

- Does not directly reduce daily energy consumption, but an indirect reduction may be seen due to the reduced water heater load.

- Can provide additional benefits by helping to control the rebound in demand seen after returning to normal operation after a critical pricing period. The addition of a built-in randomization function helps to diversify the timing of the return after a customer selects the delay option, and reduces the overall rebound from approximately 2.4 times the original peak to 1.1 times the original peak.

- Typically peak in demand is seen during the late morning or early afternoon, and may not coincide with standard CPP and high TOU time periods, when system demand is greatest.

Dishwashers:

- Are effective at reducing demand during both high and critical pricing periods (on the order of $80 \%$ of the appliance load, or $10 \mathrm{~s}$ of $\mathrm{kW}$ ). This is mainly due to the appliance's ability to notify the customer of a higher than normal price, and the customer willingness to delay the operation of the appliance until a later, lower price period.

- Can provide additional rebound management services when built-in randomization functions are utilized. Again, due to the willingness of customers to delay normal operations, the randomization period can be extended over a longer period of time than other appliances (over an hour and a half in these simulations) such that the rebound seen is relatively small and shifted much later than other appliances (reduced from 4.7 times to 2.8 times the original peak).

Hybrid water heaters:

- Are extremely effective at reducing demand during both high and critical pricing periods by locking out resistive elements and reducing the thermostat setpoint (on the order of $30-55 \%$ of appliance load, or 100s of $\mathrm{kW}$ ). This is in addition to the reduced demand naturally seen by switching from a resistive water heater to a heat pump water heater, which was not explicitly simulated.

- Significantly reduce daily energy consumption (up to 7\%) on days with a high or critical price, in addition to the reduced energy consumption naturally seen when switching from 
a resistive water heater to a heat pump water heater, due to reduced use of the resistive elements and lowered setpoints.

- Have no built-in rebound management strategy, but without a built-in strategy, they show a rebound in the demand roughly two to three times greater than the original appliance peak. However, due to the heat pump being used, rather than resistive load, the rebound is relatively small.

- Typically peak in demand during mornings and evenings, usually coinciding with system peaks, providing a greater relative resource during those time periods.

Electric ranges:

- Can be divided into two responses, the oven and the cooktop. The dual oven can provide significant peak reductions during high and critical pricing periods. This is mainly due to the appliance's ability to notify the customer of a higher than normal price, and the customer's willingness to use the upper oven rather than the lower oven (on the order of $30 \%$ of oven load, or 10 s of $\mathrm{kW}$ ). Cooktops did not provide any significant reduction in demand during high or critical time periods (less than $5 \%$ of cooktop load).

- Did not significantly contribute to the peak demand during the rebound period (on the same order as the original peak).

- Typically peaks during the evening, which coincides with standard CPP and high TOU pricing periods, when system demand is typically greatest, providing a greater relative resource.

Refrigerators:

- Provide relatively significant reductions in demand during both high and critical time periods (on the order of $30 \%$ of appliance load, or $10 \mathrm{~s}-100 \mathrm{~s}$ of $\mathrm{kW}$ ), mainly due to the shifting of the defrost cycle to a normal price period.

- Do not have a rebound mitigation strategy, but their contribution to the rebound is relatively small (roughly two times the original appliance peak) and is temporally shifted from the rest of the appliances due to the pre-chilling requirement at the beginning of the defrost cycle.

- Are relatively unobtrusive to customers in the way that they respond to a high or critical signal, only delaying the defrost cycle and allowing internal cavity air temperatures to drift slightly.

While the response of a single appliance in a home provides relatively small benefits compared to an HVAC system, because of the greater number of appliances in the home, the aggregate behavior of a suite of DR enabled appliances is significant. In Section 3, it was shown that even at low penetration levels (5\% and 25\%) of GE DR enabled appliances, the appliances 
alone are able to provide peak reduction capabilities (1-2\% and 4-5\%, respectively). For obvious reasons, as penetration levels increased, peak reduction capabilities also increased, to as high as $19 \%$ of the system peak by only utilizing the built-in DR capabilities of the GE appliances.

The increase in reduction capabilities was accompanied by an increase in the peak rebound seen immediately after returning to a normal pricing period, as high as $140 \%$ of the original system peak with $100 \%$ penetration of DR enabled appliances, even when using the built-in rebound mitigation strategies. Rebounds were significantly lower in the lower penetration cases, typically not exceeding more than $2-3 \%$ of the original system peak. However, in all cases the peak was successfully shifted from the critical pricing period to the normal pricing period. If the rebound mitigations strategies were not used, significant rebounds in the peak demand could be seen. Of course, if the system operator is concerned about local demand constraints, then the rebound may be of concern, but if the operator is focused on the effects to the larger system and temporally shifting peak demand from one time period to another, the magnitude of the rebound may not be of concern.

A comparison of the performance of the DR enabled appliances to DR enabled air conditioning systems was also performed. The air conditioning system provides a greater overall resource due to greater daily energy consumption (on a peak day) than the appliances. But, because of the built-in DR controls, the appliances provide increased demand reduction over the air conditioners alone, and in some cases, the response of the appliances actually outperformed the response of the air conditioning systems. This was due to the appliance controls being specifically designed to work with TOU and TOU plus CPP signals. While the air conditioning resource was exhausted over the four or six hour critical pricing periods, the appliance load reduction was more evenly spread across the critical pricing period. This resulted in an overall reduction in demand within the critical pricing period that was significantly increased with the addition of DR enabled appliances.

Additionally, because of the energy conservation modes (ES-mode) that are available in the GE appliances during high pricing periods, the appliances provide a reduction in overall energy consumption in addition to the peak reduction. This makes the built in controls well suited for TOU or TOU plus CPP rate structures, balancing the long term energy shifting goals of a TOU program with the peak reduction goals of a CPP program. 


\section{Table of Contents}

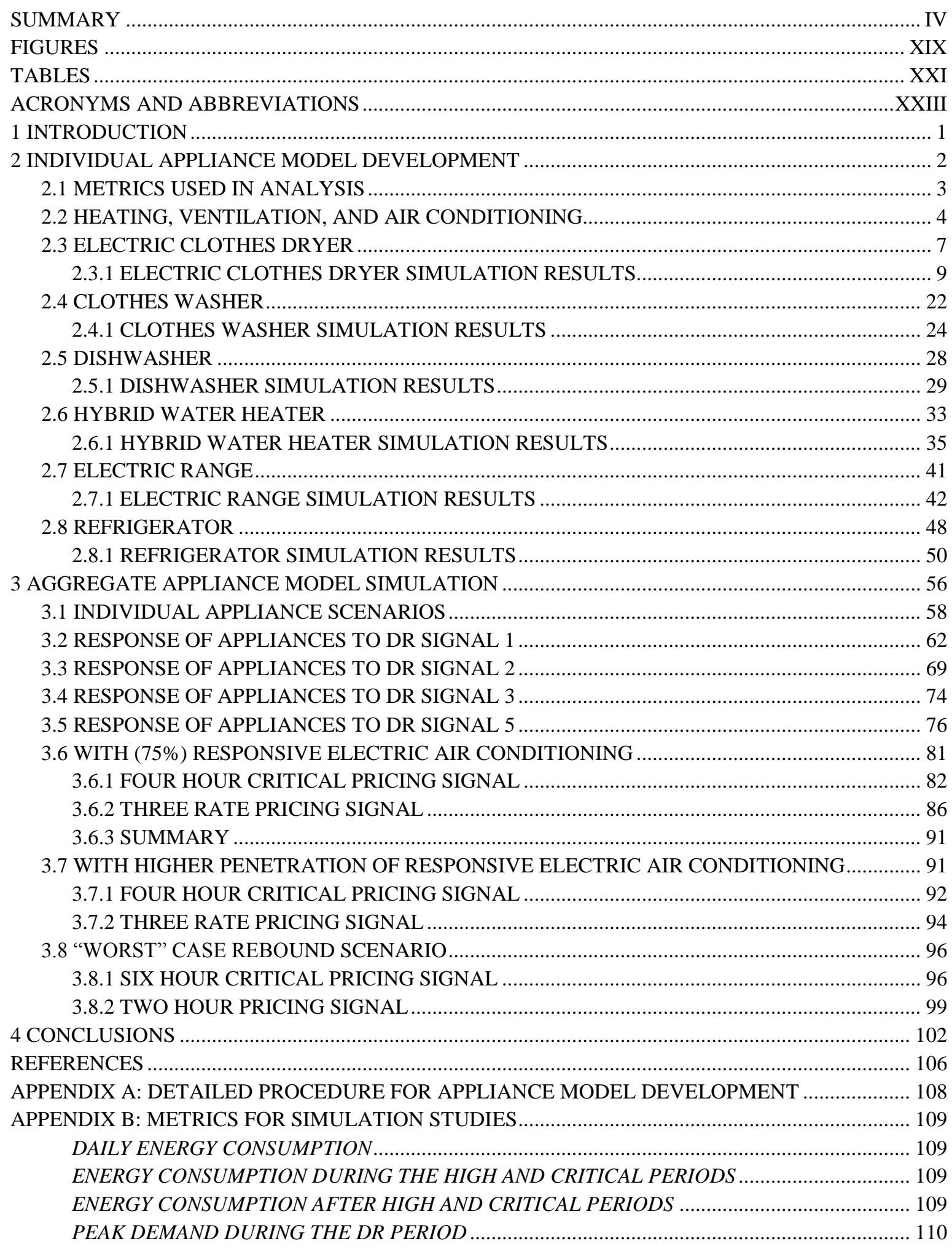

xvii 


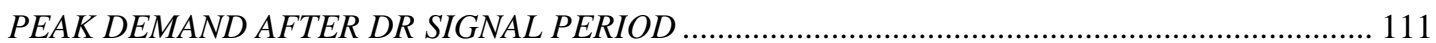

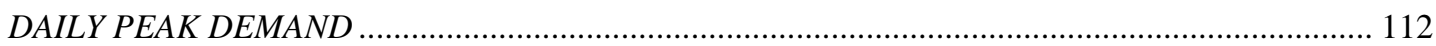

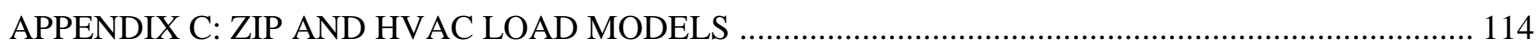

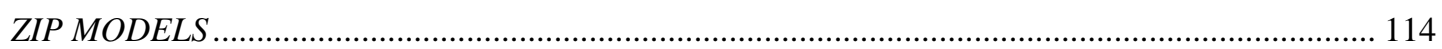

HEATING, VENTILATION, AND AIR CONDITIONING MODEL .......................................... 115

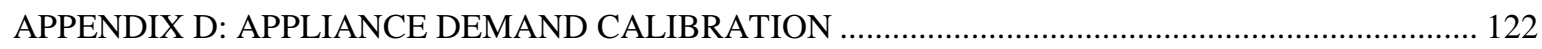

Xviii 


\section{Figures}

Figure S-1: ELCAP load shapes for the electric clothes dryer. ............................................................. vi

Figure S-2: Time series of clothes dryer load, example case 1 ............................................................... vii

Figure S-3: Time series of clothes dryer load, increased customer participation. ....................................... viii

Figure S-4: Time series of total feeder demand, with various DR-enabled appliance penetration levels.......... $\mathrm{x}$

Figure S-5: Time series of total feeder demand, including responsive HVAC systems. ................................ xi

Figure S-6: Time series of total feeder demand, "worst" case scenario. ...................................................... xii

Figure 2-1: Graphical representation of automated thermostat response................................................... 5

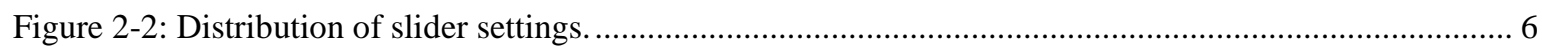

Figure 2-3: ELCAP load shapes for the electric clothes dryer............................................................... 10

Figure 2-4: Time series of dryer load for Customer Case A and Scenario 1 on a winter weekday. ................ 13

Figure 2-5: Time series of dryer load for Customer Case B and Scenario 1 on a winter weekday. ................ 14

Figure 2-6: Time series of dryer load of Customer Case A and Scenario 3 on a winter weekday................... 15

Figure 2-7: Time series of dryer load of Customer Case B and Scenario 3 on a winter weekday................... 15

Figure 2-8: Time series of dryer load of Customer Case A and Scenario 2 on a winter weekday.................. 16

Figure 2-9: Time series of dryer load of Customer Case B and Scenario 2 on a winter weekday................... 17

Figure 2-10: Time series of dryer load for Customer Case A and Scenario 4 on a winter weekday.............. 18

Figure 2-11: Time series of dryer load for Customer Case B and Scenario 1 on a winter weekday. .............. 19

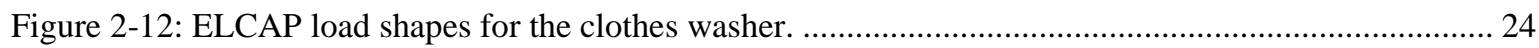

Figure 2-13: Time series comparison of clothes washer load on a winter weekday....................................... 26

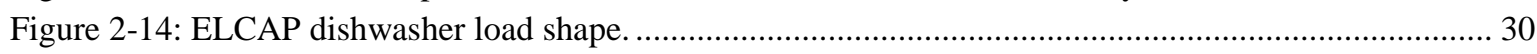

Figure 2-15: Time series of load for the dishwashers on a winter weekend.............................................. 32

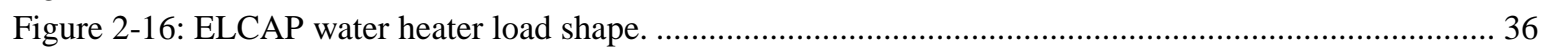

Figure 2-17: Sample water demand schedule from two separate HWHs (one minute resolution). ................. 37

Figure 2-18: Total water demand per day for all of the HWHs on a winter weekday. ................................... 37

Figure 2-19: Time series of load for all HWHs in response to DR Signal 1 on a typical winter day.............. 39

Figure 2-20: Time series of load for all HWHs in response to DR Signal 2 on a typical winter day............. 40

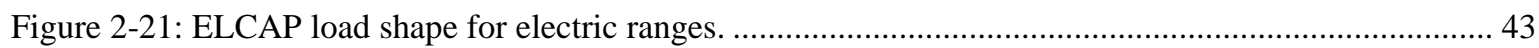

Figure 2-22: Time series of load for all ovens on a winter weekday comparing release options. ................... 45

Figure 2-23: Time series of cooktop demand on a winter weekday. .............................................................. 46

Figure 2-24: Time series of demand of all ranges on a winter weekday. ..................................................... 47

Figure 2-25: Time series comparison of the refrigerator load for a winter day using the timed door opening.51

Figure 2-26: ELCAP load shapes for the refrigerator............................................................................ 52

Figure 2-27: Response of refrigerator load for a winter day using the ELCAP door opening schedule.......... 54

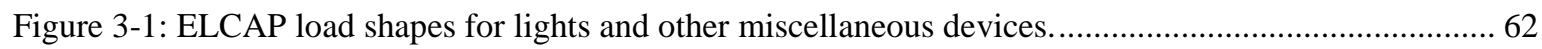

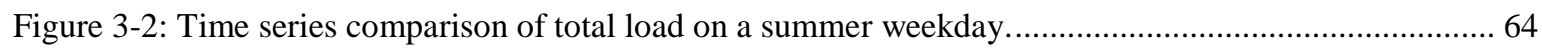

Figure 3-3: Time series comparison of energy losses on a summer weekday. ............................................. 66

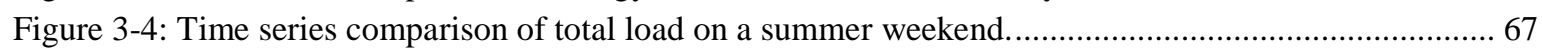

Figure 3-5: Time series comparison of total load on a summer weekday .................................................... 70

Figure 3-6: Time series comparison of total load on a summer weekend.................................................. 72

Figure 3-7: Time series comparison of total load on a summer weekday.................................................... 75

Figure 3-8: Zoomed-in portion of time series comparison of total load on a summer weekday..................... 75

Figure 3-9: Time series comparison of total load for DR Signal 5 on a summer weekday........................... 78

Figure 3-10: Time series comparison of total load for DR Signal 5 on a summer weekend. ........................ 80

Figure 3-11: Time series comparison of total load on a summer weekday for a four hour critical pricing. .... 83

Figure 3-12: Time series comparison of total on a summer weekday for a three rate pricing signal. ............. 88 
Figure 3-13: Time series comparison of total on a summer weekday for a four hour critical pricing........... 92

Figure 3-14: Time series comparison of total on a summer weekday for a three rate pricing signal. ........... 95

Figure 3-15: Time series demand on a summer weekday for a six hour critical period. ............................ 98

Figure 3-16: Time series of demand for a two hour critical period. .............................................. 100

Figure B-1: Calculation of the energy consumption during the Critical period....................................... 109

Figure B-2: Calculation of the energy consumption after the High/Critical period................................. 110

Figure B-3: Calculation of the peak demand during a Critical period................................................. 111

Figure B-4: Calculation of the peak demand after a Critical period. ..................................................... 112

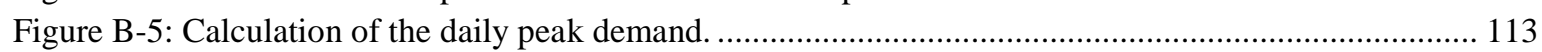

Figure C-1: Voltage-dependent energy consumption of 13W CFL...................................................... 115

Figure C-2: The ETP mode of a residential heating/cooling system. .............................................. 116

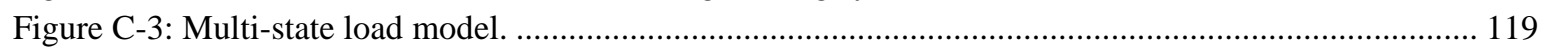

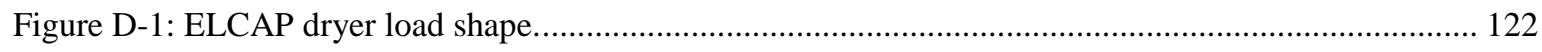

Figure D-2: ELCAP dryer load shape versus simulated load of 646 GE dryers................................... 126 


\section{Tables}

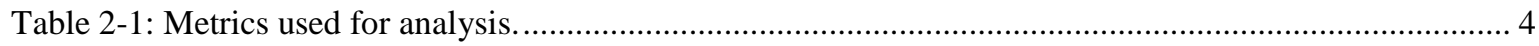

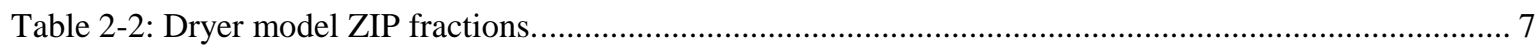

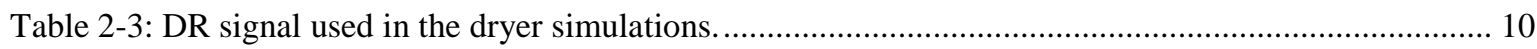

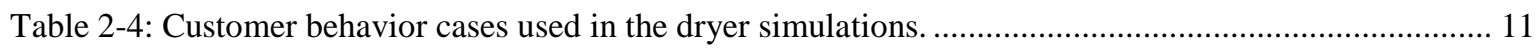

Table 2-5: Scenarios used to explore built-in dryer controls during rebound period...................................... 11

Table 2-6: Built-in release options explored in dryer simulations......................................................... 12

Table 2-7: Comparison of peak rebound for release options in Customer Case A and Scenarios 1and 2...... 17

Table 2-8: Comparison of peak rebound for release options in Customer Case B and Scenarios 1and 2...... 17

Table 2-9: Comparison of peak demand during the DR signal period for Scenarios 1 and 3....................... 20

Table 2-10: Comparison of peak demand during the DR signal period for Scenarios 2 and 4..................... 20

Table 2-11: Comparison of energy consumption during the DR signal period for Scenarios 1 and 3............ 20

Table 2-12: Comparison of energy consumption during the DR signal period for Scenarios 2 and 4............ 21

Table 2-13: Comparison of the peak power after a DR signal period for Scenarios 1 and 3........................ 21

Table 2-14: Comparison of the peak powers after a DR signal period for Scenarios 2 and 4..................... 22

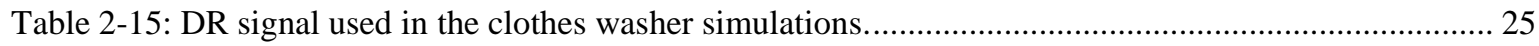

Table 2-16: Customer behavior cases used in the clothes washer simulations.......................................... 25

Table 2-17: Built-in release options explored in clothes washer simulations.............................................. 25

Table 2-18: Comparison of results for DR and Normal case on a winter weekday.................................... 27

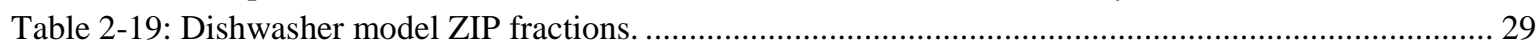

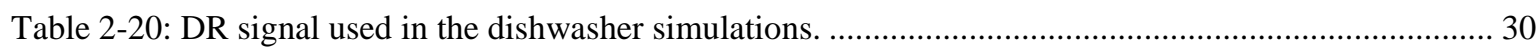

Table 2-21: Customer behavior cases used in the dishwasher simulations................................................. 30

Table 2-22: Built-in release options explored in dishwasher simulations. .................................................. 31

Table 2-23: Peak power demand of dishwashers on a winter weekday ..................................................... 32

Table 2-24: Energy consumption of dishwashers on a winter weekday. ...................................................... 33

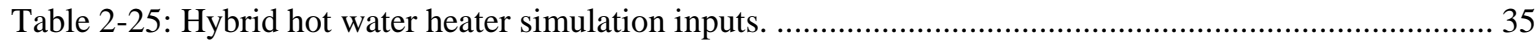

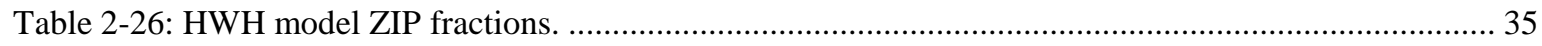

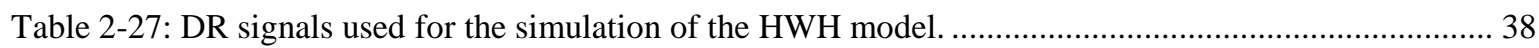

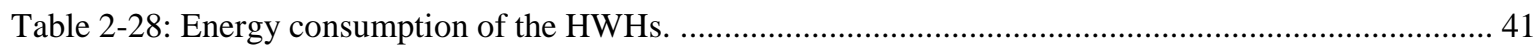

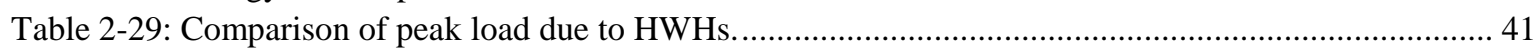

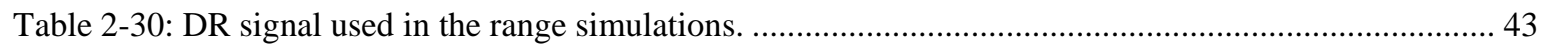

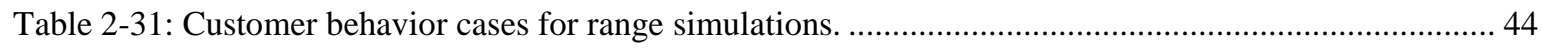

Table 2-32: Built-in release options explored in range simulations. .......................................................... 44

Table 2-33: Comparison of energy consumption for range simulations..................................................... 45

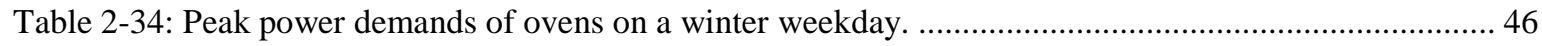

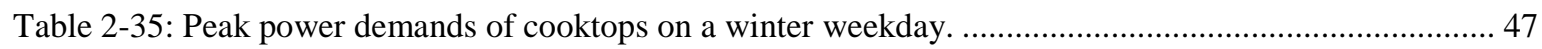

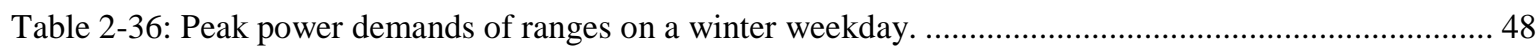

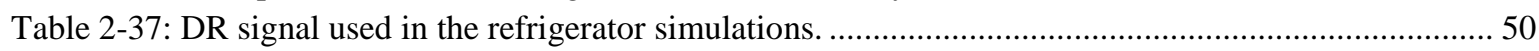

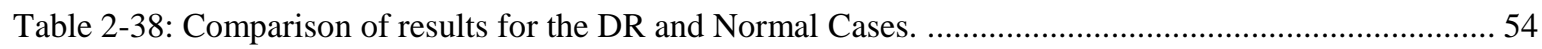

Table 3-1: Demand response scenarios for aggregated appliance model. .................................................. 56

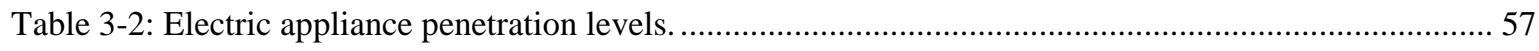

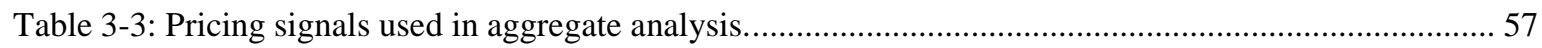

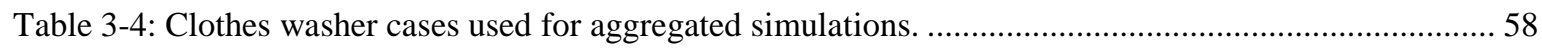

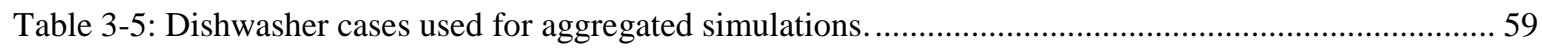

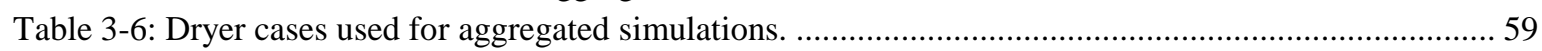

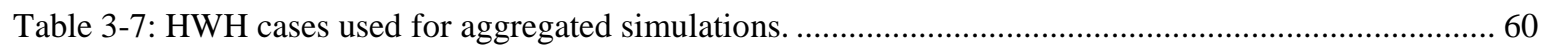


Table 3-8: Range cases used for aggregated simulations.

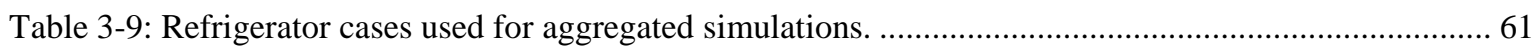

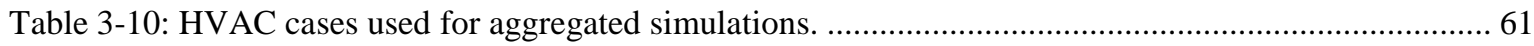

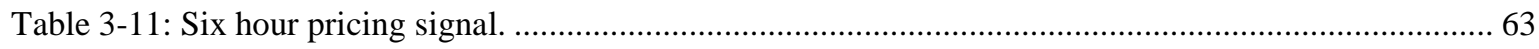

Table 3-12: Comparison of the energy consumption on a summer weekday. .........................................65

Table 3-13: Comparison of the peak demand on a summer weekday. ......................................................65

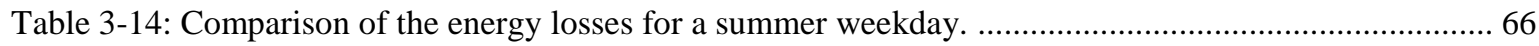

Table 3-15: Comparison of energy values for a summer weekend..........................................................67

Table 3-16: Comparison of peak demand values for a summer weekend .................................................6. 68

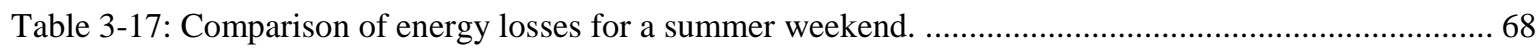

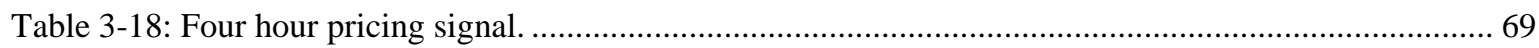

Table 3-19: Comparison of the energy values for a summer weekday. ................................................... 70

Table 3-20: Comparison of the peak demand values for a summer weekday......................................... 71

Table 3-21: Comparison of the energy values for a summer weekend. .................................................. 73

Table 3-22: Comparison of the peak demand values for a summer weekend........................................ 73

Table 3-23: Fifteen minute Critical pricing signals. .......................................................................... 74

Table 3-24: Percent reduction in load observed due to 15 min Critical signals.......................................... 76

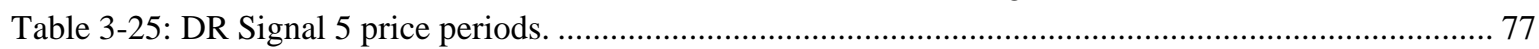

Table 3-26: Comparison of the energy values for DR Signal 5 on a summer weekday. ...............................78

Table 3-27: Comparison of the peak demand values for DR Signal 5 on a summer weekday. ..................... 79

Table 3-28: Comparison of the energy values for DR Signal 5 on a summer weekend. ..............................8 80

Table 3-29: Comparison of the peak demand values for DR Signal 5 on a summer weekend. .................... 81

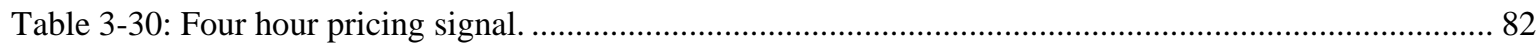

Table 3-31: Comparison of energy consumption on a summer weekday for a four hour Critical pricing....... 84

Table 3-32: Peak demand comparison on a summer weekday for a four hour Critical pricing.................... 85

Table 3-33: Loss comparison on a summer weekday for a four hour critical pricing. ................................ 86

Table 3-34: Three rate pricing signal.............................................................................................. 87

Table 3-35: Comparison of energy consumption on a summer weekday for a three rate pricing signal. ........89

Table 3-36: Comparison of peak demand on a summer weekday for a three rate pricing signal. .................90

Table 3-37: Comparison of on a summer weekday for a three rate pricing signal. .................................... 90

Table 3-38: Comparison of energy consumption on a summer weekday for a four hour critical pricing........93

Table 3-39: Comparison of peak on a summer weekday for a four hour critical pricing. ............................93

Table 3-40: Comparison of energy consumption on a summer weekday for three rate pricing signal...........95

Table 3-41: Comparison peak demand on a summer weekday for three tier pricing signal. ........................96

Table 3-42: Six hour critical pricing signal. ..................................................................................... 96

Table 3-43: Comparison of energy consumption on a summer weekday for a six hour critical period.......... 98

Table 3-44: Comparison of peak demand on a summer weekday for a six hour critical period................... 99

Table 3-45: Two hour critical pricing signal. ......................................................................................99

Table 3-46: Comparison of energy consumption on a summer weekday for a two hour critical period. ...... 101

Table 3-47: Comparison of peak demand on a summer weekday for a two hour critical period................. 101

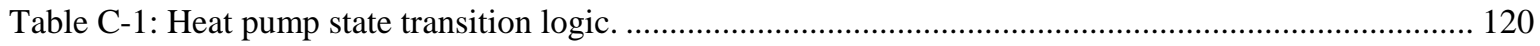




\section{Acronyms and Abbreviations}

$\begin{array}{ll}\text { Btu } & \text { British thermal units } \\ \text { CSA } & \text { Canadian Standards Association } \\ \text { COP } & \text { Coefficient of Performance } \\ \text { CFL } & \text { Compact Fluorescent Light } \\ \text { CVR } & \text { Conservation Voltage Reduction } \\ \text { CPP } & \text { Critical Peak Pricing } \\ \text { DOE } & \text { U.S. Department of Energy } \\ \text { DOE-OE } & \text { Office of Electricity and Energy Reliability } \\ \text { DR } & \text { Demand Response } \\ \text { ELCAP } & \text { End-Use Load and Consumer Assessment Program } \\ \text { ES } & \text { Energy Savings } \\ \text { ETP } & \text { Equivalent Thermal Parameter } \\ \text { GE } & \text { General Electric } \\ \text { HVAC } & \text { Heating, Ventilation, and Air Conditioning } \\ \text { HWH } & \text { Hybrid Water Heater } \\ \text { ISO } & \text { Independent System Operator } \\ \text { LCD } & \text { Liquid Crystal Display } \\ \text { MGI } & \text { Modern Grid Initiative } \\ \text { PNNL } & \text { Pacific Northwest National Laboratory } \\ \text { RTP } & \text { Real-Time Price } \\ \text { TOU } & \text { Constant Impedance, Current, and Power Model } \\ \text { RTO } & \text { ZIP }\end{array}$





\section{Introduction}

The widespread adoption of demand response (DR) enabled appliances and thermostats can result in significant reduction to peak electrical demand and provide potential grid stabilization benefits. GE has developed a line of appliances that will have the capability of offering several levels of demand reduction actions based on information received from the utility grid, often in the form of price or grid status. However due to a number of factors, including the number of DR-enabled appliances available at any given time, the reduction of diversity factor due to the synchronizing control signal, and the percentage of consumers who may override the utility signal, it can be difficult to predict the aggregate response of a large number of residences. The effects of these behaviors can be modeled and simulated in the PNNL-developed open-source software, GridLAB-D ${ }^{\mathrm{TM}}$, including evaluation of appliance controls, improvement to current algorithms, and development of aggregate control methodologies.

This report is the first in a series of three reports describing the potential of GE's DRenabled appliances to provide benefits to the utility grid. The first report will describe the modeling methodology used to represent the GE appliances in the GridLAB-D simulation environment and the estimated potential for peak demand reduction at various deployment levels. The second and third reports will explore the potential of aggregated group actions to positively impact grid stability, including frequency and voltage regulation and spinning reserves, and the impacts on distribution feeder voltage regulation, including mitigation of fluctuations caused by high penetration of photovoltaic distributed generation and the effects on volt-var control schemes.

Section 2 will briefly describe the appliance models and demonstrate the different appliance model responses to various DR signals. Section 3 will describe the feeder model with all of the appliances operating on a representative feeder; this will describe the potential for peak demand reduction utilizing various DR signals and assumptions of customer interaction, and highlight potential undesirable consequences as the load returns to normal, where appropriate. Section 4 will provide overall observations and conclusions. Appendix A will provide detailed information about the operational and model characteristics of GE Appliances' DR-enabled appliances; this section will be distributed separately from the main body of this report to protect GE Appliances' intellectual property, as per the non-disclosure agreement between GE and Battelle, as the operator of PNNL, CRADA contract number PNNL/299. 


\section{Individual Appliance Model Development}

To study the effects and potential benefits of appliances on the power system, GE's DRenabled appliances were modeled in the GridLAB-D simulation environment [1]. GridLAB-D is an open-source, state-of-the-art software designed at PNNL for the Department of Energy's Office of Electricity Delivery and Energy Reliability (DOE-OE) to simulate the complexities of the smart grid from the substation down to the end-use load. This allows users to develop and simulate models which more accurately predict the behavior of loads, and how they interact with the power system, including voltage and temperature dependencies, power system and load control functions, and the complex interactions that occur between devices in such an interconnected system. Previous work has highlighted the advantages of developing and simulating load models as multi-state load models and applying these models in a single simulation environment that can represent loads, electrical infrastructure, and energy markets in a single solution [2]-[7]. This work will build upon those efforts by developing load models which represent the GE DR-enabled appliances as multi-state models with voltage-dependent behavior.

The multi-state appliance models are required to represent not only the baseline instantaneous power demand and energy consumption, but the control systems developed by GE Appliances to enable their appliances to respond to load reduction signals, and the change in behavior of the appliance in response to the signal. This includes the power and energy consumption and the time horizon over which they operate for the various operational modes, and how changes in the DR control signal affect load behavior. This gives insight into the potential for short term reduction in power consumption versus longer term, and allows for exploration of different DR control signals without developing a new model. Additionally, it gives insight into how to improve the effectiveness of the DR enabled appliances across various time horizons.

The following sections will describe the behavior of each of the appliances in baseline mode (e.g., normal operation) and during DR signal events, and present the aggregate effects to a DR signal of each appliance on a representative distribution feeder at various penetration levels. Different scenarios will be investigated that look at the effects of customer response to the behavior of the appliances. Each of the scenarios is simulated on a representative U.S. feeder, developed by the Modern Grid Initiative (MGI) as the Taxonomy of Prototypical Feeders [8]. Standard static load models, typically found in peak load studies, are replaced with multi-state residential house and Heating, Ventilation, and Air Conditioning (HVAC) models via the methodology described in [3]-[6]. This led to a distribution feeder model which contained individual residences including appliances, each with statistically sampled parameters and behaviors.

Each of the appliance models was calibrated to available data on average hourly and annual energy consumption, typically from the End-Use Load and Consumer Assessment Program (ELCAP) residential load data [9]. Where additional information was available through GE 
about energy efficiency improvements or changes in customer behavior since the ELCAP study, it was incorporated.

All appliances manufactured by GE have four levels of control, namely Low, Normal, High and Critical. These four signals are analogous to four pricing levels, such as might be seen in a three-rate Time-of-Use (TOU) program with a Critical Peak Pricing (CPP) overlay. However, at the time of this analysis GE had not fully developed the Low mode of operation. The Low mode could be used in the future so that appliances can take advantage of low pricing periods by increasing load consumption. Thus, the Low mode is not modeled in the GridLAB-D GE appliance models. However, all appliances are modeled for the other three levels of control, which correspond to the three levels of Normal, High and Critical.

Section 2.1 will discuss the metrics used in this study to determine the effectiveness of the DR-enabled appliances. Section 2.2 will discuss the HVAC response modeled for the studies. Detailed information on the creation and calibration of each of the individual appliance models will be described in Sections 2.4 through 2.8. Appendix A, which will be released separately from this document, will compare the simulated appliance results to GE's in-house appliance testing, including time series appliance power consumption.

2.1 Metrics used in analysis

The metrics that will be used to evaluate the performance of the DR-enabled appliances are listed in Table 2-1. Not all metrics will be used with each case analyzed. Details about the metrics, including how each metric was calculated and the importance of the metric, are described in Appendix B. 
Table 2-1: Metrics used for analysis.

\begin{tabular}{|c|l|l|l|}
\hline Metric Name & Unit & \multicolumn{1}{|c|}{ Description } & Purpose \\
\hline $\begin{array}{c}\text { Daily Energy } \\
\text { Consumption }\end{array}$ & $\mathrm{kWh}$ & $\begin{array}{l}\text { Total daily energy } \\
\text { consumption. }\end{array}$ & $\begin{array}{l}\text { Used to study the energy conservation that can be } \\
\text { achieved from the appliance responding to DR } \\
\text { signals. }\end{array}$ \\
\hline $\begin{array}{c}\text { Energy Consumption } \\
\text { during the High and } \\
\text { Critical period }\end{array}$ & $\mathrm{kWh}$ & $\begin{array}{l}\text { Total energy consumption } \\
\text { during the High or Critical } \\
\text { signal period. }\end{array}$ & $\begin{array}{l}\text { Used to study the change in energy consumption } \\
\text { that is achieved when the appliance responds to } \\
\text { the DR signals during the high or critical period. }\end{array}$ \\
\hline $\begin{array}{c}\text { Energy Consumption } \\
\text { after High and Critical } \\
\text { period for six hours }\end{array}$ & $\mathrm{kWh}$ & $\begin{array}{l}\text { Total energy consumption } \\
\text { after a High or Critical } \\
\text { signal period. }\end{array}$ & $\begin{array}{l}\text { Used to study the change in the energy } \\
\text { consumption that may occur after a high or critical } \\
\text { signal period. The increase in energy consumption } \\
\text { can occur due to the appliance delaying processes } \\
\text { during a DR signal period, and later rebound, or } \\
\text { due to the appliances entering a higher energy } \\
\text { consumption mode. }\end{array}$ \\
\hline $\begin{array}{c}\text { Peak Demand during } \\
\text { the High and Critical } \\
\text { signal periods }\end{array}$ & $\mathrm{kW}$ & $\begin{array}{l}\text { Peak power during the } \\
\text { High and Critical signal } \\
\text { periods. }\end{array}$ & $\begin{array}{l}\text { Used to study the change in the peak power } \\
\text { demand that may occur due to appliance response } \\
\text { to a High or Critical signal. }\end{array}$ \\
\hline $\begin{array}{c}\text { Peak demand after } \\
\text { High and Critical } \\
\text { signal periods } \\
\text { (Rebound) }\end{array}$ & $\mathrm{kW}$ & $\begin{array}{l}\text { Peak power after a High or } \\
\text { Critical signal period for } \\
\text { six hours }\end{array}$ & $\begin{array}{l}\text { Used to determine the extent to which the } \\
\text { appliance response can cause a change in the peak } \\
\text { demand following a High or Critical signal period. }\end{array}$ \\
\hline $\begin{array}{c}\text { Daily Peak demand } \\
\text { Daily peak power. }\end{array}$ & $\mathrm{kW}$ & $\begin{array}{l}\text { Used to study the absolute change in the daily } \\
\text { peak power. }\end{array}$ \\
\hline
\end{tabular}

\subsection{Heating, Ventilation, and Air Conditioning}

To protect GE Appliances' intellectual property, descriptions of the various appliance models, and their operational DR modes, cannot be provided in great detail. In following sections, general descriptions of standard appliance operation and DR specific functions will be discussed, but the specific modes of operation will not be described. These will be discussed in Appendix A, released separately from this document. To help aid in the discussion, detailed descriptions of models available in the open-source version of GridLAB-D (constant impedance, current, and power models, also known as ZIP models, and HVAC models), which are not dependent upon GE Appliances proprietary controls, are used to demonstrate the principles behind multi-state load modeling and why they are needed. This is found in Appendix B and is intended to demonstrate the complexity that went into the development of each of the GE 
appliance models, including the DR control functions, without revealing GE Appliances proprietary information.

The DR mechanism used for the HVAC systems in this study is similar to the design used in the Pacific Northwest GridWise ${ }^{\mathrm{TM}}$ Testbed Demonstration Project [11]. The automated thermostat design was chosen due to its previous success in field demonstrations and an understanding of the distribution of customer responsiveness found during the field experiments.

Figure 2-1 graphically illustrates the behavior of the automated thermostat implemented in this analysis. Cooling response is used as an illustration, but the same effects can be achieved with heating. Essentially, the thermostat translates the current price of electricity into a shift in the temperature setpoint of the system. If price is relatively high, the cooling setpoint is adjusted upward. Conversely, if the price is relatively low, the cooling setpoint is adjusted downward. Customers have full control over the level of responsiveness of their individual system, defining the maximum downward and upward deviations $\left(T_{\min }\right.$ and $\left.T_{\max }\right)$ from their desired setpoint $(\Delta \mathrm{T}=0)$, the rate at which they respond (the slope of the line), and whether they wish to pre-cool the home. For simplicity, all of these parameters are mapped to a "slider setting". Customers can choose a value between 0 and $100 \%$, where $0 \%$ equates to "maximum comfort" (or standard, non-price response thermostat operation) and $100 \%$ equates to a pre-defined "maximum savings". For this analysis, a distribution of typical customer participation levels or slider settings was determined from the Pacific Northwest GridWise Demonstration [11]. This distribution was found to be best fit by a normal distribution centered on $45 \%$ with a standard deviation of $20 \%$ participation. Values below 0 were set to $0 \%$, while values chosen above $100 \%$ were re-chosen under the original distribution. This leads to a distribution with an approximate mean of $45 \%$ tailing off to $100 \%$, but with a large population of customers who did not participate at all (0\% setting). A plot of this distribution is shown in Figure 2-2. This was similar to results from the Pacific Northwest GridWise Demonstration Project.

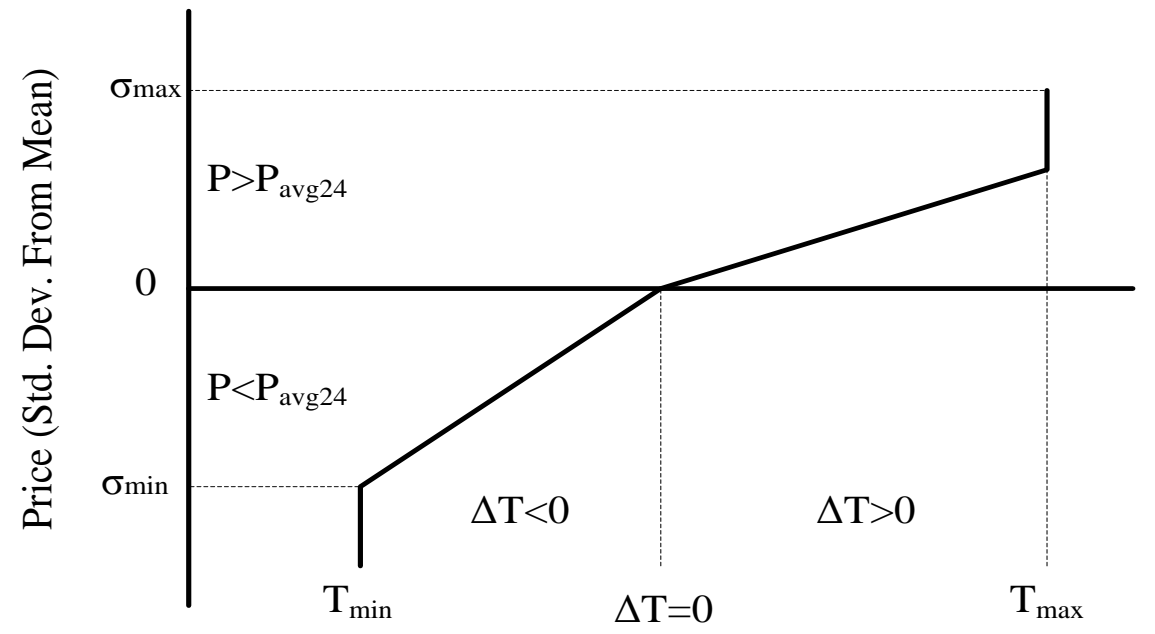

Temperature $\left({ }^{\circ} \mathrm{F}\right)$

Figure 2-1: Graphical representation of automated thermostat response. 


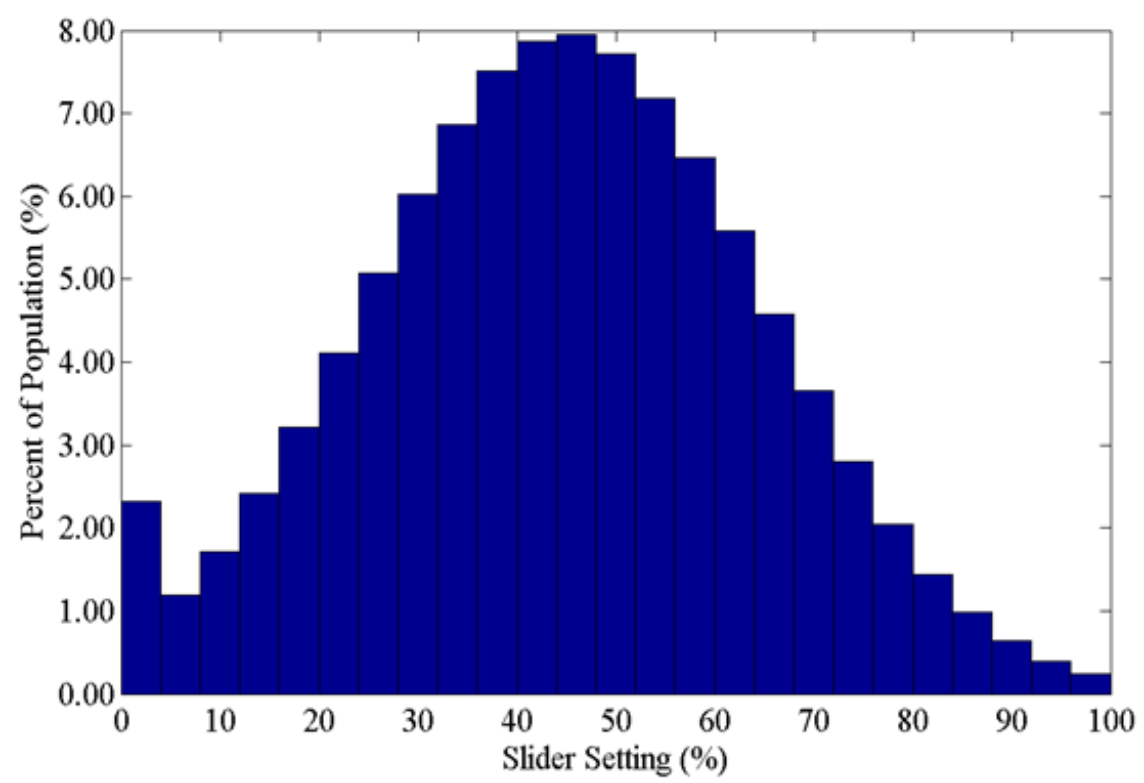

Figure 2-2: Distribution of slider settings.

Additionally, pre-cooling and pre-heating were not used in this analysis, as they are not appropriate for this type of price response due to the potential for a significant increase in energy consumption during relatively low price periods. More detailed descriptions about the operation of the automated thermostat can be found at [11]-[13]. It is important to note that when prices are continuous, such as those found in retail Real-Time Pricing (RTP) programs, the mapped response of setpoints to price is a continuous function. However, in the case of TOU or CPP, there are only two or three discrete prices which map to two or three discrete setpoint deviations. For this analysis, a Critical signal results in customers responding at their maximum selected deviation from their normal setpoint, which is defined by the slider setting. A High signal results in customers responding at a lesser deviation, also related to their slider setting. A Normal signal results in normal thermostat operation. Note, that by randomly varying the slider setting, each customer responds through customized offsets of a different amount. For example, a 100\% slider setting equates to a 5 degree offset during a Critical signal and a 2 degree offset during a High signal, while a $50 \%$ slider setting equates to 2.5 degree and 1 degree offset during a Critical and High signal, respectively.

The HVAC model and DR capabilities of the HVAC model developed in GridLAB-D has been used to illustrate the type of modeling required in the GridLAB-D environment, especially when considering the effects of a DR signal on appliance behavior. The other appliances have all been modeled using this general approach described in Appendix B. The level of detail of the model for each appliance was dependent upon the level required to capture the dynamic behavior of the loads. The details of each of the appliance models can be found in Appendix A. But to 
protect GE Appliances proprietary operational strategies, the following sections will summarize the methods used for each appliance, while Appendix A is reserved for detailed discussion of the implementations.

\subsection{Electric Clothes Dryer}

The electric clothes dryer consists of three major power consuming elements - two electric resistance heating coils and a drum drive motor. The elements heat the air in the dryer, while the motor tumbles the clothes within the drum to dry the clothes. Sensors are used to determine when the moisture content has been reduced to an acceptable level, at which point the dryer is turned off. A multi-state load model of the electric clothes dryer was developed in GridLAB-D to capture the behaviors of the different operational states. The model was designed on the basis of inputs and watt traces from laboratory testing and inputs provided by GE Appliances. The developed dryer model states were modeled and calibrated such that the power output, energy per state, time in state, and rules for state transitions for one dryer approximately matched the inputs provided by GE Appliances. Each of the dryer states was designed with different ZIP fractions for the heating coils and the motor; these values are listed in Table 2-2.

Table 2-2: Dryer model ZIP fractions.

\begin{tabular}{|c|c|c|c|}
\hline & $\mathrm{Z}$ & $\mathrm{I}$ & $\mathrm{P}$ \\
\hline Heating Coils & 1.0 & 0.0 & 0.0 \\
\hline Motor & 0.0 & 0.0 & 1.0 \\
\hline
\end{tabular}

Similar to all DR-enabled GE appliances, the electric clothes dryer has three modes of operation that, for the purpose of this study, can be classified as the Normal, ES-High, and ESCritical modes. These modes correspond to signals provided by the utility, which for the purpose of this study will be called Normal, High, and Critical. These can be thought of as being analogous to a TOU rate structure with a CPP overlay, with a lower off-peak rate (Normal), a higher on-peak rate (High), and a much higher emergency rate (Critical).

If a dryer starts during a Normal signal, it operates in the Normal mode until the completion of the cycle, unless a High or Critical signal arrives during its operation. If the dryer is started during a High or Critical signal, the dryer display alerts the customer that the price of electricity is currently higher than normal. At this point, the customer has three options. In the first option, which is also the default option, the customer can choose to delay the start of the dryer until the price returns to Normal, avoiding all consumption during the higher than normal price period. The second option allows the customer to enter an Energy Savings (ES) mode, or a reduced power or energy consuming mode of operation. When the signal is High and the customer chooses to enter the reduced consumption mode, or ES-High, the dryer reduces instantaneous power demand and overall energy consumption while extending the run time of the cycle. The 
clothes are still dried, but the dryer runs for a longer period of time. When the signal is Critical and the customer chooses to enter the reduced consumption mode, the dryer enters the ESCritical mode. This mode is similar to the ES-High mode, except that demand is reduced to near zero during the first part of the operation while the heating elements are turned off but the drum continues to tumble the clothes (e.g., 10-20 minutes). After this time period, the dryer then operates in exactly the same way as the ES-High mode until the clothes are dry. In the third option, the customer can always choose to ignore the signal and operate in Normal mode. The consumer is presented with the same options if a High or Critical signal arrives while the dryer is currently operating. These operational modes, including the transitional states, were modeled in GridLAB-D to capture the appliance behavior on a distribution feeder circuit, and to study the effects of these appliances on a distribution system.

In the dryer model, the total cycle time, or how long it takes to dry the clothes, was determined using two separate methodologies. In the first method, the energy used in all three modes of operations by the dryer model was taken as a fixed value across all appliances in a population. Since the energy usage of the dryer depends upon the time it takes to dry the clothes, or the cycle time of the dryer, the cycle time of the dryer model was more or less fixed. The power and energy consumption of the dryer are voltage-dependent, so while the energy consumed by the dryer is fixed, the cycle times vary with the voltage as the heating elements are resistive.

In the second method, the energy used by a population of dryer models varied over two distinct distributions, one for the Normal mode and one for ES-High and ES-Critical modes. The parameters of this distribution were developed through inputs based on GE Appliances' survey data which collected different dryer run times reported by users. A distribution was determined from this data. GE Appliances provided a mean for the distribution, as well as a $90 \%$ confidence interval, and a skew for the distribution. This distribution was then used to determine the energy used by a dryer in the Normal, ES-High, and ES-Critical modes of operation, which in turn was used to determine the cycle time for these modes of operation. Each dryer in a population of devices receives a different energy consumption requirement to dry the clothes, analogous to the fact that every batch of clothes has different moisture content, weight, and drying times. More details on the distribution of cycle times and appliance operation can be found in Appendix A.

One further option was included in the dryer model. As will be shown in the following section, when a large percentage of customer's delay their operation and re-start at the same time, a significant rebound in the demand can occur. In the simulations, various re-start methods were compared to explore whether built-in controls can mitigate the rebound. In one case, the dryers that delay their operation start in the Normal mode immediately after the signal returns to Normal. In a second case, the dryers that delay their operation start in the Normal mode after a certain amount of time has passed since the signal returns to Normal. In a population of dryers, this delay time is randomized so that all of the dryers do not start operation at exactly the same 
time. In the following section, different delay time distributions are used to demonstrate the effectiveness of managing the load during the rebound period.

\subsubsection{Electric Clothes Dryer Simulation Results}

To test the response of the electric clothes dryer to a DR signal, a test feeder was created that contained a population of dryers, each simulated with their own subset of parameters. All of the following simulations were run on a prototypical distribution feeder, R1-1247-2 [8], containing 544 single family homes, each fitted with a GE dryer (100\% penetration of GE dryers). To create a base case which represented a realistic scenario, load shapes from the ELCAP load study are used to estimate the usage pattern of the electric clothes dryers at different times, during the course of an average day [9]. For example, Figure 2-3 shows the ELCAP electric dryer load shapes for an average winter and summer weekday and weekend. The load shapes are used to "schedule" the dryer usage throughout the population of devices, so that the average energy consumed during each hour of the simulation approximately equals the average hourly energy consumption of the ELCAP load shapes for each season and day type. This meant that annual energy consumption of the simulated dryers matched annual energy consumption data from the ELCAP load study. However, since appliances have generally become more efficient since the ELCAP load study was performed, where appropriate, adjustments were made so that annual energy consumption matched current information. This resulted in the simulated dryer population matching the relative pattern of the ELCAP load shapes for each season (summer vs. winter) and day type (weekday vs. weekend), while matching the annual energy consumption to available updated information. A more detailed description of the methodology to calibrate the simulations to ELCAP load shapes is presented in Appendix B. After the base case was calibrated and simulated, a DR signal was applied to the population of dryers to study the effects on their behavior and the interactions with the distribution circuit. The DR signal used in this section is shown in Table 2-3. Additionally, a number of dryer scenarios were simulated to explore various cases of user interaction and delay release options. These will be described in further detail below. 


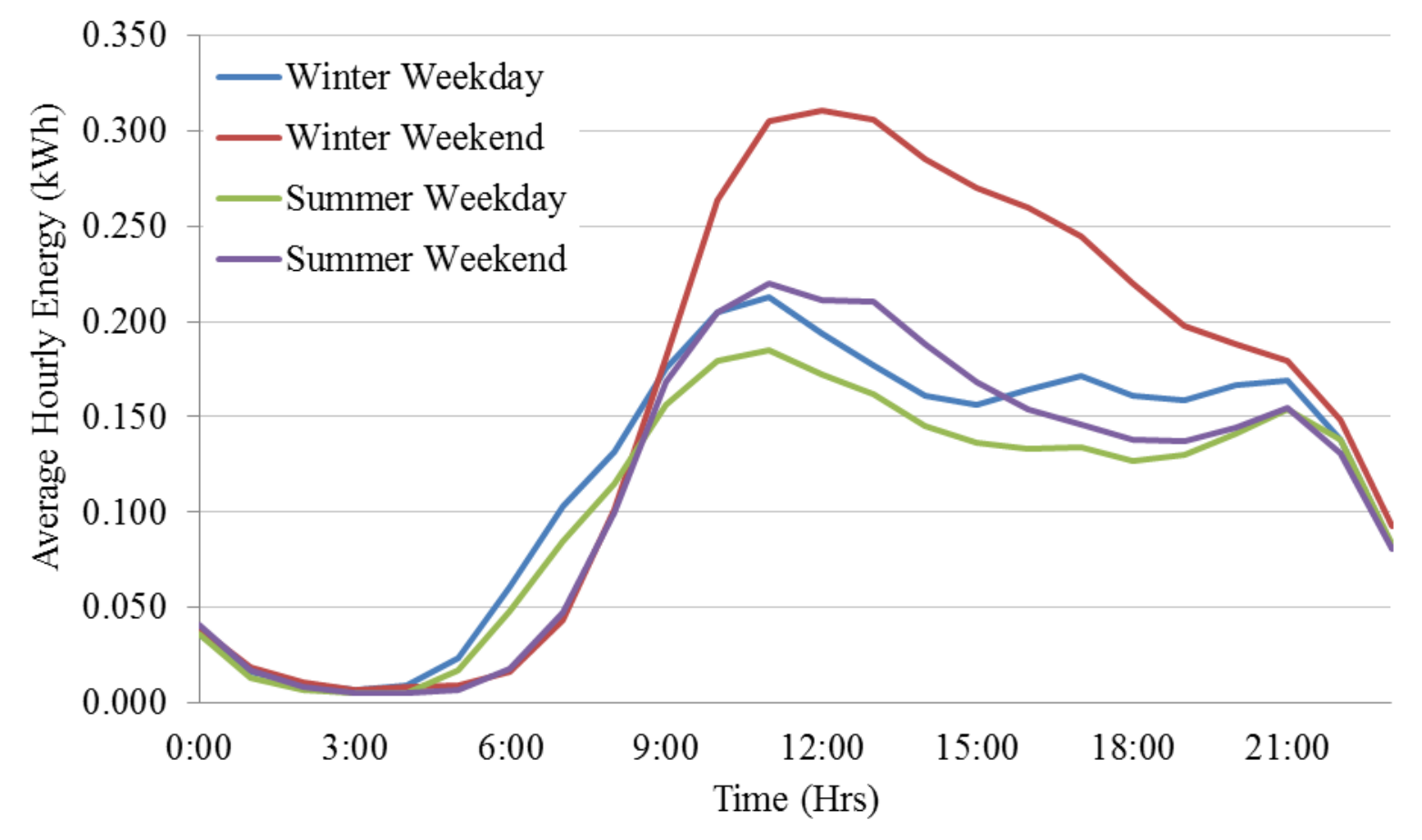

Figure 2-3: ELCAP load shapes for the electric clothes dryer.

Table 2-3: DR signal used in the dryer simulations.

\begin{tabular}{|c|c|}
\hline & Time \\
\hline Critical & $18: 00-20: 00$ \\
\hline High & $15: 30-18: 00,20: 00-21: 00$ \\
\hline Normal & all other times \\
\hline
\end{tabular}

Apart from inputs from GE Appliances from initial field studies, no survey data was available to determine the percentage of customers who will accept a delay, use the ES-mode, or override a DR signal. However, the expected benefits from the appliance response are highly dependent upon the level of consumer interaction. As such, it is important to explore a number of user response cases. For this study, two cases of user behavior were simulated as developed from inputs from GE Appliances survey data. These cases are shown in Table 2-4. 
Table 2-4: Customer behavior cases used in the dryer simulations.

\begin{tabular}{|l|c|c|c|}
\hline & $\begin{array}{c}\text { Accept } \\
\text { Delay }\end{array}$ & $\begin{array}{c}\text { Use ES- } \\
\text { mode }\end{array}$ & $\begin{array}{c}\text { Override all } \\
\text { DR options }\end{array}$ \\
\hline Customer Case A & $25 \%$ & $70 \%$ & $5 \%$ \\
\hline Customer Case B & $75 \%$ & $20 \%$ & $5 \%$ \\
\hline
\end{tabular}

One of the goals of this study was to examine different dryer design scenarios, and how built-in controls can be used to mitigate the rebound of demand often seen after the release of a DR signal. In Table 2-5, scenarios are shown which explore one aspect of this rebound. The "Rebound Mode" describes the mode of operation which the dryer uses after it has delayed its operation when a customer selects delay during a High or Critical signal, either Normal or ESHigh. The ES-High mode is used to decrease instantaneous power and energy consumption immediately following the return to Normal to help alleviate some of the increased demand during the rebound period. Additionally, the length of the simulated dryer cycle times is also explored. This is used to explore the effects of assuming that all dryers in a population have a fixed cycle length versus a distribution of cycle lengths.

Table 2-5: Scenarios used to explore built-in dryer controls during rebound period.

\begin{tabular}{|c|c|c|}
\hline & $\begin{array}{c}\text { Rebound } \\
\text { Mode }\end{array}$ & Cycle Times \\
\hline Scenario 1 & Normal & Fixed \\
\hline Scenario 2 & Normal & Distributed \\
\hline Scenario 3 & ES-High & Fixed \\
\hline Scenario 4 & ES-High & Distributed \\
\hline
\end{tabular}

Again, to explore the effects of built-in dryer controls to help mitigate the rebound in demand immediately following the return to the Normal signal, a series of DR release options are explored. Instead of immediately entering the Normal or ES-High mode upon return to the Normal signal after the delay option has been chosen, each dryer randomly selects an additional delay time so that all dryer loads do not become synchronized. Different randomization functions are explored, and are described in Table 2-6. While the randomization functions are not exactly like those currently used in the GE appliances, they are representative and capture the overall effects of additional release options when the appliances are released after a delay. 
Table 2-6: Built-in release options explored in dryer simulations.

\begin{tabular}{|c|c|}
\hline & $\begin{array}{c}\text { Additional Delay Time } \\
\text { Distribution }\end{array}$ \\
\hline $\begin{array}{c}\text { DR Release } \\
\text { Option 1 }\end{array}$ & $\begin{array}{c}\text { None - All delayed dryers start } \\
\text { immediately. }\end{array}$ \\
\hline $\begin{array}{c}\text { DR Release } \\
\text { Option 2 }\end{array}$ & $\begin{array}{c}\text { Uniform distribution between 0 } \\
\text { and 48 minutes. }\end{array}$ \\
\hline $\begin{array}{c}\text { DR Release } \\
\text { Option 3 }\end{array}$ & $\begin{array}{c}\text { Uniform distribution between 0 } \\
\text { and 72 minutes. }\end{array}$ \\
\hline
\end{tabular}

The following results represent different combinations of Customer Cases, Scenarios, and Release Options, leading to a total of 24 different DR cases ( 2 x 4 x 3); for brevity, only a few cases will be presented here. Figure 2-4 shows the simulation results for the different DR release options. The case being examined is using Customer Case A (25\% dryers accept delay) and Scenario 1, observing the differences between the various DR release options. As can be noted from Figure 2-4, DR Release Option 1 has the highest rebound while DR Release Option 3 has the lowest rebound of the three DR release options, indicating that as the additional delay time is increased, the peak rebound is decreased. Thus, as the average delay time is extended, the peak rebound on the system is reduced due to the aggregate dryer load. 


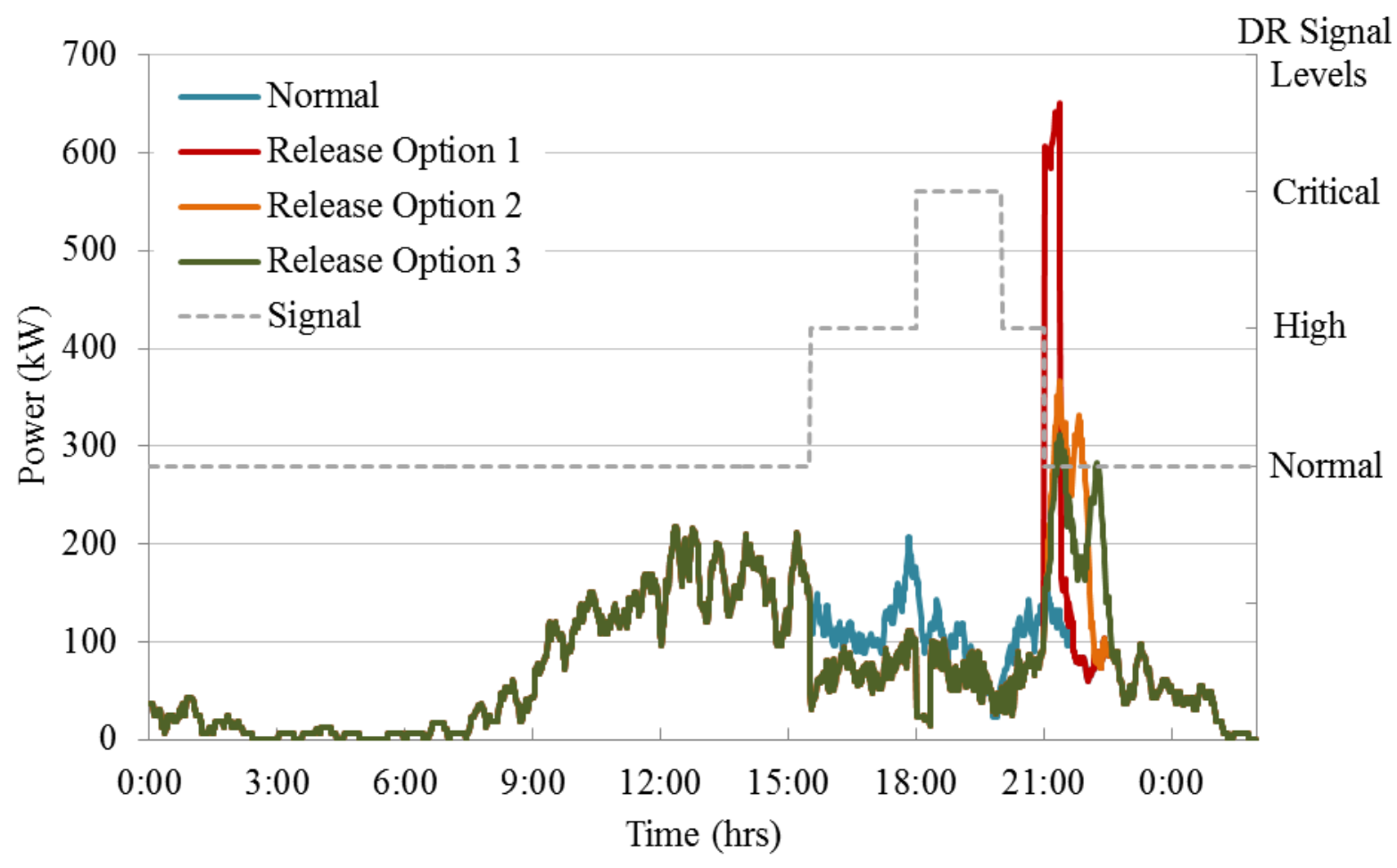

Figure 2-4: Time series of dryer load for Customer Case A and Scenario 1 on a winter weekday.

Figure 2-5 shows the simulation results for the different DR release options using Customer Case B (75\% dryers accept delay) and Scenario 1. As can be seen again, DR Release Option 1 has the highest rebound while DR Release Option 3 has the lowest rebound of all three cases. Customer Case B, as opposed to Customer Case A, has a larger percentage of dryers that accept delay during the DR signal period. Thus, while all DR release options show reduced energy consumption and peak demand during the DR signal period, the rebound observed in all of the DR release options in Customer Case B are considerably greater. This is meant to highlight the effects of assumptions made about the way users will interact with this system. Currently, this is a relatively unknown quantity that will significantly impact the behavior of the system. Further consumer studies may provide more definitive conclusions. As can also be noted from Figure 2-5, as soon as the Critical signal starts, all dryers in operation immediately enter the ES-Critical mode of operation (which consumes less energy and power) for a fixed duration or until the completion of the dryer cycle, which ever happens first. 


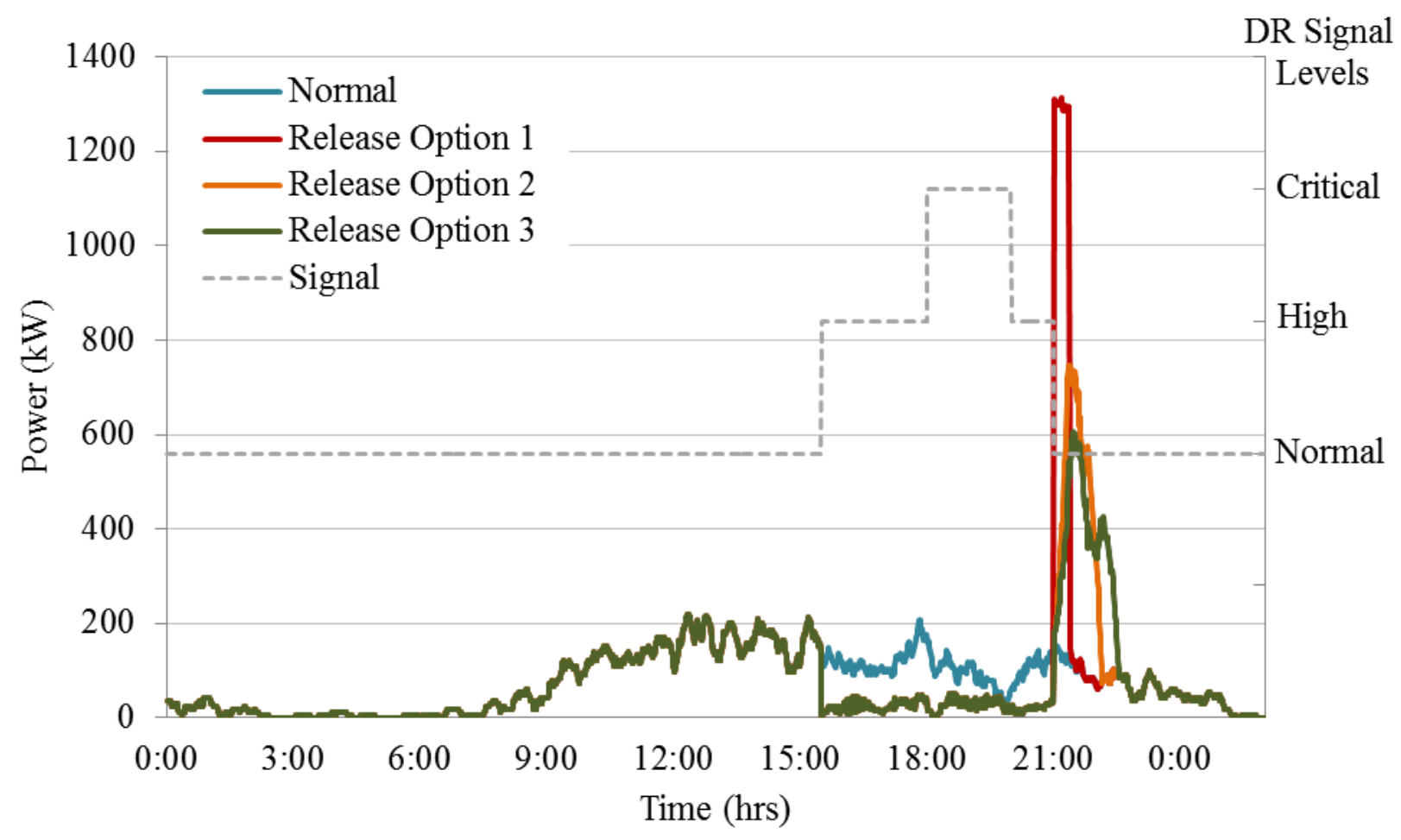

Figure 2-5: Time series of dryer load for Customer Case B and Scenario 1 on a winter weekday.

Figure 2-6 and Figure 2-7 show the simulation results for the different DR release options for Customer Cases A and B, using Scenario 3. In this case, the ES-High mode of operation is engaged during the rebound period and consumes less power and energy than the Normal mode of operation. Thus, the rebound observed in both Customer Cases A and B in Release Options 1, 2 , and 3 are lower than the rebound observed in Scenario 1. Other results are consistent with previous statements. 
DR Signal

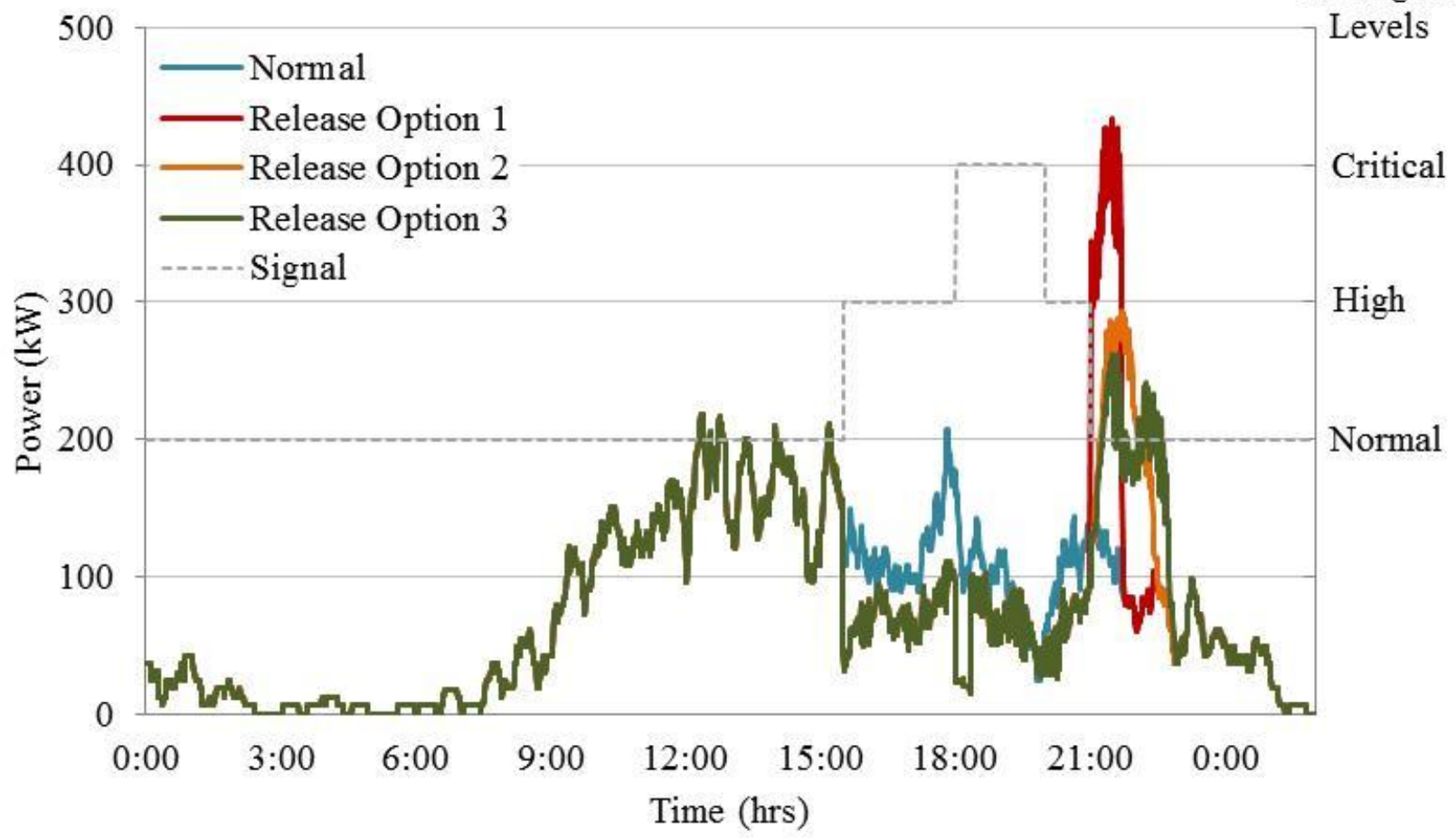

Figure 2-6: Time series of dryer load of Customer Case A and Scenario 3 on a winter weekday.

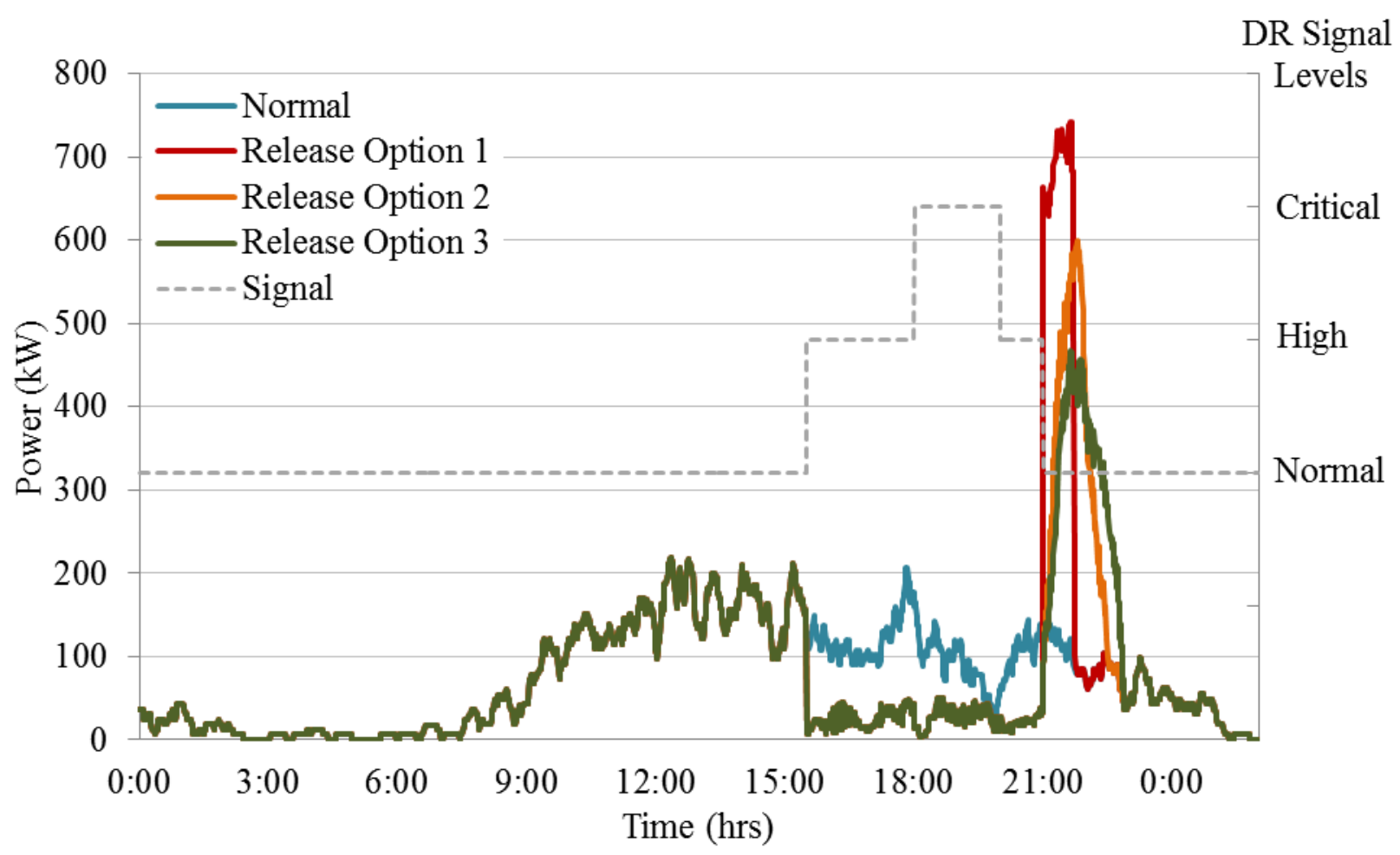

Figure 2-7: Time series of dryer load of Customer Case B and Scenario 3 on a winter weekday. 
Figure 2-8 and Figure 2-9 show the simulation results for the different DR release options for Customer Cases A and B respectively, in this case, using Scenario 2. As can be observed from Table 2-7 and Table 2-8, the peak demand rebound of all the DR release options in Scenario 2 (both Customer Cases A and B) have a lower peak demand rebound than the corresponding DR release options in Scenario 1. This is because the cycle times of the dryer vary over a wider range than in the case of Scenario 2. Again, Customer Case B has a higher rebound than Customer Case A in Scenario 2 due to more customers accepting a delay in operation.

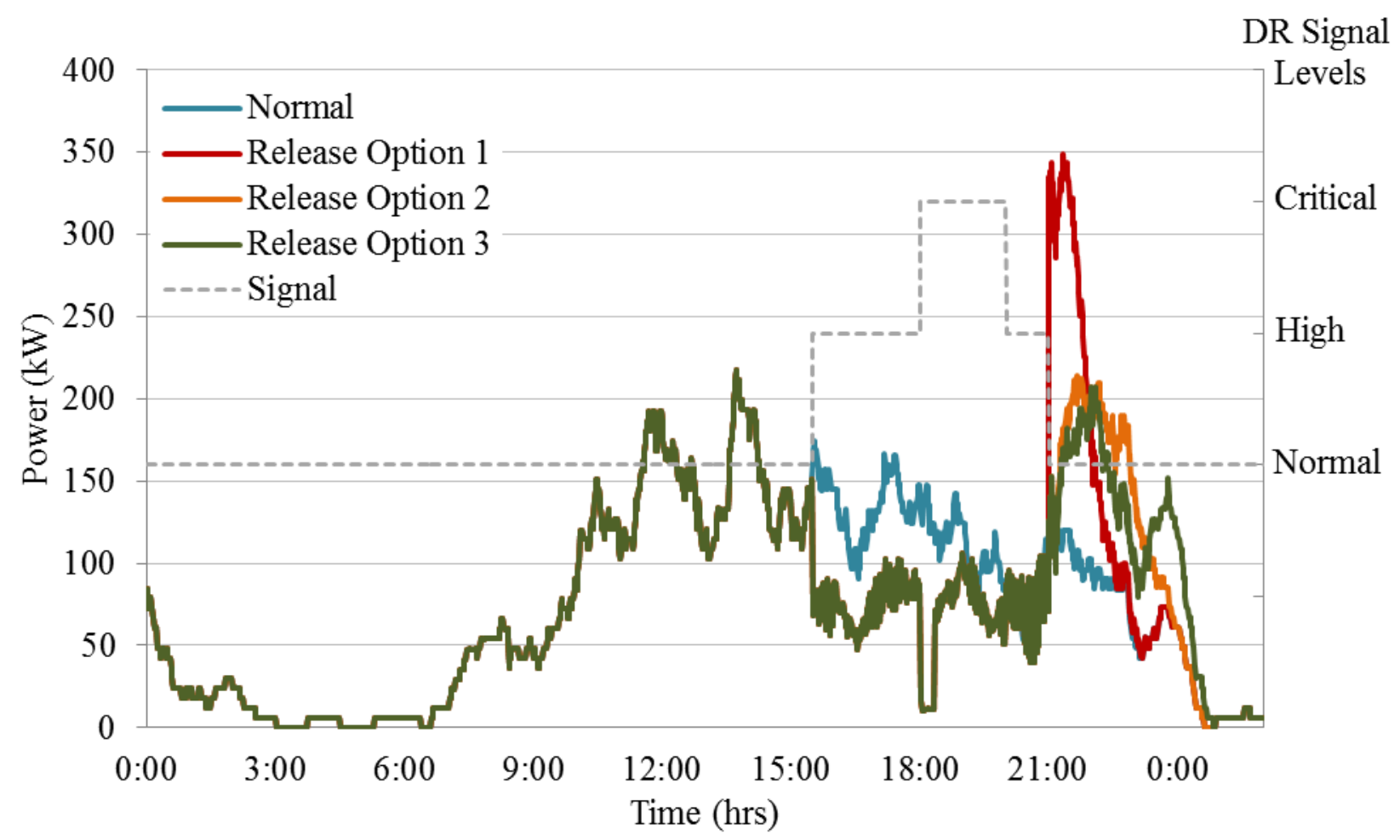

Figure 2-8: Time series of dryer load of Customer Case A and Scenario 2 on a winter weekday. 
DR Signal

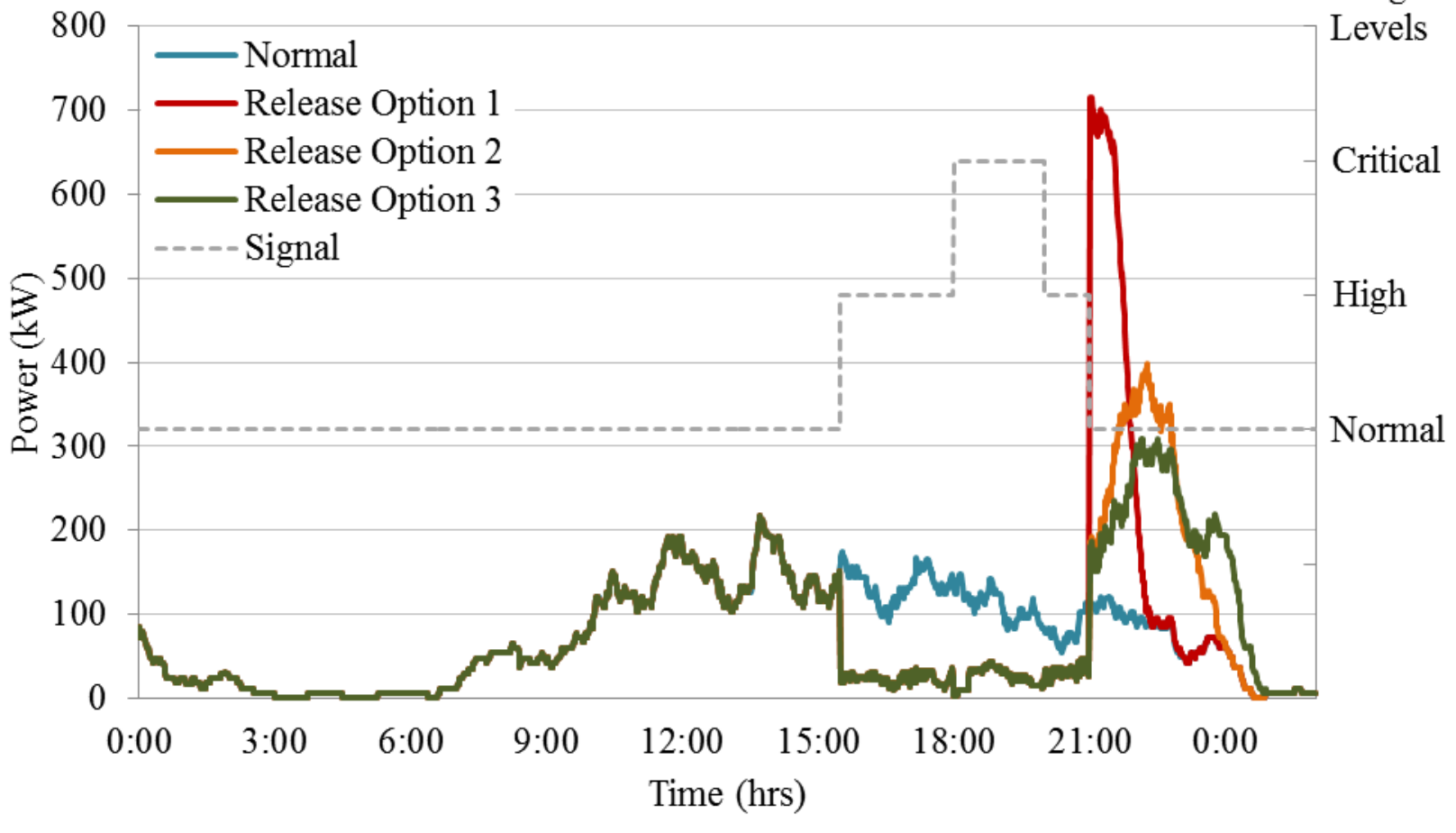

Figure 2-9: Time series of dryer load of Customer Case B and Scenario 2 on a winter weekday.

Table 2-7: Comparison of peak rebound for release options in Customer Case A and Scenarios 1 and 2.

\begin{tabular}{|l|r|r|}
\hline \multicolumn{3}{|c|}{ Rebound Peak for Customer Case A } \\
\hline & Scenario 1 & Scenario 2 \\
\hline Normal & 150.70 & 120.23 \\
\hline DR Release Option 1 & 650.59 & 349.10 \\
\hline DR Release Option 2 & 366.03 & 214.52 \\
\hline DR Release Option 3 & 312.48 & 207.22 \\
\hline
\end{tabular}

Table 2-8: Comparison of peak rebound for release options in Customer Case B and Scenarios 1 and 2.

\begin{tabular}{|l|r|r|}
\hline \multicolumn{3}{|c|}{ Rebound Peak for Customer Case B } \\
\hline & Scenario 1 & \multicolumn{1}{c|}{ Scenario 2 } \\
\hline Normal & 150.70 & 120.14 \\
\hline DR Release Option 1 & 1312.60 & 716.14 \\
\hline DR Release Option 2 & 746.74 & 398.10 \\
\hline DR Release Option 3 & 605.28 & 308.92 \\
\hline
\end{tabular}

Figure 2-10 and Figure 2-11 show the simulation results for the different DR release options for Customer Cases A and B respectively, in this case, using Scenario 4. As was previously 
stated, the ES-High mode of operation consumes less power and energy than the Normal mode operation, thus, the rebound observed in both Customer Cases A and B in Scenario 4 are lower than the rebound observed in the two cases in Scenario 1. Also, as was observed in Scenario 2, Customer Case B has a higher rebound than Customer Case A in Scenario 4.

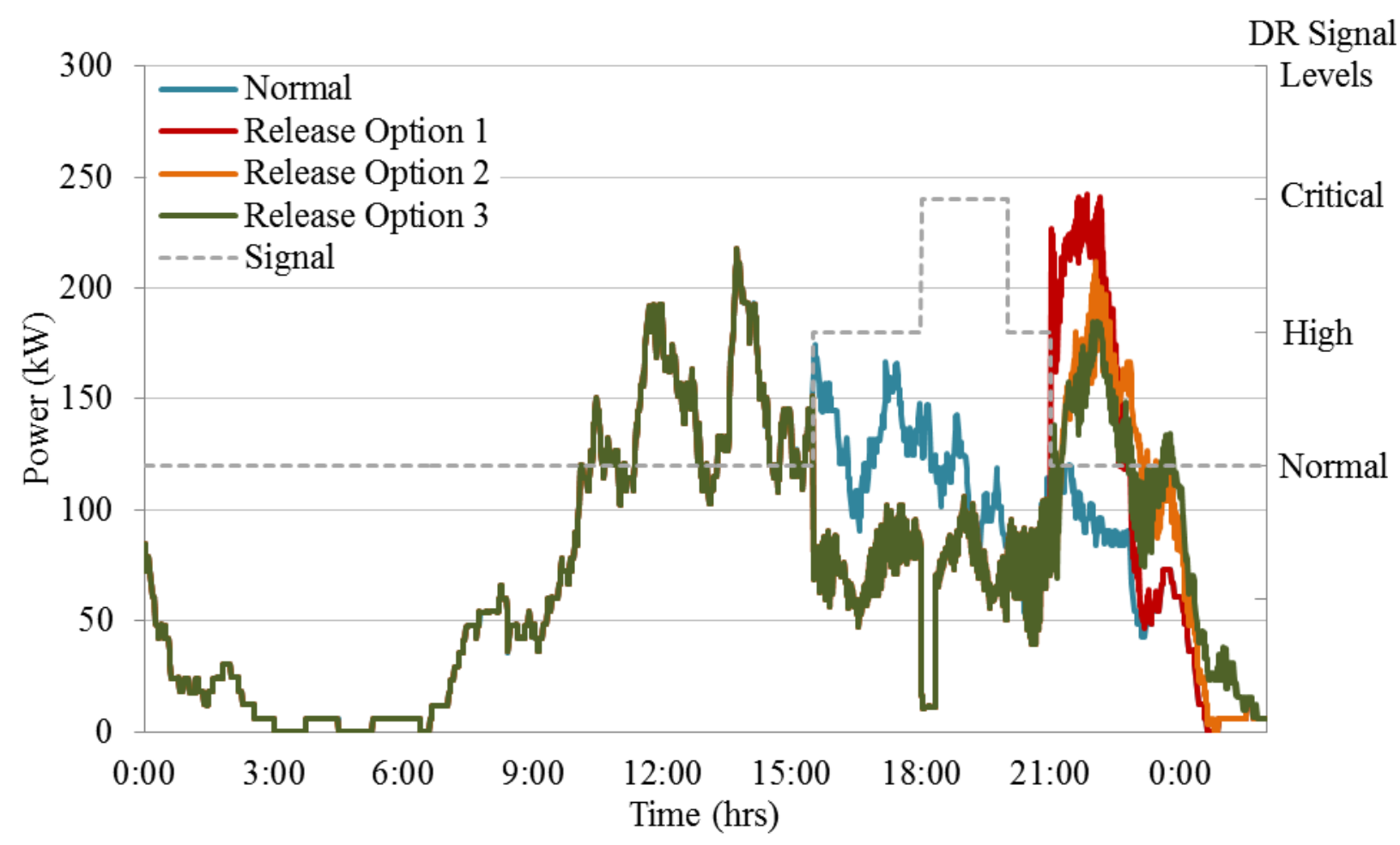

Figure 2-10: Time series of dryer load for Customer Case A and Scenario 4 on a winter weekday. 


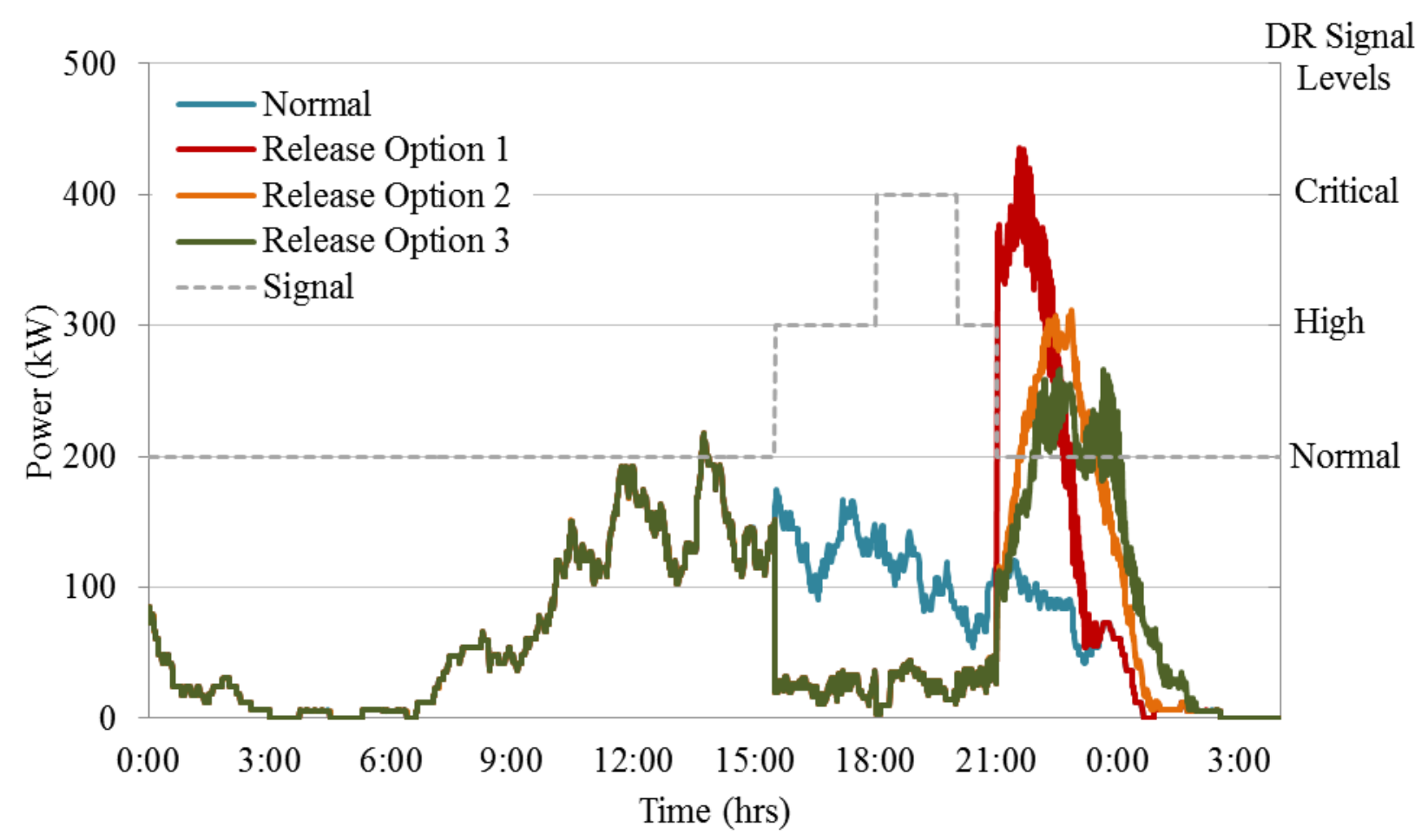

Figure 2-11: Time series of dryer load for Customer Case B and Scenario 1 on a winter weekday.

As previously discussed, peak reduction during high pricing periods is often considered a significant benefit of DR. Table 2-9 compares peak power during the DR signal period for all of the DR release options normalized against the Normal mode. Significant reduction in the peak demand occurs under both Customer Case A and Case B. Since Scenario 1 and Scenario 3 only differ in the appliance response after the DR signal period, the peak power observed for Customer Case A (and B) is the same for both scenarios. While the peak power seen during the DR Signal for Customer Case A is approximately $54 \%$ of the peak power seen in the Normal case, the peak power seen in Customer Case B is even lower, that is, it is $25 \%$ of the peak power seen in the Normal case. Table 2-10 compares peak power during the DR signal period for all DR release options normalized against the Normal mode. The peak power observed during the DR signal period for Customer Case A is $61 \%$ of the peak power observed in the Normal case and the peak power observed in Customer Case B is $27 \%$ of the peak power observed in the Normal case. 
Table 2-9: Comparison of peak demand during the DR signal period for Scenarios 1 and 3.

\begin{tabular}{|c|r|r|r|r|}
\hline \multicolumn{5}{|c|}{ Peak Power During DR signal period, Normalized against the Normal Case } \\
\hline & \multicolumn{1}{|c|}{ Normal } & $\begin{array}{c}\text { DR Release } \\
\text { Option 1 }\end{array}$ & $\begin{array}{c}\text { DR Release } \\
\text { Option 2 }\end{array}$ & $\begin{array}{c}\text { DR Release } \\
\text { Option 3 }\end{array}$ \\
\hline Scenario 1 - Customer Case A & 1.00 & 0.54 & 0.54 & 0.54 \\
\hline Scenario 1 - Customer Case B & 1.00 & 0.25 & 0.25 & 0.25 \\
\hline Scenario 3 - Customer Case A & 1.00 & 0.54 & 0.54 & 0.54 \\
\hline Scenario 3 - Customer Case B & 1.00 & 0.25 & 0.25 & 0.25 \\
\hline
\end{tabular}

Table 2-10: Comparison of peak demand during the DR signal period for Scenarios 2 and 4.

\begin{tabular}{|c|r|r|r|r|}
\hline \multicolumn{5}{|c|}{ Peak Power During DR signal period, Normalized against the Normal Case } \\
\hline & Normal & $\begin{array}{c}\text { DR Release } \\
\text { Option 1 }\end{array}$ & $\begin{array}{c}\text { DR Release } \\
\text { Option 2 }\end{array}$ & $\begin{array}{c}\text { DR Release } \\
\text { Option 3 }\end{array}$ \\
\hline Scenario 2 - Customer Case A & 1.00 & 0.61 & 0.61 & 0.61 \\
\hline Scenario 2 - Customer Case B & 1.00 & 0.27 & 0.27 & 0.27 \\
\hline Scenario 4 - Customer Case A & 1.00 & 0.61 & 0.61 & 0.61 \\
\hline Scenario 4 - Customer Case B & 1.00 & 0.27 & 0.27 & 0.27 \\
\hline
\end{tabular}

Table 2-11 shows the energy consumption during the DR signal period for both customer cases of Scenarios 1 and 3. Table 2-12 shows the energy consumption during DR signal period for both Scenarios 2 and 4. In all four of the scenarios, Customer Case A results in a lesser reduction of energy consumption during the DR signal hours as compared to Customer Case B. This is expected, as in Customer Case A, fewer dryers accept delay, "choosing" instead to run during the DR signal hours.

Table 2-11: Comparison of energy consumption during the DR signal period for Scenarios 1 and 3.

\begin{tabular}{|l|r|r|r|r|}
\hline \multicolumn{5}{|c|}{ Energy Consumption during DR signal period, Normalized against Normal case } \\
\hline & Normal & $\begin{array}{c}\text { DR Release } \\
\text { Option 1 }\end{array}$ & $\begin{array}{c}\text { DR Release } \\
\text { Option 2 }\end{array}$ & $\begin{array}{c}\text { DR Release } \\
\text { Option 3 }\end{array}$ \\
\hline Scenario 1 - Customer Case A & 1.00 & 0.62 & 0.62 & 0.62 \\
\hline Scenario 1 - Customer Case B & 1.00 & 0.23 & 0.23 & 0.23 \\
\hline Scenario 3 - Customer Case A & 1.00 & 0.62 & 0.62 & 0.62 \\
\hline Scenario 3 - Customer Case B & 1.00 & 0.23 & 0.23 & 0.23 \\
\hline
\end{tabular}


Table 2-12: Comparison of energy consumption during the DR signal period for Scenarios 2 and 4.

\begin{tabular}{|l|r|r|r|r|}
\hline \multicolumn{5}{|c|}{ Energy Consumption during DR signal period, normalized against Normal case } \\
\hline & \multicolumn{1}{|c|}{ Normal } & $\begin{array}{c}\text { DR Release } \\
\text { Option 1 }\end{array}$ & $\begin{array}{c}\text { DR Release } \\
\text { Option 2 }\end{array}$ & $\begin{array}{c}\text { DR Release } \\
\text { Option 3 }\end{array}$ \\
\hline Scenario 2 - Customer Case A & 1.00 & 0.62 & 0.62 & 0.62 \\
\hline Scenario 2 - Customer Case B & 1.00 & 0.22 & 0.22 & 0.22 \\
\hline Scenario 4 - Customer Case A & 1.00 & 0.62 & 0.62 & 0.62 \\
\hline Scenario 4 - Customer Case B & 1.00 & 0.22 & 0.22 & 0.22 \\
\hline
\end{tabular}

As previously discussed, the peak power during the rebound period, i.e., peak power after a DR signal period, may be considered an undesirable effect of DR. Table 2-13 shows the peak power in the rebound period for both customer cases for Scenarios 1 and 3. Table 2-14 shows the peak power during the rebound period for both customer cases of Scenarios 2 and 4. In all the four scenarios, Customer Case A has the smaller peak power during the rebound period as compared to Customer Case B. This is expected, as in Customer Case A, fewer dryers accept delay, "choosing" instead to run during the DR signal hours. Hence, after a DR signal period, fewer dryers start operation as compared to Customer Case B in all four of the scenarios. Also, from Table 2-13 and Table 2-14, across all scenarios, DR Release Option 3 has the lowest peak power during the rebound period, followed by DR Release Option 2. The highest peak power during the rebound period is observed in DR Release Option 1. In DR Release Option 3, after a DR signal period, the dryers re-start over a longer time period as compared to the other two release options. Hence, staggering the re-start of the dryers over a longer time period can mitigate some of the peak rebound effects.

Table 2-13: Comparison of the peak power after a DR signal period for Scenarios 1 and 3.

\begin{tabular}{|l|r|r|r|r|}
\hline \multicolumn{2}{|c|}{ Peak Rebound - Peak Power after DR signal period, Normalized against Normal case } \\
\hline & Normal & $\begin{array}{c}\text { DR Release } \\
\text { Option 1 }\end{array}$ & $\begin{array}{c}\text { DR Release } \\
\text { Option 2 }\end{array}$ & $\begin{array}{c}\text { DR Release } \\
\text { Option 3 }\end{array}$ \\
\hline Scenario 1 - Customer Case A & 1.00 & 4.32 & 2.43 & 2.07 \\
\hline Scenario 1 - Customer Case B & 1.00 & 8.71 & 4.96 & 4.02 \\
\hline Scenario 3 - Customer Case A & 1.00 & 2.88 & 1.95 & 1.74 \\
\hline Scenario 3 - Customer Case B & 1.00 & 4.93 & 3.97 & 3.10 \\
\hline
\end{tabular}


Table 2-14: Comparison of the peak powers after a DR signal period for Scenarios 2 and 4.

\begin{tabular}{|l|r|r|r|r|}
\hline \multicolumn{2}{|c|}{ Peak Rebound - Peak Power after DR signal period, Normalized against Normal case } \\
\hline & \multicolumn{1}{|c|}{ Normal } & $\begin{array}{c}\text { DR Release } \\
\text { Option 1 }\end{array}$ & $\begin{array}{c}\text { DR Release } \\
\text { Option 2 }\end{array}$ & $\begin{array}{c}\text { DR Release } \\
\text { Option 3 }\end{array}$ \\
\hline Scenario 2 - Customer Case A & 1.00 & 2.90 & 1.78 & 1.72 \\
\hline Scenario 2 - Customer Case B & 1.00 & 5.96 & 3.31 & 2.57 \\
\hline Scenario 4 - Customer Case A & 1.00 & 2.02 & 1.76 & 1.54 \\
\hline Scenario 4 - Customer Case B & 1.00 & 3.63 & 2.60 & 2.22 \\
\hline
\end{tabular}

If achieving maximum peak reduction is the most important objective, then the most optimal scenario for the dryer appliance would be when a greater percentage of consumers choose to delay the operation of their dryer's during a DR signal period. If reducing peak demand while mitigating the rebound peak effects is the most important objective, then delaying a large percentage of dryers during the DR signal and re-starting them over a longer period after the DR signal in the ES-High mode could be the best scenario for the electric clothes dryer. As will be observed in Section 3, the aggregated dryer peak demand does not align with the feeder peak (or system peak in this study). Hence, peak demand within the rebound period of the dryer response may not necessarily be the biggest factor for deciding the best dryer scenario. Depending upon the load shifting versus load reduction requirements for a particular system or feeder, the best method for running the dryer appliance can be decided. It can also be noted from the plots and the tables above that the response obtained from the dryer appliance can provide significant peak and energy reduction and hence can provide significant load shifting or load leveling benefits, again depending upon how the timing of the dryer load aligns with the load reduction needs of the system.

\subsection{Clothes Washer}

The GE clothes washer operates in the following manner - the unit is filled with water and there is an agitation period where the clothes and water are tumbled in alternating directions with a pause in between. At the end of the wash cycle, the clothes are spun out to remove the soapy/dirty water. Then, fresh rinse water is added, tumbled, and a second spin occurs to remove the diluted water. After that, a second round of fresh water is added followed by more tumbling, and there is a final spin cycle which has the following sequence. There is a preliminary low speed spin period to remove most of the water and then the partially "de-watered" clothes are tumbled to redistribute them in the drum. Then, the final high speed spin is run which progressively increases in speed until it reaches the final high spin speed. This final high speed spin reduces the remaining moisture content of the clothes to a pre-set level.

The clothes washer model in GridLAB-D was designed as a multi-state load model, similar to that used to describe the HVAC system, to represent the operation of the GE clothes washer. 
The different states, and transitions between states, were designed on the basis of the GE Appliances provided current traces from laboratory testing, as well as inputs from GE Appliances as described in this section. The states were modeled and calibrated such that the simulated power output, energy per cycle and cycle time for one clothes washer cycle closely matched the values from the provided current traces. The power output for any state was approximately equal to the power calculated from the average current observed in the current traces for the state cycle with an average voltage of $119 \mathrm{~V}$, as determined from GE Appliances test data. The ZIP components for each state were modeled as $100 \%$ constant current. This is because the GE Appliances Watt traces showed a fairly constant value of current for the different clothes washer states.

The clothes washer can respond in various ways to three signal levels: Normal, High, and Critical. The clothes washer responds to signals based on the value of the signal level at the time that the consumer attempts to start the washer. If the clothes washer is started and the signal is at the Normal level, the washer executes a Normal wash cycle, even if the signal changes during active cycle. However, if a High or Critical signal is being sent at the time the clothes washer is started, it alerts the user and recommends that the operation be delayed. The delay mode is the default option under High or Critical signal levels, and if the consumer does not override the controls, the unit will delay operation until the end of the High or Critical signal, whichever occurs last.

If the clothes washer recommends a delay due to a High or Critical signal, the consumer has the option to override and still use the washer. In the first option for the customer, the clothes washer can make use of the ES-mode, or ES-High, which is a cold water only wash which eliminates the energy use associated with heating of the water. When a Critical signal is received, the ES-Critical mode also extends the cycle to reduce the average power consumption in addition to only using cold water. If the consumer does not wish to accept the ES mode of operation, they can completely override both the delay and the ES mode and proceed with a standard cycle of their choice. The usage of hot water by the Normal mode of operation of a clothes washer in a house would need to be modeled as an extra load demand on the water heater modeled for the same house. However, since such a connection between the appliance loads (water heater plus clothes washer) has not yet been modeled in this study, only the direct electrical consumption is modeled. It should be noted that the equivalent electric energy to heat the water for an average warm cycle is approximately $40 \%$ of the energy label value per load. All of the modes of operation, including the Normal, ES-High, and ES-Critical modes consume approximately the same amount of electric energy (exclusive of water heating) to complete one clothes washer cycle.

In the GridLAB-D model, there are assumptions regarding the consumer behavior when the units are started during either a High or Critical event. The assumptions are based on GE Appliances' expected consumer response to either of these signals; that is what percentage will accept delay, what percentage will choose the ES-High or ES-Critical override, and what 
percentage will choose a full override and run in a Normal mode. For the clothes washer these assumptions were that $75 \%$ would accept a delay during a High or Critical signal, $20 \%$ would choose the ES-High or ES-Critical mode, and 5\% would choose a complete override. Additionally, as was seen in the dryer simulations, various randomization functions were tested to determine the effectiveness of built-in clothes washers controls in mitigating a peak rebound when the customer chooses to delay their operation.

\subsubsection{Clothes Washer Simulation Results}

The GridLAB-D model of the clothes washer was validated against available GE Appliances data. A model was then created which populated a representative distribution feeder containing 544 individual residences, each with statistically sampled parameters and behaviors, and each of the residences contained a clothes washer. To create a base case which represented a realistic scenario, load shapes from the ELCAP load study, shown in Figure 2-12, are used to estimate the usage pattern of the clothes washer at different times of the day, during the course of an average day [9]. Again, updated information for annual energy consumption was used to create a case which more accurately represented actual appliance usage patterns, while still using the overall shape from the ELCAP studies. More details on the calibration process can be found in Appendix B.

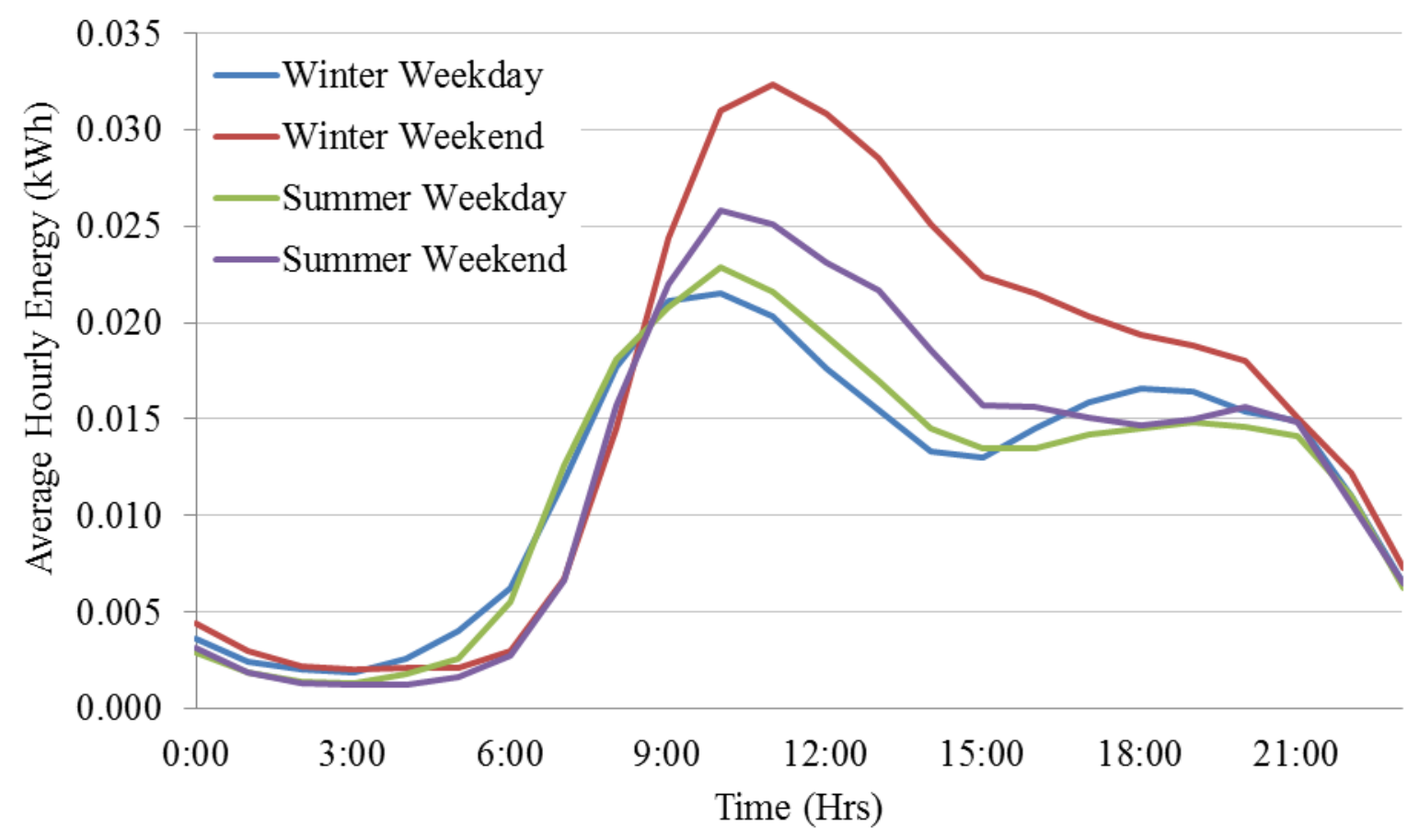

Figure 2-12: ELCAP load shapes for the clothes washer. 
Additionally, two DR cases were simulated and compared to the base case. The DR signal used for testing the clothes washer model is shown in Table 2-15. Table 2-16 shows the percentage of customers who interact with the DR signal via the three pre-defined options. Notice, in this case, the assumptions during the High signal indicate that none of the customers' will accept a delay, but $95 \%$ will switch to the ES-mode. This has the effect that there will be no net reduction of clothes washer load during the High signal, only reduction in water heater load, which is not currently captured by this model. Again, these are inputs into the model, and can be adjusted to meet a variety of assumptions. Table 2-17 shows the two release option cases explored, ranging from no additional delay where all of customers which accepted delay immediately re-start when the Normal signal returns, to a uniform distribution of time equal to a Normal clothes washer cycle length following the return to a Normal signal.

Table 2-15: DR signal used in the clothes washer simulations.

\begin{tabular}{|c|c|}
\hline & Time \\
\hline Critical & $18: 00-20: 00$ \\
\hline High & $16: 00-18: 00,20: 00-22: 00$ \\
\hline Normal & all other times \\
\hline
\end{tabular}

Table 2-16: Customer behavior cases used in the clothes washer simulations.

\begin{tabular}{|c|c|c|c|c|c|c|}
\hline \multirow{2}{*}{} & \multicolumn{3}{|c|}{ During the High Signal } & \multicolumn{2}{c|}{ During the Critical Signal } \\
\cline { 2 - 7 } & $\begin{array}{c}\text { Accept } \\
\text { Delay }\end{array}$ & $\begin{array}{c}\text { Use ES- } \\
\text { mode }\end{array}$ & $\begin{array}{c}\text { Override all } \\
\text { DR options }\end{array}$ & $\begin{array}{c}\text { Accept } \\
\text { Delay }\end{array}$ & $\begin{array}{c}\text { Use ES- } \\
\text { mode }\end{array}$ & $\begin{array}{c}\text { Override all } \\
\text { DR options }\end{array}$ \\
\hline Customer Case A & $0 \%$ & $95 \%$ & $5 \%$ & $75 \%$ & $20 \%$ & $5 \%$ \\
\hline
\end{tabular}

Table 2-17: Built-in release options explored in clothes washer simulations.

\begin{tabular}{|c|c|}
\hline & Additional Delay Time Distribution \\
\hline $\begin{array}{c}\text { DR Release } \\
\text { Option 1 }\end{array}$ & None - All delayed clothes washers start \\
immediately.
\end{tabular}


Figure 2-13 shows the time series of the daily power consumption of all of the clothes washers for all three cases (Normal, DR Release Option 1, and DR Release Option 2). Table 2-18 compares the data from the three cases. Also note that until the ends of the DR signal periods, DR Release Options 1 and 2 have identical demand; the difference in the two cases is not evident until the return to the Normal signal. Again, note that this simulation does not take into account the secondary effects of reduced water heater loads.

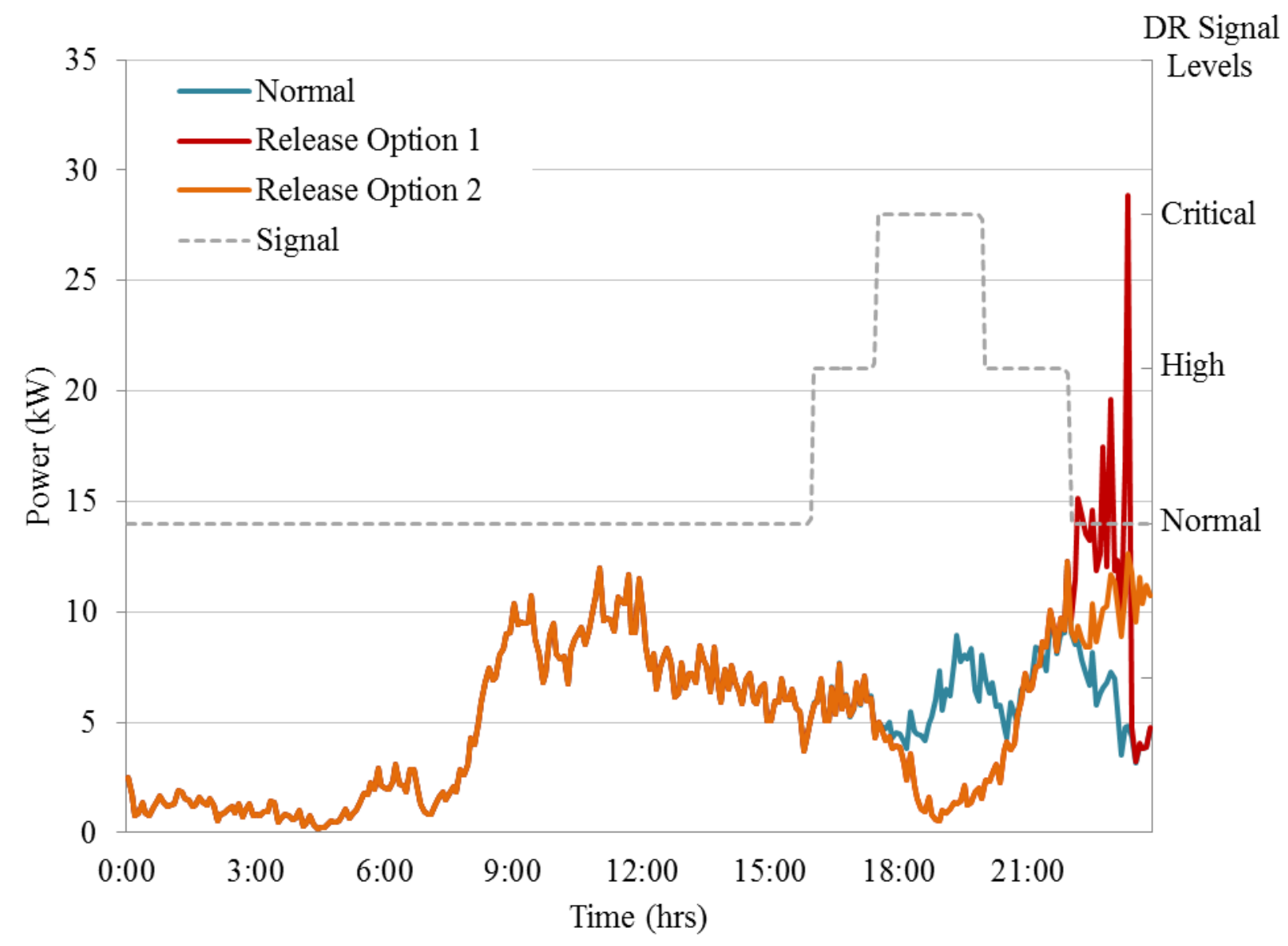

Figure 2-13: Time series comparison of clothes washer load on a winter weekday. 
Table 2-18: Comparison of results for DR and Normal case on a winter weekday.

\begin{tabular}{|c|c|c|c|}
\hline Metric & Normal & $\begin{array}{c}\text { DR Release } \\
\text { Option 1 }\end{array}$ & $\begin{array}{c}\text { DR Release } \\
\text { Option 2 }\end{array}$ \\
\hline Daily Energy Consumption (kWh) & 122 & 122 & 119 \\
\hline $\begin{array}{c}\text { Energy Consumption during DR } \\
\text { signal period (kWh) }\end{array}$ & 38 & 27 & 27 \\
\hline $\begin{array}{c}\text { Energy Consumption during Critical } \\
\text { signal period (kWh) }\end{array}$ & 15 & 5 & 5 \\
\hline $\begin{array}{c}\text { Energy Consumption after the DR } \\
\text { signal period (kWh) }\end{array}$ & 12 & 22 & 19 \\
\hline Peak during DR signal period (kW) & 12 & 12 & 12 \\
\hline $\begin{array}{c}\text { Peak during the Critical signal period } \\
\text { (kW) }\end{array}$ & 9 & 5 & 13 \\
\hline $\begin{array}{c}\text { Peak Rebound after the DR signal } \\
\text { period (kW) }\end{array}$ & 9 & 29 & 13 \\
\hline Daily Peak Power (kW) & 12 & 29 & 5 \\
\hline
\end{tabular}

As can be seen from Table 2-18, DR Release Option 1 has the highest daily peak power value at $29 \mathrm{~kW}$, which occurs during the rebound period when all of the clothes washers that accepted delay during the Critical signal period start as soon as the Normal signal arrives. This rebound peak is more than twice the daily peak observed in the Normal case $(12 \mathrm{~kW})$. This is not surprising, considering that in DR Release Option 1, the delayed clothes washers (75\% of the total population in these simulations) simultaneously start their operation when the Normal signal arrives, temporarily decreasing diversity within the system. However, if the clothes washers that accepted a delay during the Critical signal period randomize their restart time following the return to the Normal signal, the rebound effect is less severe, as can be seen from DR Release Option 2; this value is reduced to $13 \mathrm{~kW}$.

During the High and Critical signal periods (DR signal period), the peak demand is nearly identical for all the three cases $(\sim 12 \mathrm{~kW})$, and occurs at the very end of the final High period. This is indicative of the fact that certain loads are not coincidental with system peaks. However, since the clothes washer load changes in response to the Critical signal, the peak within the Critical period is still reduced. As can be noted from Table 2-18, the peak during the Critical signal period for the two release options is only $5 \mathrm{~kW}$, as compared to the $9 \mathrm{~kW}$ for the Normal case. Similarly, the energy consumed during the Critical signal period is only $5 \mathrm{kWh}$ in both DR Release Options as compared to $15 \mathrm{kWh}$ in the Normal case.

As can be observed in Table 2-18, there is a $29 \%$ reduction in energy consumption in both of the DR Release Options during the DR signal period in comparison to the energy consumed in the Normal case during the DR signal period. Daily energy consumption for DR Release Option 2 is shown as reducing daily energy consumption $(119 \mathrm{kWh})$ as compared to the other two cases $(122 \mathrm{kWh})$; however this is strictly a consequence of how the metric is determined. Some clothes washers specifying a delay for the start of their operation do not complete their cycle before the 
end of the day (midnight). Hence the energy required to complete their cycle does not get added to the daily calculations presented in Table 2-18. Indications are that there are no direct energy savings, except where the reduced hot water usage decreases water heater demand.

\subsection{Dishwasher}

A dishwasher is equipped with two motors, a main pump supplying the spray arms of the washer, a small drain pump to pump the water out of the unit, a heating element, control switches, and thermostats. Wash cycles, drying cycles, and temperature selection can be performed using selector switches. The heating element is used to heat the water for wash cycles to a pre-set value $\left(120^{\circ} \mathrm{F}\right)$ and if selected provides heat to dry the dishes. When the unit is started, the unit fills with water and the main pump starts pumping water to the spray arms and the heating element heats the water to the pre-set value if it is below the desired temperature. There are several pre-wash spray cycles followed by dispensing of the detergent and additional wash/spray cycles. The unit is drained using the drain pump, refilled, and a rinse cycle takes place. Once the rinse cycle is complete, the motor drains the last rinse water and the heating elements heat the air in the dishwasher to dry the dishes.

The dishwasher model developed in GridLAB-D is a multi-state load model. These states are defined by the level of their electricity consumption and are discussed in more detail in Appendix A. GE Appliances developed DR control strategies for dishwasher operation based on control signals: Normal, High, and Critical. When the operator starts a unit during a High or Critical signal, the default mode is for the dishwasher to be delayed. If the consumer chooses to override the dishwasher during the High or Critical signal, the unit can be operated in a reduced energy or ES-mode. This reduced energy setting operates by consuming less energy than the Normal cycle by eliminating the heated dry stage of the dishwasher cycle. The customer always has the option to completely override the DR signal and run the dishwasher in Normal mode. If the operation of the dishwasher is delayed, then the entire process, including the mechanical energy and the hot water energy, both in terms of the hot water heater and the inline dishwasher water heater, will be delayed until the signal returns to Normal. The basic assumption made in the GridLAB-D implementation of the dishwasher model is that for each mode, the amount of energy needed by a dishwasher is constant. As the actual value of the distribution feeder voltage continuously changes, ZIP fractions are used in dishwasher model in order to capture how the energy consumption of dishwashers vary with respect to the distribution feeder voltage. The ZIP values used for this model are shown in Table 2-19. 
Table 2-19: Dishwasher model ZIP fractions.

\begin{tabular}{|c|c|c|c|}
\hline & $Z$ & $I$ & $P$ \\
\hline Main pump motor & 0.1 & 0.1 & 0.8 \\
\hline Drain pump motor & 0.1 & 0.1 & 0.8 \\
\hline Heating coil & 1.0 & 0.0 & 0.0 \\
\hline
\end{tabular}

\subsubsection{Dishwasher Simulation Results}

To estimate the potential benefits of GE dishwasher in reducing the peak demand, detailed time series simulations were conducted in GridLAB-D using a prototypical feeder, R1-1247-2 [1], with 646 residences, each containing a DR-enabled GE dishwasher. Note, that this is a different distribution feeder (with a different number of residences) than previous simulations. In preparation for an "all appliances" simulation, the test feeder circuit was changed to a prototypical feeder from the West Coast. The individual appliance simulations are performed on two different feeder circuits, though only a single one is used for each appliance, while in the final analysis in Section 3 only a single circuit model is used.

Load shapes from the ELCAP load study are used to estimate the usage pattern of dishwashers at different times, during the course of an average day to create an initial base case [9]. Figure 2-14 shows the ELCAP dishwasher load shapes for each day type. Again, updated information on annual energy consumption was used to create a more realistic simulation. However, the general shape of the ELCAP load shapes were used to dispatch the appliance usage. The calibration methodology for matching ELCAP load shapes to GridLAB-D aggregate simulations is presented in Appendix B. 


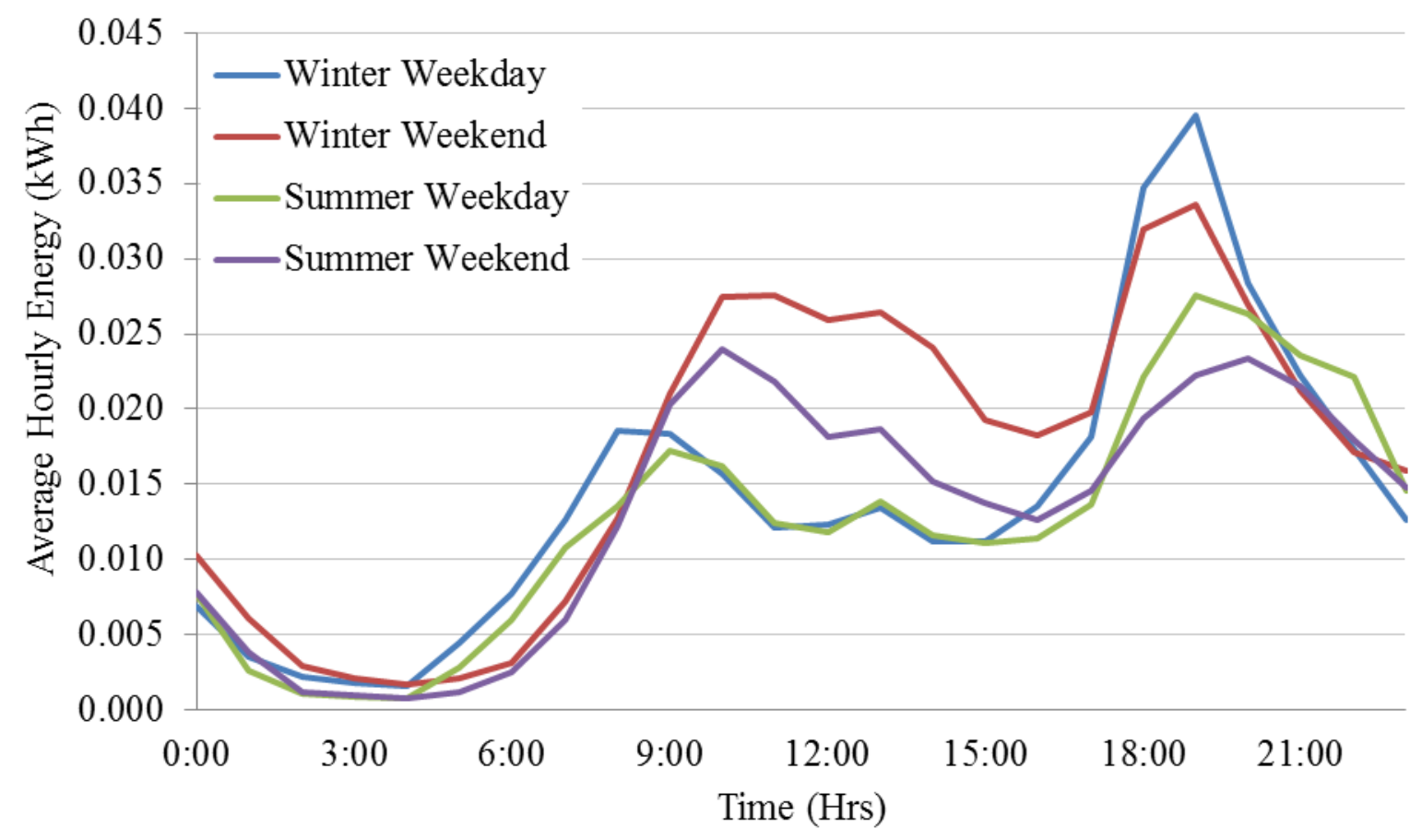

Figure 2-14: ELCAP dishwasher load shape.

The response of the dishwasher was tested against a series of DR signals, as shown in Table 2-20. Table 2-21 shows the assumptions for what percentage of customers accept a delay versus use the ES-mode, versus override the DR options and operate in Normal mode when receiving a High or Critical signal. Table 2-22 shows the two built-in release options tested for the dishwasher, after returning to a Normal signal after a High or Critical signal.

Table 2-20: DR signal used in the dishwasher simulations.

\begin{tabular}{|c|c|}
\hline & Time \\
\hline Critical & $18: 00-20: 00$ \\
\hline High & $15: 30-18: 00,20: 00-21: 00$ \\
\hline Normal & all other times \\
\hline
\end{tabular}

Table 2-21: Customer behavior cases used in the dishwasher simulations.

\begin{tabular}{|l|c|c|c|}
\hline & $\begin{array}{c}\text { Accept } \\
\text { Delay }\end{array}$ & $\begin{array}{c}\text { Use ES- } \\
\text { mode }\end{array}$ & $\begin{array}{c}\text { Override all } \\
\text { DR options }\end{array}$ \\
\hline Customer Case A & $90 \%$ & $10 \%$ & $0 \%$ \\
\hline
\end{tabular}


Table 2-22: Built-in release options explored in dishwasher simulations.

\begin{tabular}{|c|c|}
\hline & Additional Delay Time Distribution \\
\hline $\begin{array}{c}\text { DR Release } \\
\text { Option 1 }\end{array}$ & $\begin{array}{c}\text { None }- \text { All delayed dishwashers start } \\
\text { immediately. }\end{array}$ \\
\hline $\begin{array}{c}\text { DR Release } \\
\text { Option 2 }\end{array}$ & $\begin{array}{c}\text { Uniform distribution between 0 and 5000 } \\
\text { seconds. }\end{array}$ \\
\hline
\end{tabular}

Figure 2-15 shows the time series power consumption of the population of dishwashers (Normal, Release Options 1 and 2) to the shown DR signal on a winter weekend as compared to the base case. As per the GE Appliances' DR strategies for dishwashers, the aggregate dishwasher loads consume less energy during the High and Critical periods. However, much of the reduction during the High and Critical periods can be attributed to the acceptance of the delayed start of $90 \%$ of the users. The reduction in the average energy consumption per dishwasher for the day, in response to the DR signal, is $2.07 \%$. This is due to the $10 \%$ of dishwashers that do not accept delay and run in ES-mode.

At the end of the High period, however, a significant rebound in the demand can be seen as the signal returns to Normal. The rebound peak in this scenario is significantly greater than the original peak, but for only a short period of time. The peak power consumption of dishwashers after the signal drops from High to Normal are $472.94 \%(72.3 \mathrm{~kW})$ and $285.27 \%(43.6 \mathrm{~kW})$ higher than that of normal operation $(15.3 \mathrm{~kW})$, for Release Options 1 and 2, respectively. This rebound is due to the fact that all of the dishwashers which accepted delay start running in Normal mode when the Normal signal arrives after the end of the High period. The advantage of using the randomized re-start (Release Option 2) is that the peak power consumption of the dishwashers, after the end of the High signal, is $39.7 \%(28.7 \mathrm{~kW})$ lower than that in Release Option 1 (without random re-start). 


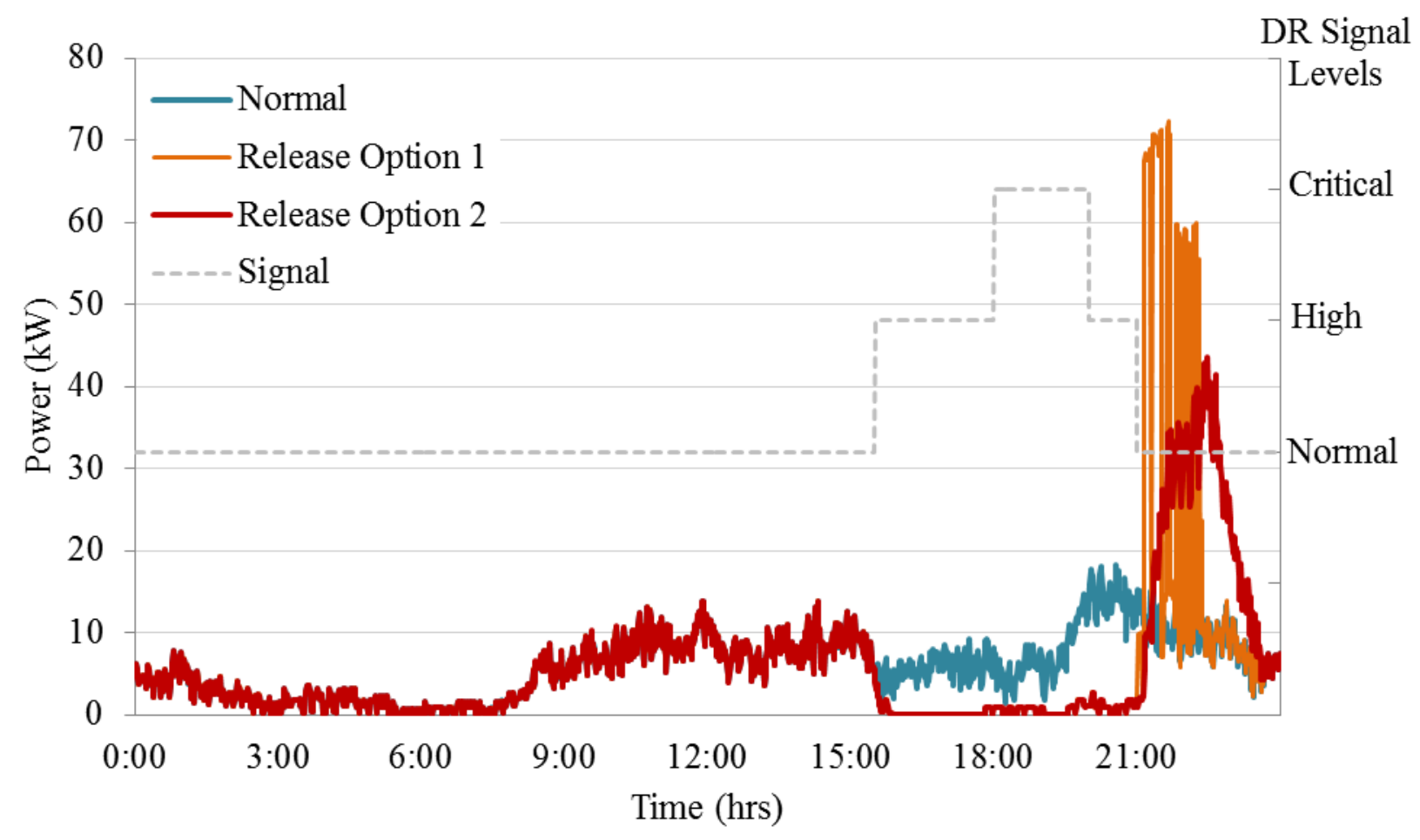

Figure 2-15: Time series of load for the dishwashers on a winter weekend.

Table 2-23 shows the peak power consumption of dishwashers during and soon after the signal drops from High or Critical to Normal. The change in peak power demand of the dishwashers in response to the DR signal (in percentage) with respect to normal consumption is also shown.

Table 2-23: Peak power demand of dishwashers on a winter weekday.

\begin{tabular}{|c|c|c|c|c|c|c|}
\hline \multirow{2}{*}{ Case name } & \multicolumn{2}{|c|}{ Base } & \multicolumn{2}{c|}{$\begin{array}{c}\text { DR Release } \\
\text { Option 1 }\end{array}$} & \multicolumn{2}{c|}{$\begin{array}{c}\text { DR Release } \\
\text { Option 2 }\end{array}$} \\
\cline { 2 - 7 } & $(\mathrm{kW})$ & $(\%)$ & $(\mathrm{kW})$ & $(\%)$ & $(\mathrm{kW})$ & $(\%)$ \\
\hline $\begin{array}{c}\text { Peak power during High/Critical } \\
\text { pricing }(\mathrm{kW})\end{array}$ & 18.3 & 100.0 & 4.0 & 21.9 & 4.0 & 21.9 \\
\hline $\begin{array}{c}\text { Peak power after High/Critical } \\
\text { period }(\mathrm{kW})\end{array}$ & 15.3 & 100.0 & 43.6 & 285.3 & 72.3 & 472.9 \\
\hline
\end{tabular}

The total energy consumptions of all of the dishwashers for the Normal and two release options are shown in Table 2-24. The change in energy consumptions of population of dishwashers in response to the DR signals (in percentage), with respect to Normal energy consumption on a winter weekday are also shown in Table 2-24. 
Table 2-24: Energy consumption of dishwashers on a winter weekday.

\begin{tabular}{|c|c|c|c|c|c|}
\hline \multirow{2}{*}{ Case } & \multicolumn{3}{|c|}{ Energy consumption (kWh) } & \multicolumn{2}{c|}{ Total energy consumption } \\
\cline { 2 - 6 } & $\begin{array}{c}\text { Before High or } \\
\text { Critical pricing }\end{array}$ & $\begin{array}{c}\text { During High or } \\
\text { Critical pricing }\end{array}$ & $\begin{array}{c}\text { After High or } \\
\text { Critical pricing }\end{array}$ & $(\mathrm{kWh})$ & $(\%)$ \\
\hline Normal & 74 & 43 & 27 & 143 & 100.0 \\
\hline $\begin{array}{c}\text { DR Release } \\
\text { Options 1 and 2 }\end{array}$ & 74 & 3 & 63 & 140 & 97.9 \\
\hline
\end{tabular}

From the previous results, it can be observed that the GE dishwasher DR strategies are effective at reducing energy consumption, as well as reducing peak power demand, during the High and Critical period, mainly by shifting the actual dishwasher cycle from a High or Critical period to the Normal signal period. However, the rebound in the load due to DR operations can be significant, and thought should be given to controlling the recovery period. In the presented case, this was done by introducing a delay or randomization operation to increase the diversity factor of the appliances, but other methods may be equally effective. Additionally, it should be noted that the assumptions used for customer participation (i.e., $90 \%$ of people accept delay and $10 \%$ run in ES-mode during High/Critical signal) will greatly affect these results, and are built as inputs into the model to test various other test scenarios.

\subsection{Hybrid Water Heater}

The GE Appliances hybrid water heater $(\mathrm{HWH})$, also called the Geospring ${ }^{\mathrm{TM}}$ hybrid water heater, like most water heaters, is equipped with two resistance heating elements, each rated at $4500 \mathrm{~W}$. The GE Appliances hybrid hot water heater includes a heat pump in addition to the standard coils, and operates on the same basic principle of heat transfer as that seen in an airsource heat pump for space heating drawing 500-550 watts to provide approximately 2.3 (seasonally adjusted energy factor) times larger equivalent amount of thermal energy per electric energy applied. The heat pump has the same basic components as the refrigerator: coils to carry refrigerant gas, a compressor, and fans. The fans draw the surrounding air to pass across the coils to draw heat from the ambient air. The compressor pressurizes the gas in the coil, raising the temperature even higher, in order to transfer this heat to the tank and thereby heat the water.

Additionally, to help consumers reduce peak electricity usage at home, the DR module has been developed. When the signal is Normal, the water heater uses the Normal cycle. During a High or Critical signal, the water heater runs in ES-mode. This setting operates by consuming less energy than that required by the Normal mode. The GE Appliances HWH temperature settings, and thus the energy consumption, vary based on the level of the signal. During a High or Critical period, the temperature setpoint is decreased from its normal operating setpoint and 
the resistive heating elements are locked out from use. During the High period, the temperature setpoint is reduced to $110^{\circ} \mathrm{F}$, while in the Critical period the temperature setpoint is lowered even further to $100^{\circ} \mathrm{F}$. The base temperature setpoints and the allowable setpoint deltas during High or Critical events are controlled electronically from a control panel on the water heater through a digital user interface, rather than a classical mechanical thermostat. In other words, all of the responses are automated, either by default from the factory, or as the customer programs the response. The GE Appliances control strategies for $\mathrm{HWH}$ are discussed in detail in Appendix A.

The GridLAB-D model uses a common two-element design with the possibility of inverted thermostat settings, wherein the upper element maintains a higher temperature than the lower element. The following assumptions were made:

1) Thermal stratification in the tank is not directly modeled. Depending on the situation, the water will be considered to be either of uniform temperature throughout the tank or lumped into two temperature regions (hot and cold layers).

2) The injection of cold inlet water at the bottom of the tank results in either complete mixing with the hot water in the tank or no mixing at all, depending on the volumetric flow rate.

3) The hybrid hot water heater model is a temperature based model rather than energy based one. This means that the duration of the ON period of the heating elements and heat pump depends on the temperature setpoints and the current water temperature.

The GridLAB-D implementation of the HWH model simulation uses two very different models depending on the state of the tank at any given moment [14]. The two models are:

1) One-Node Model - This is a simple, lumped-parameter electric analogue model that considers the entire tank to be a single "slug" of water at a uniform temperature. This model tracks the temperature of the water at any given time and the time required for the temperature to move between two specified points.

2) Two-Node Model - This model, which applies when the heater is in a state of partial depletion, considers the tank to consist of two slugs of water, each at a uniform temperature. The upper "hot" node is near the heater's setpoint temperature, while the lower "cold" node is near the inlet water temperature. This model tracks the location of the boundary between the hot and cold nodes, calculating the movement of that boundary as hot water is drawn from the tank and/or heat is added to the tank.

It was determined that a one-node model with an additional damping factor more accurately matched laboratory testing data from GE Appliances, and is used to model the HWH. The model uses the inputs presented in Table 2-25 for all of the simulations. The temperature dampening concept is borrowed from the oscillatory system dampening. This damping is a force that applies opposite to direction and proportional to the slope based on thermodynamic energy balance [15]. This is discussed in more detail in Appendix A. 
Table 2-25: Hybrid hot water heater simulation inputs.

\begin{tabular}{|c|c|c|}
\hline Variable name & Units & Value \\
\hline Specific heat $(\mathrm{Cp})$ & $\mathrm{BTU} /\left(\mathrm{lb}{ }^{*}\right.$ deg F) & 1 \\
\hline Water density & ${\mathrm{lb} / \mathrm{ft}^{3}}^{3}$ & 62 \\
\hline Volume of tank & Gallons & 45.5 \\
\hline Heating efficiency & Constant & 2.4 \\
\hline Inlet temperature & deg F & 56.5 \\
\hline Output temperature & deg F & 135 \\
\hline Starting temperature & deg F & 131.5 \\
\hline Water demand & Gallons & 79.2 \\
\hline Damping factor & Constant & 1.25 \\
\hline
\end{tabular}

Because the actual value of the distribution feeder voltage continuously changes, ZIP fractions are used in the HWH model. This enables an understanding of how the energy consumption of HWHs varies with respect to the power system it is attached to. The ZIP values used in this model are listed in Table 2-26.

Table 2-26: HWH model ZIP fractions.

\begin{tabular}{|c|c|c|c|}
\hline & $Z$ & $I$ & $P$ \\
\hline Heat pump & 0.1 & 0.1 & 0.8 \\
\hline Heating element & 1.0 & 0.0 & 0.0 \\
\hline
\end{tabular}

\subsubsection{Hybrid Water Heater Simulation Results}

To estimate the potential benefits of HWH model in reducing peak demand, detailed time series simulations were conducted in GridLAB-D using prototypical feeder R1-12.47-2 [1]. The system was modeled from the substation, to the secondary service transformer, down through the triplex service line, into single family residence. In these simulations, 544 single family residences were populated with GE Appliances' DR-enabled HWHs. The tank temperature is set to $135^{\circ} \mathrm{F}$ as long as the DR signal is Normal. If the water temperature drops to half of the thermostat deadband below the desired setpoint, either the heat pump, the heating elements, or both turn on to reheat the water in the water heater and maintain the storage tank water temperature. Although, the heat pump runs longer to reheat the water, on an average, it consumes $62 \%$ lesser energy than that by the heating elements.

As per GE Appliances' recommendation, the Canadian Standards Association (CSA) [16] schedules were used to determine the number of gallons of water consumed by each HWH per 
day. For a population of HWHs in each of the simulations, approximately $50 \%$ of the HWHs use the CSA B ( 59.5 gallons/day) and the remaining use CSA C ( 79.3 gallons/day). However, the actual water draw schedules were designed using a modified version of the ELCAP water heater load shapes to create a distribution of water draw schedules across the population. The load shapes were constructed to generate a sequence of modulated pulses (water demand) by using the ELCAP water heater load shape, so that each appliance received an individualized water draw schedule. However, while each appliance received a randomized schedule, the energy consumption of the population matched the relative pattern of the ELCAP load shape, while also consuming the amount of hot water dictated by the CSA schedules. Of course, daily and annual energy consumption was not matched to the ELCAP load shapes, as the HWH uses considerably less energy than a standard resistance heating element. To illustrate this process, Figure 2-16 shows the ELCAP load shapes for a water heater, while Figure 2-17 shows two individual water heater draw schedules for a winter day and Figure 2-18 shows the total draw of the entire population of 544 water heaters over the course of a single winter day. The average water demand is approximately 68 gallons/day/HWH.

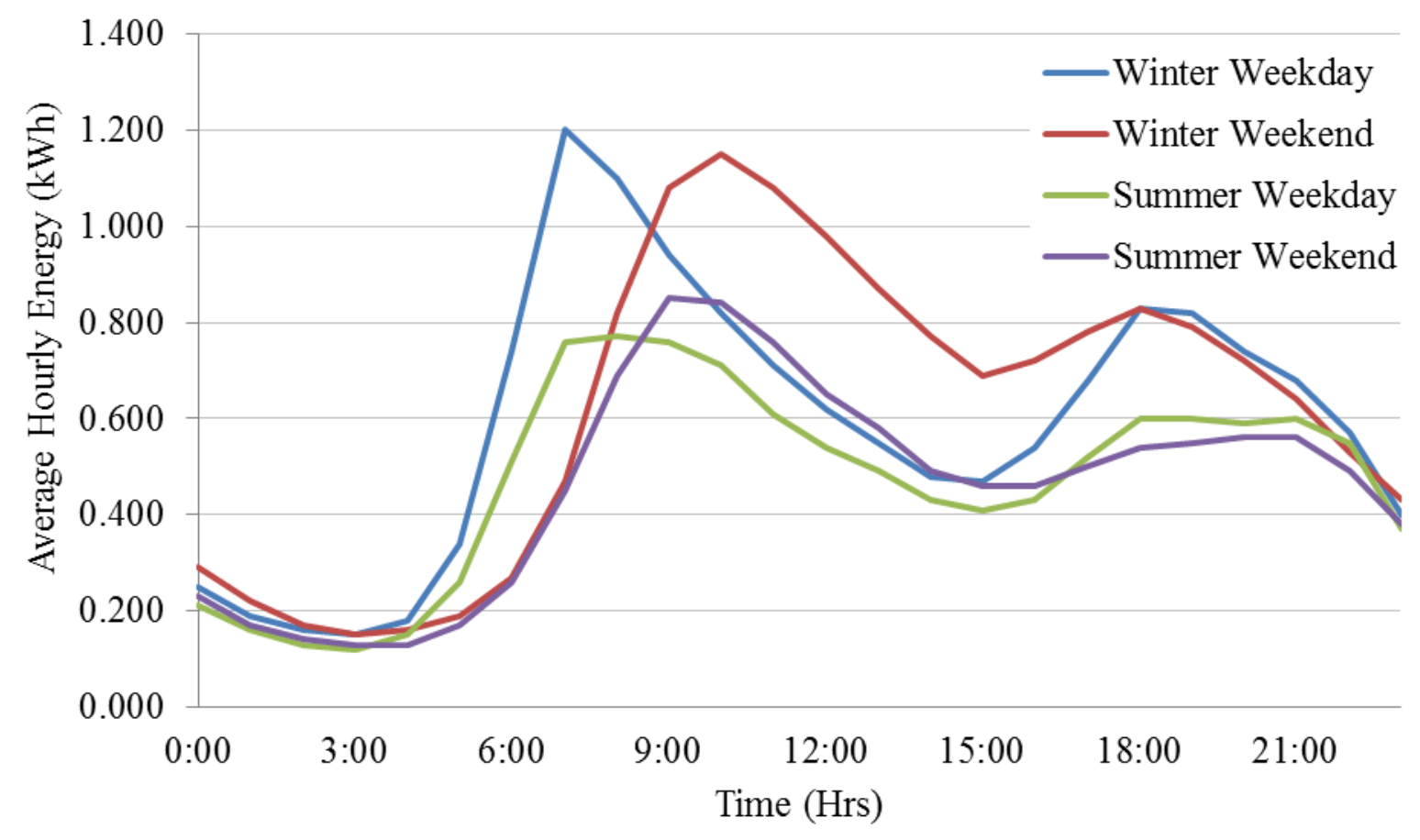

Figure 2-16: ELCAP water heater load shape. 


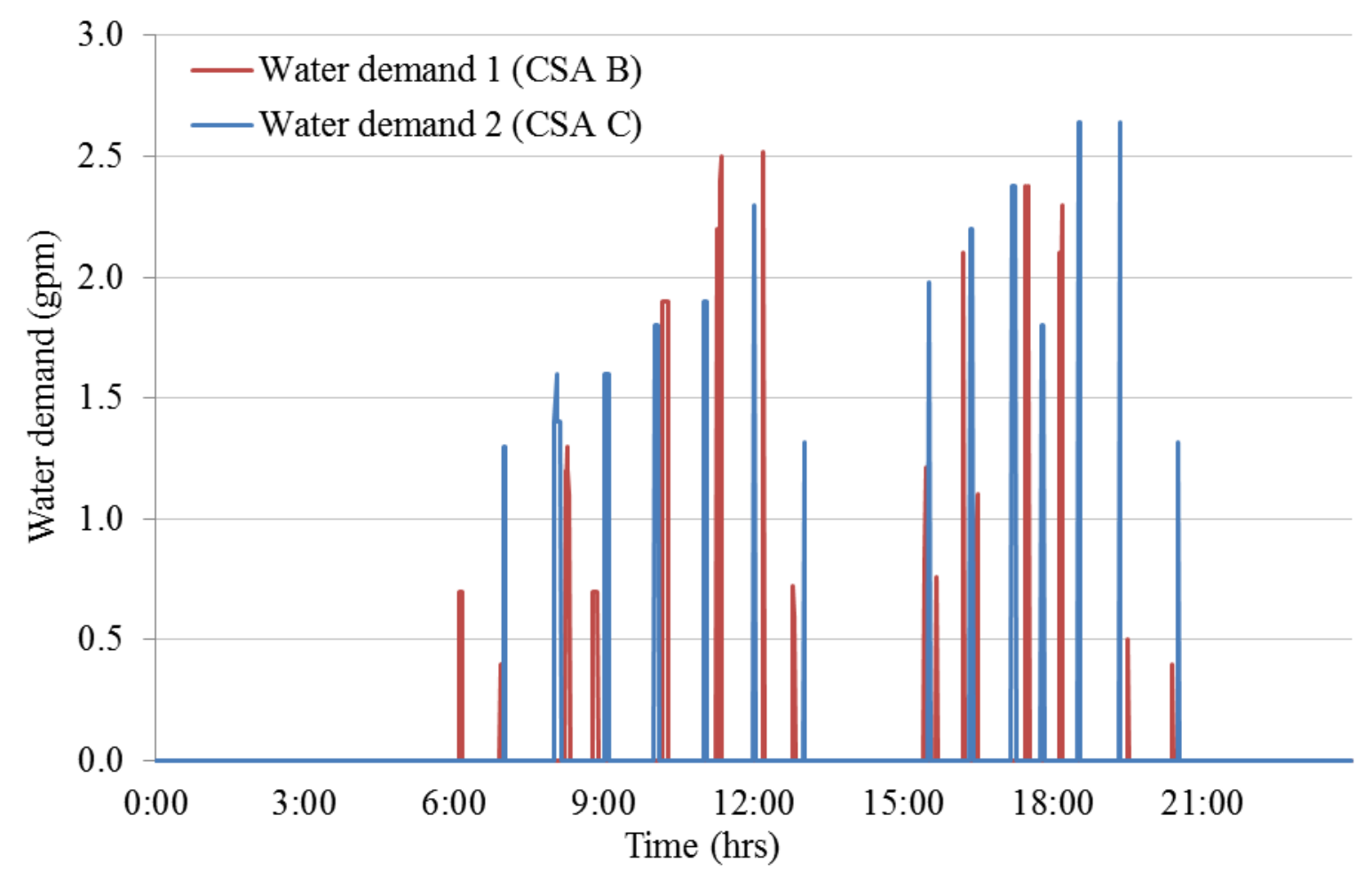

Figure 2-17: Sample water demand schedule from two separate HWHs (one minute resolution).

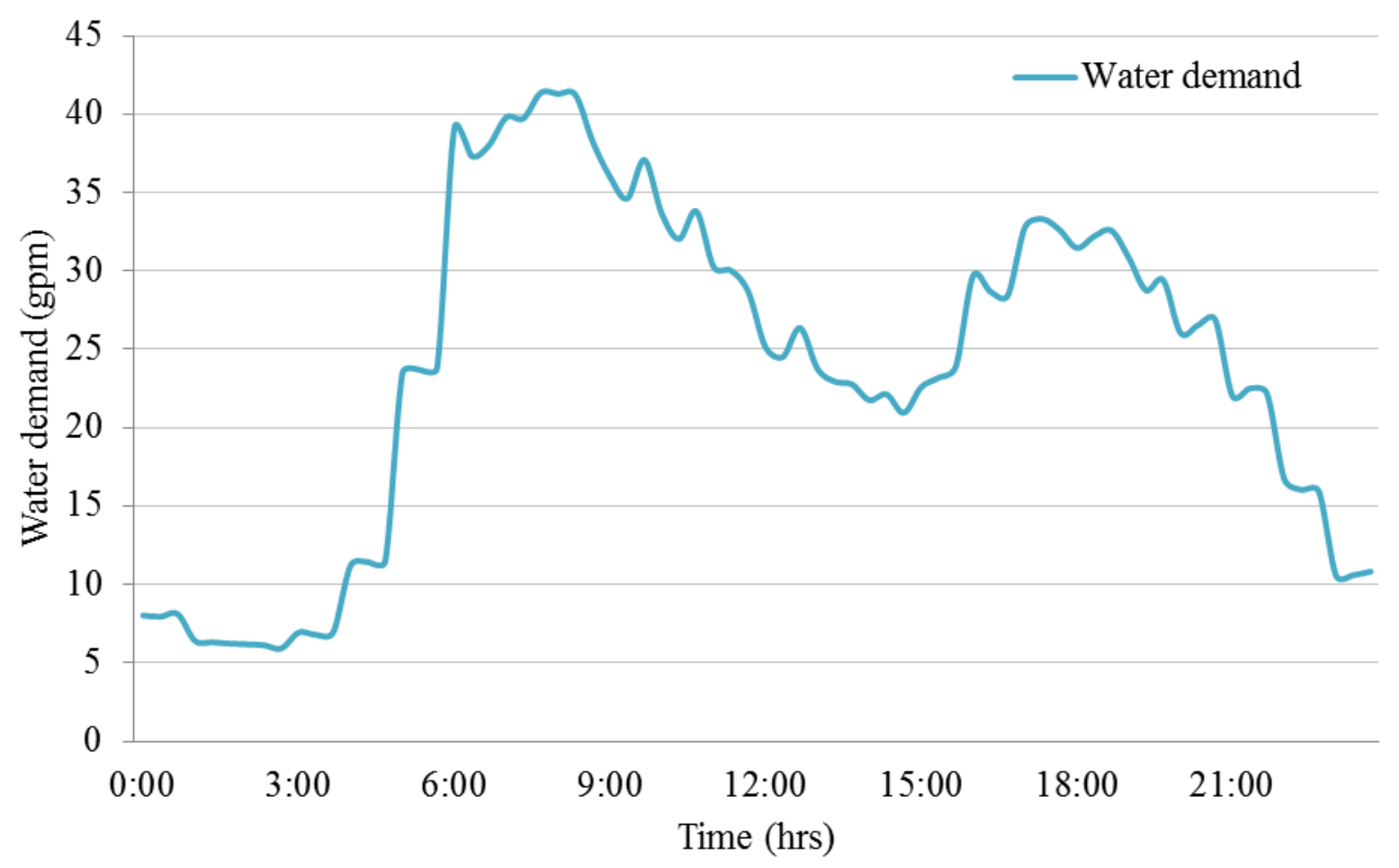

Figure 2-18: Total water demand per day for all of the HWHs on a winter weekday. 
A base case scenario was created from these inputs, using the functionality of the GE HWH in the Normal mode of operation. It should be noted that the energy consumption of the base case is already reduced from that of a standard water heater, as the heat pump water heater consumes less electrical energy to heat the water than a conventional resistance element (only) water heater. However, for the purposes of this study, the Normal mode of operation of the GE HWH will be considered the base case. Additionally, a number of DR signals were created to test the DR functions in GE HWH; those selected for discussion are listed in Table 2-27. It should be noted, that unlike previous appliances, no release options were studied.

Table 2-27: DR signals used for the simulation of the HWH model.

\begin{tabular}{|c|c|c|}
\hline \multirow{2}{*}{} & \multicolumn{2}{|c|}{ Time } \\
\cline { 2 - 3 } Critical & DR Signal 1 & DR Signal 2 \\
\hline High & $18: 00-20: 00$ & none \\
\hline Normal & all other times & $16: 00-20: 00$ \\
\hline
\end{tabular}

Figure 2-19 shows the time series output of the HWHs in response to the DR Signal 1 on a typical winter day, which is used to represent a utility TOU with CPP overlay rate structure. The average daily energy consumption per HWH, in response to DR Signal 1, is $9.17 \mathrm{kWh}$, versus $9.78 \mathrm{kWh}$ in normal operation. The decrease in average energy consumption, with respect to normal energy consumption, is $6.27 \%(0.61 \mathrm{kWh})$. Due to the response of the GE HWHs, the peak demand during the Critical and High periods, in response to DR Signal 1, is reduced from $273 \mathrm{~kW}$, in the Normal case, to $212 \mathrm{~kW}$, or a reduction of approximately $22 \%$. This is due to the fact that, during High and Critical period, the temperature setpoints are decreased from the normal operating setpoint and the two heating elements are locked out. However, at the end of the High period, a significant rebound in the demand can be seen, and is significantly greater than the original peak. The peak power consumption of the HWHs after the signal drops from the High period in this scenario is $233 \%(637 \mathrm{~kW})$ higher than in normal operation. This rebound is due to the fact that the thermostat setpoints are moved back to their normal settings when the Normal signal arrives at the end of the High period, temporarily synchronizing the loads within the system and often kicking in the backup resistance heating elements (which are no longer locked out). Additionally, there is an increase in power consumption (a small "blip" before the beginning of the Critical signal) for a period of time during the High signal. This is because some of the heat pumps begin to turn on during the High signal in order to keep the water temperature near to the new setpoint. In other words, the resource used for reducing load, gained by setting the thermostats back to $110^{\circ} \mathrm{F}$, is being exhausted and water heaters are starting to activate to 
maintain the water temperature. As the water setpoint temperature is further reduced during the Critical signal, the heat pumps that are on during the High signal are turned immediately turned off. Notice that the load is increased for nearly eight hours (until 4:00 am), as the heat pumps slowly increase the water temperature back to the normal setpoint without using the resistive elements (as is done immediately following a return to the Normal signal).

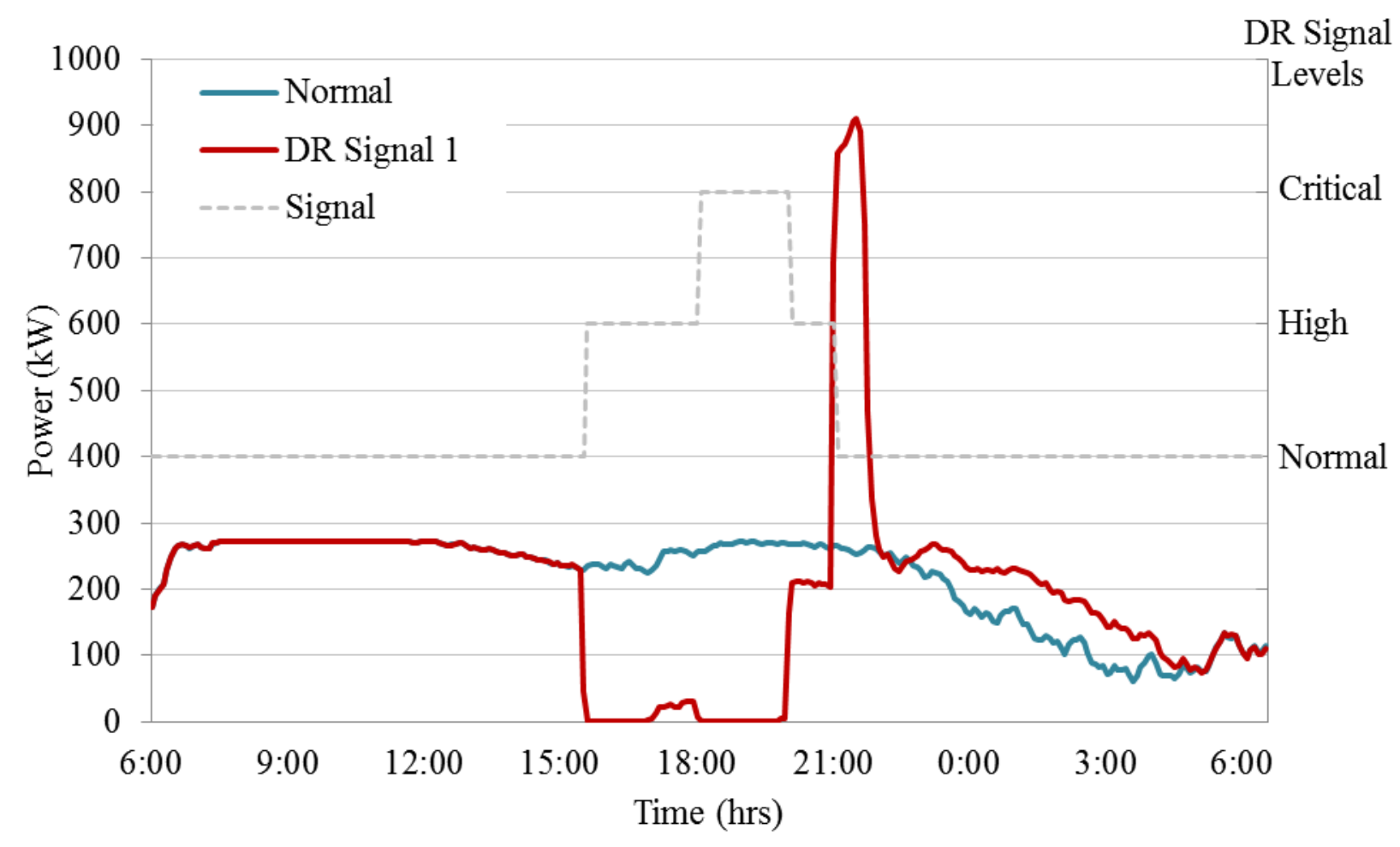

Figure 2-19: Time series of load for all HWHs in response to DR Signal 1 on a typical winter day.

DR Signal 2 is used to observe the GE HWH response to a four hour High signal to estimate how long the HWH resource is available due to the setback of the thermostat setpoint. This type of TOU signal covers a shorter time frame than it takes for the temperature to drift down to the new setpoints in all of the units. A time series of the load for the Normal and DR Signal 1 cases are shown in Figure 2-20. The average daily energy consumption per HWH in response to DR Signal 2 is $9.32 \mathrm{kWh}$. The decrease in average energy consumption, with respect to the normal energy consumption is $4.72 \%$, or $0.46 \mathrm{kWh}$. Due to the response of GE HWHs, the peak demand during the High period, in response to DR Signal 2, is reduced from $273 \mathrm{~kW}$ to $128 \mathrm{~kW}$, or a reduction of approximately $53 \%$. However, at the end of the High period, a significant rebound in the demand can be seen. The rebound peak in this scenario is significantly greater than the original peak (although not as great as that seen in the DR Signal 1 case). The peak power consumption of all of the HWHs soon after the signal drops from the High period in this scenario is $138.8 \%$, or $379 \mathrm{~kW}$, higher than that in normal operation. This rebound is due to the fact that 
the water temperature setpoints move back to their normal settings when the Normal signal arrives at the end of the High period temporarily synchronizing the loads within the system and activating the resistive elements. Again, notice that load is increased for nearly eight hours following the return to a Normal signal.

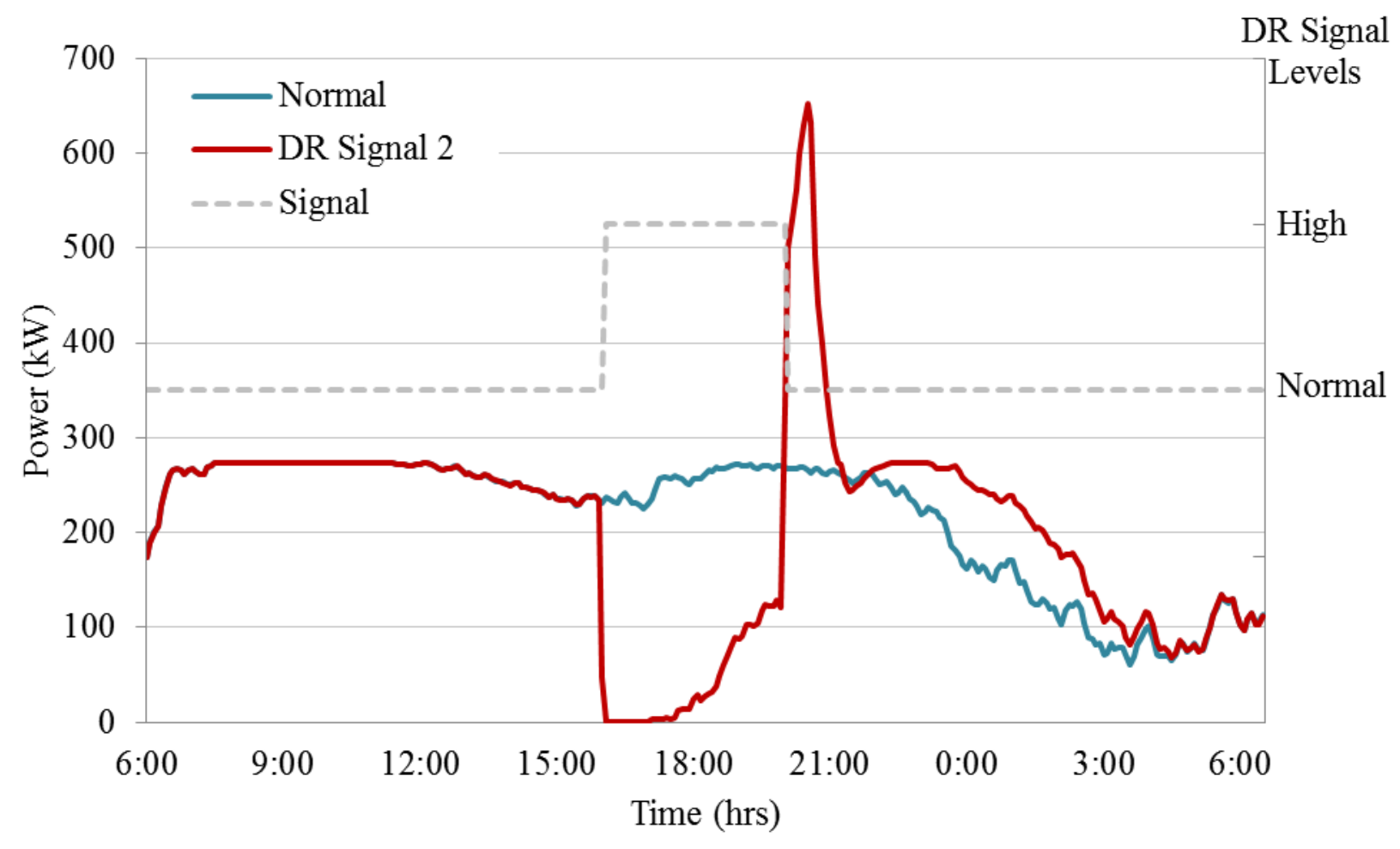

Figure 2-20: Time series of load for all HWHs in response to DR Signal 2 on a typical winter day.

The total energy consumption of all of the HWHs in the Normal, DR Signal 1, and DR Signal 2 cases are compared in Table 2-28. The change in energy consumption of the HWHs due to the DR 1 and DR 2 signals (in percentage), with respect to the Normal energy consumption, are also shown. Table 2-29 gives the peak power demand of the HWHs during and immediately after the signal drops from High or Critical to Normal. The change in peak power demands of the HWHs to DR Signal 1 and 2 (in percentage), with respect to the Normal peak demand, are also shown. 
Table 2-28: Energy consumption of the HWHs.

\begin{tabular}{|c|c|c|}
\hline \multirow{2}{*}{ Case } & \multicolumn{2}{|c|}{ Energy consumption } \\
\cline { 2 - 3 } & $(\mathrm{kWh})$ & $(\%)$ \\
\hline Normal & 5319.5 & 100.0 \\
\hline DR1 & 4986.1 & 93.7 \\
\hline DR2 & 5068.3 & 95.3 \\
\hline
\end{tabular}

Table 2-29: Comparison of peak load due to HWHs.

\begin{tabular}{|c|c|c|c|c|c|c|}
\hline \multirow{2}{*}{ Case name } & \multicolumn{2}{|c|}{ Base } & \multicolumn{2}{c|}{ DR Signal 1 } & \multicolumn{2}{c|}{ DR Signal 2 } \\
\cline { 2 - 7 } & $(\mathrm{kW})$ & $(\%)$ & $(\mathrm{kW})$ & $(\%)$ & $(\mathrm{kW})$ & $(\%)$ \\
\hline $\begin{array}{c}\text { Peak power during High/Critical } \\
\text { pricing (kW) }\end{array}$ & 273 & 100.0 & 212 & 77.7 & 128 & 46.9 \\
\hline $\begin{array}{c}\text { Peak power after High/Critical } \\
\text { period (kW) }\end{array}$ & 273 & 100.0 & 910 & 333.6 & 652 & 238.6 \\
\hline
\end{tabular}

From the results obtained, it is observed that the response of the HWHs to DR Signal 1 (three rate pricing) and DR Signal 2 (two rate pricing), lead to a decrease in the average daily energy consumption, when compared to the normal daily energy consumption. This is due to the fact that, during the High and Critical periods, the temperature setpoints are lowered from the normal operating setpoint while the heating elements are locked out. The heat pump alone is on during that period. However, the rebound in the load due to DR operations could be significant, and thought should be given to control during the recovery period. Additionally, it should be noted that the duration of DR signal and setpoint temperatures of HWH during Normal, High, and Critical periods will greatly affect these results.

\subsection{Electric Range}

The GE Appliances electric range has a dual cavity oven (upper and lower oven) and has an electronic control for the resistance element cooktop. The upper and lower oven models are based on the assumption that for each mode of operation, the amount of energy needed for an oven, as a function of voltage, for a particular state is constant. The cooktops (both normal operation and DR operation) are timer-based models, implying that the operating time of the cooktops depends on timed settings rather than on energy consumed. Unlike previous simulations, only the High signal is used to test the electric range, as the operation of the GE range during both High and Critical signals is identical.

During High and Critical signals, the range runs in the ES-mode. This setting operates by consuming less energy or average power than that in the Normal mode. During a DR signal, the range uses only the upper oven and "locks out" the lower oven while the cooktop enters the ES- 
mode. The upper oven consumes less energy than the lower oven, whereas the cooktop ES-mode settings cause the cooktop to restrict the power below the maximum. Thus for a given cooking task the elements will run longer and consume slightly more energy than in the Normal mode. However, cooktop the ES setting consumes less instantaneous power than normal cooktop operation. When the control signal reaches High or Critical, the first option the user has is to delay the operation of the unit until after the end of the period. If overridden, the unit enters ESmode. Of course, the customer always has the option to override the DR signal and run the range in the Normal mode. The range model developed in GridLAB-D treats the oven and the cooktop power consumptions separately, and the sum of the two is the total range consumption. The ZIP components for each state were modeled as $100 \%$ constant impedance. A detailed description of the approach for the range model is presented in Appendix A.

\subsubsection{Electric Range Simulation Results}

To estimate the potential of the DR control strategies designed for the GE Appliances electric range, in reducing peak demand, detailed time series simulations are conducted in GridLAB-D on a representative feeder, R1-12.47-2 [1]. The system is modeled from the substation, to the secondary service transformer, down through the triplex line, into the single family residence. There are 544 single family residences, each with a GE range able to receive a DR signal (100\% penetration). ELCAP load shapes are used to estimate the usage pattern of ranges at different times during the course of an average day and across different seasons [9]. Figure 2-21 shows the ELCAP electric range load shapes for summer and winter weekends and weekdays. However, as ELCAP data is somewhat outdated, only the usage pattern is used to simulate the aggregate demand behavior of the range. To effectively determine the amount of load on the system due to range events or how often each component is used, GE Appliances survey data was used. The average number of bake events per household, as provided by GE Appliances, is 133 events per year. The average number of cooktop events per household, as provided by GE Appliances, is 360 events per year. By incorporating these averages, in conjunction with the ELCAP load shape pattern, an individualized usage schedule was determined for each appliance in the population to create a base case. 


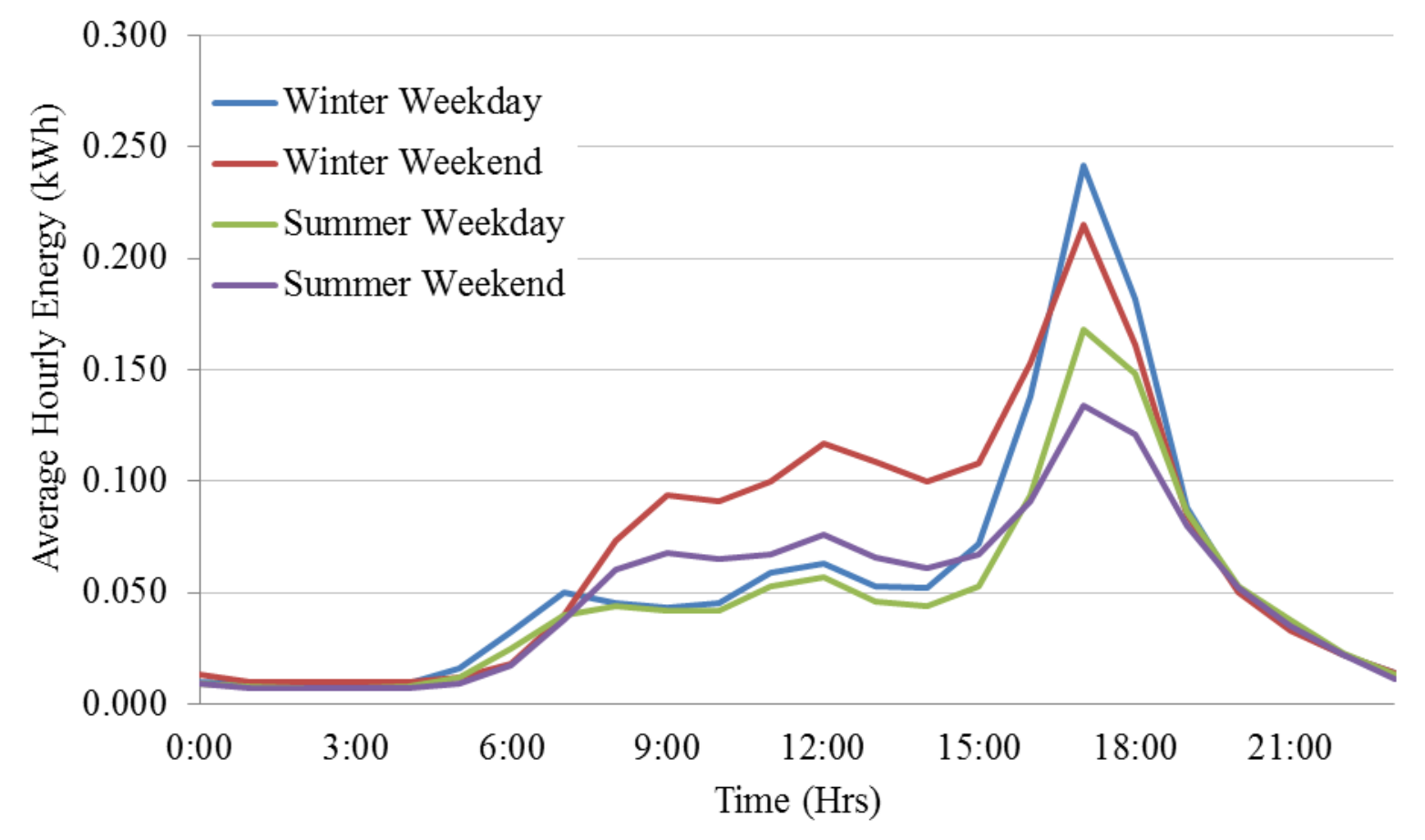

Figure 2-21: ELCAP load shape for electric ranges.

To test the response of the ranges to a DR signal, a number of scenarios were explored. The DR signal used to test the response is shown in Table 2-30. Table 2-31 discusses the assumptions used in how customers will interact with the appliance, both in terms of what percentage will use the upper and lower ovens during Normal operation versus during a DR event, and what percentage of customers will accept a delay versus using the ES-mode. Notice that the percentage of customers that are believed to be amenable to a delay action in the range operation is much lower than previous appliances. Table 2-32 shows two release options explored for their effects on the rebound period as the signal returns to Normal. These scenarios are used in the aggregated simulations that are discussed in Section 3.

Table 2-30: DR signal used in the range simulations.

\begin{tabular}{|c|c|}
\hline & Time \\
\hline Critical & none \\
\hline High & $15: 30-21: 00$ \\
\hline Normal & all other times \\
\hline
\end{tabular}


Table 2-31: Customer behavior cases for range simulations.

\begin{tabular}{|c|c|c|c|c|c|c|c|c|c|c|}
\hline \multirow{2}{*}{ Case } & \multicolumn{4}{|c|}{ During Normal signal } & \multicolumn{4}{c|}{ During High or Critical signal } \\
\cline { 2 - 11 } & \multicolumn{2}{|c|}{ Oven } & \multicolumn{2}{c|}{ Cooktop } & \multicolumn{3}{c|}{ Oven } & \multicolumn{3}{c|}{ Cooktop } \\
\cline { 2 - 11 } & $\begin{array}{c}\text { Use } \\
\text { Upper }\end{array}$ & $\begin{array}{c}\text { Use } \\
\text { Lower }\end{array}$ & Base & $\begin{array}{c}\text { ES- } \\
\text { mode }\end{array}$ & $\begin{array}{c}\text { Use } \\
\text { Upper }\end{array}$ & $\begin{array}{c}\text { Use } \\
\text { Lower }\end{array}$ & $\begin{array}{c}\text { Accept } \\
\text { Delay }\end{array}$ & Base & $\begin{array}{c}\text { ES- } \\
\text { mode }\end{array}$ & $\begin{array}{c}\text { Accept } \\
\text { Delay }\end{array}$ \\
\hline Normal & $65 \%$ & $35 \%$ & $100 \%$ & $0 \%$ & $65 \%$ & $35 \%$ & $0 \%$ & $100 \%$ & $0 \%$ & $0 \%$ \\
\hline $\begin{array}{c}\text { Customer } \\
\text { Case A }\end{array}$ & $65 \%$ & $35 \%$ & $100 \%$ & $0 \%$ & $90 \%$ & $0 \%$ & $10 \%$ & $0 \%$ & $90 \%$ & $10 \%$ \\
\hline
\end{tabular}

Table 2-32: Built-in release options explored in range simulations.

\begin{tabular}{|c|c|}
\hline & Additional Delay Time Distribution \\
\hline $\begin{array}{c}\text { DR Release } \\
\text { Option } 1\end{array}$ & None - All delayed ranges start immediately. \\
\hline $\begin{array}{c}\text { DR Release } \\
\text { Option 2 }\end{array}$ & Uniform distribution between 0 and 40 minutes. \\
\hline
\end{tabular}

Figure 2-22 compares the aggregated simulation outputs of all ovens of the Normal, DR Release Option 1, and DR Release Option 2 cases. The total energy consumption of all ovens in both DR Release Options 1 and 2 is $9.3 \%$, or $18.6 \mathrm{kWh}$, lower than that of the Normal case. This is due to the fact that more of the ranges use the upper oven $(90 \%)$ during High signal, as opposed to during Normal operation (65\%). The daily energy consumption of all of the ovens and cooktops are given in Table 2-33. 


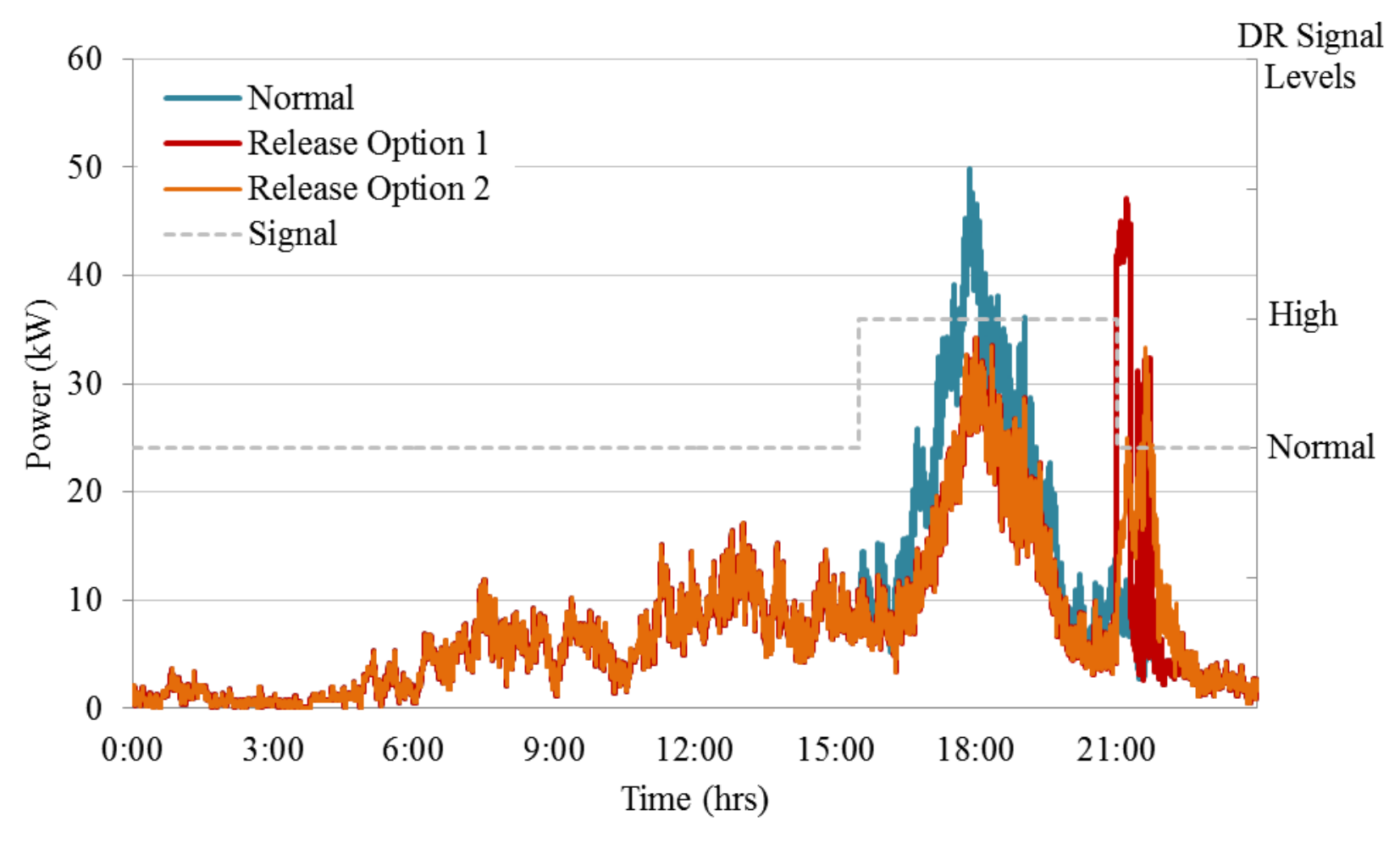

Figure 2-22: Time series of load for all ovens on a winter weekday comparing release options.

Table 2-33: Comparison of energy consumption for range simulations.

\begin{tabular}{|c|c|c|c|}
\hline \multirow{2}{*}{} & \multicolumn{3}{|c|}{ Total energy consumption $(\mathrm{kWh})$} \\
\cline { 2 - 4 } & Normal & $\begin{array}{c}\text { DR Release } \\
\text { Option 1 }\end{array}$ & $\begin{array}{c}\text { DR Release } \\
\text { Option 2 }\end{array}$ \\
\hline Oven & 199.9 & 181.3 & 181.3 \\
\hline Cooktop & 285.1 & 298.2 & 298.2 \\
\hline Range & 485.1 & 479.5 & 479.5 \\
\hline
\end{tabular}

The peak demand of the ovens after the DR signal period in DR Release Options 1 and 2 are $395.8 \%(47.1 \mathrm{~kW})$ and $279.8 \%(33.3 \mathrm{~kW})$ higher than that of the Normal case. The peak power consumption in the DR Release Option 1 is higher than that in DR Release Option 2; this is due to the fact that in DR Release Option 1 all ranges which accepted delay start immediately after the Normal signal arrives at the end of the High signal period, while in DR Release Option 2, the delayed ranges randomize their start over a period of 40 minutes when the Normal signal arrives. The peak demand during the High or Critical signal period in DR Release Options 1 and 2 is the same, and is equal to $68.6 \%(34.2 \mathrm{~kW})$ of the peak demand of the Normal case during the DR period. A comparison of the peak power of the ovens on a winter day is given in Table 2-34. 
Table 2-34: Peak power demands of ovens on a winter weekday.

\begin{tabular}{|c|c|c|c|c|c|c|}
\hline \multirow{2}{*}{ Case name } & \multicolumn{2}{|c|}{ Normal } & \multicolumn{2}{c|}{ DR Release Option 1 } & \multicolumn{2}{c|}{ DR Release Option 2 } \\
\cline { 2 - 7 } & $(\mathrm{kW})$ & $(\%)$ & $(\mathrm{kW})$ & $(\%)$ & $(\mathrm{kW})$ & $(\%)$ \\
\hline Peak power during High period & 49.9 & 100.0 & 34.2 & 68.6 & 34.2 & 68.6 \\
\hline Peak power after High period & 11.9 & 100.0 & 47.1 & 395.8 & 33.3 & 279.8 \\
\hline
\end{tabular}

Figure 2-23 compares the aggregated simulated load of all cooktops for the Normal, DR Release Option 1, and DR Release Option 2 cases. The peak demand during the High signal period for both DR Release Options 1 and 2 is the same, and is equal to $95.6 \%$ of Normal operation during the DR period, or a $2.4 \mathrm{~kW}$ reduction in demand. A comparison of the peak demand of the cooktops on a winter day is given in Table 2-35. The peak power demand of cooktops, after the High or Critical period, for DR Release Options 1 and 2 are $523 \%(65.9 \mathrm{~kW})$ and $250.8 \%(31.6 \mathrm{~kW})$, respectively, when compared to the peak power in the Normal case. The energy consumption of the cooktops in both DR Release Options 1 and 2 is $104.6 \%$ of the Normal case, or $298.2 \mathrm{kWh}$, as shown in Table 2-33. This is due to the fact that more of the cooktops use the ES-mode settings during the High signal, which reduce instantaneous power but increase energy consumption.

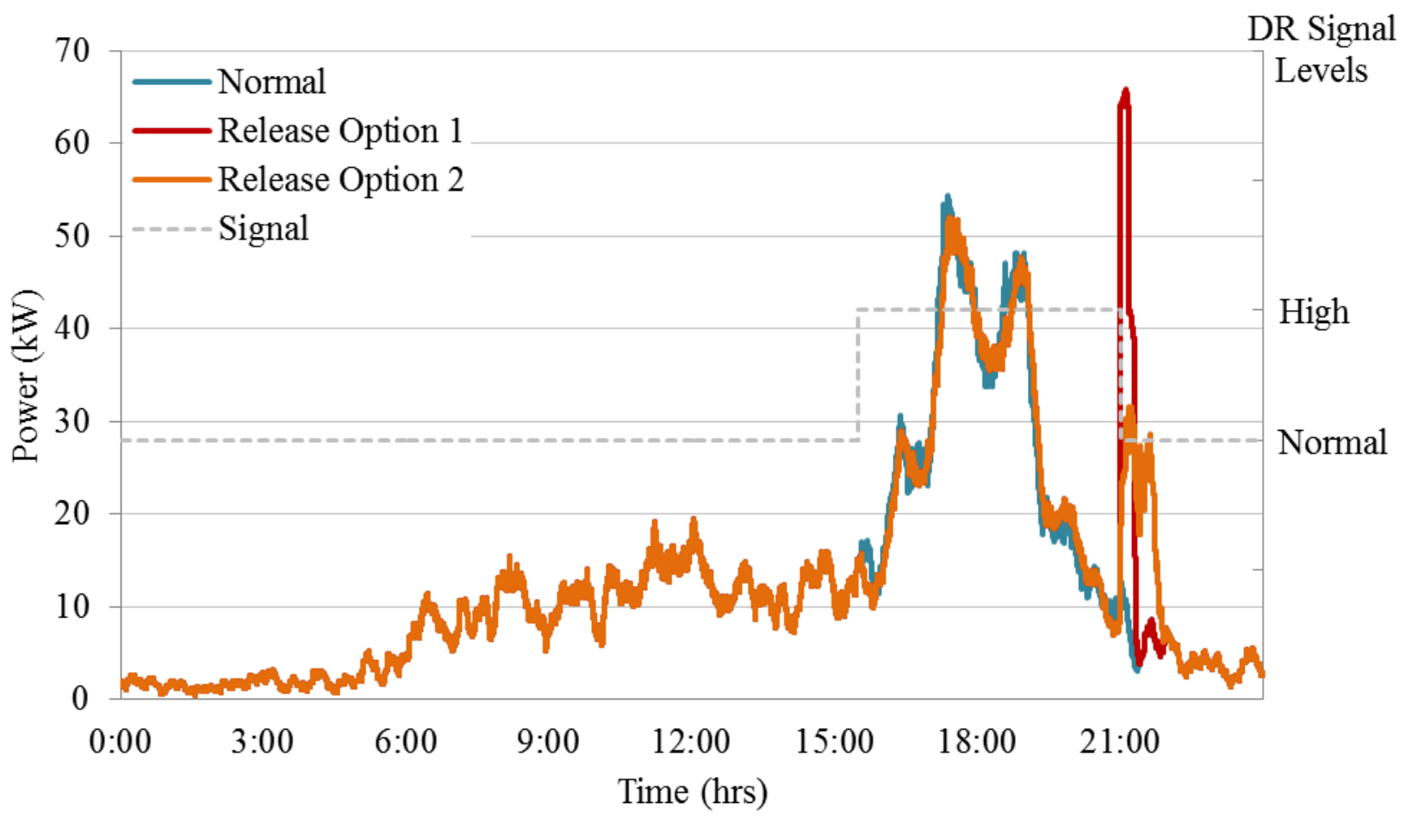

Figure 2-23: Time series of cooktop demand on a winter weekday. 
Table 2-35: Peak power demands of cooktops on a winter weekday.

\begin{tabular}{|c|c|c|c|c|c|c|}
\hline \multirow{2}{*}{ Case name } & \multicolumn{2}{|c|}{ Normal } & \multicolumn{2}{c|}{ DR Release Option 1 } & \multicolumn{2}{c|}{ DR Release Option 2 } \\
\cline { 2 - 7 } & $(\mathrm{kW})$ & $(\%)$ & $(\mathrm{kW})$ & $(\%)$ & $(\mathrm{kW})$ & $(\%)$ \\
\hline $\begin{array}{c}\text { Peak power during High/Critical } \\
\text { pricing }(\mathrm{kW})\end{array}$ & 54.4 & 100.0 & 52.0 & 95.6 & 52.0 & 95.6 \\
\hline $\begin{array}{c}\text { Peak power after High/Critical } \\
\text { period }(\mathrm{kW})\end{array}$ & 12.6 & 100.0 & 65.9 & 523 & 31.6 & 250.8 \\
\hline
\end{tabular}

Figure 2-24 compares the demand of the range (oven plus cooktop) simulations for the Normal case and both release options. The peak demand of the ranges is the highest during Release Option 1, because all of the delayed oven and cooktop events during the High signal period start as soon as the Normal signal arrives after the end of the High signal period. The cumulative effects of the oven and cooktop events cause a rebound in the demand. Peak power demands of all ranges on a winter day are given in Table 2-36. The peak power demand reduction in both release options is the same because the number of ranges that use the ES-mode versus the Normal setting of the cooktops, and upper and lower ovens are the same. For the same reason, peak power demand during High or Critical period in both release options is the same, and is equal to $82 \%(79 \mathrm{~kW})$ of the peak demand of the Normal case during the DR period.

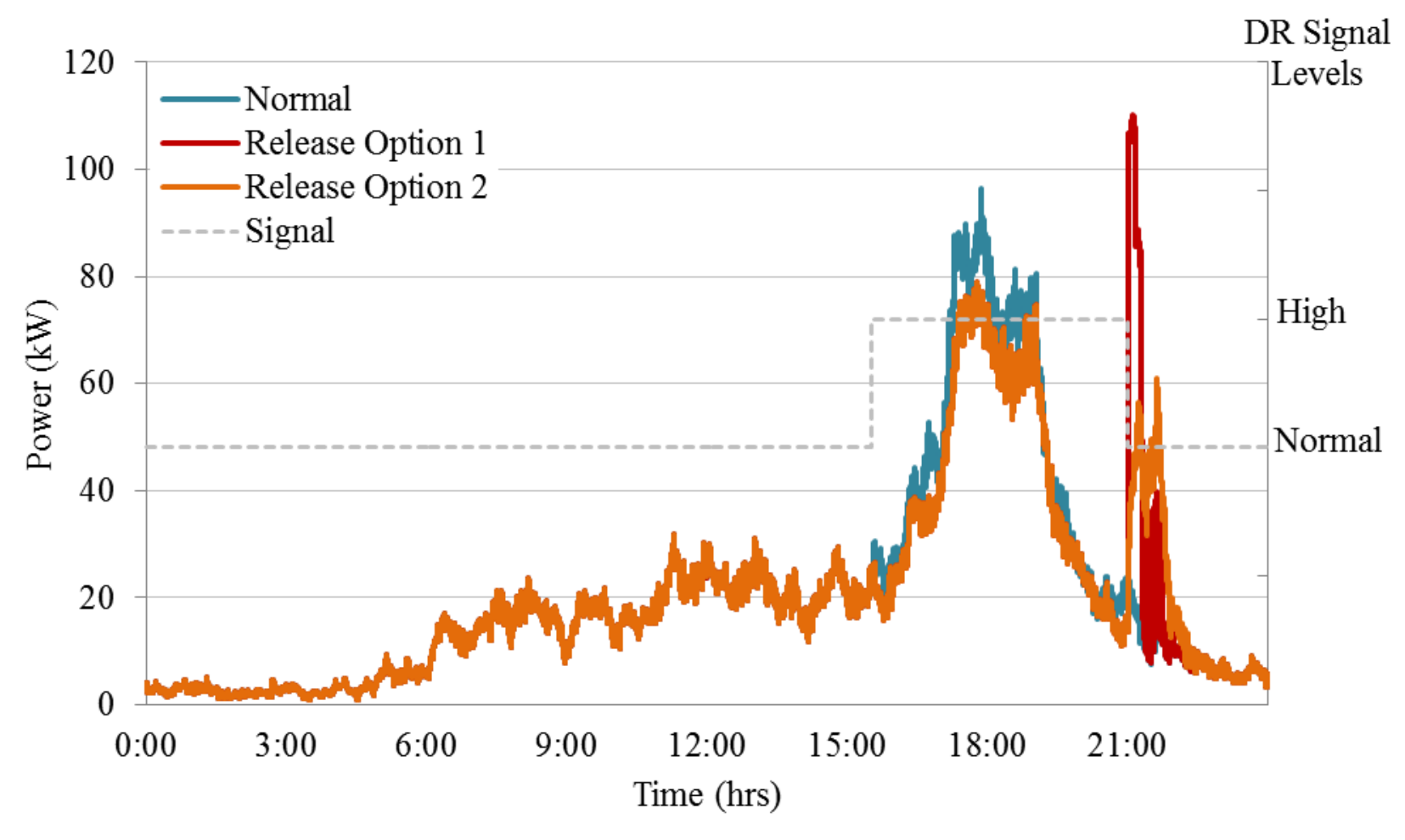

Figure 2-24: Time series of demand of all ranges on a winter weekday. 
Table 2-36: Peak power demands of ranges on a winter weekday.

\begin{tabular}{|c|c|c|c|c|c|c|}
\hline \multirow{2}{*}{ Case name } & \multicolumn{2}{|c|}{ Normal } & \multicolumn{2}{c|}{ DR Release Option 1 } & \multicolumn{2}{c|}{ DR Release Option 2 } \\
\cline { 2 - 7 } & $(\mathrm{kW})$ & $(\%)$ & $(\mathrm{kW})$ & $(\%)$ & $(\mathrm{kW})$ & $(\%)$ \\
\hline $\begin{array}{c}\text { Peak power during High/Critical } \\
\text { pricing (kW) }\end{array}$ & 96.3 & 100.0 & 79.0 & 82.0 & 79.0 & 82.0 \\
\hline $\begin{array}{c}\text { Peak power after High/Critical } \\
\text { period (kW) }\end{array}$ & 23.8 & 100.0 & 110.1 & 462.6 & 60.8 & 255.5 \\
\hline
\end{tabular}

From the results obtained, it is observed that total energy consumption is reduced by the ovens during a DR signal, whereas the total energy consumption of all the cooktops is slightly increased. This is due to the fact that more of the cooktops, in both of the release options use the ES-mode settings during the High signal, and that more of the ranges use the upper oven during the High signal. Peak demand reduction of over $20 \%$, or approximately $17 \mathrm{~kW}$, is also obtained when using the DR settings, however, nearly all of this is obtained from the ovens rather than the cooktop response. The peak during the rebound period is greatly affected by the type of strategy used in releasing the ranges after the High signal period. The use of a randomized delay period significantly reduces the coincidental peak rebound. Additionally, it should be noted that the assumptions used for customer participation (i.e. $65 \%$ of people use the upper oven during the Normal signal versus $90 \%$ during DR) will greatly affect these results.

\subsection{Refrigerator}

The largest power consuming components of refrigerator operation include a compressor which cycles on and off to maintain the internal air temperature of the refrigerator and freezer cavities, and a defrost cycle which prevents ice build-up on the evaporative coils. Additional components are also used, but consume relatively low amounts of energy. The specific components in the GE refrigerator and the details of these cycles are further discussed in Appendix A.

Additionally, the refrigerator door openings affect the refrigerator model. Door openings increase energy consumption by allowing the cold air to escape the cavity (increasing the duty cycle of the compressor) and also play a part in determining the frequency of the defrost cycle for the freezer, as a door opening can increase the humidity within the cavities.

A refrigerator is continuously in use, and is not driven by a customer activating it like many of the other appliances such as the clothes washer or dryer. User behavioral changes, or a shift in when the appliance is used by the consumer, cannot be used in the case of refrigerators. Hence, the response of the refrigerator needs to be technology driven, and for the most part, automated without the need for human interactions. In fact, at this stage, GE Appliances' DR module for the refrigerator is not accessible by the customer and does not have an override like other appliances. 
The refrigerator model in this study is designed as a multi-state load model. The refrigerator cycles discussed above (and in further detail in Appendix A), such as the compressor on, the compressor off, and the various components of the defrost cycles, were modeled as independent states within the refrigerator model. Apart from these, the GE Appliances-specific cycles were also modeled as states. The different refrigerator states were also designed and modeled based on other inputs and refrigerator watt traces from laboratory testing provided by GE Appliances. The different states were calibrated such that the power output, energy per cycle and cycle time for each state in the GridLAB-D model approximately matched the watt traces provided by GE Appliances. The power output modeled for a refrigerator state was roughly equal to the average power observed in the watt traces for that state cycle. The states were modeled as $90 \%$ constant current and 10\% constant impedance. The state transition rules were modeled as per cycle transition inputs from GE Appliances.

At the start of the DR signal period, the refrigerators stop compressor operation for a limited duration. During a High or Critical signal period, the duty cycle of the compressor unit changes such that less energy is consumed by the refrigerator, as opposed to what is consumed during Normal operation. The refrigerators also postpone defrost cycles until the Normal signal arrives when a High or Critical signal is present. As per inputs provided by GE Appliances, the defrost cycle is modeled as a function of a certain number of door openings. A door opening causes the moisture content inside the refrigerator to increase. Since the frost formed on the evaporator coils in the freezer is formed due to the moisture content of the air in the unit, the amount of moisture is to large degree driven by the number of door openings; hence, door openings and other parameters are used by some refrigerator manufacturers as a metric for initiating the defrost cycle. The GE Appliances refrigerator model created in GridLAB-D also uses the door openings as one of the metrics for initiating a defrost cycle. Hence, for this refrigerator model, modeling of the door openings is an important aspect. More details on the state transition rules and the DR rules can be found in Appendix A.

One of the significant issues with the refrigerator modeling in this study is that while the energy used by the refrigerator during the DR signal period is reduced, the energy used after the DR signal period is not increased as is evident in the watt traces provided by GE Appliances of the refrigerator. During the DR signal period, the thermostat setpoint is temporarily raised to reduce demand. After the DR signal period, the refrigerator consumes extra energy to bring the refrigerator temperature back to temperature levels around the normal thermostat setpoint established by the consumer. This effect is not currently captured in this model, as a temperature based model was considered too complicated to be implemented with the DR strategies for this analysis. Also, since the extra energy consumption was deemed relatively minor compared to all the overall energy used by the refrigerator, it was decided to not explicitly model it. However it is important to note that this extra energy consumption will change the daily energy consumption calculations of the GE Appliances' refrigerators. GE Appliances testing indicates that there is no appreciable difference in energy consumption between normal usage and a four-hour DR event. 


\subsubsection{Refrigerator Simulation Results}

Using the appliance model developed in the previous section, a representative feeder model was used to simulate the effects on the electrical power grid of the response of a population of refrigerators to DR signals. The distribution feeder model contained 646 individual residences, each with statistically sampled parameters and behaviors. Each of the residences contained a refrigerator. The aggregated response of the 646 refrigerators is presented here. Table 2-37 lists the DR signal used for the refrigerator model testing. As was seen in previous appliances, the refrigerator does not have a release option or additional customer cases to explore; only Normal operation and a single DR case will be explored.

Table 2-37: DR signal used in the refrigerator simulations.

\begin{tabular}{|c|c|}
\hline & Time \\
\hline Critical & $18: 00-20: 00$ \\
\hline High & $15: 30-18: 00,20: 00-21: 00$ \\
\hline Normal & all other times \\
\hline
\end{tabular}

The watt traces provided by GE used a particular door opening schedule while recording the watt traces. As per this schedule, a door opening event was timed to occur every 30 min, with no time of day dependence upon the frequency of the openings. This door opening schedule was initially the basis for the door opening schedule used in the GridLAB-D refrigerator model. Figure 2-25 shows the results of the refrigerator model to the Normal and DR signal. 


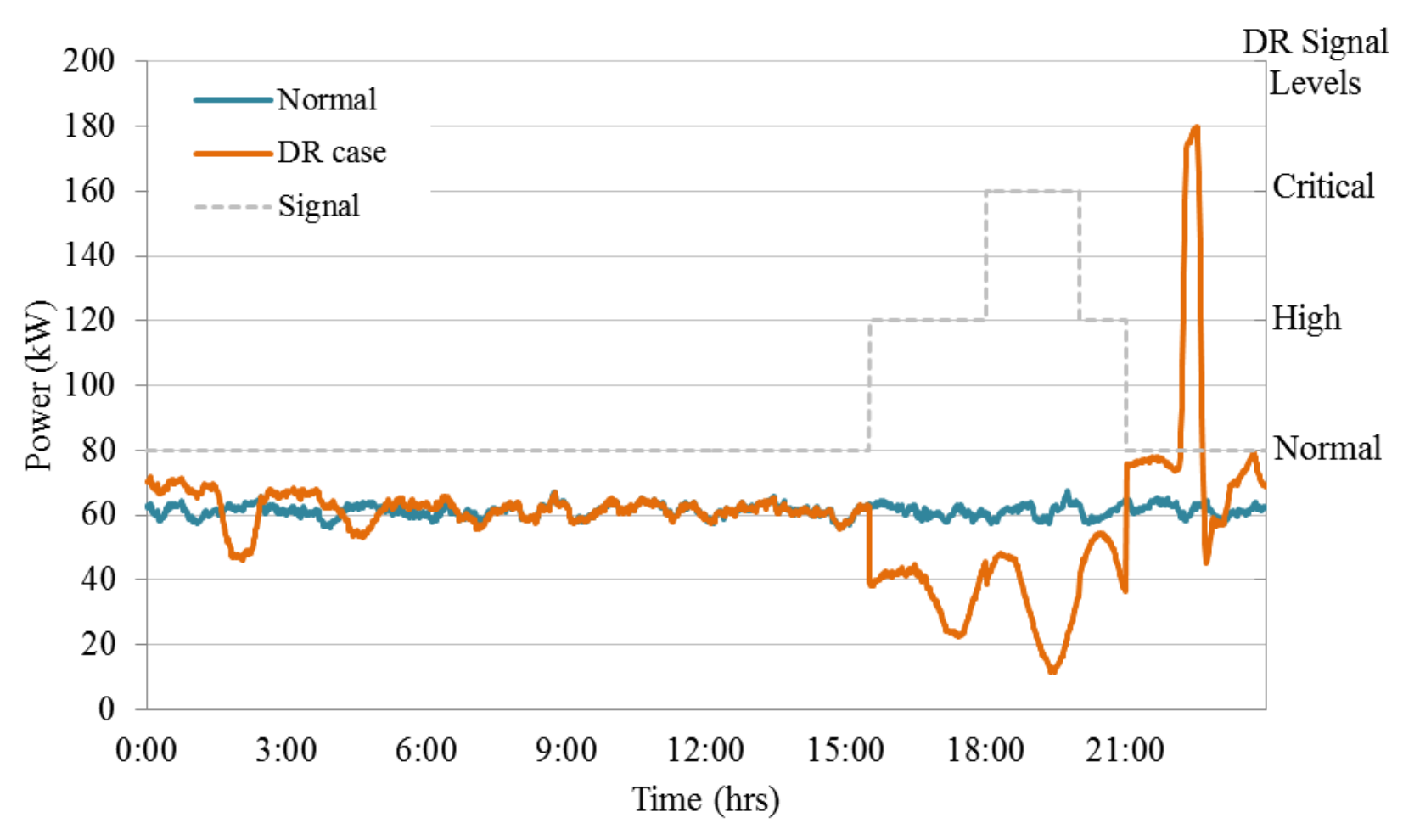

Figure 2-25: Time series comparison of the refrigerator load for a winter day using the timed door opening.

From the simulation result shown Figure 2-25, the aggregated refrigerator load is fairly constant through the day of simulation. However, this does not match observed refrigerator consumption patterns from ELCAP studies as shown in Figure 2-26 [9]. The aggregated refrigerator load is not constant during the course of a day, and there are variations between the daily maximum and daily minimum loads of the refrigerator. 


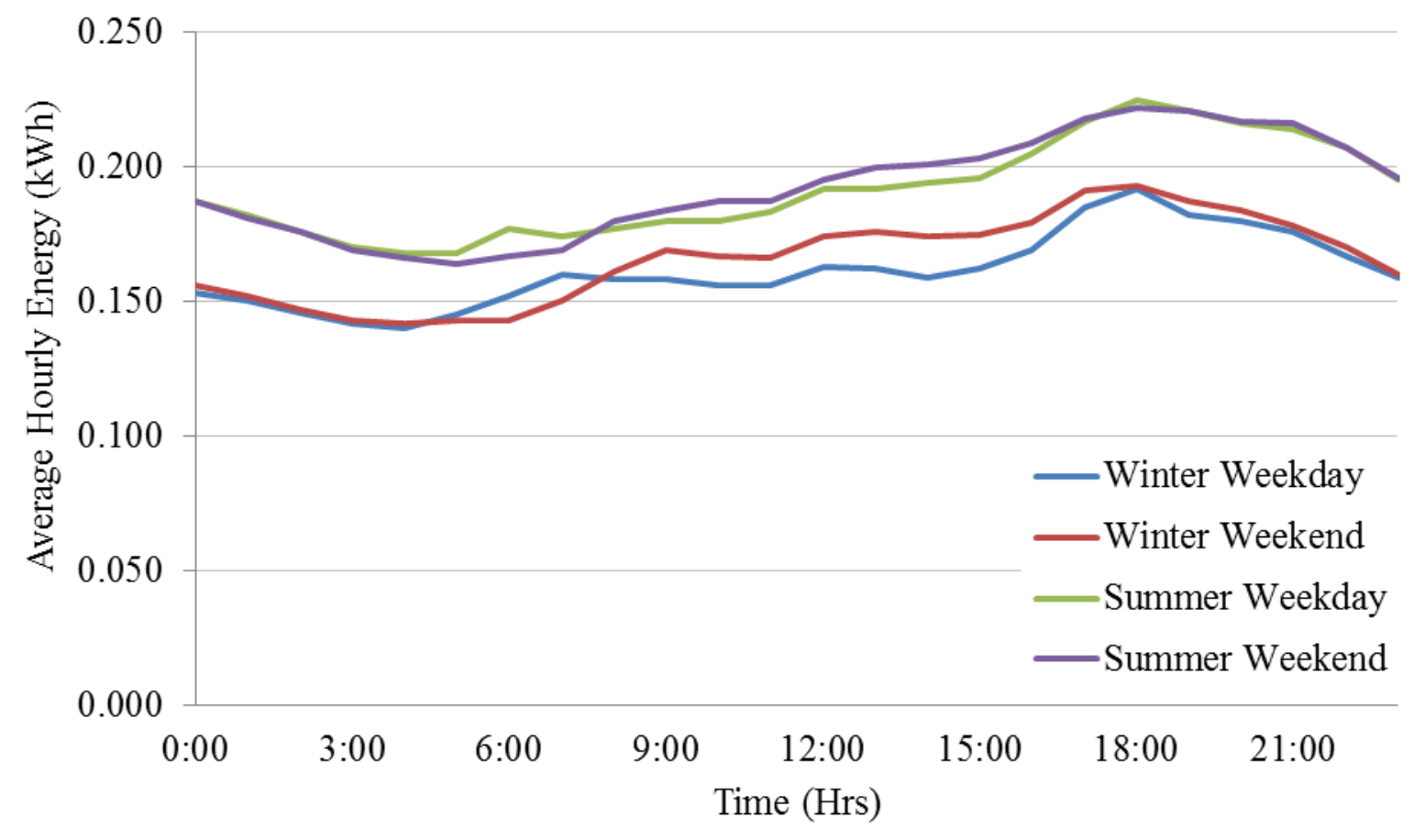

Figure 2-26: ELCAP load shapes for the refrigerator.

To correct this, the ELCAP load shape for the refrigerators was incorporated to help define the daily cycles of the customer usage patterns. Note that the ELCAP load shape was not used to define the energy consumption of the refrigerator model, but rather to help define the daily cyclic patterns of the refrigerator. The refrigerator has a base cyclic load in form of the compressor on and compressor off cycles. The other refrigerator states are the defrost cycle and the door openings. However, the defrost cycle is not a base load and occurs depending on the design of the refrigerator (in the case of GE appliances, the number of door openings). The door openings also are not a constant base load and occur as per human interaction patterns. Thus, the variations observed in the refrigerator ELCAP data from a 'near constant' base load, can be interpreted to occur due to either the defrost cycle power or due to the power consumed by door openings events. As previously mentioned, in the refrigerator model used in this study, the defrost cycle is dependent on the number of refrigerator door openings. So it is important to model the door openings as realistically as possible. Thus, to make the door opening schedule realistic, the refrigerator ELCAP data was taken as the basis for modeling the door opening schedule.

From the refrigerator ELCAP hourly data for the given day, the lowest value of the ELCAP data was determined. This value is taken was taken as the base value of the refrigerator ELCAP data, representing the relatively constant, cyclic demand from the compressor cycle. It can be observed from Figure 2-26 that this base value is approximately equal to $0.14 \mathrm{kWh} / \mathrm{h}$. This base value was then subtracted from all 24 ELCAP data points for the day. After the base value of the ELCAP data was subtracted from all of the hourly ELCAP data points, the non-base variations in 
the refrigerator ELCAP data were obtained for a day. These non-base variations in the ELCAP data thus obtained were then used as one of the inputs for modeling the schedule for the daily door openings.

The other important parameter that was used to model the door opening schedule was the total number of door openings per day. The total number of refrigerator door openings per day, along with non-base ELCAP data, was used to model the number of door openings of a refrigerator at any given hour of the refrigerator simulation.

Thus a new simulation of the refrigerator model was designed utilizing this new door opening schedule. This is not designed to test in a way similar to federal testing standards, but to be a more realistic representation of average customer usage. As discussed above, the new door opening schedule was designed such that, the number of door openings in any hour was a function of both the non-base ELCAP data for that hour and the total number of daily door openings modeled for a refrigerator. The total daily door opening values for all refrigerators in a given simulation were modeled from a normal distribution. The mean of this normal distribution was taken as 48 door openings per day and the standard deviation was taken as 16 door openings. As mentioned previously, in the watt traces provided by GE, a door opening event was timed to occur every $30 \mathrm{~min}$. This gives a total of 48 door openings per day and it was decided to use this number as the mean number of daily door openings. The daily door openings were also limited within three standard deviations of this distribution. Thus all refrigerators were modeled with daily door openings between 0 and 96 door openings per day. The time of occurrence of the door openings within an hour are also randomized during the course of that hour using a uniform distribution.

The simulation results using the new door opening schedules are shown in Figure 2-27, using the previously described aggregate model. As can be seen from the figure, the daily pattern of the refrigerators more closely follows the refrigerator ELCAP load shape. Figure 2-27 shows the simulation results of the aggregate load of the refrigerators responding to the previously described DR signal. Of note, is the fact that the peak rebound does not occur immediately following the return to the Normal signal, but rather in two steps, with the highest peak on the order of one and a half hours later. The initial rise in demand at the transition is due to the delayed compressors turning on to pre-cool the refrigerators prior to the actual defrost operation. The second rise is due to the synchronization of the defrost operation. This is interesting to note because this indicates that the rebound peak does not coincide with the timing of most of the other appliances. 


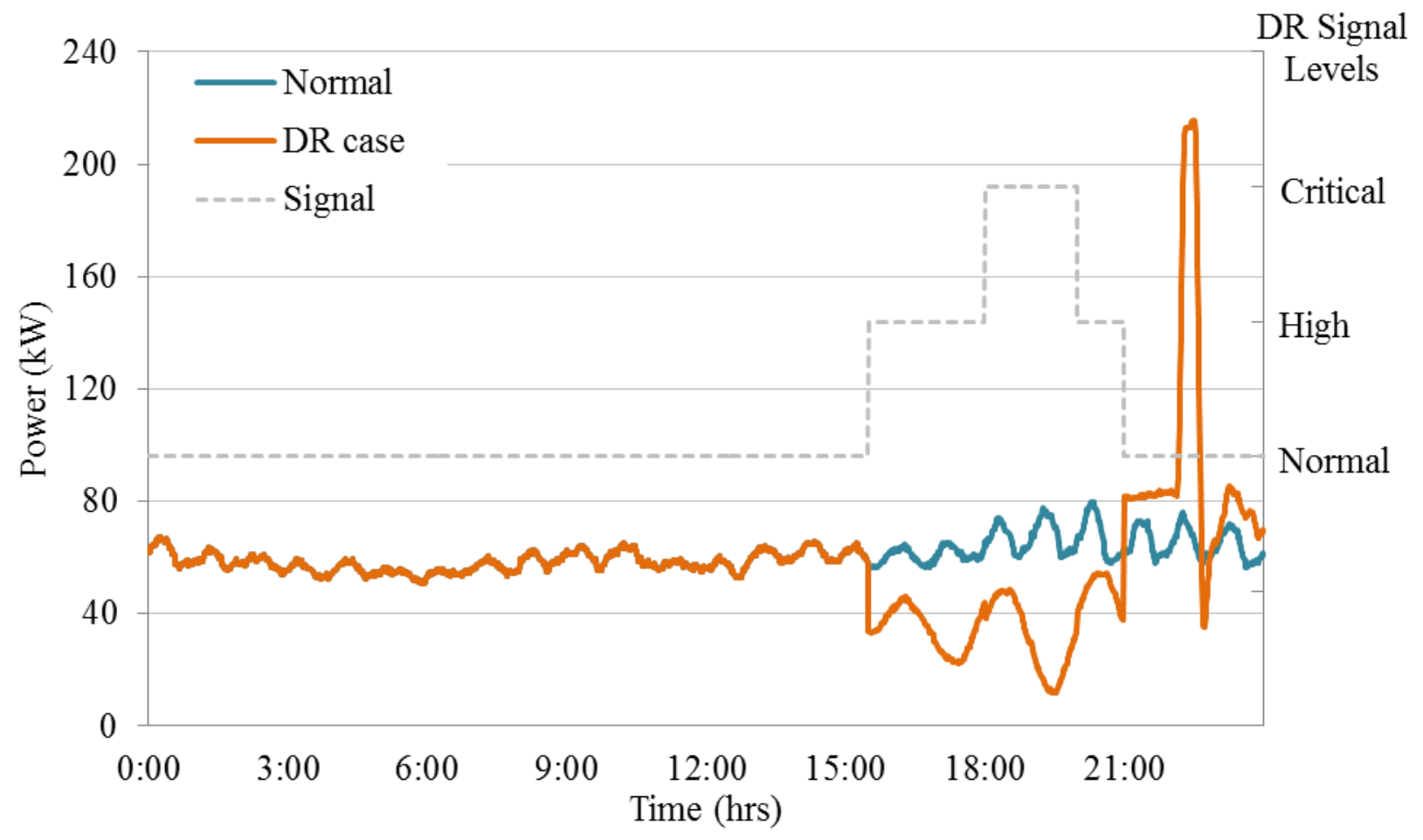

Figure 2-27: Response of refrigerator load for a winter day using the ELCAP door opening schedule.

Table 2-38: Comparison of results for the DR and Normal Cases.

\begin{tabular}{|c|c|c|}
\hline Case Name & Normal & DR Case \\
\hline Daily Energy Consumption (kWh) & 1452 & 1380 \\
\hline $\begin{array}{c}\text { Energy Consumption during the } \\
\text { High or Critical Period (kWh) }\end{array}$ & 354 & 54 \\
\hline $\begin{array}{c}\text { Peak demand during the } \\
\text { High/Critical signal period (kW) }\end{array}$ & 80 & 216 \\
\hline $\begin{array}{c}\text { Peak (Rebound) after a } \\
\text { High/Critical Signal period (kW) }\end{array}$ & 76 & 216 \\
\hline Daily Instantaneous Peak (kW) & 80 & 57 \\
\hline
\end{tabular}

From the results shown Table 2-38, in the DR case, energy consumption during the DR signal period is reduced by $44 \%$ (197 $\mathrm{kWh}$ in the DR case compared to $354 \mathrm{kWh}$ in the Normal case) in comparison to the Normal case within the time period of the Critical and High signals. Additionally, it is observed that the daily energy consumption in the DR Case is reduced to 1380 $\mathrm{kWh}$ as compared to the energy consumption of $1452 \mathrm{kWh}$ in the Normal case; however, as mentioned in the previous section, the model does not fully account for extra energy 
consumption after a DR signal period and hence the reduction in daily energy consumption may not be a fully accurate measure for daily energy conservation. GE Appliances' preliminary field tests indicate that returning the freezer to its normal operating regime results in the DR operation being somewhat energy neutral, as the decreased energy losses across the freezer walls due to the reduced temperature difference is quite small, and is lost in the normal operational noise (e.g., door openings, hot food additions, etc.).

The peak demand during the DR signal period reduces from $80 \mathrm{~kW}$ to $54 \mathrm{~kW}$, a reduction of $32 \%$, which shows that the refrigerator is capable of significant demand reduction during the DR signal period. However, the instantaneous peak power during the rebound period and the instantaneous daily peak power in the DR case $(216 \mathrm{~kW})$ is more than twice that of the Normal case $(80 \mathrm{~kW})$. Hence, while there is a considerable reduction in peak demand during the DR signal period, there is a significant demand rebound after the DR signal period. However, as previously mentioned, this peak would not coincidental with the peaks from other appliances. 


\section{Aggregate Appliance Model Simulation}

While the previous section focused on the response of a single class of DR-enabled appliance to understand the class behavior in response to a DR signal, this section will focus on a more holistic approach to estimate the aggregate benefit of GE's appliances. A number of penetration and pricing scenarios were developed and simulated to estimate the ability of DRenabled appliances to reduce peak demand. Table 3-1 gives the scenarios discussed in this section. The first set of scenarios (1a-1d) are designed to investigate the potential peak load reduction, and the resultant rebound, when the penetration levels of DR-enabled GE appliances vary from $0 \%$ to $100 \%$ on a representative feeder model of an electrical distribution system.

The second scenario (2) will study the addition of responsive HVAC systems to the appliances that respond to a DR signal. The third set of scenarios (3a, 3b, 4 and 5) will look at similar situations to scenarios 1 and 2, except the weather will be that of a more humid climate with a higher penetration of electric HVAC systems (Houston, TX versus Los Angeles, CA). Scenarios 4 and 5 will address "worst case" scenarios or the potential rebound when every user tries to recover as soon as the critical signal is released, synchronizing all of the delayed loads. Table 3-2 shows the penetration levels of the appliances and Table 3-3 shows the pricing signals used in the aggregated simulation, indicating when they start and when they end during weekdays and weekends for summer, and winter.

Table 3-1: Demand response scenarios for aggregated appliance model.

\begin{tabular}{|c|c|c|c|c|c|c|}
\hline Scenario & $\begin{array}{l}\text { Responsive } \\
\text { GE Appliance } \\
\text { Penetration }\end{array}$ & $\begin{array}{c}\text { HVAC } \\
\text { Penetration }\end{array}$ & $\begin{array}{c}\text { HVAC } \\
\text { Responsive }\end{array}$ & DR Signal(s) & $\begin{array}{c}\text { Response } \\
\text { Case }^{1}\end{array}$ & Region \\
\hline $1 \mathrm{a}$ & $0 \%$ & $75 \%$ & $0 \%$ & $1,2,3,4,5$ & none & Los Angeles \\
\hline $1 b$ & $5 \%$ & $75 \%$ & $0 \%$ & $1,2,3,4,5$ & I & Los Angeles \\
\hline $1 \mathrm{c}$ & $25 \%$ & $75 \%$ & $0 \%$ & $1,2,3,4,5$ & I & Los Angeles \\
\hline $1 d$ & $100 \%$ & $75 \%$ & $0 \%$ & $1,2,3,4,5$ & I & Los Angeles \\
\hline 2 & $100 \%$ & $75 \%$ & $100 \%$ & 2,5 & I & Los Angeles \\
\hline $3 a$ & $0 \%$ & $95 \%$ & $0 \%$ & 2,5 & none & Houston \\
\hline $3 b$ & $100 \%$ & $95 \%$ & $100 \%$ & 2,5 & I & Houston \\
\hline 4 & $100 \%$ & $95 \%$ & $100 \%$ & 1,6 & II & Houston \\
\hline 5 & $100 \%$ & $95 \%$ & $0 \%$ & 1 & II & Houston \\
\hline
\end{tabular}

${ }^{1}$ None means that all appliances are unresponsive. Response case I assumes that all of the appliances which accepted delay randomize their start time when the normal signal arrives; in case II the appliances start immediately after receiving the normal signal. 
Table 3-2: Electric appliance penetration levels.

\begin{tabular}{|l|c|}
\hline Appliance & Penetration Level \\
\hline Refrigeration & $100 \%$ \\
Electric Water Heater & $50 \%$ \\
Electric Range & $59 \%$ \\
Clothes Washer & $83 \%$ \\
Electric Dryer & $61 \%$ \\
Dishwasher & $58 \%$ \\
\hline
\end{tabular}

Table 3-3: Pricing signals used in aggregate analysis.

\begin{tabular}{|c|c|c|c|c|c|c|}
\hline \multirow{2}{*}{ Signal } & \multicolumn{3}{|c|}{ Summer } & \multicolumn{3}{|c|}{ Winter } \\
\hline & Weekday & Type & Weekend & Weekday & Type & Weekend \\
\hline $\begin{array}{c}\text { DR } \\
\text { signal } 1\end{array}$ & $9: 00-15: 00$ & Critical & $10: 00-16: 00$ & $16: 00-22: 00$ & Critical & $16: 00-22: 00$ \\
\hline $\begin{array}{c}\text { DR } \\
\text { signal } 2\end{array}$ & $9: 00-13: 00$ & Critical & $11: 30-3: 30$ & $17: 00-21: 00$ & Critical & $17: 00-21: 00$ \\
\hline \multirow{3}{*}{$\begin{array}{c}\text { DR } \\
\text { signal } 3\end{array}$} & $10: 00-10: 15$ & Critical & $10: 00-10: 15$ & $16: 30-16: 45$ & Critical & $16: 30-16: 45$ \\
\hline & $12: 15-12: 30$ & Critical & $12: 15-12: 30$ & $18: 45-19: 00$ & Critical & $18: 45-19: 00$ \\
\hline & $14: 30-14: 45$ & Critical & $14: 30-14: 45$ & $21: 00-21: 15$ & Critical & $21: 00-21: 15$ \\
\hline \multirow{2}{*}{$\begin{array}{c}\text { DR } \\
\text { signal } 4\end{array}$} & \multirow{2}{*}{$7: 00-17: 00$} & \multirow{2}{*}{ High } & \multirow{2}{*}{$7: 00-17: 00$} & $6: 00-12: 00$ & High & $9: 00-14: 00$ \\
\hline & & & & $17: 00-23: 00$ & High & $17: 00-23: 00$ \\
\hline \multirow{3}{*}{$\begin{array}{c}\mathrm{DR} \\
\text { signal } 5\end{array}$} & $9: 00-9: 30$ & High & $10: 00-11: 0$ & $16: 00-17: 30$ & High & $16: 00-17: 30$ \\
\hline & $9: 30-13: 00$ & Critical & $11: 00-15: 00$ & $17: 30-20: 00$ & Critical & $17: 30-20: 00$ \\
\hline & $13: 00-15: 00$ & High & $15: 00-16: 00$ & $20: 00-22: 00$ & High & $20: 00-22: 00$ \\
\hline $\begin{array}{c}\text { DR } \\
\text { signal } 6\end{array}$ & 9:00 - 11:00 & Critical & $12: 00-14: 00$ & $18: 00-20: 00$ & Critical & $18: 00-20: 00$ \\
\hline
\end{tabular}

The following scenarios are simulated on a prototypical distribution feeder, representative of a moderately populated suburban and rural area, mainly composed of single family residences, with a small amount of light commercial [8]. For these simulations, the circuit is populated with buildings using a distribution of physical properties described in [4], with electric HVAC penetration of $75 \%$ to $95 \%$, depending upon case, indicative of the West coast of the United States. In total, there are 544 single family homes on the circuit, with electric appliances randomly selected to populate the homes using the penetration levels from Table 3-2. This leads 
to a peak demand of approximately 1.4 MW. TMY2 data from Los Angeles and Houston is used to represent the climate. Because of the nature of TMY2 data (average months stitched together), the peak load in both climate regions occur in early September, typically around the noon hour, rather than a more typical example of peak demand, usually seen in the afternoon in June through August.

\subsection{Individual appliance scenarios}

The individual appliance scenarios used for the aggregated simulations will be discussed, in order to investigate the potential benefits and effects of the GE Appliances control strategies on a distribution feeder. These scenarios were selected to explore the most likely, the worst, and the best cases for DR capabilities on the system in terms of how the appliance controls affect the demand during the Critical or High price periods, and during the rebound period.

Each of the appliances was simulated using the calibration methodologies described in Section 2. The result is that the aggregate population of appliances roughly matches the ELCAP load shapes and the most up-to-date information on annual energy consumption. Each residence with an appliance follows its own probabilistic nature in when the appliances are used, resulting in an aggregate simulation which provides a realistic representation of an actual feeder circuit. This means for some residences, multiple operations of an appliance will occur per day, while for other residences it may be several days between events.

Three clothes washer scenarios were used in the aggregated simulations, using the DR functions described in Section 2.4. DR Case A is used to describe the "best" case, in terms the peak demand during the rebound period, while DR Case B is used to describe the "worst" case, by leaving the rebound unmanaged. This is common throughout each of the appliance scenarios. Table 3-4 shows the various clothes washer scenarios used.

Table 3-4: Clothes washer cases used for aggregated simulations.

\begin{tabular}{|c|c|c|c|c|c|c|c|}
\hline \multirow{2}{*}{ Case } & \multicolumn{2}{|c|}{ During Normal signal } & \multicolumn{2}{|c|}{ During DR signal } & \multicolumn{2}{c|}{$\begin{array}{c}\text { Delay } \\
\text { Period }\end{array}$} & $\begin{array}{c}\text { Used in } \\
\text { scenarios }\end{array}$ \\
\cline { 2 - 7 } & $\begin{array}{c}\text { Normal } \\
\text { mode }\end{array}$ & ES-mode & $\begin{array}{c}\text { Normal } \\
\text { mode }\end{array}$ & ES-mode & Delay & Zero & $1 \mathrm{a}, 1 \mathrm{~b}, 1 \mathrm{c}, 3 \mathrm{a}$ \\
\hline Normal & $100 \%$ & $0 \%$ & $100 \%$ & $0 \%$ & $0 \%$ & $75 \%$ & $\begin{array}{c}\text { One clothes } \\
\text { washer cycle }\end{array}$ \\
\hline DR Case A & $100 \%$ & $0 \%$ & $5 \%$ & $20 \%$ & Zero $, 1 \mathrm{c}, 1 \mathrm{~d}, 2$ \\
\hline DR Case B & $100 \%$ & $0 \%$ & $5 \%$ & $20 \%$ & $75 \%$ & $3 \mathrm{a}, 3 \mathrm{~b}, 4,5$ \\
\hline
\end{tabular}


Three dishwasher scenarios were used in the aggregated simulations, and are described in detail in Section 2.5. A summary of the dishwasher cases that are used in the aggregated simulations are listed in Table 3-5.

Table 3-5: Dishwasher cases used for aggregated simulations.

\begin{tabular}{|c|c|c|c|c|c|c|c|}
\hline \multirow{2}{*}{ Case } & \multicolumn{2}{|c|}{ During Normal signal } & \multicolumn{3}{|c|}{ During DR signal } & \multirow{2}{*}{$\begin{array}{c}\text { Delay } \\
\text { Period }\end{array}$} & $\begin{array}{c}\text { Used in } \\
\text { scenarios }\end{array}$ \\
\cline { 2 - 7 } & $\begin{array}{c}\text { Normal } \\
\text { mode }\end{array}$ & ES-mode & $\begin{array}{c}\text { Normal } \\
\text { mode }\end{array}$ & ES-mode & Delay & Zero & $1 \mathrm{a}, 1 \mathrm{~b}, 1 \mathrm{c}, 3 \mathrm{a}$ \\
\hline Normal & $100 \%$ & $0 \%$ & $100 \%$ & $0 \%$ & $0 \%$ & $1 \mathrm{X}_{\mathrm{DW}}$ & $1 \mathrm{~b}, 1 \mathrm{c}, 1 \mathrm{~d}, 2$ \\
\hline DR Case A & $100 \%$ & $0 \%$ & $0 \%$ & $10 \%$ & $90 \%$ & Zero & $3 \mathrm{a}, 3 \mathrm{~b}, 4,5$ \\
\hline DR Case B & $100 \%$ & $0 \%$ & $0 \%$ & $10 \%$ & $90 \%$ & & \\
\hline
\end{tabular}

Three electric clothes dryer scenarios were used in the aggregated simulations using DR operational strategies discussed in Section 2.3. Table 3-6 shows the various electric clothes dryer scenarios simulated.

Table 3-6: Dryer cases used for aggregated simulations.

\begin{tabular}{|c|c|c|c|c|c|c|c|}
\hline \multirow{2}{*}{ Case } & \multicolumn{2}{|c|}{$\begin{array}{c}\text { During Normal } \\
\text { signal }\end{array}$} & \multicolumn{2}{c|}{ During DR signal } & \multirow{2}{*}{$\begin{array}{c}\text { Delay } \\
\text { Period }\end{array}$} & $\begin{array}{c}\text { Used in } \\
\text { scenarios }\end{array}$ \\
\cline { 2 - 7 } & $\begin{array}{c}\text { Normal } \\
\text { mode }\end{array}$ & $\begin{array}{c}\text { ES- } \\
\text { mode }\end{array}$ & $\begin{array}{c}\text { Normal } \\
\text { mode }\end{array}$ & $\begin{array}{c}\text { ES- } \\
\text { mode }\end{array}$ & $\begin{array}{c}\text { Accept } \\
\text { Delay }\end{array}$ & Perion \\
\hline Normal & $100 \%$ & $0 \%$ & $100 \%$ & $0 \%$ & $0 \%$ & Zero & $1 \mathrm{a}, 1 \mathrm{~b}, 1 \mathrm{c}, 3 \mathrm{a}$ \\
\hline DR Case A & $100 \%$ & $0 \%$ & $5 \%$ & $20 \%$ & $75 \%$ & 3 X XRYER & $1 \mathrm{~b}, 1 \mathrm{c}, 1 \mathrm{~d}, 2$ \\
\hline DR Case B & $100 \%$ & $0 \%$ & $5 \%$ & $20 \%$ & $75 \%$ & Zero & $3 \mathrm{a}, 3 \mathrm{~b}, 4,5$ \\
\hline
\end{tabular}

Two different HWH scenarios are used in the aggregated simulations. Since the HWH did not have a built-in function for mitigating the peak rebound, both DR Case A and DR Case B are the same. A summary of the HWH cases that are used in the aggregated simulations are listed in Table 3-7. 
Table 3-7: HWH cases used for aggregated simulations.

\begin{tabular}{|c|c|c|c|}
\hline \multirow{2}{*}{ Case } & During Normal signal & During DR signal & \multirow{2}{*}{$\begin{array}{c}\text { Used in } \\
\text { scenarios }\end{array}$} \\
\cline { 2 - 3 } & Setpoint temperature & Setpoint temperature & $1 \mathrm{a}, 1 \mathrm{~b}, 1 \mathrm{c}, 3 \mathrm{a}$ \\
\hline Normal & $135^{\circ} \mathrm{F}$ & $135^{\circ} \mathrm{F}$ & $\begin{array}{c}1 \mathrm{~b}, 1 \mathrm{c}, 1 \mathrm{~d}, 2, \\
3 \mathrm{a}, 3 \mathrm{~b}, 4,5\end{array}$ \\
\hline $\begin{array}{c}\text { DR Case A } \\
\text { DR Case B }\end{array}$ & $135^{\circ} \mathrm{F}$ & $\begin{array}{c}110^{\circ} \mathrm{F} \text { when signal is High } \\
100^{\circ} \mathrm{F} \text { when signal is Critical }\end{array}$ & \\
\hline
\end{tabular}

Three range scenarios were used in the aggregated simulations, using the scenarios described in Section 2.7. A summary of the range cases that are used in the aggregated simulations are listed in Table 3-8.

Table 3-8: Range cases used for aggregated simulations.

\begin{tabular}{|c|c|c|c|c|c|c|c|c|c|c|c|}
\hline \multirow{3}{*}{ Case } & \multicolumn{3}{|c|}{ During Normal signal } & \multicolumn{6}{|c|}{ During DR signal } & \multirow{3}{*}{$\begin{array}{l}\text { Delay } \\
\text { Period }\end{array}$} & \multirow{3}{*}{$\begin{array}{l}\text { Used in } \\
\text { scenarios }\end{array}$} \\
\hline & \multicolumn{2}{|c|}{ Oven } & \multirow{2}{*}{$\begin{array}{c}\text { Cooktop } \\
\text { Base }\end{array}$} & \multicolumn{3}{|c|}{ Oven } & \multicolumn{3}{|c|}{ Cooktop } & & \\
\hline & Upper & Lower & & Upper & Lower & $\begin{array}{l}\text { Accept } \\
\text { Delay }\end{array}$ & Base & $\begin{array}{c}\text { ES- } \\
\text { mode }\end{array}$ & $\begin{array}{l}\text { Accept } \\
\text { Delay }\end{array}$ & & \\
\hline Normal & $65 \%$ & $35 \%$ & $100 \%$ & $65 \%$ & $35 \%$ & $0 \%$ & $100 \%$ & $0 \%$ & $0 \%$ & Zero & $\begin{array}{l}1 \mathrm{a}, 1 \mathrm{~b}, \\
1 \mathrm{c}, 3 \mathrm{a}\end{array}$ \\
\hline $\begin{array}{c}\text { DR } \\
\text { Case A }\end{array}$ & $65 \%$ & $35 \%$ & $100 \%$ & $90 \%$ & $0 \%$ & $10 \%$ & $0 \%$ & $90 \%$ & $10 \%$ & Zero & $\begin{array}{c}1 \mathrm{~b}, 1 \mathrm{c}, \\
1 \mathrm{~d}, 2\end{array}$ \\
\hline $\begin{array}{c}\text { DR } \\
\text { Case B }\end{array}$ & $65 \%$ & $35 \%$ & $100 \%$ & $90 \%$ & $0 \%$ & $10 \%$ & $0 \%$ & $90 \%$ & $10 \%$ & $\begin{array}{c}40 \\
\text { min }\end{array}$ & $\begin{array}{c}3 a, 3 b, 4, \\
5\end{array}$ \\
\hline
\end{tabular}

Two refrigerator scenarios were used in the aggregate simulation. Both cases use the refrigerator door openings are modeled as per the refrigerator ELCAP data as discussed in Section 2.8. The first scenario, which is normal operation, provides a base case, as shown in Table 3-9. The second scenario uses the DR characteristics described in Section 2.8, and is used for both the "best" and "worst" case scenarios (DR Case A and DR Case B). 
Table 3-9: Refrigerator cases used for aggregated simulations.

\begin{tabular}{|c|c|c|c|}
\hline Case & During Normal signal & During DR signal & $\begin{array}{c}\text { Used in } \\
\text { scenarios }\end{array}$ \\
\hline Normal & Normal Operation & Normal Operation & $1 \mathrm{a}, 1 \mathrm{~b}, 1 \mathrm{c}, 3 \mathrm{a}$ \\
\hline $\begin{array}{c}\text { DR Case A } \\
\text { DR Case B }\end{array}$ & Normal Operation & $\begin{array}{c}\text { Reduced Compressor Usage } \\
\text { Delayed Defrost Cycles }\end{array}$ & $\begin{array}{c}1 \mathrm{~b}, 1 \mathrm{c}, 1 \mathrm{~d}, 2, \\
3 \mathrm{a}, 3 \mathrm{~b}, 4,5\end{array}$ \\
\hline
\end{tabular}

The HVAC scenarios that were used in the following simulations are shown in Table 3-10. The setpoints are selected from a distribution of setpoints as indicated by data from the EIA website [17], where each residence is assigned a unique heating and cooling setpoint, and a unique daily setback (daytime settings versus nighttime settings). A more detailed description on how these distributions are formulated can be found at [4]. Each residence is also assigned a unique thermostat setback during a DR signal, following the distribution of slider settings shown in Figure 2-2. This equates to a range of setbacks $(\Delta \mathrm{T})$ from 0 to $2^{\circ} \mathrm{F}$ during a High signal and 0 to $5^{\circ} \mathrm{F}$ during a Critical signal, depending upon what level of participation is assigned to the residence. This is used to represent a smart thermostat which allows the customer to choose their amount of setback during each DR event, and automatically adjusts the thermostat setpoints during a price change.

Table 3-10: HVAC cases used for aggregated simulations.

\begin{tabular}{|c|c|c|c|c|}
\hline \multirow{2}{*}{ Case } & During Normal signal & \multicolumn{2}{|c|}{ During DR signal } & \multirow{2}{*}{$\begin{array}{c}\text { Used in } \\
\text { scenarios }\end{array}$} \\
\cline { 2 - 4 } Normal & High $(\Delta \mathrm{T})$ & Critical $(\Delta \mathrm{T})$ & no change & $\begin{array}{c}1 \mathrm{a}, 1 \mathrm{~b}, 1 \mathrm{c}, \\
1 \mathrm{~d}, 3 \mathrm{a}\end{array}$ \\
\hline $\begin{array}{c}\text { DR Case A } \\
\text { DR Case B }\end{array}$ & $\begin{array}{c}\text { Distribution of cooling and } \\
\text { heating setpoints from EIA data. }\end{array}$ & no change & $0-5.0^{\circ} \mathrm{F}$ & $2,3 \mathrm{~b}, 4,5$ \\
\hline
\end{tabular}

Lights and other miscellaneous loads are also simulated. These are represented as a simple load shape based off of ELCAP data, and are scaled as a function of square footage of the residence. The load shapes do not respond to changes in the price signal. The load shapes used are shown in Figure 3-1, as defined for a 2500 square foot home. More information about the scaling factor and the ELCAP load shape used can be found at [4]. 


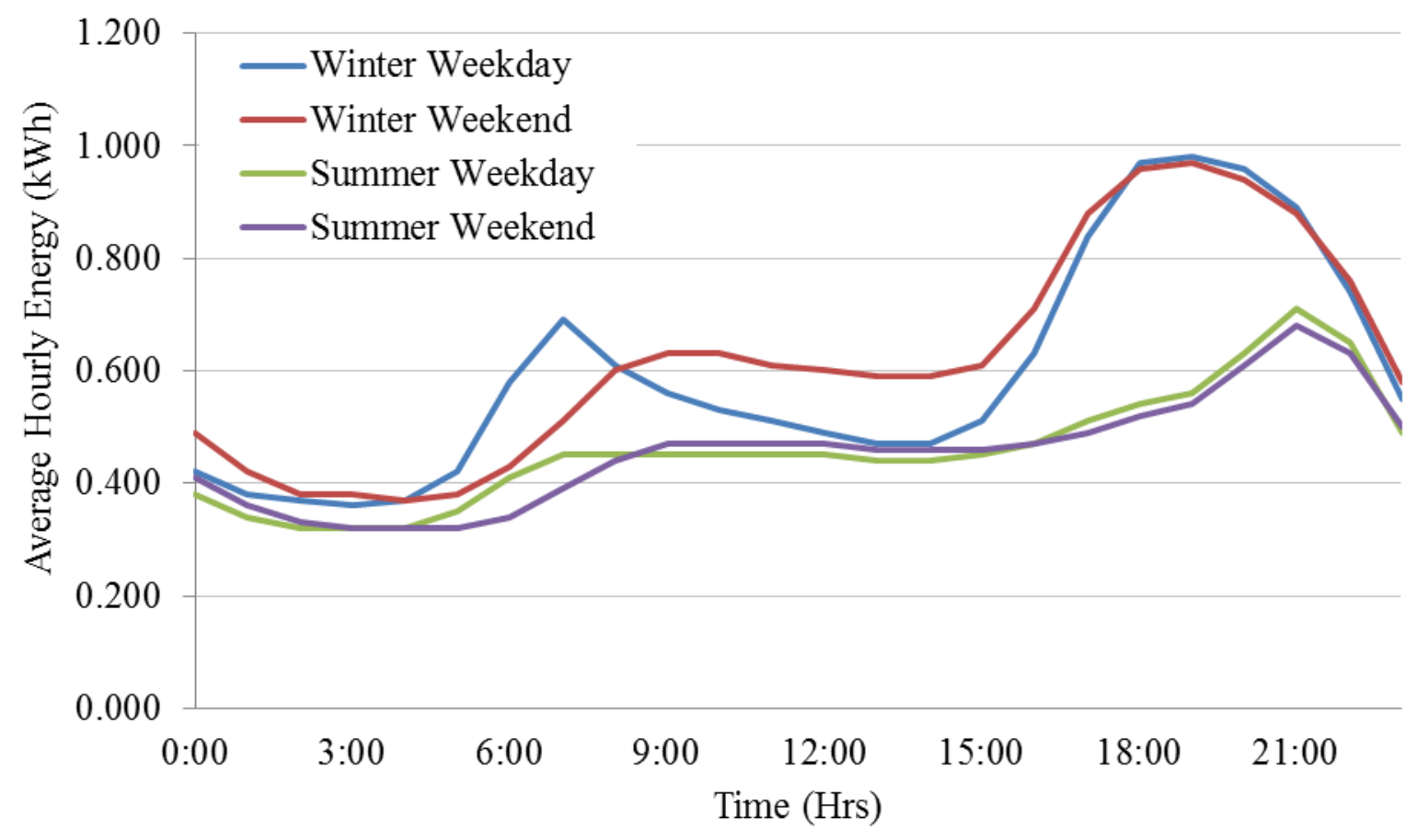

Figure 3-1: ELCAP load shapes for lights and other miscellaneous devices.

\subsection{Response of appliances to DR Signal 1}

The aggregated simulation results being presented here use DR Signal 1 (six hour Critical period only). Critical pricing signals are used by utilities to achieve demand reduction on the most extreme peak demand days of the year. Annual peak demand values for a utility are used to determine whether future capacity must be added, often leading to significant capital investment. However, values close to the annual peak are usually observed roughly 40 to 60 hours spread throughout the year and across roughly 10 to 15 days of the year. Hence, the capacity usually built into a utility system is used to its maximum value only for about 60 hours in the entire year, which is less than $1 \%$ of the hours [18]-[20]. A case for DR for utilities is to curtail the demand, such that underutilized excess capacity is never needed by the system. Also, future capacity upgrades can be performed at a less aggressive rate and postponed further, if the load during the peak hours of the year could somehow be curtailed to a requisite value.

Studying the capabilities and effects of a critical pricing period on appliance DR thus becomes critical in this study. Most regulations and rules however do not allow utilities to call on critical pricing periods for more than four to six hours during a day [19][20]. Hence, in this study, the effects of aggregated appliance response to a four hour and a six hour critical pricing period will be examined. This section discusses the six hour critical pricing period effects, while section 3.3 discusses the four hour critical pricing period effects. In this section, only summer results are discussed, as most of the peak days occur during the summer time frame. 
The timing of the Critical price signal varied per the season and type of day being simulated. This was done because of the seasonal and weekday/weekend variations that are observed in the daily load pattern (as can also be observed from the ELCAP data). Such variations in seasonal and weekday/weekend load patterns lead to variations in the peak period of electricity usage observed on any given day. Thus, in this study, the period of the Critical signal was adjusted as per the season and type of day being simulated. This signal is analogous to a CPP period of six hours, typically used by utilities 10-15 times per year to reduce peak demand. While it is not common for CPP programs to include weekends, these events were simulated for completeness. The Critical signal used in this simulation is shown in Table 3-11. The individual appliance scenarios considered in this scenario are as described in Section 3.1. In this scenario, HVACs are simulated, but they are not price responsive. As mentioned previously, three different GE DRenabled appliance penetration levels are being considered, namely 5\%, 25\% and 100\%. In the figures and tables below, the penetration cases are identified as 5\% GE, 25\% GE and 100\% GE, while the base case, when appliances are not responding to a signal, is identified as Normal.

Table 3-11: Six hour pricing signal.

\begin{tabular}{|c|c|c|}
\hline Season & Weekday & Weekend \\
\hline Summer & $9: 00-15: 00$ & $10: 00-16: 00$ \\
\hline Winter & $16: 00-22: 00$ & $16: 00-22: 00$ \\
\hline
\end{tabular}

In Figure 3-2, the total demand at the feeder substation for the Normal case and the three DR cases for a summer weekday are compared, including HVAC, all appliances, miscellaneous end use and lighting loads, and system losses. The DR signal used has also been plotted for reference. As can be observed, the daily peak has both shifted in time and reduced in magnitude in all DR cases as compared to the Normal case, but is particularly significant in the $100 \%$ penetration of GE DR-enabled appliances case. 


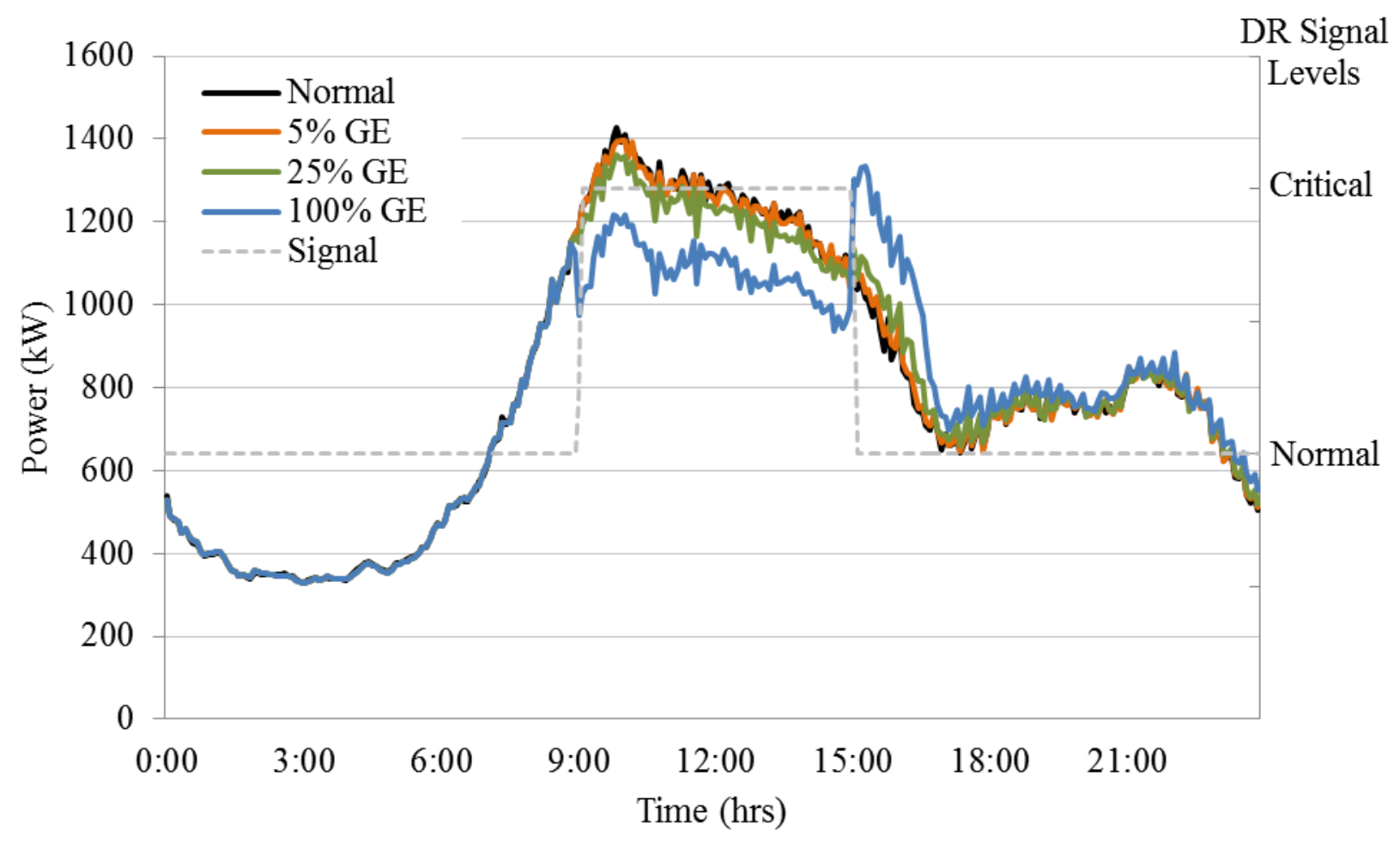

Figure 3-2: Time series comparison of total load on a summer weekday.

Table 3-12 compares the aggregated daily energy consumption, the aggregated energy consumption during the DR signal period, and the aggregated energy consumption after the DR signal period. As can be observed from Table 3-12, there is a significant reduction in the energy consumption during the DR signal period in the $100 \%$ GE case as compared to the Normal case. The energy consumption during the critical pricing period reduces to $6,478 \mathrm{kWh}$ from 7,525 $\mathrm{kWh}$ if all appliances on this feeder went from being unresponsive appliances (Normal case) to GE DR-enabled appliances. This is a nearly $14 \%$ reduction in the energy consumption during the DR signal period due to the appliances entering the ES-mode of operation, or a reduced energy consumption mode during the High and Critical signal periods. It can also be observed that with a $25 \%$ penetration of GE appliances, there is a $3 \%$ reduction in DR signal period energy consumption, and with a $5 \%$ penetration of GE appliances there is a less than $1 \%$ reduction in energy consumption during the DR signal period. 
Table 3-12: Comparison of the energy consumption on a summer weekday.

\begin{tabular}{|c|c|c|c|c|c|c|c|c|}
\hline & \multicolumn{2}{|c|}{ Normal } & \multicolumn{2}{c|}{$5 \%$ GE } & \multicolumn{2}{c|}{$25 \% \mathrm{GE}$} & \multicolumn{2}{c|}{$100 \%$ GE } \\
\cline { 2 - 9 } Case name & $\mathrm{kWh}$ & $\%$ & $\mathrm{kWh}$ & $\%$ & $\mathrm{kWh}$ & $\%$ & $\mathrm{kWh}$ & $\%$ \\
\hline $\begin{array}{c}\text { Daily Energy } \\
\text { Consumption (kWh) }\end{array}$ & 18,937 & 100.00 & 18,924 & 99.93 & 18,849 & 99.53 & 18,539 & 97.90 \\
\hline $\begin{array}{c}\text { Energy Consumption } \\
\text { during the High/Critical } \\
\text { Period (kWh) }\end{array}$ & 7,525 & 100.00 & 7,478 & 99.37 & 7,278 & 96.72 & 6,478 & 86.08 \\
\hline $\begin{array}{c}\text { Energy consumption after } \\
\text { High/Critical period for } \\
\text { six hours (kWh) }\end{array}$ & 4,696 & 100.00 & 4,722 & 100.57 & 4,839 & 103.05 & 5,281 & 112.46 \\
\hline
\end{tabular}

Table 3-13 compares the daily peak, peak demand during the DR signal period and the maximum observed demand, or rebound, after a DR signal period. As previously mentioned, in the simulation outputs, the daily peak has both shifted in time and reduced in magnitude in all cases as compared to the Normal case due to the GE appliances reducing demand during the DR signal period. The daily peak reduces from $1,428 \mathrm{~kW}$ in the Normal case to $1,335 \mathrm{~kW}$ in the $100 \%$ GE case, a reduction of approximately $6.5 \%$. There is a $4.7 \%$ and $2.2 \%$ reduction in the daily peak in the $25 \%$ GE case and $5 \%$ GE case, respectively, in comparison to the daily peak of the Normal case. These results indicate that smart appliances can provide significant DR, and as expected they provide higher DR at higher penetrations. In fact, if this were compared to a feeder with standard resistance hot water heaters (rather than hybrid hot water heaters), the reductions would be even greater, both in terms of peak demand and energy consumption.

Table 3-13: Comparison of the peak demand on a summer weekday.

\begin{tabular}{|c|c|c|c|c|c|c|c|c|}
\hline \multirow{2}{*}{ Case name } & \multicolumn{2}{|c|}{ Normal } & \multicolumn{2}{c|}{$5 \%$ GE } & \multicolumn{2}{c|}{$25 \%$ GE } & \multicolumn{2}{c|}{$100 \%$ GE } \\
\cline { 2 - 9 } & $\mathrm{kW}$ & $\%$ & $\mathrm{~kW}$ & $\%$ & $\mathrm{~kW}$ & $\%$ & $\mathrm{~kW}$ & $\%$ \\
\hline Daily Instantaneous Peak $(\mathrm{kW})$ & 1,428 & 100.00 & 1,396 & 97.76 & 1,361 & 95.32 & 1,335 & 93.49 \\
\hline $\begin{array}{c}\text { Peak in demand during } \\
\text { High/Critical period (kW) }\end{array}$ & 1,428 & 100.00 & 1,396 & 97.76 & 1361 & 95.32 & 1,217 & 85.26 \\
\hline $\begin{array}{c}\text { Maximum rebound peak after } \\
\text { High/Critical period (kW) }\end{array}$ & 1,086 & 100.00 & 1,091 & 100.40 & 1,132 & 104.24 & 1,335 & 122.87 \\
\hline
\end{tabular}

When the feeder peak load coincides with the system wide peak, utilities may require a reduction of feeder peak power during the high pricing period with limited concern as to the load during the rebound period. The peak observed during the high/critical pricing period is of significant interest to see the decrease in the feeder peak during a system peak period. From Table 3-13, it can clearly be seen that the feeder peak during DR signal period reduces to 1,217 $\mathrm{kW}$ from $1,428 \mathrm{~kW}$, a reduction of $14.7 \%$ for the $100 \%$ penetration case, while the $25 \%$ and $5 \%$ penetration cases provide a $4.7 \%$ and $2.2 \%$ reduction, respectively. 
Loss reduction is often described as a benefit of DR and peak reduction. The results in the simulation study here are consistent with this statement. The time series of loss values in $\mathrm{kW}$, recorded from the simulation, are presented in Figure 3-3. As can be observed, the losses follow the load values in terms of the profile. Hence, there is a clear reduction in losses due to responses from the DR enabled appliances. As can be observed from Table 3-14, the reduction in daily losses in the $100 \%$ GE case in comparison losses to the Normal case is about $13 \mathrm{kWh}$. It should be noted however, that when analyzed with respect to the total load of the respective cases, the losses in terms of percentage remain approximately the same. In the simulations presented, the losses are approximately $4 \%$ of the total system daily load.

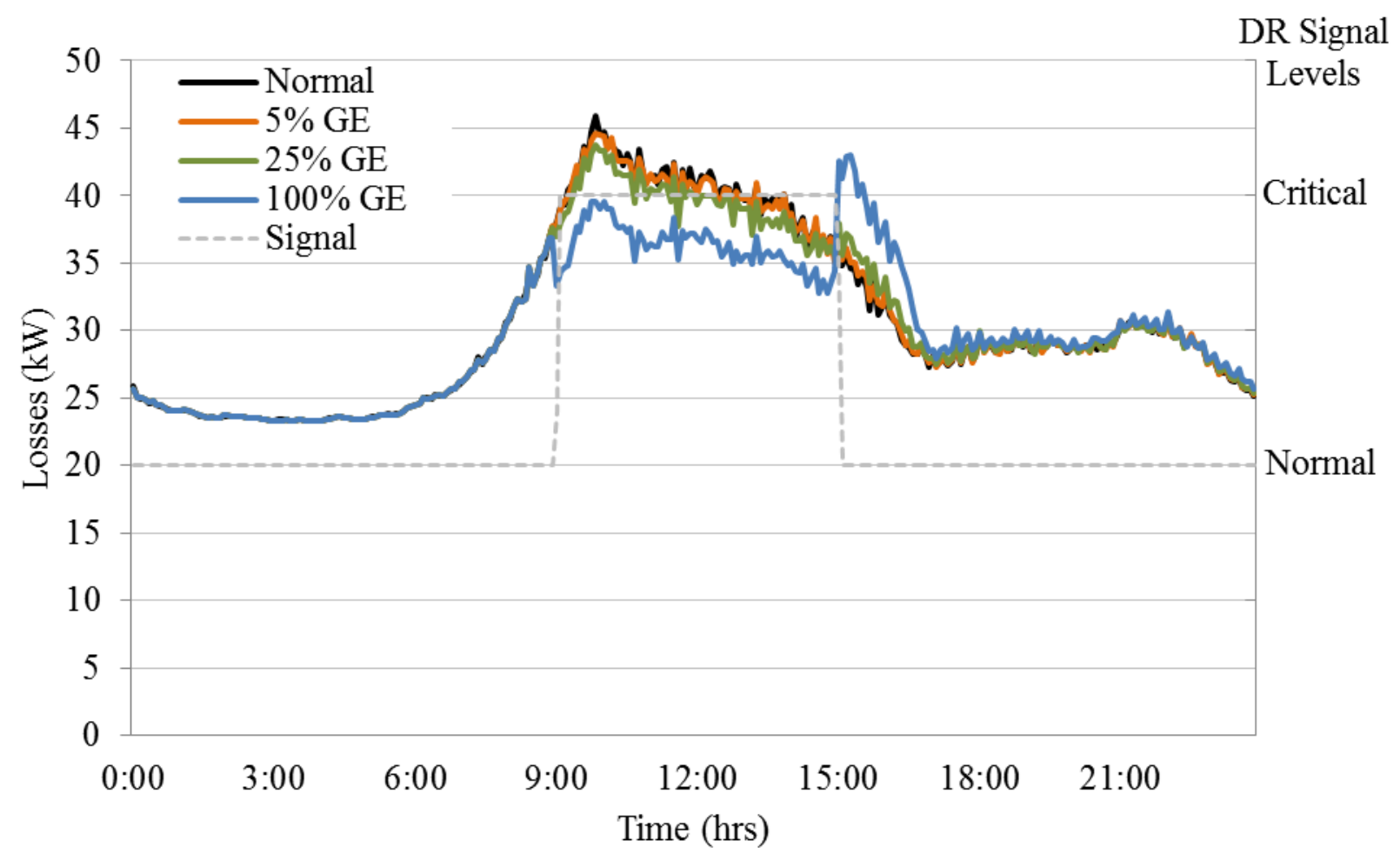

Figure 3-3: Time series comparison of energy losses on a summer weekday.

Table 3-14: Comparison of the energy losses for a summer weekday.

\begin{tabular}{|c|c|c|c|c|}
\hline Case name & Normal & $5 \% \mathrm{GE}$ & $25 \% \mathrm{GE}$ & $100 \% \mathrm{GE}$ \\
\hline Daily Losses (kWh) & 737 & 736 & 733 & 724 \\
\hline $\begin{array}{c}\text { Losses during the High/Critical } \\
\text { Period (kWh) }\end{array}$ & 243 & 242 & 237 & 217 \\
\hline $\begin{array}{c}\text { Losses after High/Critical period till } \\
\text { end of day (kWh) }\end{array}$ & 39 & 40 & 40 & 46 \\
\hline
\end{tabular}


Figure 3-4 shows the time series load values for the Normal case and the DR cases for a summer weekend. The DR signal used is again plotted for reference.

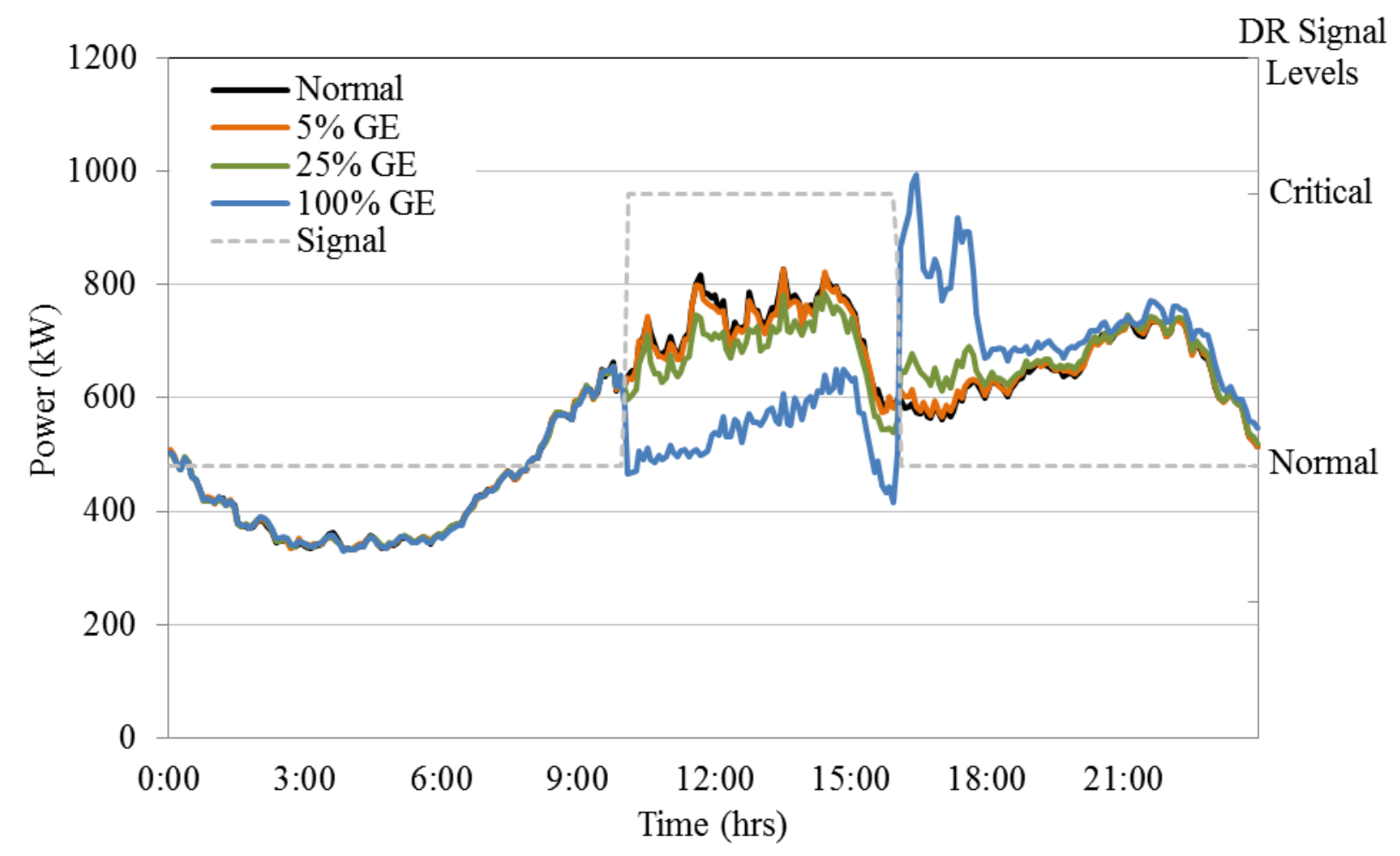

Figure 3-4: Time series comparison of total load on a summer weekend.

Table 3-15 compares the aggregated daily energy consumption, the aggregated energy consumption during the DR signal period, and the aggregated energy consumption after the DR signal period. As can be observed, there is a $25 \%$ reduction in energy consumption during the critical pricing period for the $100 \%$ GE case in comparison to the Normal case.

Table 3-15: Comparison of energy values for a summer weekend.

\begin{tabular}{|c|c|c|c|c|c|c|c|c|}
\hline \multirow{2}{*}{ Case name } & \multicolumn{2}{|c|}{ Normal } & \multicolumn{2}{c|}{$5 \%$ GE } & \multicolumn{2}{c|}{$25 \%$ GE } & \multicolumn{2}{c|}{$100 \%$ GE } \\
\cline { 2 - 9 } & $\mathrm{kWh}$ & $\%$ & $\mathrm{kWh}$ & $\%$ & $\mathrm{kWh}$ & $\%$ & $\mathrm{kWh}$ & $\%$ \\
\hline $\begin{array}{c}\text { Daily Energy Consumption } \\
\text { (kWh) }\end{array}$ & 13,786 & 100.00 & 13,773 & 99.90 & 13,692 & 99.32 & 13,355 & 96.87 \\
\hline $\begin{array}{c}\text { Energy Consumption during the } \\
\text { High/Critical Period (kWh) }\end{array}$ & 4,361 & 100.00 & 4,316 & 98.97 & 4,112 & 94.27 & 3,241 & 74.32 \\
\hline $\begin{array}{c}\text { Energy consumption after } \\
\text { High/Critical period for six hours } \\
(\mathrm{kWh})\end{array}$ & 3,885 & 100.00 & 3,911 & 100.68 & 4,030 & 103.72 & 4,519 & 116.33 \\
\hline
\end{tabular}


However as can be observed from Table 3-16, this reduction also comes with a penalty of a rebound peak which is higher than the peak observed in the Normal case by $33 \%$. Thus, for a summer weekend, while the goal of shifting the daily peak was achieved, the daily peak increased in magnitude. This may or may not be a problem if the utility imposing the critical pricing has more than one feeder in its system and the feeder peaks do not align. In such a scenario, unless the feeder has other capacity constraints, such an increase in peak due to the rebound may not cause any serious issues. In the best case, it may also help in leveling the total utility system load.

Table 3-16: Comparison of peak demand values for a summer weekend

\begin{tabular}{|c|c|c|c|c|c|c|c|c|}
\hline \multirow{2}{*}{ Case name } & \multicolumn{2}{|c|}{ Normal } & \multicolumn{2}{c|}{$5 \% \mathrm{GE}$} & \multicolumn{2}{c|}{$25 \% \mathrm{GE}$} & \multicolumn{2}{c|}{$100 \% \mathrm{GE}$} \\
\cline { 2 - 9 } & $\mathrm{kW}$ & $\%$ & $\mathrm{~kW}$ & $\%$ & $\mathrm{~kW}$ & $\%$ & $\mathrm{~kW}$ & $\%$ \\
\hline Daily Instantaneous Peak (kW) & 828 & 100.00 & 827 & 99.84 & 784 & 94.84 & 996 & 126.95 \\
\hline $\begin{array}{c}\text { Peak in demand during } \\
\text { High/Critical period (kW) }\end{array}$ & 828 & 100.00 & 827 & 99.84 & 784 & 94.84 & 649 & 82.81 \\
\hline $\begin{array}{c}\text { Maximum rebound peak after } \\
\text { High/Critical period (kW) }\end{array}$ & 741 & 100.00 & 741 & 100.09 & 747 & 100.75 & 996 & 133.32 \\
\hline
\end{tabular}

Table 3-17 compares the loss values. As can be observed, the total daily losses in the DR cases are lower than the Normal cases, with the lowest losses occurring in the $100 \%$ GE Case. In the $5 \%$ GE case there is only a small reduction in the daily peak and there is also a relatively small peak rebound after the DR signal in comparison to the Normal case. In the $25 \%$ case, there is a $5 \%$ reduction in energy used during the DR period, while there is a $<1 \%$ peak rebound after the DR signal. As can be noted, in percentage terms, the response from the appliances in the summer weekend case is higher than the corresponding value in the summer weekday case. Also, the energy reduction in the summer weekend case in terms of percentage is significantly lower than the summer weekday case. In percentage terms, the rebound after the Critical signal is also higher for the summer weekend case as opposed to the summer weekday case. Thus, it can be concluded that peak load on a summer weekend is due to a higher percentage of appliance load than during the summer weekday.

Table 3-17: Comparison of energy losses for a summer weekend.

\begin{tabular}{|c|c|c|c|c|}
\hline Case name & Normal & $5 \% \mathrm{GE}$ & $25 \% \mathrm{GE}$ & $100 \% \mathrm{GE}$ \\
\hline Daily Losses (kWh) & 631 & 630 & 629 & 626 \\
\hline $\begin{array}{c}\text { Losses during the High/Critical } \\
\text { Period (kWh) }\end{array}$ & 171 & 170 & 167 & 155 \\
\hline $\begin{array}{c}\text { Losses after High/Critical period till } \\
\text { end of day (kWh) }\end{array}$ & 29 & 29 & 29 & 35 \\
\hline
\end{tabular}


Thus, GE appliances, in conjunction with a six hour critical pricing signal, can significantly help reduce peak load during the Critical pricing period. It can also help reduce the overall daily peak in certain cases, as was observed in the summer weekday case.

\subsection{Response of appliances to DR Signal 2}

The aggregated simulation results being presented here use DR Signal 2 (four hour Critical period). As mentioned in the previous section, critical pricing signals are used by utilities to achieve a greater extent of demand reduction on some of the very high peak days of the year. Studying the benefits and issues with using such a critical pricing period on appliance DR becomes critical in this study. The previous section discusses a six hour critical pricing period effects, while this section focuses on the effects of a four hour critical pricing period. Again, only summer results are discussed in this section.

For reasons discussed in the previous section, the timing of the Critical signal varied per the season and type of day being simulated. Thus, in this study, the period of the Critical signal was adjusted as per the season and type of day being simulated. This signal is analogous to a CPP period of four hours, typically used by utilities 10-15 times per year to reduce peak demand. The simulated DR signal is shown in Table 3-18. While it is not common for CPP programs to include weekends, these events were simulated to provide a complete set of possible responses. The individual appliance scenarios considered in this scenario are as described in Section 3.1. In this scenario, no price responsive HVACs are considered. As mentioned previously, three different GE DR-enabled appliance penetration levels are being considered, namely 5\%, 25\% and $100 \%$.

Table 3-18: Four hour pricing signal.

\begin{tabular}{|c|c|c|}
\hline Season & Weekday & Weekend \\
\hline Summer & $9: 00-13: 00$ & $11: 30-3: 30$ \\
\hline Winter & $17: 00-21: 00$ & $17: 00-21: 00$ \\
\hline
\end{tabular}

In Figure 3-5, the total load at the feeder substation for the Normal case and the three DR cases $(5 \%, 25 \%$ and $100 \% \mathrm{GE})$ for a summer weekday are compared. The DR signal used has also been plotted for reference. 


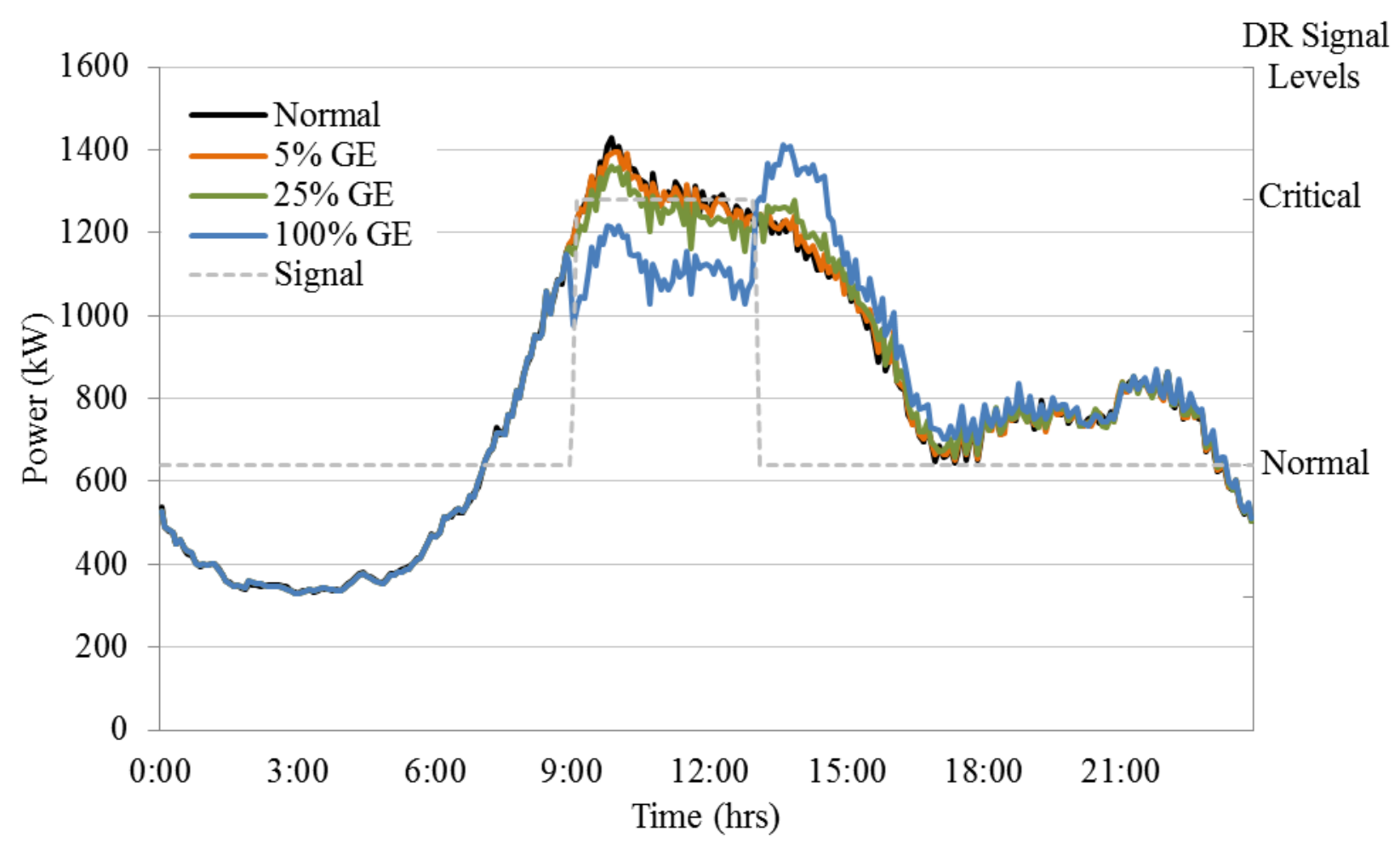

Figure 3-5: Time series comparison of total load on a summer weekday.

Table 3-19 compares the aggregated daily energy consumption, the aggregated energy consumption during the DR signal period, and the aggregated energy consumption after the DR signal period. Table 3-20 compares the daily peak, maximum observed demand during a DR signal period and after the DR signal period.

Table 3-19: Comparison of the energy values for a summer weekday.

\begin{tabular}{|c|c|c|c|c|c|c|c|c|}
\hline \multirow{2}{*}{ Case name } & \multicolumn{2}{|c|}{ Normal } & \multicolumn{2}{c|}{$5 \% \mathrm{GE}$} & \multicolumn{2}{c|}{$25 \% \mathrm{GE}$} & \multicolumn{2}{c|}{$100 \% \mathrm{GE}$} \\
\cline { 2 - 9 } & $\mathrm{kW}$ & $\%$ & $\mathrm{~kW}$ & $\%$ & $\mathrm{~kW}$ & $\%$ & $\mathrm{~kW}$ & $\%$ \\
\hline $\begin{array}{c}\text { Daily Energy Consumption } \\
(\mathrm{kWh})\end{array}$ & 18,937 & 100.00 & 18,929 & 99.96 & 18,899 & 99.80 & 1,8727 & 98.89 \\
\hline $\begin{array}{c}\text { Energy Consumption during the } \\
\text { Critical Period (kWh) }\end{array}$ & 5,190 & 100.00 & 5,154 & 99.32 & 5,018 & 96.69 & 4,443 & 85.61 \\
\hline $\begin{array}{c}\text { Energy consumption for six } \\
\text { hours after Critical period (kWh) }\end{array}$ & 4,085 & 100.00 & 4,115 & 100.73 & 4,198 & 102.77 & 4,517 & 110.57 \\
\hline
\end{tabular}


Table 3-20: Comparison of the peak demand values for a summer weekday.

\begin{tabular}{|c|c|c|c|c|c|c|c|c|}
\hline \multirow{2}{*}{ Case name } & \multicolumn{2}{|c|}{ Normal } & \multicolumn{2}{c|}{$5 \%$ GE } & \multicolumn{2}{c|}{$25 \%$ GE } & \multicolumn{2}{c|}{$100 \%$ GE } \\
\cline { 2 - 9 } & $\mathrm{kW}$ & $\%$ & $\mathrm{~kW}$ & $\%$ & $\mathrm{~kW}$ & $\%$ & $\mathrm{~kW}$ & $\%$ \\
\hline $\begin{array}{c}\text { Daily Instantaneous Peak } \\
(\mathrm{kW})\end{array}$ & 1,428 & 100.00 & 1,396 & 97.76 & 1,361 & 95.32 & 1,411 & 98.84 \\
\hline $\begin{array}{c}\text { Peak demand during } \\
\text { Critical period (kW) }\end{array}$ & 1,428 & 100.00 & 1,396 & 97.76 & 1,361 & 95.32 & 1,217 & 85.26 \\
\hline $\begin{array}{c}\text { Maximum peak demand } \\
\text { after Critical period }(\mathrm{kW})\end{array}$ & 1,245 & 100.00 & 1,255 & 100.78 & 1,279 & 102.77 & 1,411 & 113.37 \\
\hline
\end{tabular}

As can be observed from Figure 3-5, there is a significant reduction in the energy consumption during the DR signal periods in the $100 \%$ GE case as compared to the Normal case. As can also be observed, the daily peak has both shifted in time and reduced in magnitude in the $100 \%$ GE Case as compared to the Normal case. The energy consumption during the DR signal period reduces to $4443 \mathrm{kWh}$ from $5190 \mathrm{kWh}$ in the $100 \%$ GE case as compared to the Normal case. During the critical pricing period, energy consumption is reduced by $14.4 \%$ if all appliances on this feeder went from being unresponsive appliances to GE Smart appliances. It can also be observed that with a $25 \%$ penetration of GE appliances, there is a $3.3 \%$ reduction in energy consumption during the DR signal period and with a 5\% penetration of GE appliances there is a less than $1 \%$ reduction in energy consumption.

The daily peak is reduced by $2.2 \%$ in the $5 \%$ GE case and by $4.7 \%$ in the $25 \%$ GE case in comparison to the Normal case. Because of a significant demand rebound after the DR signal, the daily peak in the $100 \%$ GE case is only reduced by $1.2 \%$ in comparison to the Normal case. Hence, when a four hour Critical signal is imposed on a feeder where there is high penetration of GE demand responsive appliances, there is shift in the time that the peak occurs, but only a $1 \%$ decrease in magnitude of the peak. This is different from what was observed in the previous scenario, where a six hour critical period led to both a shift in time and a significant decrease in the magnitude of the daily peak value. As can be seen from Table 3-1, the six hour Critical signal covers most of the hours of observed peak load in the base case. Hence, the rebound peaks in the DR cases occur during the off-peak period. The same does not happen in the four hour Critical signal case, where the rebound peak occurs while the system load is still relatively high. Hence, the rebound in the four hour Critical signal case is higher than the daily peak. In cases where a Critical signal cannot be imposed for more than four hours, and if the observed peak load is longer than four hours, like is observed in this summer weekday example, a three period pricing signal, with a High signal imposed on the remaining peak hours can be used. More details on a three period pricing signal's effect on the system response will be discussed in section 3.5 below.

For reasons discussed in the section 3.2, the peak observed during the High and Critical pricing periods is of significant interest. From Table 3-20, it can be seen that in the $100 \%$ GE case, the feeder peak during the DR signal period reduces to $1,217 \mathrm{~kW}$ from $1,428 \mathrm{~kW}$, a total 
reduction of $14.7 \%$. This reduction is identical with the reduction observed in the six hour critical signal case (DR Signal 1). The peak rebound in this case is $13.4 \%$ higher than what is observed in the Normal case. In the $5 \%$ GE case, there is a $2.2 \%$ reduction in the peak seen during the DR signal period as compared to the Normal case and the rebound peak is less than $1 \%$ greater that the peak demand value observed in the Normal case after the DR signal period. In the $25 \% \mathrm{GE}$ case, while there is a reduction of $4.7 \%$ in the peak value observed during the DR signal period, there is an increase in the peak demand of $2.7 \%$ after the DR signal value, when compared to the values of the Normal case.

In Figure 3-6, the total load at the feeder substation for the Normal case and the three DR cases for a summer weekend are compared. The DR signal used has also been plotted for reference.

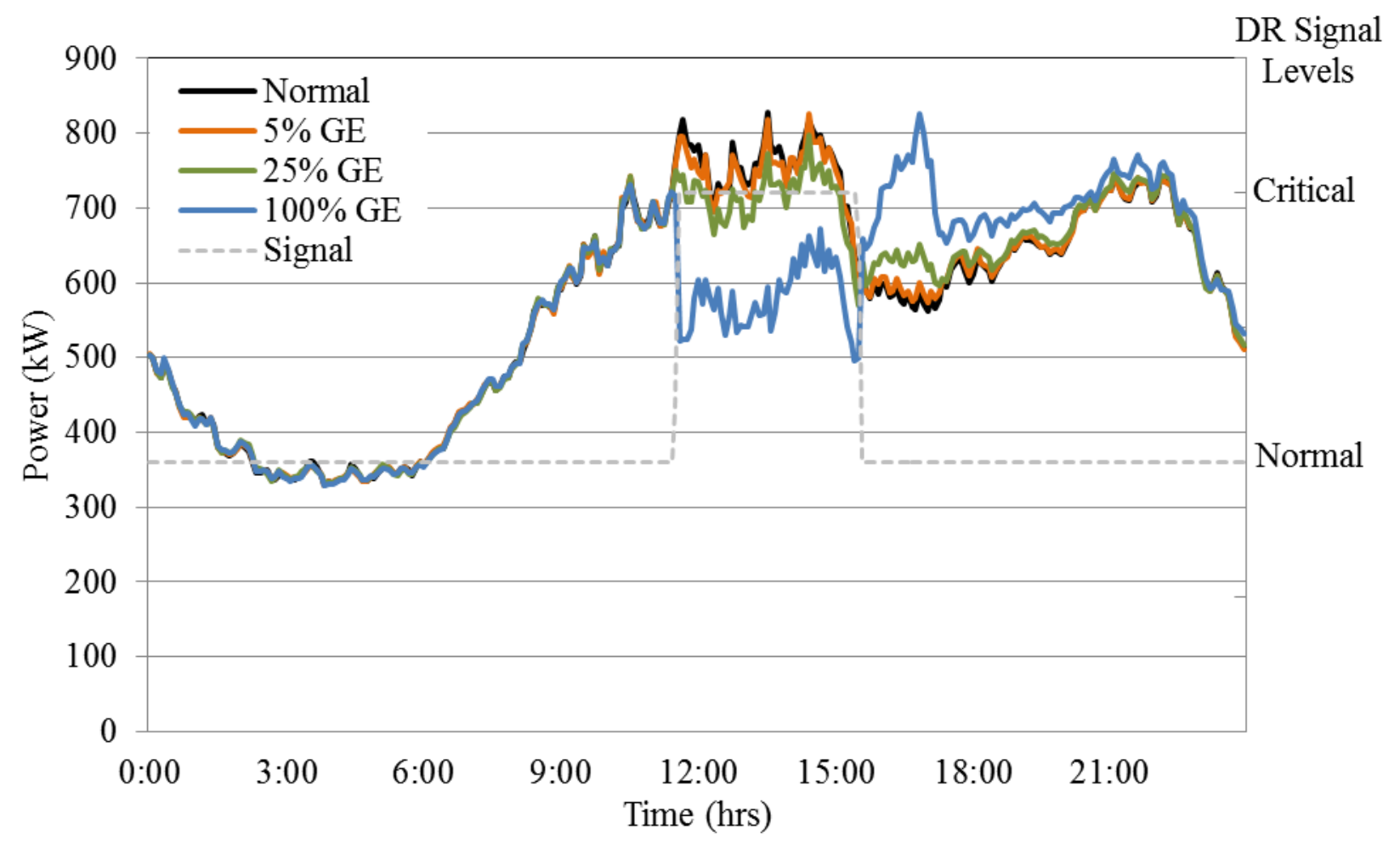

Figure 3-6: Time series comparison of total load on a summer weekend.

Table 3-21 compares the aggregated daily energy consumption, the aggregated energy consumption during the DR signal period, and the aggregated energy consumption after the DR signal period. 
Table 3-21: Comparison of the energy values for a summer weekend.

\begin{tabular}{|c|c|c|c|c|c|c|c|c|}
\hline \multirow{2}{*}{ Case name } & \multicolumn{2}{|c|}{ Normal } & \multicolumn{2}{c|}{$5 \%$ GE } & \multicolumn{2}{c|}{$25 \%$ GE } & \multicolumn{2}{c|}{$100 \%$ GE } \\
\cline { 2 - 9 } & $\mathrm{kW}$ & $\%$ & $\mathrm{~kW}$ & $\%$ & $\mathrm{~kW}$ & $\%$ & $\mathrm{~kW}$ & $\%$ \\
\hline $\begin{array}{c}\text { Daily Energy Consumption } \\
\text { (kWh) }\end{array}$ & 13,803 & 100.00 & 1,3793 & 99.93 & 13,749 & 99.61 & 13,559 & 98.23 \\
\hline $\begin{array}{c}\text { Energy Consumption during } \\
\text { the High/Critical Period } \\
\text { (kWh) }\end{array}$ & 3,028 & 100.00 & 2,992 & 98.81 & 2,855 & 94.28 & 2,313 & 76.39 \\
\hline $\begin{array}{c}\text { Energy consumption after } \\
\text { High/Critical period for six } \\
\text { hours (kWh) }\end{array}$ & 5,444 & 100.00 & 5,467 & 100.42 & 5,559 & 102.12 & 5,912 & 108.59 \\
\hline
\end{tabular}

Table 3-27 compares the daily peak, maximum observed demand during a DR signal period and after a DR signal period.

Table 3-22: Comparison of the peak demand values for a summer weekend.

\begin{tabular}{|c|c|c|c|c|c|c|c|c|}
\hline \multirow{2}{*}{ Case name } & \multicolumn{2}{|c|}{ Normal } & \multicolumn{2}{c|}{$5 \%$ GE } & \multicolumn{2}{c|}{$25 \%$ GE } & \multicolumn{2}{c|}{$100 \% \mathrm{GE}$} \\
\cline { 2 - 9 } & $\mathrm{kW}$ & $\%$ & $\mathrm{~kW}$ & $\%$ & $\mathrm{~kW}$ & $\%$ & $\mathrm{~kW}$ & $\%$ \\
\hline $\begin{array}{c}\text { Daily Instantaneous Peak } \\
(\mathrm{KW})\end{array}$ & 828 & 100.00 & 827 & 99.82 & 797 & 96.24 & 826 & 99.69 \\
\hline $\begin{array}{c}\text { Peak in demand during } \\
\text { High/Critical period (kW) }\end{array}$ & 828 & 100.00 & 827 & 99.82 & 797 & 96.24 & 673 & 81.24 \\
\hline $\begin{array}{c}\text { Maximum peak in demand } \\
\text { after High/Critical period } \\
(\mathrm{kW})\end{array}$ & 663 & 100.00 & 665 & 100.26 & 670 & 100.97 & 826 & 124.50 \\
\hline
\end{tabular}

As can be seen from Table 3-21 and Table 3-22, as compared to the Normal case the $100 \%$ GE case has a $23.6 \%$ reduction in energy consumption during the DR signal period and an $18.8 \%$ reduction in the peak value observed during the DR signal period. There is, however, an increase of $24.5 \%$ in the peak demand observed when compared with peak value of the Normal case after the DR signal period. The daily peak observed in the $100 \%$ GE case, however, is lower than the daily peak observed in the Normal case. In the $25 \%$ GE case, there is a $5.7 \%$ reduction in energy use from the Normal case and a $3.7 \%$ reduction in the peak during the DR signal period. In the $5 \% \mathrm{GE}$ case, there is a $1.1 \%$ reduction in energy consumption during the DR signal period and less than $1 \%$ reduction in the peak observed during the DR signal case. There is a less than $1 \%$ peak rebound in both the $25 \%$ GE and $5 \%$ GE cases.

Hence, depending on the penetration level of appliances, significant demand response can be obtained from GE DR-enabled appliances during the four hour critical signal period. Higher penetrations of the appliances result in greater reduction during the signal period, but typically result in a greater peak rebound. However, with a four hour critical signal, this peak rebound 
does not worsen the original daily peak of the system in the case of a summer simulations observed here. The shorter critical signal period leads to fewer appliances delaying operation than during the six hour period. This means that fewer appliances turn on during the recovery period, leading to a reduced rebound in the demand when the signal returns to normal. In other words, the longer the aggregate appliances are asked to reduce demand, the greater the rebound at the end of the reduction period.

\subsection{Response of appliances to DR Signal 3}

The aggregated simulation results being presented in this section are for DR Signal 3. DR Signal 3 was designed to represent a 15 minute regulating or load following signal. Short term DR resources are often discussed as a means for providing spinning reserve and for load following or regulation needs of a system [21]-[24]. Thus, the analysis here is being performed to assess the spinning reserve, downward load following and downward regulating capabilities of GE DR enabled appliances at different penetration levels. The control signal was designed as three Critical signals of 15 min duration each, with a two hour Normal signal period between these Critical signals. The Critical signals used in this analysis are shown in Table 3-23. The individual appliance scenarios examined in this scenario are as described in Section 3.1. As mentioned previously, three different GE appliance penetration levels are being considered, namely $5 \%, 25 \%$ and $100 \%$.

Table 3-23: Fifteen minute Critical pricing signals.

\begin{tabular}{|c|c|c|c|}
\hline \multirow{2}{*}{ Season } & \multicolumn{3}{|c|}{ Weekday and Weekend } \\
\cline { 2 - 4 } & $\begin{array}{c}\text { First Critical } \\
\text { Signal }\end{array}$ & $\begin{array}{c}\text { Second Critical } \\
\text { Signal }\end{array}$ & $\begin{array}{c}\text { Third Critical } \\
\text { Signal }\end{array}$ \\
\hline Summer & $10: 00-10: 15$ & $12: 15-12: 30$ & $14: 30-14: 45$ \\
\hline Winter & $16: 30-16: 45$ & $18: 45-19: 00$ & $21: 00-21: 15$ \\
\hline
\end{tabular}

In Figure 3-7, the total system load at the feeder substation for the Normal case and DR cases $(5 \%, 25 \%$ and $100 \%$ GE case) for a summer weekday are compared. The DR signal used has also been plotted for reference. Figure 3-8 shows a "zoomed in" version of the plot shown in Figure 3-7. As can be seen from Figure 3-8, there is a 13\%-15\% ( 140-200 kW) reduction in load for the $15 \mathrm{~min}$ period in the $100 \%$ GE case in comparison to the Normal case. The actual load reductions are shown in Table 3-24. The percentage reduction in load for the three fifteen minute Critical price signals for the different DR cases is as shown in the figure. As can be noted, the $25 \%$ case on an average has a reduction of $\sim 2.5 \%-5 \%$. The $5 \%$ case has a reduction of $\sim 1 \%-2 \%$ for the first two 15 min Critical price signal periods. During the third 15 min signal, there is an increased load noticed as compared to the Normal case. 


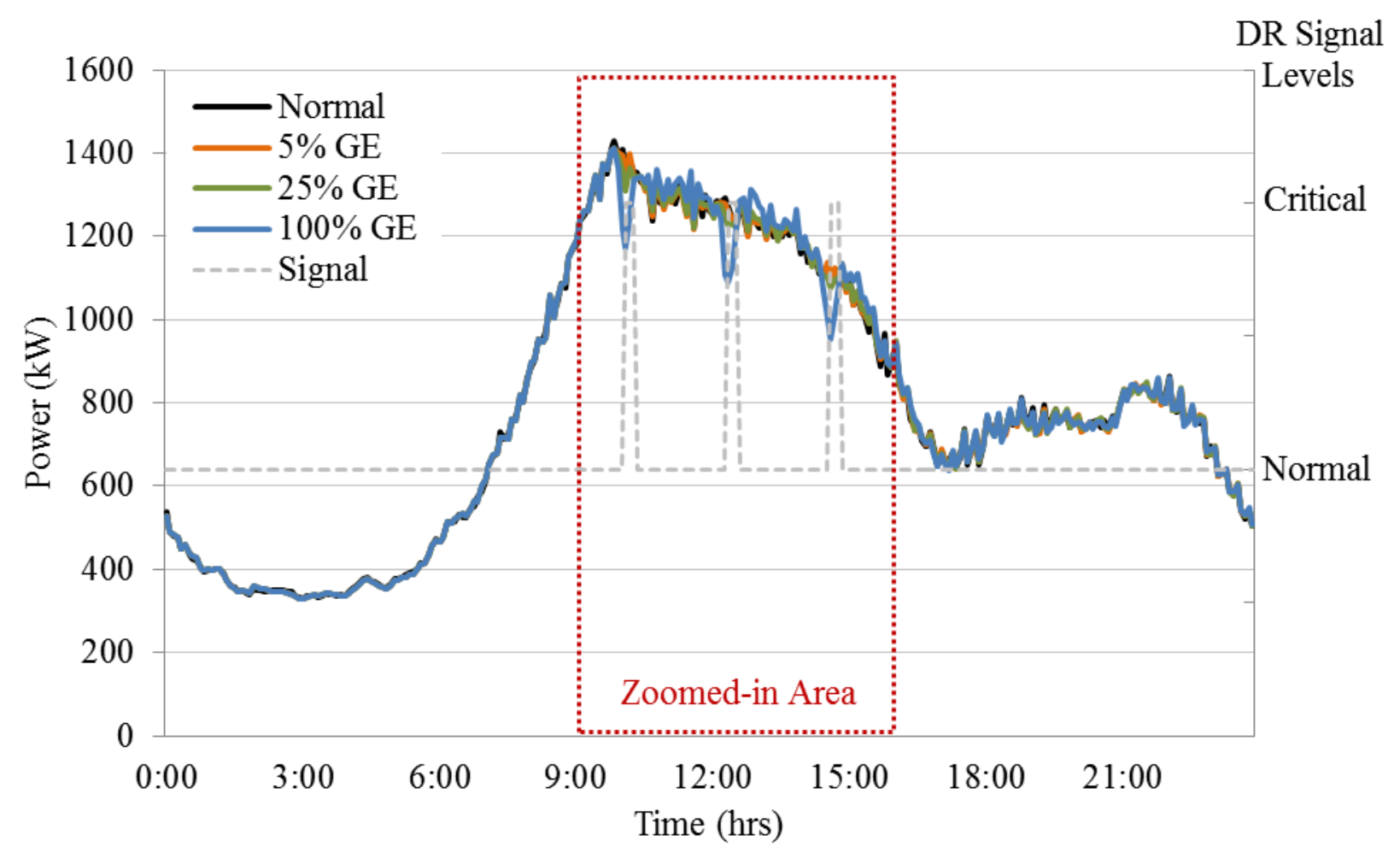

Figure 3-7: Time series comparison of total load on a summer weekday.

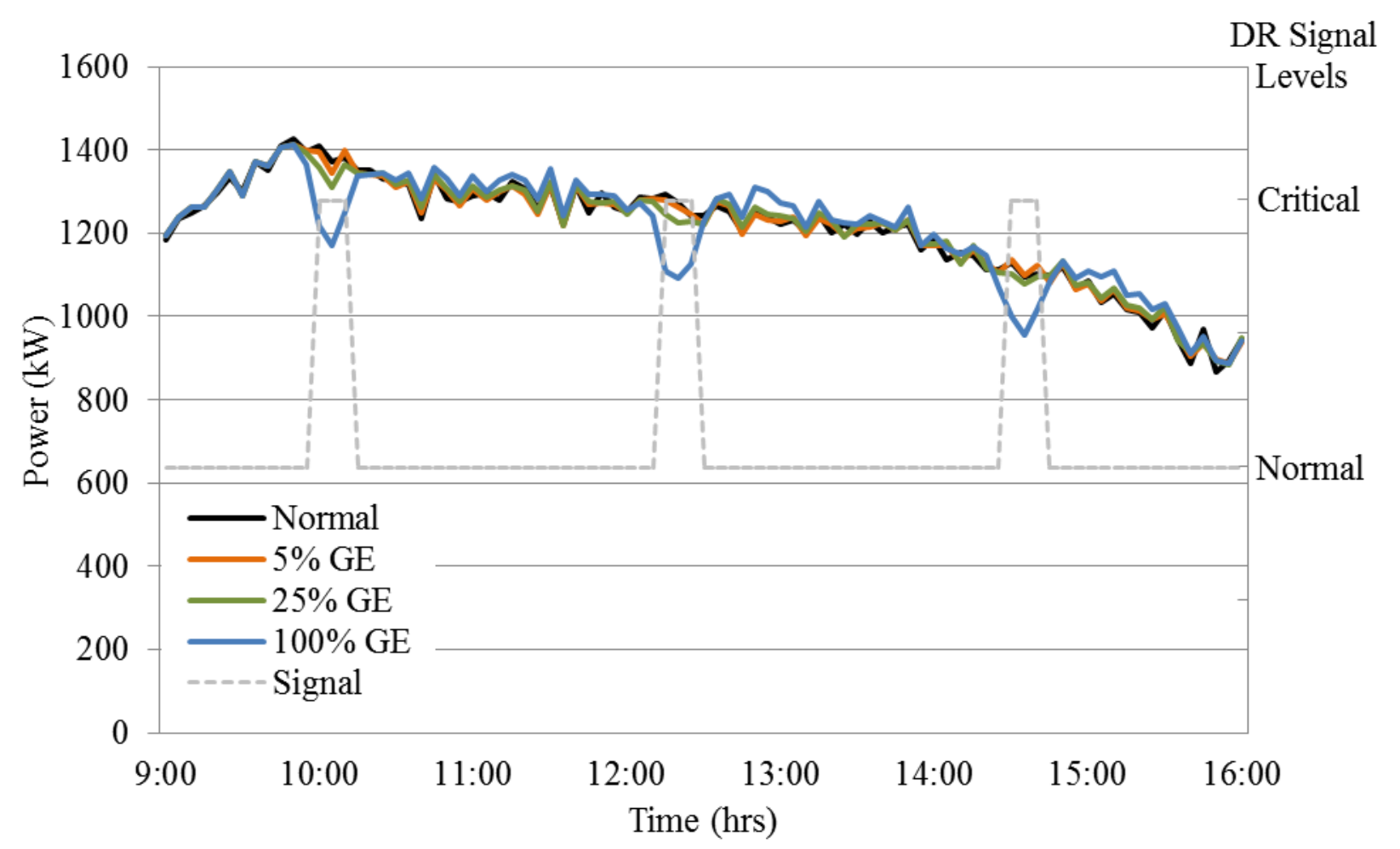

Figure 3-8: Zoomed-in portion of time series comparison of total load on a summer weekday. 
There is no significant rebound observed after any of the Critical signal periods. The reduction in load is greater when the load is higher. Thus, these simulation results show that there is a significant short term spinning reserve capability that could be provided by the use of smart appliances and this benefit should be further examined. However it is important to note that the spinning reserve capabilities of GE appliances at lower penetrations (like 5\%) must be further examined, as the simulation results show there may not be a decrease in load for a $15 \mathrm{~min}$ Critical signal in certain cases; this may be due to a lack of diversity in the lesser number of DRenabled appliances available for response.

Table 3-24: Percent reduction in load observed due to 15 min Critical signals.

\begin{tabular}{|c|c|c|c|}
\hline & $5 \% \mathrm{GE}$ & $25 \% \mathrm{GE}$ & $100 \% \mathrm{GE}$ \\
\cline { 2 - 4 } & $\%$ & $\%$ & $\%$ \\
\hline First 15 min period & 1.79 & 4.47 & 14.55 \\
\hline Second 15 min period & 1.13 & 3.79 & 14.25 \\
\hline Third 15 min period & -0.41 & 2.48 & 12.84 \\
\hline
\end{tabular}

However, for providing both upward and downward load following or regulation services, the appliances would not only need to reduce consumption during the Critical or High price periods, but also increase energy consumption during periods of time when more energy consumption is needed (Low price period). Since the appliance models implemented in this study are not designed to consume higher energy during Low pricing periods (as mentioned previously, the low control mode has not been implemented in the appliances), a perfect assessment of the load following and regulation capabilities of smart appliances cannot be made. However, based on these simulations results, it can be concluded that GE DR enabled appliances could provide significant load following and regulation capabilities in the downward direction, i.e. when overall system load needs to be reduced, and this benefit should be further examined. Currently frequency effects cannot be implemented in GridLAB-D and an assessment cannot be made on the frequency regulation capabilities of these appliances. However, the 15 minute signal does give an indication of the magnitude of the available frequency regulation resources from the DR appliances.

\subsection{Response of appliances to DR Signal 5}

The previous scenarios examined the responses of the appliances to a Critical price signal. However, as was discussed in Section 2, all appliances in this study, except for the clothes 
washer, have been modeled with a High price signal response (ES-High mode of operation). The ES-High mode of operation for all of the appliances is different and less aggressive in terms of energy reduction than the ES-Critical mode of operation, while typically reducing the apparent effects to the customer. Hence, it is important to look at the appliance response to the High signal as well. Additionally, utilities are in most cases restricted from the number of days and hours that a Critical signal (CPP pricing) can be imposed. However, the same restriction does not apply to a High pricing signal. Many utilities have a rate structure that has a two rate pricing program for all days of the year. One of the important points to note is that CPP pricing is mostly used for curtailing loads during extremely high peak power periods. However, the high pricing, or TOU structure, is mostly used as a methodology for load shifting and/or load leveling.

Some utilities may combine a two rate pricing program with the CPP pricing to obtain the benefits of both. This can be done in two ways. Utilities can choose to have a two rate pricing structure during all of the days of the year except for a few peak days where the utility could impose a CPP pricing. Alternatively, the utilities could have a three rate pricing structure for certain high peaks days of the year. The utilities could impose the CPP for a few hours of the top peaks days and have two rate pricing for the other hours of the same peak days and two rate pricing for all the other days of the year. As discussed in section 3.2, this may also help in situations when the number of hours a Critical signal can be imposed is smaller than the number of hours peak load is observed on the system. This three rate pricing structure for certain peak days of the year is commonly used to curtail load during extremely high peak power periods and helps shift the load away from peak periods to the off-peak periods during all days of the year. Hence, the appliance response to a three rate pricing scheme is examined here.

For reasons discussed in Section 3.1 the timing of the High and Critical signal varied as per the season and type of day being simulated and is shown in Table 3-25. Note that while it is not common for CPP programs to include weekends, these events were simulated for completeness. In this scenario, HVAC systems are simulated but are not price responsive. Three different GE DR-enabled appliance penetration levels are being considered, namely 5\%, 25\% and 100\%.

Table 3-25: DR Signal 5 price periods.

\begin{tabular}{|c|c|c|c|c|c|c|}
\hline \multirow{2}{*}{ Signal } & \multicolumn{3}{|c|}{ Summer } & \multicolumn{3}{c|}{ Winter } \\
\cline { 2 - 7 } & Weekday & Type & Weekend & Weekday & Type & Weekend \\
\hline \multirow{3}{*}{ DR } & $9: 00-9: 30$ & High & $10: 00-11: 0$ & $16: 00-17: 30$ & High & $16: 00-17: 30$ \\
signal 5 & $9: 30-13: 00$ & Critical & $11: 00-15: 00$ & $17: 30-20: 00$ & Critical & $17: 30-20: 00$ \\
& $13: 00-15: 00$ & High & $15: 00-16: 00$ & $20: 00-22: 00$ & High & $20: 00-22: 00$ \\
\hline
\end{tabular}


In Figure 3-9, the loads for the Normal case and the three DR cases for a summer weekday are compared. The DR signal used has also been plotted for reference. Table 3-26 compares the aggregated daily energy consumption, the aggregated energy consumption during the DR signal period, and the aggregated energy consumption after the DR signal period. Table 3-27 compares the peak demand for the entire day, within the DR signal period, and immediately following the DR period.

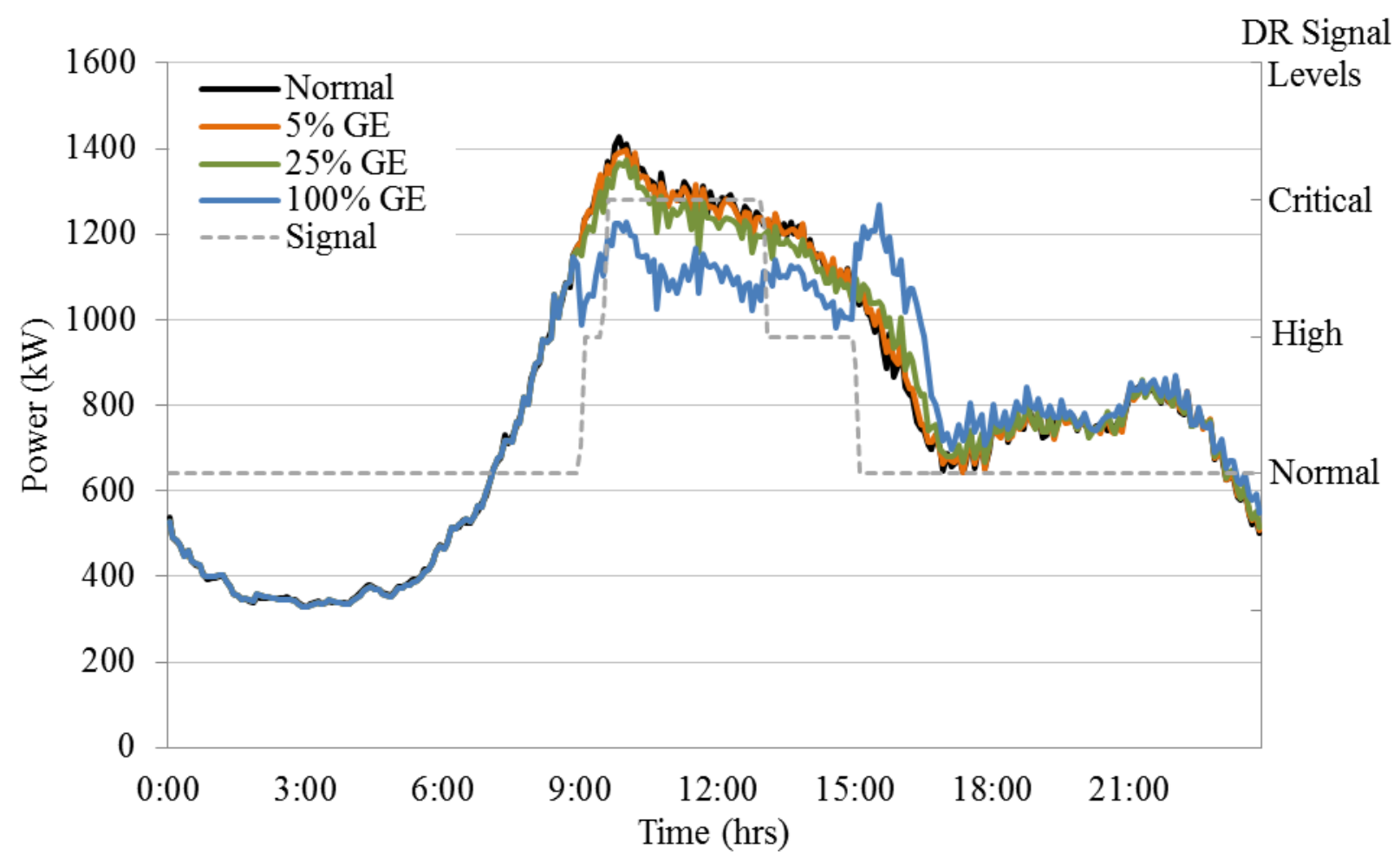

Figure 3-9: Time series comparison of total load for DR Signal 5 on a summer weekday.

Table 3-26: Comparison of the energy values for DR Signal 5 on a summer weekday.

\begin{tabular}{|c|c|c|c|c|c|c|c|c|}
\hline \multirow{2}{*}{ Case name } & \multicolumn{2}{|c|}{ Normal } & \multicolumn{2}{c|}{$5 \%$ GE } & \multicolumn{2}{c|}{$25 \%$ GE } & \multicolumn{2}{c|}{$100 \%$ GE } \\
\cline { 2 - 9 } & $\mathrm{kWh}$ & $\%$ & $\mathrm{kWh}$ & $\%$ & $\mathrm{kWh}$ & $\%$ & $\mathrm{kWh}$ & $\%$ \\
\hline $\begin{array}{c}\text { Daily Energy Consumption } \\
\text { (kWh) }\end{array}$ & 18,937 & 100.00 & 18,923 & 99.93 & 18,851 & 99.54 & 18,567 & 98.04 \\
\hline $\begin{array}{c}\text { Energy Consumption during } \\
\text { the High/Critical Period } \\
(\mathrm{kWh})\end{array}$ & 7,525 & 100.00 & 7,484 & 99.46 & 7,298 & 96.98 & 6,589 & 87.56 \\
\hline $\begin{array}{c}\text { Energy consumption after } \\
\text { High/Critical period for six } \\
\text { hours (kWh) }\end{array}$ & 3,183 & 100.00 & 3,212 & 100.94 & 3,308 & 103.94 & 3,653 & 114.78 \\
\hline
\end{tabular}


Table 3-27: Comparison of the peak demand values for DR Signal 5 on a summer weekday.

\begin{tabular}{|c|c|c|c|c|c|c|c|c|}
\hline \multirow{2}{*}{ Case name } & \multicolumn{2}{|c|}{ Normal } & \multicolumn{2}{c|}{$5 \% \mathrm{GE}$} & \multicolumn{2}{c|}{$25 \% \mathrm{GE}$} & \multicolumn{2}{c|}{$100 \% \mathrm{GE}$} \\
\cline { 2 - 9 } & $\mathrm{kW}$ & $\%$ & $\mathrm{~kW}$ & $\%$ & $\mathrm{~kW}$ & $\%$ & $\mathrm{~kW}$ & $\%$ \\
\hline $\begin{array}{c}\text { Daily Instantaneous Peak } \\
(\mathrm{kW})\end{array}$ & 1,483 & 100.00 & 1,466 & 98.85 & 1440 & 97.07 & 1,330 & 89.68 \\
\hline $\begin{array}{c}\text { Peak in demand during } \\
\text { High/Critical period (kW) }\end{array}$ & 1,428 & 100.00 & 1,396 & 97.76 & 1,372 & 96.10 & 1,229 & 86.08 \\
\hline $\begin{array}{c}\text { Maximum peak in demand } \\
\text { after High/Critical period } \\
(\mathrm{kW})\end{array}$ & 1,160 & 100.00 & 1,186 & 102.24 & 1,201 & 103.59 & 1,330 & 114.70 \\
\hline
\end{tabular}

As can be observed from Figure 3-9, there is a significant reduction in the energy usage during the DR signal periods in the $100 \%$ GE case as compared to the Normal case. The daily peak has both shifted in time and reduced in magnitude in the $100 \%$ GE Case as compared to the Normal case.

As can be seen in Table 3-26, the energy consumption during the DR signal period reduces to $6589 \mathrm{kWh}$ from $7525 \mathrm{kWh}$ if all appliances on this feeder went from being unresponsive appliances to GE Smart appliances. This is a $12.4 \%$ reduction in the energy consumption during the DR signal period. It can also be observed that with a $25 \%$ penetration of GE appliances, there is a $3 \%$ reduction in energy consumption during the DR signal period and with a $5 \%$ penetration of GE appliances there is a less than $1 \%$ reduction in energy consumption during the DR signal period.

Table 3-27 compares the daily peak, peak power during DR signal and the maximum demand after the DR signal period. In the GE 5\% case, there is a reduction in the daily peak value of $1.1 \%$, while in the $25 \% \mathrm{GE}$, the daily peak is reduced by approximately $2.9 \%$. In the $100 \%$ GE Case, the daily peak reduces to $1330 \mathrm{~kW}$ from $1483 \mathrm{~kW}$, a reduction of $10.3 \%$. In the $100 \%$ GE case, the daily peak is also shifted to the hours after the DR signal period. Hence, at higher penetrations of GE appliances, for a summer weekday and with a three rate pricing structure, a shift and decrease in the daily peak is observed. It can also be seen that the feeder peak during the DR signal period reduces to $1229 \mathrm{~kW}$ from $1428 \mathrm{~kW}$, a total reduction of $13.9 \%$ in the $100 \%$ GE case. The feeder peak during the DR signal period reduces by approximately $3.9 \%$ in the $25 \%$ GE case and $2.2 \%$ in the $5 \%$ GE case. Hence, significant reduction in peak can be achieved from smart appliances responding to a three rate pricing program. Since the daily peak is reduced in all of the DR cases, the rebound is lower than the daily peak of the base case in all DR cases for the simulation of a summer weekday.

In Figure 3-10, the Normal case and the three DR cases for a summer weekend are compared. The DR signal used has also been plotted for reference. 


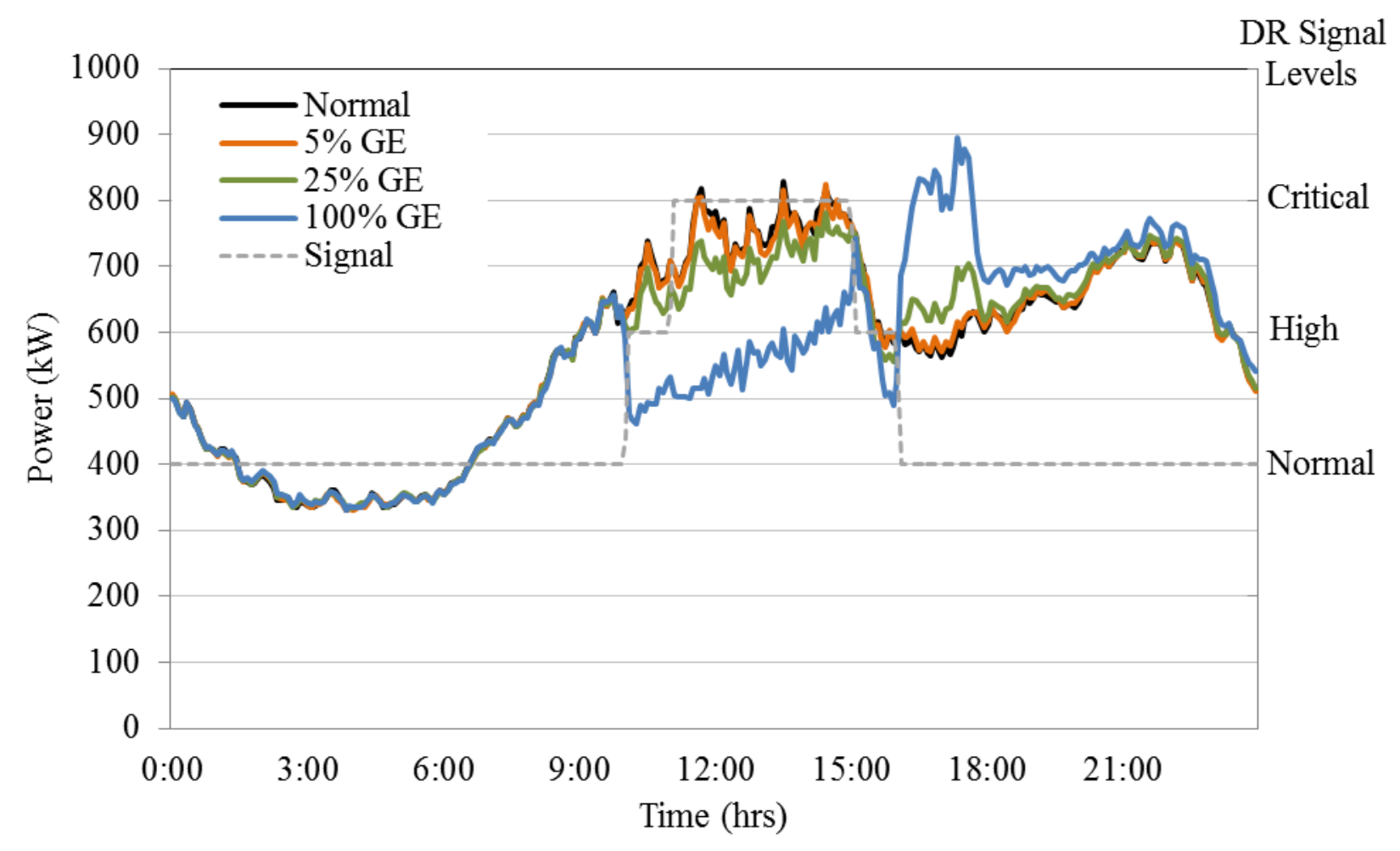

Figure 3-10: Time series comparison of total load for DR Signal 5 on a summer weekend.

Table 3-28 compares the aggregated daily energy consumption, the aggregated energy consumption during the DR signal period, and the aggregated energy consumption after the DR signal period. Table 3-29 compares the peak demand for the entire day, within the DR signal period, and immediately following the DR period.

Table 3-28: Comparison of the energy values for DR Signal 5 on a summer weekend.

\begin{tabular}{|c|c|c|c|c|c|c|c|c|}
\hline \multirow{2}{*}{ Case name } & \multicolumn{2}{|c|}{ Normal } & \multicolumn{2}{c|}{$5 \%$ GE } & \multicolumn{2}{c|}{$25 \%$ GE } & \multicolumn{2}{c|}{$100 \%$ GE } \\
\cline { 2 - 9 } & $\mathrm{kWh}$ & $\%$ & $\mathrm{kWh}$ & $\%$ & $\mathrm{kWh}$ & $\%$ & $\mathrm{kWh}$ & $\%$ \\
\hline $\begin{array}{c}\text { Daily Energy Consumption } \\
\text { (kWh) }\end{array}$ & 13,786 & 100.00 & 13,768 & 99.87 & 13,688 & 99.29 & 13,363 & 96.93 \\
\hline $\begin{array}{c}\text { Energy Consumption during } \\
\text { the High/Critical Period } \\
\text { (kWh) }\end{array}$ & 4,361 & 100.00 & 4,327 & 99.21 & 4,114 & 94.33 & 3,341 & 76.60 \\
\hline $\begin{array}{c}\text { Energy consumption after } \\
\text { High/Critical period for six } \\
\text { hours (kWh) }\end{array}$ & 2,460 & 100.00 & 2,479 & 100.78 & 2,592 & 105.37 & 2,964 & 120.51 \\
\hline
\end{tabular}


Table 3-29: Comparison of the peak demand values for DR Signal 5 on a summer weekend.

\begin{tabular}{|c|c|c|c|c|c|c|c|c|}
\hline \multirow{2}{*}{ Case name } & \multicolumn{2}{|c|}{ Normal } & \multicolumn{2}{c|}{$5 \%$ GE } & \multicolumn{2}{c|}{$25 \% \mathrm{GE}$} & \multicolumn{2}{c|}{$100 \% \mathrm{GE}$} \\
\cline { 2 - 10 } & $\mathrm{kW}$ & $\%$ & $\mathrm{~kW}$ & $\%$ & $\mathrm{~kW}$ & $\%$ & $\mathrm{~kW}$ & $\%$ \\
\hline $\begin{array}{c}\text { Daily Instantaneous Peak } \\
(\mathrm{KW})\end{array}$ & 872 & 100.00 & 889 & 101.95 & 828 & 94.92 & 957 & 109.64 \\
\hline $\begin{array}{c}\text { Peak in demand during } \\
\text { High/Critical period (kW) }\end{array}$ & 828 & 100.00 & 824 & 99.46 & 781 & 94.26 & 742 & 89.58 \\
\hline $\begin{array}{c}\text { Maximum peak in demand } \\
\text { after High/Critical period } \\
(\mathrm{kW})\end{array}$ & 666 & 100.00 & 673 & 101.08 & 733 & 110.09 & 957 & 143.69 \\
\hline
\end{tabular}

As can be observed Table 3-29, for the 5\% GE case as compared to the Normal case, there is very little reduction in the peak during the DR signal $(0.54 \%)$. There is also no significant peak rebound after the DR signal period in the $5 \%$ GE case $(0.08 \%)$. In the $25 \%$ GE case, there is a $5.6 \%$ reduction in the peak during the DR signal period as compared to the Normal case and a peak rebound of $10.1 \%$ of the Normal case. In the $100 \%$ GE case, there is a $10.4 \%$ reduction in the peak during the DR signal period as compared to the Normal case and a peak rebound of $43.7 \%$ of the Normal case. Hence, as compared to the Normal case, there is a noticeable rebound in the $25 \%$ GE case, while in the $100 \%$ GE case, there is significant rebound observed. The $100 \%$ penetration case shows a rebound which is higher than the daily peak observed in the Normal case. This higher rebound peak however, need not be a concern if this new peak does not violate any feeder constraints. Hence, if the goal is to move the peak to different time frame, and a new peak is not an issue on the feeder for a summer weekend, then higher penetrations of GE appliances can give significant reduction in peak during the DR signal hours to a three rate pricing program.

The three rate pricing structure can take advantage of the load shifting/load leveling capabilities of the two rate pricing scheme and the load curtailment benefit of a CPP pricing scheme. Also, as mentioned before, most utilities can only impose a CPP for a fixed number of days and for a fixed number of hours. However, for most utilities, the same restriction does not apply to a high price signal. Hence a combination of the two programs can be used by utilities for obtaining maximum DR benefits.

\subsection{With $(75 \%)$ responsive electric air conditioning}

Previous scenarios have looked at the potential for peak reduction while only utilizing a suite of specific DR enabled GE appliances. However, a more realistic DR deployment scenario would likely also control the HVAC system of a residence. The following scenarios will simulate the effects of DR appliances, including HVAC systems, on a distribution feeder during peak loading. For this scenario, $75 \%$ of the homes include electric air conditioning, all of which are responsive to the DR signal as described in Section 2.2, and $100 \%$ of the appliances are 
responsive to the signal (at the penetration levels described in Table 3-2). The simulations were conducted with two kinds of DR signals, during both summer weekends and weekdays. The first DR signal is a four hour critical pricing period as shown in Table 3-30, and the simulation results are discussed in Section 3.6.1. The second DR signal evaluated is a three rate pricing structure, and the simulation results are discussed in Section 3.6.2.

In this scenario, four cases were considered; one with unresponsive GE appliances and air conditioning (Base), the second one is unresponsive GE appliances and 100\% responsive air conditioning, the third one is $100 \%$ responsive GE appliances with $100 \%$ responsive air conditioning, and the last case is $100 \%$ responsive GE appliances and unresponsive air conditioning. The following observations are made from the time series simulations of a peak summer weekday.

\subsubsection{Four hour critical pricing signal}

Table 3-30 describes the four hour critical pricing signal used in this scenario. In order to investigate the effects of responsive air conditioning and GE appliances on distribution feeder during high pricing period, time series simulations were conducted in GridLAB-D.

Table 3-30: Four hour pricing signal.

\begin{tabular}{|c|c|c|}
\hline Season & Weekday & Weekend \\
\hline Summer & $9: 00-13: 00$ & $11: 30-3: 30$ \\
\hline Winter & $17: 00-21: 00$ & $17: 00-21: 00$ \\
\hline
\end{tabular}

From the simulation results shown in Figure 3-11, it is observed that the daily energy consumption of responsive air conditioning case with unresponsive GE appliances (Normal with responsive air conditioning) is $1.05 \%(199 \mathrm{kWh})$, less than that of the unresponsive air conditioning case with unresponsive GE appliances (Base). This reduction is because the temperature setpoints of air conditioners are lowered from normal operating setpoints during the Critical signal, temporarily reducing air conditioning load. By adding $100 \%$ penetration of responsive GE appliances to the same case (Normal with responsive air conditioning) the daily energy consumption is further reduced by $1.21 \%(227 \mathrm{kWh})$ when compared to unresponsive GE appliances and responsive air conditioning (Normal with responsive air conditioning). This is due to the fact that some of the GE appliances accept delay and some of them run in ES-mode (Energy Saver mode). 


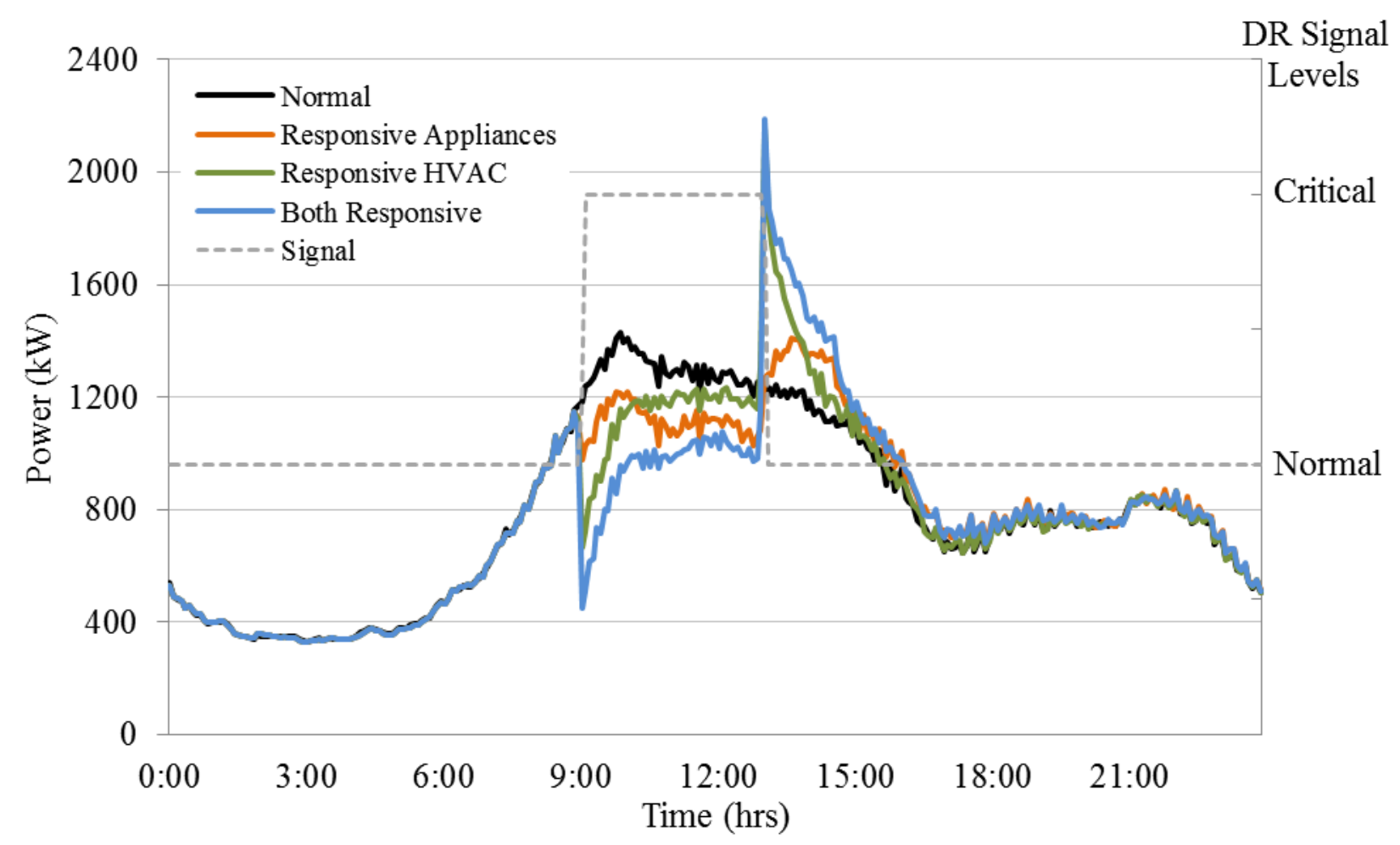

Figure 3-11: Time series comparison of total load on a summer weekday for a four hour critical pricing.

The total energy consumption during Critical pricing period with both appliances and air conditioning responding to the signal is $16.74 \%(754 \mathrm{kWh})$ lower than with only responsive air conditioning. The energy consumption after the Critical pricing period (except for the Base case), which is the recovery or rebound period, may be more than that deferred in the peak period. In this scenario, the energy consumption after the Critical pricing period, when both appliances and air conditioners respond, is $9.14 \%(418 \mathrm{kWh})$ more than is consumed with only the air conditioning responding. This is because all of the GE appliances that are delayed during the Critical signal randomize their start with some delay when the Normal signal arrives after the end of the Critical period. A comparison of the energy consumption for each of the four cases is shown in Table 3-31. 
Table 3-31: Comparison of energy consumption on a summer weekday for a four hour Critical pricing.

\begin{tabular}{|c|c|c|c|c|c|c|c|c|}
\hline \multirow{2}{*}{ Case name } & \multicolumn{3}{|c|}{ Unresponsive air conditioning } & \multicolumn{3}{c|}{ Responsive air conditioning } \\
\cline { 2 - 10 } & \multicolumn{2}{|c|}{ Normal (Base) } & \multicolumn{2}{|c|}{$100 \%$ GE } & \multicolumn{2}{|c|}{ Normal } & \multicolumn{2}{|c|}{$100 \%$ GE } \\
\cline { 2 - 10 } & $(\mathrm{kWh})$ & $(\%)$ & $(\mathrm{kWh})$ & $(\%)$ & $(\mathrm{kWh})$ & $(\%)$ & $(\mathrm{kWh})$ & $(\%)$ \\
\hline $\begin{array}{c}\text { Daily Energy } \\
\text { Consumption (kWh) }\end{array}$ & 18,937 & 100.0 & 18,727 & 98.9 & 18,738 & 98.9 & 18,511 & 97.7 \\
\hline $\begin{array}{c}\text { Energy Consumption } \\
\text { during the High/Critical } \\
\text { Period (kWh) }\end{array}$ & 5,190 & 100.0 & 4,443 & 85.6 & 4,504 & 86.8 & 3,750 & 72.2 \\
\hline $\begin{array}{c}\text { Energy consumption after } \\
\text { High/Critical period till } \\
\text { end of day (kWh) }\end{array}$ & 4,085 & 100.0 & 4,516 & 110.6 & 4,575 & 112.0 & 4,993 & 122.2 \\
\hline
\end{tabular}

A comparison of the peak demand of the base case and the three DR cases with a $75 \%$ penetration of air conditioning on a summer weekday for a four hour Critical pricing is shown in Table 3-32. Due to the response of the air conditioners and GE appliances, the peak demand during the critical period is reduced from $1,428 \mathrm{~kW}$, in the base unresponsive case, to $1,153 \mathrm{~kW}$, in the case with both responsive air conditioning and appliances, or a reduction of approximately $19 \%$. There is a $14.8 \%$ reduction in the peak demand during the Critical period in the responsive appliance only case versus an $8.3 \%$ reduction in the responsive air conditioning only case. This is because in all the cases, excepting the Base case, some population of GE appliances responds to Critical pricing and/or the air conditioning units lower their setpoint temperatures from the normal setpoints. Notice that a greater portion of the peak reduction within the signal period was provided by the appliances rather than the air conditioners (14.8\% versus $8.3 \%)$. While the air conditioning resource is a greater portion of the reduction at the beginning of the critical period, as evident by the initial drop-off in the load in Figure 3-11, notice that after roughly two hours, the appliance only reduction is greater than the air conditioning reduction (orange line versus the black line). This is due to the fact that the air conditioner resource is exhausted as time progresses as the internal air temperature of the residence returns to equilibrium around the new thermostat setpoint. This is a common phenomenon associated with thermostat setback programs [4], that as time progress during the signal period, fewer air conditioning resources become available for reduction. The appliance demand, however, can be reduced at a fairly consistent rate throughout the time period, providing an overall greater reduction of demand within the DR signal time frame. 
Table 3-32: Peak demand comparison on a summer weekday for a four hour Critical pricing.

\begin{tabular}{|c|c|c|c|c|c|c|c|c|}
\hline \multirow{2}{*}{ Case name } & \multicolumn{3}{|c|}{ Unresponsive air conditioning } & \multicolumn{3}{c|}{ Responsive air conditioning } \\
\cline { 2 - 9 } & \multicolumn{2}{|c|}{ Normal (Base) } & \multicolumn{2}{|c|}{$100 \%$ GE } & \multicolumn{2}{|c|}{ Normal } & \multicolumn{2}{c|}{$100 \%$ GE } \\
\cline { 2 - 9 } & $(\mathrm{kW})$ & $(\%)$ & $(\mathrm{kW})$ & $(\%)$ & $(\mathrm{kW})$ & $(\%)$ & $(\mathrm{kW})$ & $(\%)$ \\
\hline $\begin{array}{c}\text { Daily Instantaneous } \\
\text { Peak (kW) }\end{array}$ & 1,428 & 100.0 & 1,411 & 98.8 & 2,155 & 150.9 & 2,189 & 153.3 \\
\hline $\begin{array}{c}\text { Peak demand during } \\
\text { Critical period (kW) }\end{array}$ & 1,428 & 100.0 & 1,217 & 85.2 & 1,310 & 91.7 & 1,153 & 80.7 \\
\hline $\begin{array}{c}\text { Peak demand after } \\
\text { Critical period (kW) }\end{array}$ & 1,245 & 100.0 & 1,411 & 113.3 & 2,155 & 173.1 & 2,189 & 175.8 \\
\hline
\end{tabular}

A comparison of the peak power demands on a summer weekday for a four hour Critical pricing are shown in Table 3-32. Due to the DR of the air conditioners and GE appliances, the peak demand during critical period is reduced from $1,428 \mathrm{~kW}$, in the unresponsive air conditioning and GE appliances case (Base), to 1,153 kW, in comparison to the responsive air conditioning and GE appliances case, which is a reduction of approximately 19\%. There are $14.8 \%$ and $8.3 \%$ reductions in the peak demand during Critical period in the unresponsive air conditioning and responsive appliances, and responsive air conditioning and unresponsive appliances cases, respectively, in comparison to the base case. This is because in all the cases, excepting the base case, some population of the GE appliances responds to the Critical pricing and/ or the air conditioning units lower their setpoint temperatures from the normal setpoints. The DR operation of the responsive appliances and air conditioning can create a rebound after the end of the Critical pricing signal. The rebound may create a new peak load that is much higher than the original load, which lasts for a few minutes. However, this depends on the level of participation of the individual GE appliances and air conditioning units. The peak demand of the system, soon after the signal drops from the Critical pricing, in the responsive air conditioning only case is $173 \%(2,155 \mathrm{~kW})$ of the unresponsive base case. This is because all of the air conditioning units that are running at higher temperature setpoints than normal, during the Critical pricing, return to their normal temperature setpoints soon after the Normal signal returns after the Critical pricing. The peak demand of the system, soon after the signal drops from Critical pricing, with both appliances and the air conditioning responding is $175 \%(2,189 \mathrm{~kW})$ of the unresponsive base case. Notice that this is roughly the same as the case with only the air conditioning, indicating that the appliances did not significantly contribute to the peak rebound immediately following the change of the signal. This is because all of the GE appliances that are delayed during the Critical signal start with a small random delay when the Normal signal arrives after the end of the Critical period. 
In this scenario, daily losses with both appliances and air conditioning responding are $0.55 \%$ $(4 \mathrm{kWh})$, less than that with unresponsive appliances and air conditioning responding. Losses during the Critical pricing period with both responsive appliances and air conditioning are $0.46 \%$ $(0.69 \mathrm{kWh})$ lower than that of unresponsive appliances and responsive air conditioning. The changes in system losses are fairly minimal compared to changes in energy consumption. Comparisons of losses for the DR cases on a summer weekday are listed in Table 3-33.

Table 3-33: Loss comparison on a summer weekday for a four hour critical pricing.

\begin{tabular}{|c|c|c|c|c|c|c|c|c|}
\hline \multirow{2}{*}{ Case name } & \multicolumn{3}{|c|}{ Unresponsive air conditioning } & \multicolumn{3}{c|}{ Responsive air conditioning } \\
\cline { 2 - 10 } & \multicolumn{2}{|c|}{ Normal (Base) } & \multicolumn{2}{|c|}{$100 \%$ GE } & \multicolumn{2}{|c|}{ Normal } & \multicolumn{2}{c|}{$100 \%$ GE } \\
\cline { 2 - 10 } & $(\mathrm{kWh})$ & $(\%)$ & $(\mathrm{kWh})$ & $(\%)$ & $(\mathrm{kWh})$ & $(\%)$ & $(\mathrm{kWh})$ & $(\%)$ \\
\hline Daily Losses (kWh) & 737 & 100.0 & 730 & 99.1 & 734 & 99.6 & 730 & 99.1 \\
\hline $\begin{array}{c}\text { Losses during the } \\
\text { High/Critical Period (kWh) }\end{array}$ & 167 & 100.0 & 148 & 88.6 & 149 & 89.0 & 148 & 88.6 \\
\hline $\begin{array}{c}\text { Losses after High/Critical } \\
\text { period till end of day (kWh) }\end{array}$ & 340 & 100.0 & 353 & 103.8 & 356 & 104.7 & 353 & 103.8 \\
\hline
\end{tabular}

\subsubsection{Three rate pricing signal}

Similar to the previous section, four cases were simulated; however, a different price signal was applied to the loads. The simulations were conducted in GridLAB-D with a three rate pricing signal analogous to a TOU rate overlaid with a CPP signal. Table 3-34 describes the three rate pricing signal used in this scenario. 
Table 3-34: Three rate pricing signal.

\begin{tabular}{|c|c|c|c|}
\hline & Normal & High & Critical \\
\hline $\begin{array}{c}\text { Summer- } \\
\text { Weekday }\end{array}$ & $\begin{array}{c}00: 00-9: 00 \\
15: 00-23.59\end{array}$ & $\begin{array}{c}9: 00-9: 30 \\
13: 00-15: 00\end{array}$ & $9: 30-13: 00$ \\
\hline Summer- & $00: 00-10: 00$ & $10: 00-11: 00$ & $11: 00-15: 00$ \\
Weekend & $16: 00-23.59$ & $15: 00-16: 00$ & \\
\hline Winter- & $00: 00-16: 00$ & $16: 00-17: 30$ & $17: 30-20: 00$ \\
Weekday & $22: 00-23.59$ & $20: 00-22: 00$ & \\
\hline Winter- & $00: 00-16: 00$ & $16: 00-17: 30$ & $17: 30-20: 00$ \\
Weekend & $22: 00-23.59$ & $20: 00-22: 00$ & \\
\hline
\end{tabular}

From the simulation results shown in Figure 3-15, it is observed that the daily energy consumption of the responsive air conditioning and unresponsive appliance case is 1.3\% (246 $\mathrm{kWh}$ ) less than that of the unresponsive base case. This reduction is because the temperature setpoints of the air conditioners are increased from their normal operating setpoints during the Critical signal, temporarily decreasing air conditioning load. Adding 100\% responsive GE appliances to the same case further reduces daily energy consumption an additional $386 \mathrm{kWh}$ to a total reduction of $3.3 \%$. This is due to the fact that some of the GE appliances accept delay and some of them run in ES-mode, decreasing overall energy consumption. 


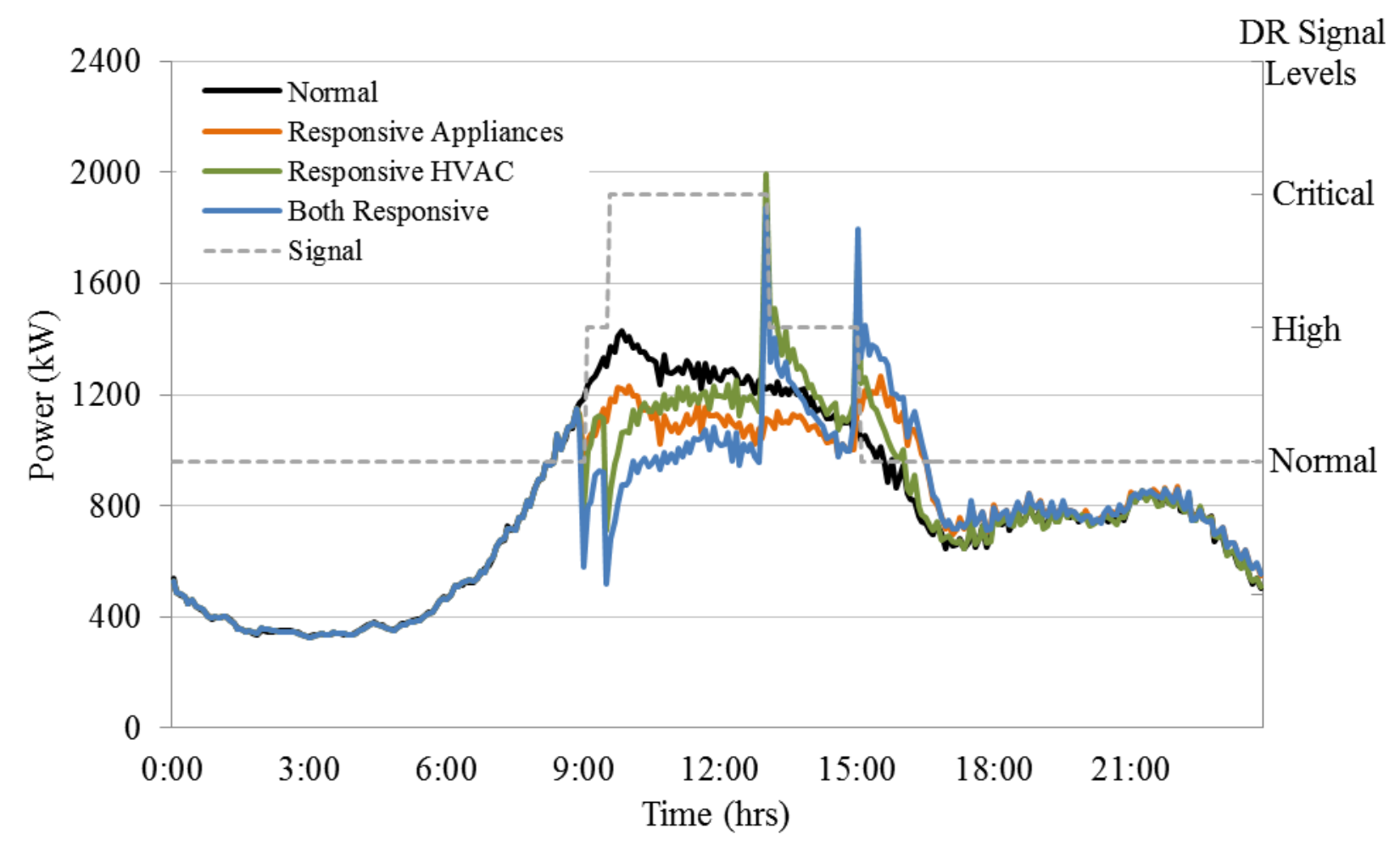

Figure 3-12: Time series comparison of total on a summer weekday for a three rate pricing signal.

A comparison of the energy consumptions during different periods of the day for the four cases is shown in Table 3-35. The total energy consumption during the High and Critical pricing periods with appliances and air conditioning responding is $18.6 \%(1,403 \mathrm{kWh})$ less than that of the no response case, while the appliance response is $12.4 \%$ (936 kWh) less and the air conditioning response is $6.1 \%(458 \mathrm{kWh})$ less than the no response case. This indicates that the appliances provide a greater energy reduction during the signal period than the air conditioning. For the energy consumption after the DR signal is released, during the rebound period, the increase is $11.3 \%, 8.3 \%$, and $3.1 \%$ for the responsive appliance and air conditioning, responsive appliance, and responsive air conditioning cases, respectively. Note that the required recovery energy for the appliances is greater than the energy needed for recovery in the air conditioners. This is because the air conditioners controls actually have two recovery periods, one during the transition from Critical to High, and another from High to Normal. The controls for the GE appliances, however, are such that when moving from a Critical to High signal, the appliances still operate in an energy saver mode, decreasing the likelihood of creating a coincidental peak rebound while still in the High price period. 
Table 3-35: Comparison of energy consumption on a summer weekday for a three rate pricing signal.

\begin{tabular}{|c|c|c|c|c|c|c|c|c|}
\hline \multirow{2}{*}{ Case name } & \multicolumn{3}{|c|}{ Unresponsive air conditioning } & \multicolumn{3}{c|}{ Responsive air conditioning } \\
\cline { 2 - 10 } & \multicolumn{2}{|c|}{ Normal (Base) } & \multicolumn{2}{|c|}{$100 \%$ GE } & \multicolumn{2}{|c|}{ Normal } & \multicolumn{2}{c|}{$100 \%$ GE } \\
\cline { 2 - 10 } & $(\mathrm{kWh})$ & $(\%)$ & $(\mathrm{kWh})$ & $(\%)$ & $(\mathrm{kWh})$ & $(\%)$ & $(\mathrm{kWh})$ & $(\%)$ \\
\hline $\begin{array}{c}\text { Daily Energy Consumption } \\
(\mathrm{kWh})\end{array}$ & 18,937 & 100.0 & 18,567 & 98.0 & 18,691 & 98.7 & 18,305 & 96.7 \\
\hline $\begin{array}{c}\text { Energy Consumption } \\
\text { during the High/Critical } \\
\text { Period (kWh) }\end{array}$ & 7,525 & 100.0 & 6,589 & 87.6 & 7,067 & 93.9 & 6,122 & 81.4 \\
\hline $\begin{array}{c}\text { Energy consumption after } \\
\text { High/Critical period till } \\
\text { end of day (kWh) }\end{array}$ & 6,873 & 100.0 & 7,440 & 108.3 & 7,087 & 103.1 & 7,646 & 111.3 \\
\hline
\end{tabular}

A comparison of the peak demands of the four cases on a summer weekday for three rate pricing signal is shown in Table 3-36. Due to the DR of the air conditioners and GE appliances, the peak demand during critical period is reduced from $1,428 \mathrm{~kW}$, in the unresponsive base case, to $1,136 \mathrm{~kW}$ in case where both air conditioners and appliances response, which is a reduction of approximately $20.5 \%$. There is a $13.9 \%$ and $8.0 \%$ reduction in the peak demand during the Critical period in the responsive appliances only and responsive air conditioning only cases, respectively. Again, notice that the appliances actually provide a greater overall reduction than the air conditioners $(13.9 \%$ versus $8.0 \%$ ) due to the ability of appliances to maintain a fairly consistent reduction throughout the Critical period.

The rebound seen after the Normal signal returns, or the Critical signal returns to High, creates a new peak load that is much higher than the original load, lasting for a few minutes. However, the magnitude of this rebound depends on the level of participation of the individual GE appliances and air conditioning units. The peak power consumption of the total load, soon after the signal drops from Critical to High pricing in the responsive air conditioning only case is $160.2 \%$ of the unresponsive base case, while the responsive air condition and appliance case is $150.4 \%$. This indicates that the energy reduction strategy of the GE appliances during the return to the High signal actually helps buffer against the air conditioning rebound, and reduces the observed rebound peak. The peak power consumption of the total load, soon after the signal drops from High to Normal pricing in the responsive air conditioning only case is $155.5 \%$ of the unresponsive base case, while the responsive air conditioning and appliance case is $165.5 \%$. While the appliances do not help buffer the rebound in this case, they do contribute far less to the rebound than the air conditioners, as the random restart of the appliances tempers the response. 
Table 3-36: Comparison of peak demand on a summer weekday for a three rate pricing signal.

\begin{tabular}{|c|c|c|c|c|c|c|c|c|}
\hline \multirow{2}{*}{ Case name } & \multicolumn{3}{|c|}{ Unresponsive air conditioning } & \multicolumn{3}{c|}{ Responsive air conditioning } \\
\cline { 2 - 10 } & \multicolumn{2}{|c|}{ Normal (Base) } & \multicolumn{2}{|c|}{$100 \%$ GE } & \multicolumn{2}{|c|}{ Normal } & \multicolumn{2}{c|}{$100 \%$ GE } \\
\cline { 2 - 10 } & $(\mathrm{kW})$ & $(\%)$ & $(\mathrm{kW})$ & $(\%)$ & $(\mathrm{kW})$ & $(\%)$ & $(\mathrm{kW})$ & $(\%)$ \\
\hline $\begin{array}{c}\text { Daily Instantaneous Peak } \\
(\mathrm{kW})\end{array}$ & 1,428 & 100.0 & 1,269 & 88.9 & 1,994 & 139.6 & 1,872 & 131.0 \\
\hline $\begin{array}{c}\text { Peak demand during } \\
\text { Critical period (kW) }\end{array}$ & 1,428 & 100.0 & 1,229 & 86.0 & 1,314 & 92.0 & 1,136 & 79.6 \\
\hline $\begin{array}{c}\text { Peak demand after } \\
\text { Critical period (before the } \\
\text { end of High period) (kW) }\end{array}$ & 1,245 & 100.0 & 1,141 & 91.6 & 1,994 & 160.2 & 1,872 & 150.4 \\
\hline $\begin{array}{c}\text { Peak demand after High } \\
\text { period (kW) }\end{array}$ & 1,086 & 100.0 & 1,269 & 116.9 & 1,689 & 155.5 & 1,797 & 165.5 \\
\hline
\end{tabular}

Comparisons of losses for the four cases on a summer weekday for the three rate pricing signal are listed in Table 3-37. Again, note that while loss reduction is significant in all DR cases during the Critical and High signals (as much as 9.7\%), the overall daily losses are only reduced by $1.8 \%$, or $13 \mathrm{kWh}$, on a day where $18,000 \mathrm{kWh}$ are consumed and total losses are approximately $737 \mathrm{kWh}$.

Table 3-37: Comparison of on a summer weekday for a three rate pricing signal.

\begin{tabular}{|c|c|c|c|c|c|c|c|c|}
\hline \multirow{2}{*}{ Case name } & \multicolumn{3}{|c|}{ Unresponsive air conditioning } & \multicolumn{3}{c|}{ Responsive air conditioning } \\
\cline { 2 - 10 } & \multicolumn{2}{|c|}{ Normal (Base) } & \multicolumn{2}{|c|}{$100 \%$ GE } & \multicolumn{2}{|c|}{ Normal } & \multicolumn{2}{c|}{$100 \%$ GE } \\
\cline { 2 - 10 } & $(\mathrm{kWh})$ & $(\%)$ & $(\mathrm{kWh})$ & $(\%)$ & $(\mathrm{kWh})$ & $(\%)$ & $(\mathrm{kWh})$ & $(\%)$ \\
\hline Daily Losses (kWh) & 737 & 100.0 & 724 & 98.2 & 731 & 99.2 & 724 & 98.2 \\
\hline $\begin{array}{c}\text { Losses during the } \\
\text { High/Critical Period (kWh) }\end{array}$ & 240 & 100.0 & 219 & 91.3 & 228 & 95.0 & 219 & 91.3 \\
\hline $\begin{array}{c}\text { Losses after High/Critical } \\
\text { period till end of day (kWh) }\end{array}$ & 301 & 100.0 & 310 & 103.0 & 307 & 102.0 & 310 & 103.0 \\
\hline
\end{tabular}




\subsubsection{Summary}

A total of four different cases (combinations of responsive and unresponsive GE appliances and air conditioning) were simulated using a four hour critical signal and a three rate pricing signal. The goal was to compare the performance of the DR enabled appliances to a DR enable air conditioning system. The air conditioning system provides an overall greater resource due to the overall demand being greater than the appliances, but because of GE's DR algorithms specifically designed to work with TOU and TOU/CPP signals, the appliances can provide greater demand reduction than the air conditioners alone. Specifically, due the exhaustion of the air conditioning resource and the appliance load reduction being more evenly spread across the time interval, demand reduction within the Critical signal is significantly increased with the addition of DR enabled appliances. Additionally, energy saver controls in the GE appliances during High signal periods help alleviate some of the peak rebound seen during the transition from a Critical signal to a High signal. Overall, the DR enabled appliances significantly contribute to the peak demand reduction within a critical period, while mitigating a number of the side effects during the recovery periods.

\subsection{With higher penetration of responsive electric air conditioning}

This scenario will look at similar situations to scenarios in Section 3.6, except that the weather will be hotter and more humid with a higher penetration of electric air conditioning systems (Houston, TX). The motivation for considering this scenario is to observe the influence of higher penetration of air conditioners on feeder load during peak periods along with GE appliances. The simulations were conducted in GridLAB-D with two kinds of DR signals. The first DR signal simulated was a four hour critical pricing period, and the simulation results with this pricing signal are discussed in Section 0. The second DR signal simulated was a three rate pricing signal and is discussed in Section 3.7.2.

In this scenario, $95 \%$ of residences contain an electric air conditioning system. It is assumed that during the DR cases, all of these residences use a DR enabled thermostat control, responding at the rate described in Section 2.2. Appliance penetration in the residences is again described by Table 3-2. This leads to three cases: a base case with no response, a case where only the air conditioning units respond, and a case where both the air conditioner and the appliances respond. Detailed time series simulations were conducted in GridLAB-D with a four hour critical pricing period during summer weekdays. In order to investigate the effect of DR response of air conditioners and GE appliances on distribution feeder during Critical period, time series simulations were conducted in GridLAB-D for winter and summer. 


\subsubsection{Four hour critical pricing signal}

Table 3-30 in Section 3.6.1 describes the four hour Critical pricing signal used in this scenario. Figure 3-13 compares time series demand of the three cases on a summer weekday. A comparison of the energy consumption of the three cases on a summer weekday is shown in Table 3-38. Table 3-39 compares the peak demand of the three cases.

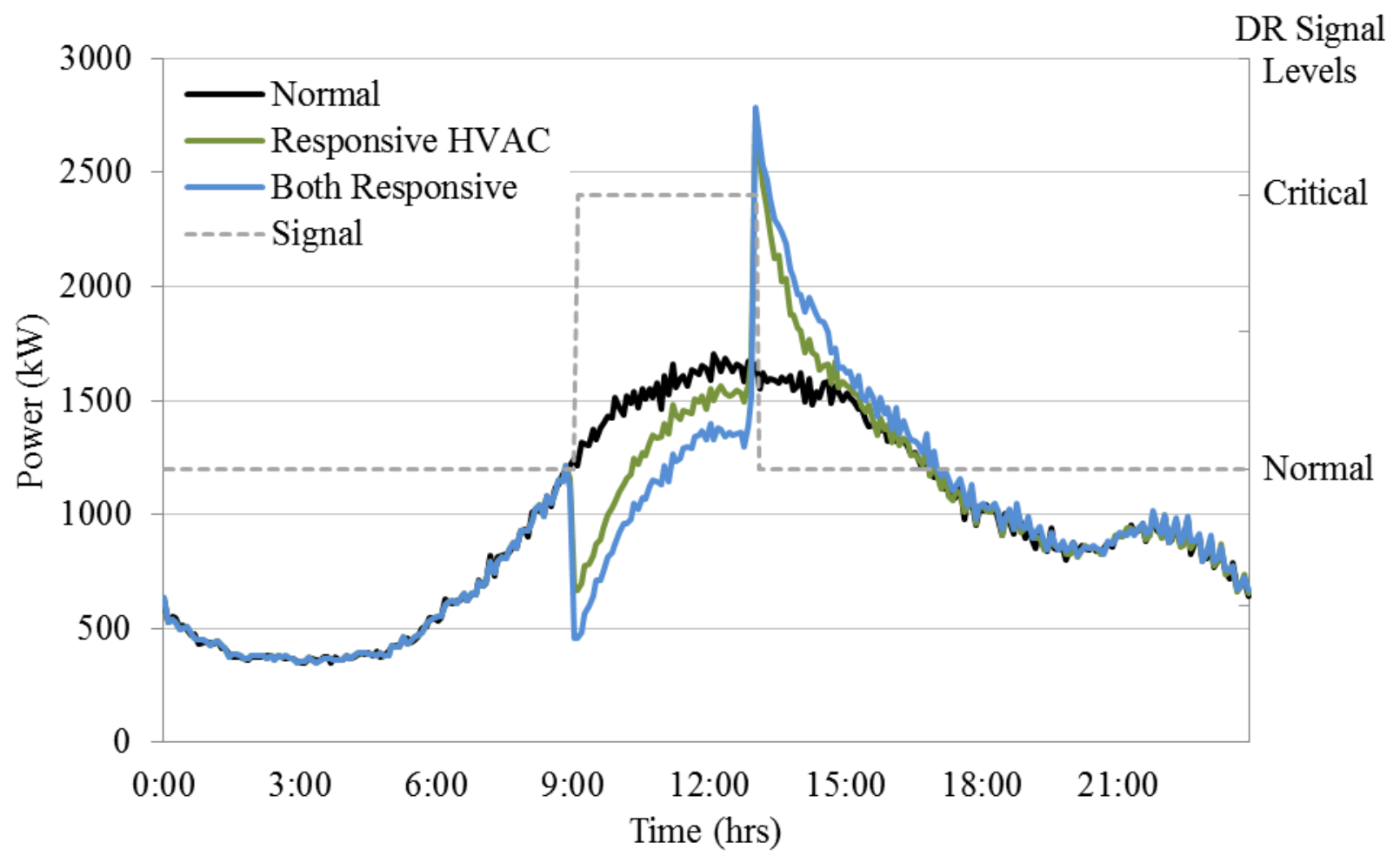

Figure 3-13: Time series comparison of total on a summer weekday for a four hour critical pricing.

Results are relatively similar to those seen in Section 3.6.1 in terms of energy consumption, peak reduction, and rebound, so a detailed discussion of the individual results will not be presented here. However, a few points of interest can be discussed in relation to the previous 75\% HVAC penetration case. Of course, daily energy consumption and peak demand are increased in the base case, from $18,937 \mathrm{kWh}$ to $23,296 \mathrm{kWh}$ and $1,428 \mathrm{~kW}$ and $1,706 \mathrm{~kW}$, respectively. This is due the increased penetration of the air conditioners and the increased duty cycle due to the increased air temperature and more humid air. This means that the air conditioner is a larger percentage of the DR resource in the $95 \%$ air conditioner penetration case versus the $75 \%$ case, making the appliance resource relatively smaller. Because of this, peak demand during the critical period is not reduced as much relative to the $75 \%$ case $(18.0 \%$ reduction in the $95 \%$ penetration case versus $19.3 \%$ in the $75 \%$ case) and the reduction in the overall energy consumption is lower (2.0\% versus $2.3 \%)$. However, it also leads to a greater 
increase the peak rebound. In the 95\% penetration case, the peak after the critical signal increases from $1,661 \mathrm{~kW}$ to $2,785 \mathrm{~kW}$, while in the $75 \%$ penetration case, it increases from 1,245 $\mathrm{kW}$ to $2,189 \mathrm{~kW}$. Because of the higher penetration of air conditioners, the rebound is greater and the appliance rebound is further dwarfed by the air conditioner rebound. Overall, in the higher air condition penetration case, the appliances are not able to provide as much of a leveling ability during the critical period and have a lesser effect on the rebound peak as opposed to the lower air conditioner penetration case.

Table 3-38: Comparison of energy consumption on a summer weekday for a four hour critical pricing.

\begin{tabular}{|c|c|c|c|c|c|c|}
\hline \multirow{2}{*}{ Case name } & \multicolumn{2}{|c|}{$\begin{array}{c}\text { Unresponsive air } \\
\text { conditioning }\end{array}$} & \multicolumn{3}{|c|}{ Responsive air conditioning } \\
\cline { 2 - 6 } & \multicolumn{2}{|c|}{\begin{tabular}{c} 
Normal (Base) \\
\cline { 2 - 6 }
\end{tabular}} & \multicolumn{2}{|c|}{ Normal } & \multicolumn{2}{c|}{$100 \%$ GE } \\
\cline { 2 - 7 } $\begin{array}{c}\text { Daily Energy } \\
\text { Consumption (kWh) }\end{array}$ & 23,296 & 100.0 & 23,044 & 98.9 & 22,822 & 98.0 \\
\hline $\begin{array}{c}\text { Energy Consumption } \\
\text { during the High/Critical } \\
\text { Period (kWh) }\end{array}$ & 6,105 & 100.0 & 5,065 & 83.0 & 4,331 & 70.9 \\
\hline $\begin{array}{c}\text { Energy consumption after } \\
\text { High/Critical period till } \\
\text { end of day (kWh) }\end{array}$ & 5,836 & 100.0 & 12,981 & 222.4 & 13,493 & 231.2 \\
\hline
\end{tabular}

Table 3-39: Comparison of peak on a summer weekday for a four hour critical pricing.

\begin{tabular}{|c|c|c|c|c|c|c|}
\hline \multirow{2}{*}{ Case name } & \multicolumn{2}{|c|}{$\begin{array}{c}\text { Unresponsive air } \\
\text { conditioning }\end{array}$} & \multicolumn{4}{|c|}{ Responsive air conditioning } \\
\cline { 2 - 7 } & \multicolumn{2}{|c|}{ Normal (Base) } & \multicolumn{2}{|c|}{ Normal } & \multicolumn{2}{|c|}{$100 \%$ GE } \\
\cline { 2 - 7 } & $(\mathrm{kW})$ & $(\%)$ & $(\mathrm{kW})$ & $(\%)$ & $(\mathrm{kW})$ & $(\%)$ \\
\hline $\begin{array}{c}\text { Daily Instantaneous } \\
\text { Peak (kW) }\end{array}$ & 1,706 & 100.0 & 2,763 & 162.0 & 2,785 & 163.2 \\
\hline $\begin{array}{c}\text { Peak demand during } \\
\text { Critical period (kW) }\end{array}$ & 1,706 & 100.0 & 1,568 & 91.9 & 1,399 & 82.0 \\
\hline $\begin{array}{c}\text { Peak demand after } \\
\text { Critical period (kW) }\end{array}$ & 1,661 & 100.0 & 2,763 & 166.4 & 2,785 & 167.7 \\
\hline
\end{tabular}




\subsubsection{Three rate pricing signal}

Table 3-34 describes the three rate pricing signal used in this scenario, analogous to a TOU pricing program with CPP overlay. A time series of the demand of the three cases are shown in Figure 3-14. A comparison of the energy consumption for each of the cases on a summer weekday is shown in Table 3-40. Table 3-41 compares the peak demand on a summer weekday for the three rate pricing signal.

Results are relatively similar to those seen in Section 3.6.2 in terms of energy consumption, peak reduction, and rebound, so a detailed discussion of the individual results will not be presented here. However, a few points of interest can be discussed in relation to the previous 75\% HVAC penetration case. Again, daily energy consumption and peak demand are increased in the base case, from $18,937 \mathrm{kWh}$ to $23,296 \mathrm{kWh}$ and $1,428 \mathrm{~kW}$ and $1,706 \mathrm{~kW}$, respectively. This is due the increased penetration of the air conditioners and the increased duty cycle due to the increased air temperature and more humid air. Because of this, the peak demand during the critical period is not reduced as much relative to the $75 \%$ case $(9.1 \%$ reduction in the $95 \%$ penetration case versus $20.4 \%$ in the $75 \%$ case) and the reduction in the overall energy consumption is lower (3.0\% versus 3.3\%). However, it also leads to a greater increase the peak rebound in both the period following a transition from a Critical signal to a High signal and a High signal back to Normal. In the 95\% penetration case, the peak after the Critical signal increases from $1,661 \mathrm{~kW}$ to $2,526 \mathrm{~kW}$, while in the $75 \%$ penetration case, it increases from 1,245 $\mathrm{kW}$ to $1,994 \mathrm{~kW}$. The peak after the High signal increases from $1,530 \mathrm{~kW}$ to $2,506 \mathrm{~kW}$ in the $95 \%$ case, while it only increases from $1,086 \mathrm{~kW}$ to $1,797 \mathrm{~kW}$ in the $75 \%$ case. Because of the higher penetration of air conditioners, the rebound is greater and the appliance rebound is further dwarfed by the air conditioner rebound. Overall, in the higher air condition penetration case, the appliances are not able to provide as much of a leveling ability during the critical period and have a lesser effect on the rebound peak as opposed to the lower air conditioner penetration case. 


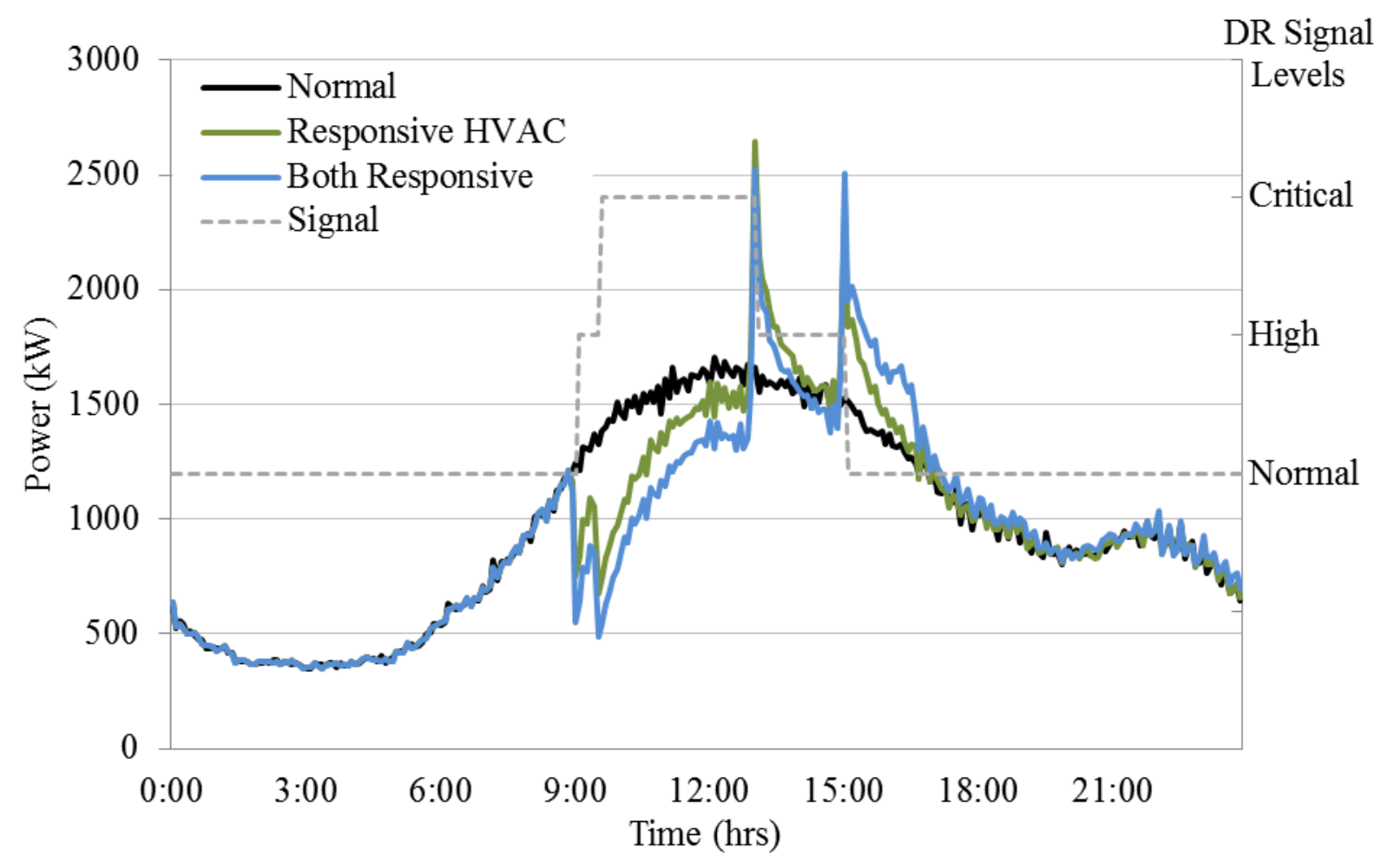

Figure 3-14: Time series comparison of total on a summer weekday for a three rate pricing signal.

Table 3-40: Comparison of energy consumption on a summer weekday for three rate pricing signal.

\begin{tabular}{|c|c|c|c|c|c|c|}
\hline \multirow{2}{*}{ Case name } & \multicolumn{2}{|c|}{$\begin{array}{c}\text { Unresponsive air } \\
\text { conditioning }\end{array}$} & \multicolumn{4}{|c|}{ Responsive air conditioning } \\
\cline { 2 - 7 } & \multicolumn{2}{|c|}{ Normal (Base) } & \multicolumn{2}{|c|}{ Normal } & \multicolumn{2}{|c|}{$100 \%$ GE } \\
\cline { 2 - 7 } & $(\mathrm{kWh})$ & $(\%)$ & $(\mathrm{kWh})$ & $(\%)$ & $(\mathrm{kWh})$ & $(\%)$ \\
\hline $\begin{array}{c}\text { Daily Energy } \\
\text { Consumption (kWh) }\end{array}$ & 23,296 & 100.0 & 22,990 & 98.7 & 22,592 & 97.0 \\
\hline $\begin{array}{c}\text { Energy Consumption } \\
\text { during the High/Critical } \\
\text { Period (kWh) }\end{array}$ & 9,240 & 100.0 & 8,573 & 92.8 & 7,654 & 82.8 \\
\hline $\begin{array}{c}\text { Energy consumption after } \\
\text { High/Critical period till } \\
\text { end of day (kWh) }\end{array}$ & 9,059 & 100.0 & 9,418 & 104.0 & 9,940 & 109.7 \\
\hline
\end{tabular}


Table 3-41: Comparison peak demand on a summer weekday for three tier pricing signal.

\begin{tabular}{|c|c|c|c|c|c|c|}
\hline \multirow{2}{*}{ Case name } & \multicolumn{2}{|c|}{$\begin{array}{c}\text { Unresponsive air } \\
\text { conditioning }\end{array}$} & \multicolumn{3}{|c|}{ Responsive air conditioning } \\
\cline { 2 - 7 } & \multicolumn{2}{|c|}{ Normal (Base) } & \multicolumn{2}{|c|}{ Normal } & \multicolumn{2}{|c|}{$100 \%$ GE } \\
\cline { 2 - 7 } & $(\mathrm{kW})$ & $(\%)$ & $(\mathrm{kW})$ & $(\%)$ & $(\mathrm{kW})$ & $(\%)$ \\
\hline $\begin{array}{c}\text { Daily Instantaneous Peak } \\
(\mathrm{kW})\end{array}$ & 1,706 & 100.0 & 2,644 & 155.0 & 2,526 & 148.0 \\
\hline $\begin{array}{c}\text { Peak demand during Critical } \\
\text { period (kW) }\end{array}$ & 1,706 & 100.0 & 1,711 & 100.3 & 1,550 & 90.9 \\
\hline $\begin{array}{c}\text { Peak demand after Critical } \\
\text { period (before the end of } \\
\text { High period) }(\mathrm{kW})\end{array}$ & 1,661 & 100.0 & 2,644 & 159.0 & 2,526 & 152.0 \\
\hline $\begin{array}{c}\text { Peak demand after } \\
\text { High period (kW) }\end{array}$ & 1,530 & 100.0 & 2,390 & 156.0 & 2,506 & 163.8 \\
\hline
\end{tabular}

\section{8 "Worst" case rebound scenario}

This scenario uses similar penetration of air conditioners and appliances as discussed in Section 3.7, with a $95 \%$ penetration of air conditioning and $100 \%$ penetration of GE DR enabled appliances. However, to simulate the "worst" case during the rebound period, it is assumed that the GE appliances that accepted delay during the critical signal will start immediately after the normal signal arrives without randomizing the start times as was done in the previous sections. This leads to considerable synchronization of the appliance loads, and should represent the largest rebound that could be seen on this feeder due to both the appliances and the air conditioning units. Both a six hour and two hour critical price signal are simulated. The simulation results using the six hour critical price signal are discussed in Section 3.8.1 and the simulation results for the two hour critical price signal are discussed in Section 3.8.2.

\subsubsection{Six hour critical pricing signal}

Table 3-42 shows the six hour critical pricing signals' start and end times during weekdays and weekends for a summer simulation.

Table 3-42: Six hour critical pricing signal.

\begin{tabular}{|c|c|c|}
\hline & Weekday & Weekend \\
\hline Critical Period & $9: 00-15: 00$ & $10: 00-16: 00$ \\
\hline
\end{tabular}


Figure 3-15 compares the time series demand of the two cases for a six hour Critical price period on a summer weekday. A comparison of the energy consumption of the three cases is shown in Table 3-43. Table 3-44 compares the peak demand of the three cases across three time intervals: daily, during the DR signal, and immediately following the DR signal. Detailed results for each of the metrics will not be discussed in this section. However, there are a couple of points of considerable note that can be discussed. Of obvious note is the magnitude of the peak during the rebound period, as all of the appliance and air conditioning loads synchronize. This produces a peak which is nearly two times greater than the original peak on the feeder, and is roughly 600 $\mathrm{kW}$ greater than any case looked at previously. This is caused by two major factors. First, the critical period has been extended to six hours causing a greater number of appliances to delay their start times as more and more consumers use the delay option. Second, no mitigating controls were used to help ease the transition into the rebound period; every load which delayed action, immediately tried to recover as soon as the critical period ended. While it is understood that most utilities use reasonable actions to mitigate rebounds (such as dividing customers into different signal groups), this example is used to highlight the possible negative effects were this control strategy to be implemented without thought of the consequences.

Of final note is the behavior of the load during the critical price period. Notice that there is a significant reduction of demand during the first hour or two, but by hour three, the reduction has decreased to relatively steady value of about half of what was seen at the beginning of the period. Again, this is due to the exhaustion of the air conditioning resources as customers' internal air temperatures reach equilibrium around their new, higher setpoint. After about hour three, most of the reduction is coming from the appliance load. Again, this is indicative of the fact that while air conditioning units are not able to provide prolonged reduction without considerable customer dissatisfaction (high internal air temperatures), the appliance loads are far more capable of providing extended, consistent reduction in demand. 


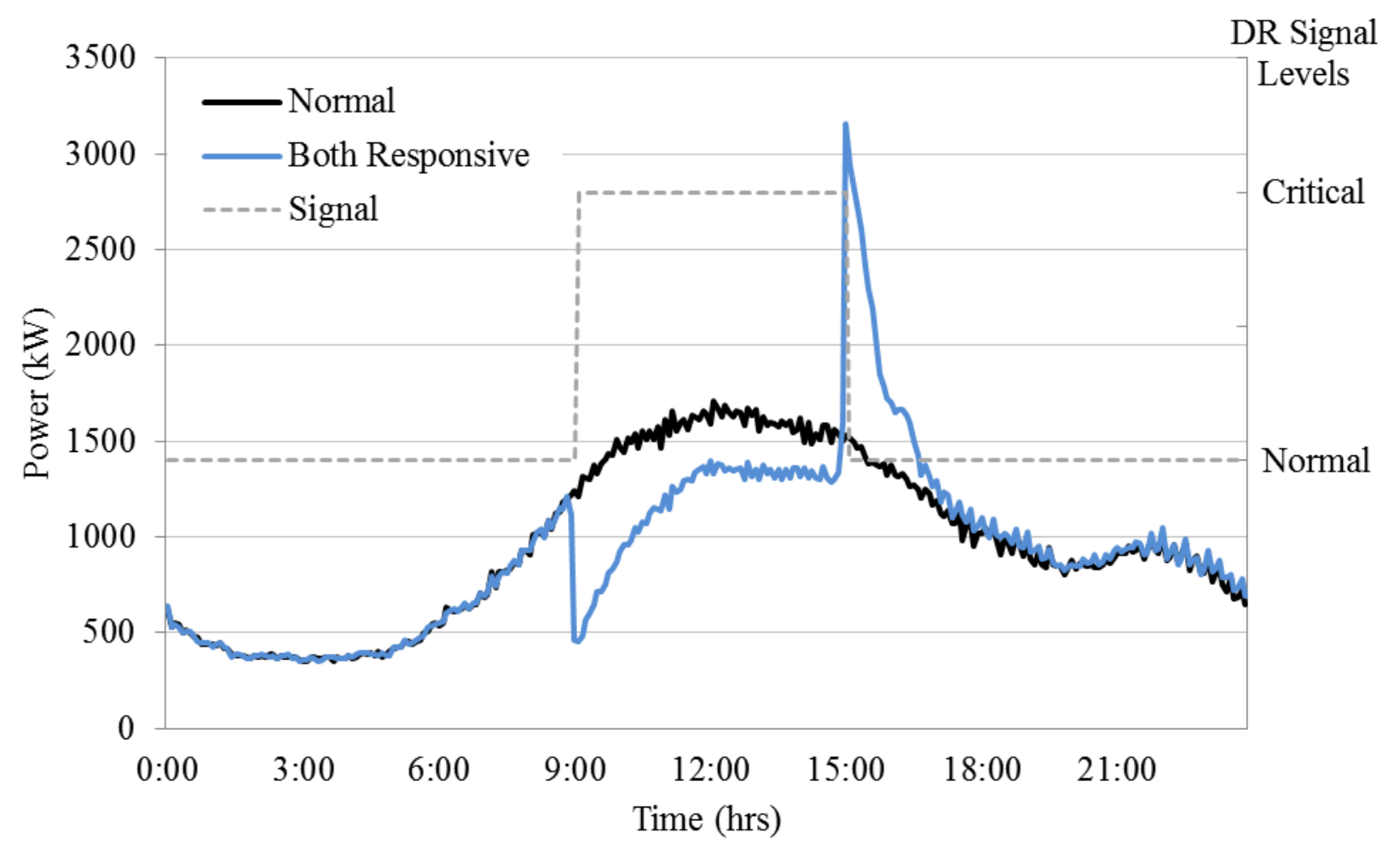

Figure 3-15: Time series demand on a summer weekday for a six hour critical period.

Table 3-43: Comparison of energy consumption on a summer weekday for a six hour critical period.

\begin{tabular}{|c|c|c|c|c|}
\hline \multirow{2}{*}{} & \multicolumn{2}{|c|}{ Normal (Base) } & \multicolumn{2}{c|}{ Responsive } \\
\cline { 2 - 5 } & $(\mathrm{kWh})$ & $(\%)$ & $(\mathrm{kWh})$ & $(\%)$ \\
\hline $\begin{array}{c}\text { Daily Energy Consumption } \\
(\mathrm{kWh})\end{array}$ & 23,296 & 100.0 & 22,468 & 96.4 \\
\hline $\begin{array}{c}\text { Energy Consumption during } \\
\text { the High/Critical Period } \\
(\mathrm{kWh})\end{array}$ & 9,240 & 100.0 & 6,986 & 75.6 \\
\hline $\begin{array}{c}\text { Energy consumption after } \\
\text { High/Critical period till end } \\
\text { of day (kWh) }\end{array}$ & 9,059 & 100.0 & 10,484 & 115.7 \\
\hline
\end{tabular}


Table 3-44: Comparison of peak demand on a summer weekday for a six hour critical period.

\begin{tabular}{|c|c|c|c|c|}
\hline \multirow{2}{*}{} & \multicolumn{2}{|c|}{ Normal (Base) } & \multicolumn{2}{c|}{ Responsive } \\
\cline { 2 - 5 } & $(\mathrm{kW})$ & $(\%)$ & $(\mathrm{kW})$ & $(\%)$ \\
\hline $\begin{array}{c}\text { Daily Instantaneous } \\
\text { Peak (kW) }\end{array}$ & 1,706 & 100.0 & 3,160 & 185.2 \\
\hline $\begin{array}{c}\text { Peak demand during } \\
\text { Critical period (kW) }\end{array}$ & 1,706 & 100.0 & 1,598 & 93.7 \\
\hline $\begin{array}{c}\text { Peak demand after } \\
\text { Critical period (kW) }\end{array}$ & 1,530 & 100.0 & 3,160 & 206.5 \\
\hline
\end{tabular}

\subsubsection{Two hour pricing signal}

Table 3-45 lists the two hour critical pricing signals' start and end times during weekdays and weekends for a summer simulation.

Table 3-45: Two hour critical pricing signal.

\begin{tabular}{|c|c|c|}
\hline & Weekday & Weekend \\
\hline Critical Period & $12: 00-14: 00$ & $12: 00-14: 00$ \\
\hline
\end{tabular}

Figure 3-16 compares the time series demand of the two cases for a two hour critical pricing on a summer weekday. A comparison of the energy consumption of the three cases is shown in Table 3-46. Table 3-47 compares the peak demand of the two cases across three time intervals: daily, during the DR signal, and immediately following the DR signal. Detailed results for each of the metrics will not be discussed in this section. However, there are a couple of points of considerable note that can be discussed. Of obvious note is the magnitude of the peak during the rebound period, as all of the appliance and air conditioning loads synchronize. This produces a peak which is nearly $70 \%$ greater than the base case, but far less than in the six hour critical period case. Since the critical period has been shortened to two hours, fewer appliances have had to delay their start times and fewer air conditioners have been exhausted. No mitigating controls were used to help ease the transition into the rebound period and every load which delayed action immediately tried to recover as soon as the critical period ended, and since fewer resources had been exhausted or delayed within the shorter critical period, the rebound is significantly less than in the six hour case.

Again, of note is the behavior of the load during the critical price period. Notice that there is a significant reduction of demand during the first hour which steadily reduces, but does not reach 
a consistent reduction by the end of the second hour. The reduction indicates exhaustion some of the air conditioning resources as customers' internal air temperatures reach equilibrium around their new, higher setpoint. However, since a consistent reduction is not reached, it indicates that some air conditioning resource is still available. During the shorter critical signal period, the air conditioning systems are able to provide a fairly substantial reduction as compared to the appliance load.

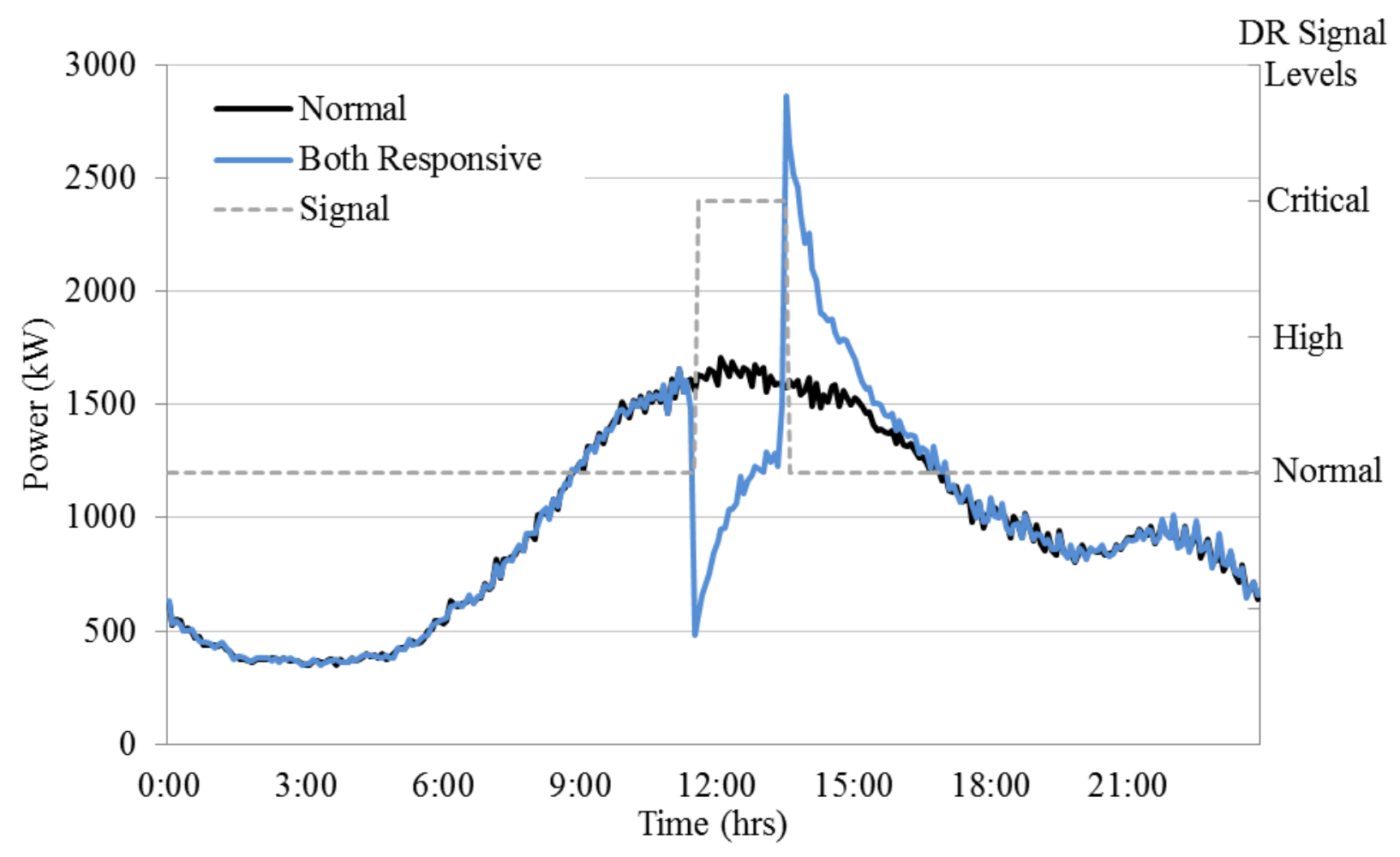

Figure 3-16: Time series of demand for a two hour critical period. 
Table 3-46: Comparison of energy consumption on a summer weekday for a two hour critical period.

\begin{tabular}{|c|c|c|c|c|}
\hline & \multicolumn{2}{|c|}{ Normal (Base) } & \multicolumn{2}{c|}{ Responsive } \\
\cline { 2 - 5 } & $(\mathrm{kWh})$ & $(\%)$ & $(\mathrm{kWh})$ & $(\%)$ \\
\hline $\begin{array}{c}\text { Daily Energy Consumption } \\
(\mathrm{kWh})\end{array}$ & 23,296 & 100.0 & 23,081 & 99.0 \\
\hline $\begin{array}{c}\text { Energy Consumption } \\
\text { during the High/Critical } \\
\text { Period (kWh) }\end{array}$ & 3,258 & 100.0 & 1,831 & 56.2 \\
\hline $\begin{array}{c}\text { Energy consumption after } \\
\text { High/Critical period till } \\
\text { end of day (kWh) }\end{array}$ & 11,393 & 100.0 & 12,395 & 108.8 \\
\hline
\end{tabular}

Table 3-47: Comparison of peak demand on a summer weekday for a two hour critical period.

\begin{tabular}{|c|c|c|c|c|}
\hline \multirow{2}{*}{} & \multicolumn{2}{|c|}{ Normal (Base) } & \multicolumn{2}{c|}{ Responsive } \\
\cline { 2 - 5 } & $(\mathrm{kW})$ & $(\%)$ & $(\mathrm{kW})$ & $(\%)$ \\
\hline $\begin{array}{c}\text { Daily Instantaneous } \\
\text { Peak (kW) }\end{array}$ & 1,706 & 100.0 & 2,861 & 167.7 \\
\hline $\begin{array}{c}\text { Peak demand during } \\
\text { Critical period (kW) }\end{array}$ & 1,706 & 100.0 & 1,500 & 87.9 \\
\hline $\begin{array}{c}\text { Peak demand after } \\
\text { Critical period (kW) }\end{array}$ & 1,619 & 100.0 & 2,861 & 176.7 \\
\hline
\end{tabular}




\section{Conclusions}

The widespread adoption of demand response enabled appliances and thermostats can result in a significant reduction in the peak electrical demand. GE has developed a line of appliances that will have the capability of offering several levels of demand reduction actions based on information from the utility grid, often in the form of price. The levels of demand reduction are roughly designed to correspond to a TOU plus CPP overlay pricing structure, reducing demand significantly during a critical pricing period, and less so during a high TOU pricing period. Outside of these time periods, the price is considered normal and the operation of the appliance is standard operation. The operation and system effects of these appliances were modeled and simulated in open-source software, GridLAB-D, including evaluation of appliance controls, improvement to current algorithms, and development of aggregate control methodologies.

From the individual appliance simulations presented in Section 2, conclusions about the effectiveness of the DR control strategies can be drawn for each of the appliances.

Electric clothes dryers:

- Can provide significant reduction in demand during both high and critical pricing periods due to the fact that they have a greater instantaneous demand than other appliances (on the order $40-70 \%$ of appliance load, or $10 \mathrm{~s}-100 \mathrm{~s}$ of $\mathrm{kW}$ ).

- Provide very significant short term reductions (on the order of $100 \mathrm{~s}$ of $\mathrm{kW}$ for 15 minutes or less) due to the critical signal operational strategy.

- Because of the ES-mode of operation, energy consumption can be reduced by nearly $10 \%$ during a high or critical period, while extending the amount of time it takes the clothes to dry.

- Are significantly affected by the addition of a randomization function during the rebound period, reducing the peak rebound significantly when applied. Without a control method during the rebound period, load can increase by as much as 8.5 times the original appliance peak demand, while with built-in mitigation methods this can be reduced by a factor of two to three.

- Typically peak in demand during the late morning or early afternoon, which does not coincide with typical CPP and TOU time periods, when system demand is greatest.

Clothes washers:

- Can provide peak reductions during critical pricing periods (on the order of $50 \%$ of the appliance load, or a few $\mathrm{kW}$ ), in addition to the secondary effects of reduced water heater load. Secondary effects of reduced water heater load were not explicitly modeled in this analysis.

- Does not directly reduce daily energy consumption, but an indirect reduction may be seen due to the reduced water heater load.

- Can provide additional benefits by helping to control the rebound in demand seen after returning to normal operation after a critical pricing period. The addition of a built-in 
randomization function helps to diversify the timing of the return after a customer selects the delay option, and reduces the overall rebound from approximately 2.4 times the original peak to 1.1 times the original peak.

- Typically peak in demand is seen during the late morning or early afternoon, and may not coincide with standard CPP and high TOU time periods, when system demand is greatest.

Dishwashers:

- Are effective at reducing demand during both high and critical pricing periods (on the order of $80 \%$ of the appliance load, or 10 s of $\mathrm{kW}$ ). This is mainly due to the appliance's ability to notify the customer of a higher than normal price, and the customer willingness to delay the operation of the appliance until a later, lower price period.

- Can provide additional rebound management services when built-in randomization functions are utilized. Again, due to the willingness of customers to delay normal operations, the randomization period can be extended over a longer period of time than other appliances (over an hour and a half in these simulations) such that the rebound seen is relatively small and shifted much later than other appliances (reduced from 4.7 times to 2.8 times the original peak).

Hybrid water heaters:

- Are extremely effective at reducing demand during both high and critical pricing periods by locking out resistive elements and reducing the thermostat setpoint (on the order of $30-55 \%$ of appliance load, or $100 \mathrm{~s}$ of $\mathrm{kW}$ ). This is in addition to the reduced demand naturally seen by switching from a resistive water heater to a heat pump water heater, which was not explicitly simulated.

- Significantly reduce daily energy consumption (up to 7\%) on days with a high or critical price, in addition to the reduced energy consumption naturally seen when switching from a resistive water heater to a heat pump water heater, due to reduced use of the resistive elements and lowered setpoints.

- Have no built-in rebound management strategy, but without a built-in strategy, they show a rebound in the demand roughly two to three times greater than the original appliance peak. However, due to the heat pump being used, rather than resistive load, the rebound is relatively small.

- Typically peak in demand during mornings and evenings, usually coinciding with system peaks, providing a greater relative resource during those time periods.

Electric ranges:

- Can be divided into two responses, the oven and the cooktop. The dual oven can provide significant peak reductions during high and critical pricing periods. This is mainly due to the appliance's ability to notify the customer of a higher than normal price, and the customer's willingness to use the upper oven rather than the lower oven (on the order of 
$30 \%$ of oven load, or 10s of $\mathrm{kW}$ ). Cooktops did not provide any significant reduction in demand during high or critical time periods (less than $5 \%$ of cooktop load).

- Did not significantly contribute to the peak demand during the rebound period (on the same order as the original peak).

- Typically peaks during the evening, which coincides with standard CPP and high TOU pricing periods, when system demand is typically greatest, providing a greater relative resource.

Refrigerators:

- Provide relatively significant reductions in demand during both high and critical time periods (on the order of $30 \%$ of appliance load, or 10s-100s of $\mathrm{kW}$ ), mainly due to the shifting of the defrost cycle to a normal price period.

- Do not have a rebound mitigation strategy, but their contribution to the rebound is relatively small (roughly two times the original appliance peak) and is temporally shifted from the rest of the appliances due to the pre-chilling requirement at the beginning of the defrost cycle.

- Are relatively unobtrusive to customers in the way that they respond to a high or critical signal, only delaying the defrost cycle and allowing internal cavity air temperatures to drift slightly.

While the response of a single appliance in a home provides relatively small benefits compared to an HVAC system, because of the greater number of appliances in the home, the aggregate behavior of a suite of DR enabled appliances is significant. In Section 3, it was shown that even at low penetration levels (5\% and 25\%) of GE DR enabled appliances, the appliances alone are able to provide peak reduction capabilities (1-2\% and 4-5\%, respectively). For obvious reasons, as penetration levels increased, peak reduction capabilities also increased, to as high as $19 \%$ of the system peak by only utilizing the built-in DR capabilities of the GE appliances.

The increase in reduction capabilities was accompanied by an increase in the peak rebound seen immediately after returning to a normal pricing period, as high as $140 \%$ of the original system peak with $100 \%$ penetration of DR enabled appliances, even when using the built-in rebound mitigation strategies. Rebounds were significantly lower in the lower penetration cases, typically not exceeding more than 2-3\% of the original system peak. However, in all cases the peak was successfully shifted from the critical pricing period to the normal pricing period. If the rebound mitigations strategies were not used, significant rebounds in the peak demand could be seen. Of course, if the system operator is concerned about local demand constraints, then the rebound may be of concern, but if the operator is focused on the effects to the larger system and temporally shifting peak demand from one time period to another, the magnitude of the rebound may not be of concern. 
A comparison of the performance of the DR enabled appliances to DR enabled air conditioning systems was also performed. The air conditioning system provides a greater overall resource due to greater daily energy consumption (on a peak day) than the appliances. But, because of the built-in DR controls, the appliances provide increased demand reduction over the air conditioners alone, and in some cases, the response of the appliances actually outperformed the response of the air conditioning systems. This was due to the appliance controls being specifically designed to work with TOU and TOU plus CPP signals. While the air conditioning resource was exhausted over the four or six hour critical pricing periods, the appliance load reduction was more evenly spread across the critical pricing period. This resulted in an overall reduction in demand within the critical pricing period that was significantly increased with the addition of DR enabled appliances.

Additionally, because of the energy conservation modes (ES-mode) that are available in the GE appliances during high pricing periods, the appliances provide a reduction in overall energy consumption in addition to the peak reduction. This makes the built in controls well suited for TOU or TOU plus CPP rate structures, balancing the long term energy shifting goals of a TOU program with the peak reduction goals of a CPP program. 


\section{References}

[1] “GridLAB-D”. September 2011. [Online]. Available: http://www.gridlabd.org.

[2] K. P. Schneider, J. C. Fuller, and D. P. Chassin, "Multi-State Load Models for Distribution System Analysis," published in IEEE Transaction on Power Systems, May 2011.

[3] K. P. Schneider and C. A. Bonebrake, "Evaluation of Smart Grid Investment Grant Project Technologies: Distribution Automation," PNNL-20546, Pacific Northwest National Laboratory, Richland, WA, 2011.

[4] J. C. Fuller, N. Prakash Kumar, and C. A. Bonebrake, "Evaluation of Smart Grid Investment Grant Project Technologies: Demand Response," PNNL-20772, Pacific Northwest National Laboratory, Richland, WA, 2011.

[5] F. K. Tuffner and C. A. Bonebrake, "Evaluation of Smart Grid Investment Grant Project Technologies: Thermal Energy Storage," PNNL-20584, Pacific Northwest National Laboratory, Richland, WA, 2011.

[6] R. Singh and B. Vyakaranam, "Evaluation of Smart Grid Investment Grant Project Technologies: Distributed Generation," PNNL-20792, Pacific Northwest National Laboratory, Richland, WA, 2011.

[7] K. P. Schneider and J. C. Fuller, "Detailed end-use models for distribution system analysis," in Proc. 2010 IEEE PES General Meeting, pp. 1-7.

[8] K. Schneider, Y. Chen, D. Chassin, R. Pratt, D. Engel, and S. Thompson, "Modern Grid Initiative Distribution Taxonomy Final Report," PNNL-18035, Pacific Northwest National Laboratory, Richland, WA, 2008.

[9] R. G. Pratt, C. C. Conner, E. E. Richman, K. G. Ritland, W. F. Sandusky, and M. E. Taylor, "Description of Electric Energy Use in Single Family Residences in the Pacific Northwest," DOE/BP 13795 21, Bonneville Power Administration, Portland, OR, 1989.

[10] K. P. Schneider, J. C. Fuller, F. K. Tuffner, and R. Singh, "Evaluation of Conservation Voltage Reduction (CVR) on a National Level," PNNL-19596, Pacific Northwest National Laboratory, Richland, WA, 2010.

[11] D. J. Hammerstrom, et al., "Pacific Northwest GridWise Testbed Demonstration Projects, Part I: Olympic Peninsula Project," PNNL-17079, Pacific Northwest National Laboratory, Richland, WA, Oct. 2007.

[12] K. P. Schneider, J. C. Fuller, and D. Chassin, "Analysis of Distribution Level Residential Demand Response," in Proc. of 2011 IEEE PSCE, Mar. 2011.

[13] J. C. Fuller, K. P. Schneider, and D. Chassin, "Analysis of Residential Demand Response and Double-Auction Markets," in Proc. of 2011 IEEE PES General Meeting, July 2011.

[14] Z. T. Taylor, K. Gowri, and S. Katipamula, "GridLAB-D Technical Support Document: Residential End-Use Module Version 1.0," PNNL-17694, Pacific Northwest National Laboratory, Richland, WA, 2008.

[15] GE Global Research, "Water heater model” Apr 5, 2010.

[16] An Information Bulletin from CSA international, October. 2004 
[17] "U.S. Energy Information Administration". September 2011. [Online]. Available: http://www.eia.gov.

[18] (Jan, 2012). We Energies: Critical-Peak Pricing Program. [Online].

Available: http://www.we-energies.com/residential/acctoptions/cpp.htm

[19] (Jan, 2012). Southern California Edison: Large Business - Critical Peak Pricing. [Online]. Available: http://www.sce.com/b-rs/large-business/cpp/critical-peak-pricing.htm

[20] (2010). San Diego Gas and Electric Company, Sempra Energy Utility: Critical Peak Pricing. [Online]. Available: http://sdge.com/sites/default/files/documents/cpp factsheet.pdf.

[21] Brendan Kirby and Eric Hirst. New England Demand Response Initiative: Demand Supply of Contingency Reserves. Oak Ridge National Laboratory Consulting in Electric-Industry Restructuring. [Online]. Available: nedri.raabassociates.org/Articles/Ancillary_Services.ppt

[22] (Mar, 2007). Joseph H. Eto, et al. Demand Response Spinning Reserve Demonstration. Lawrence Berkeley National Laboratory. [Online]. Available: http://certs.lbl.gov/pdf/62761.pdf

[23] (Jan, 2012). PJM: Demand Response Regulation Market. [Online]. Available: http://www.pjm.com/markets-and-operations/demand-response/dr-regulation-market.aspx

[24] (Jul, 2012). Ken Corum. Load Following from Demand Response: Developments in the Pacific NW: National Action Plan on Demand Response Workshop. NW Power and Conservation Council. [Online]. Available:

http://www.demandresponsesmartgrid.org/Resources/Documents/NTM\%20Presentations/K en\%20Corum\%20(NW)\%20-\%20NAP\%20Tech.pdf

[25] R. T. Guttromson, D. P. Chassin, and S. E. Widergren, "Residential Energy Resource Models for Distribution Feeder Simulation," in Proc. of 2003 IEEE PSE GM, Mar. 2003. 


\section{Appendix A: Detailed Procedure for Appliance Model Development}

This appendix has been released as a separate document to protect GE Appliances intellectual property. It includes very detailed procedures for developing the appliance models, and proprietary laboratory testing data. Please contact GE Appliances' representatives to request further documentation. 


\section{Appendix B: Metrics for Simulation Studies}

\section{Daily energy consumption}

This metric will be used to study the change in energy consumption due to the appliances responding to a DR signal. Depending upon the case studied, this may be defined as the energy consumed by the appliances only, or it may be the entire distribution feeder load at the substation. The daily energy value is reported in $\mathrm{kWh}$.

\section{Energy consumption during the High and Critical periods}

This metric is used to study the change in energy consumption due to the appliances responding to a signal during the High and Critical periods. This metric measures the total energy consumed by the appliances, or the entire distribution circuit depending upon the case, when responding to a DR signal. When using only a Critical or High signal, the energy consumption during the Critical or High signal is measured. When both a Critical and High signal are used in conjunction (e.g., during a CPP event overlaying a high TOU signal), the energy consumption is measured as energy during both the High and Critical time periods. Figure B-1 shows an example using a Critical period (within the dotted box), which will be the time frame used for calculating the energy value. Note that only a Critical signal is shown in the Figure B-1. Energy consumption during the High and/or Critical period is reported in kWh.

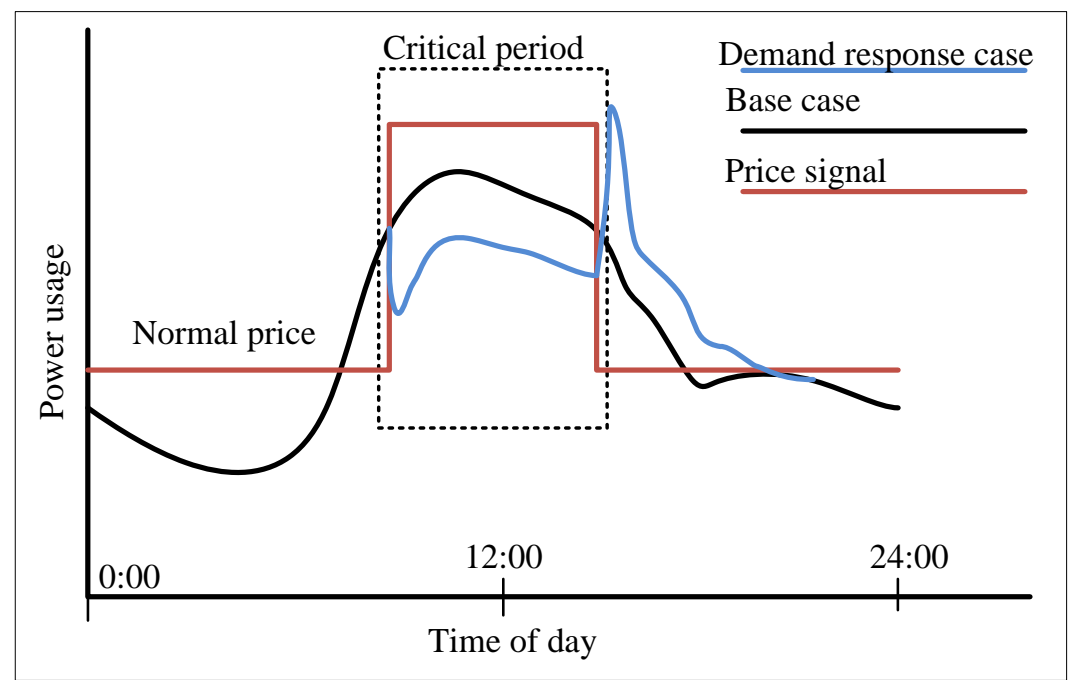

Figure B-1: Calculation of the energy consumption during the Critical period.

Energy consumption after High and Critical periods 
This metric is used to study the change in the energy consumption that may occur after the DR signal period. This increase in aggregate energy consumption can occur due to the appliance delaying processes during a DR signal period, and a later "payback", or due to a larger number of appliances being operated during time periods where appliance is normally lower. This means that the energy consumption was shifted from the High or Critical signal periods to the Normal signal period. For a utility or system operator, this can mean the potential for deferment of buying energy at a high price, and buying it at a lower price instead. The total energy consumption of the appliance, or distribution circuit depending upon the case, is measured for the six hours immediately following the return to a Normal signal, whether the DR signal was High or Critical. A six hour period was chosen as the simulation results indicated that the demand of the appliances during the DR cases typically settled back to the base case values within six hours. Hence, a six hour period was chosen as the "payback" period. Figure B-2 shows an example of the time frame (within the dotted box) that is used for calculating this value. Again, the energy consumption is reported in $\mathrm{kWh}$.

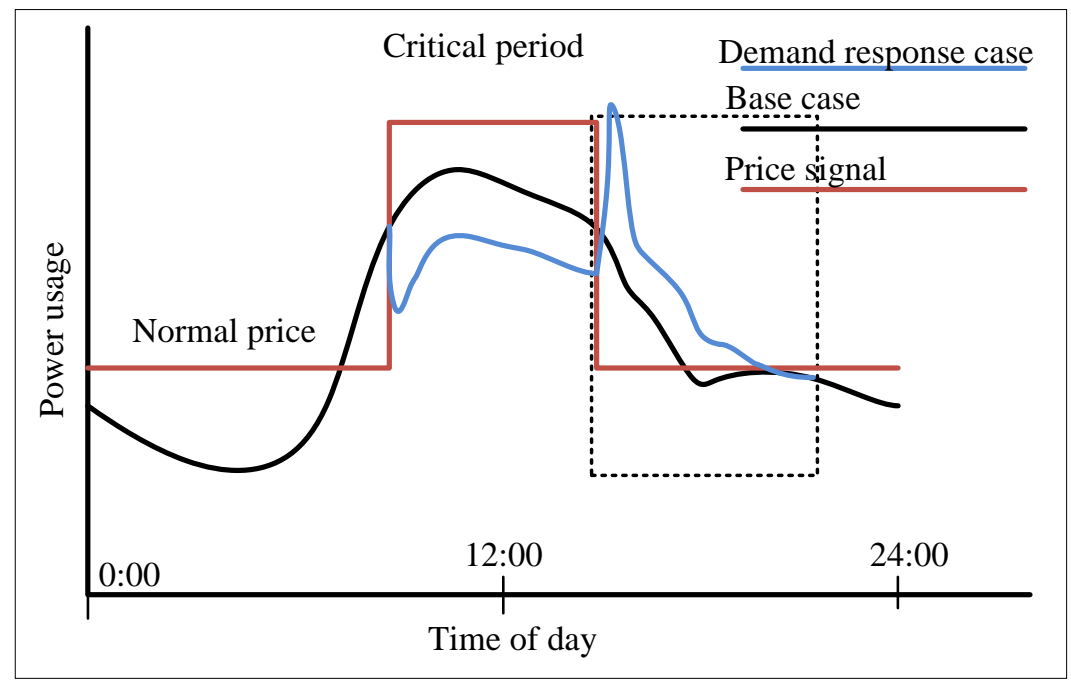

Figure B-2: Calculation of the energy consumption after the High/Critical period.

\section{Peak demand during the DR period}

This metric is used to study the effect that the appliance response to pricing signals have on the peak system load during the DR signal period. There can be many objectives for trying to reduce the system and/or feeder peak load. When the system load exceeds the physical limits of the system, system reliability and life expectancy can be reduced. Hence, one objective of reducing the peak load using DR can help increase the system reliability. Another key reason for reducing peak load is that the cost of energy $(\$ / \mathrm{kWh})$ is highest during system peaks. Thus decreasing peak load can result in a significant reduction in overall system costs at both the 
Independent System Operator or Regional Transmission Organization (ISO or RTO) and the retail level. When this metric is applied to study the reduction in the feeder load during DR signal periods, the purpose is to study the extent to which the feeder load can be reduced during system peak periods. When several feeders are present in a system, a particular feeder peak need not align with the system peak. Figure B-3 shows an example of the time frame (within the dotted box) that is used for calculating this value. The peak values to be determined are represented in the figure by the dotted circles, and may not be correspond to the same time step across various cases, as the peak load may shift in time. The value is reported in $\mathrm{kW}$ and is the maximum load observed during the High and Critical signal time periods.

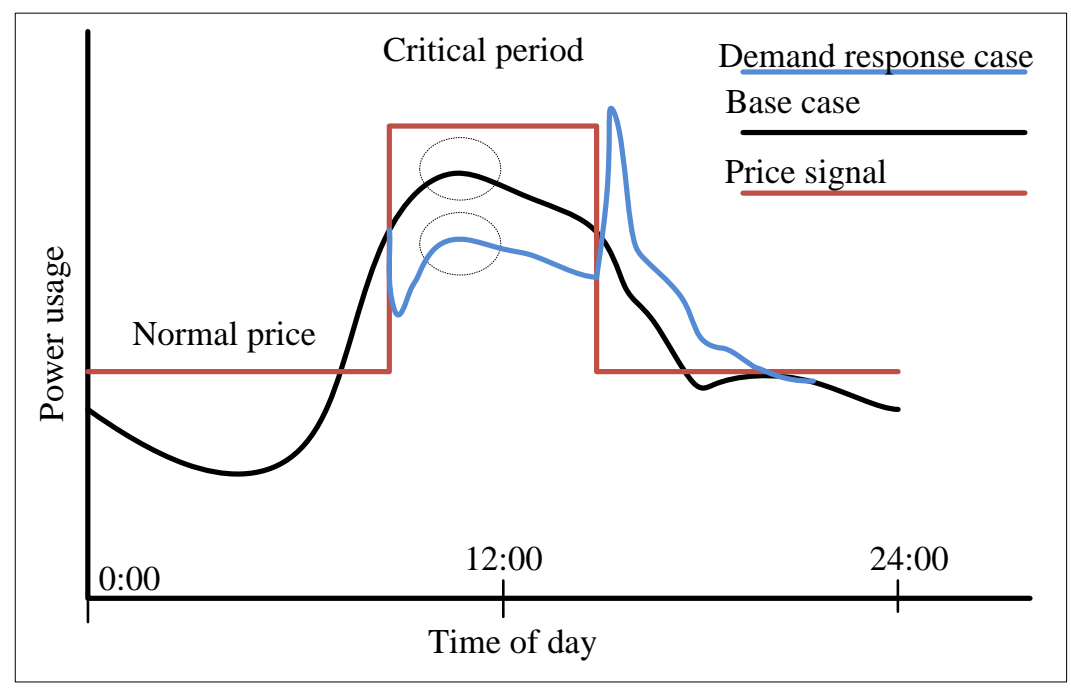

Figure B-3: Calculation of the peak demand during a Critical period.

\section{Peak demand after DR signal period}

One of the possible detriments to adopting certain DR strategies has been the concern that after a DR period, a short term increase in the demand is observed in the system caused by a reduced diversity factor of the system loads. This is often referred to as a "payback" or "rebound". The purpose of this metric is to determine the extent to which the appliance response can cause an increase in demand following a DR signal period. This metric is measured as the greatest load value of the appliances, or of the distribution circuit depending upon the case, during a six hour period following the return to a Normal signal. A six hour period was chosen as the simulation results indicated that the DR case responses settled to the base case values typically within a period of six hours. It should be noted this "rebound" is a function of the control strategy chosen to "release" the appliances from their delay status. If the start-up of the delayed appliances when the normal signal is received is randomized over a given period, the peak of the rebound can be reduced and spread over the subsequent period; however this also 
causes a larger inconvenience to the consumer by delaying the operation of their appliance beyond the critical/high period. Figure B-4 shows an example of the time frame (within the dotted box) that is used for calculating this value. The peak values to be determined are represented in the figure by the dotted circles. The value is reported in $\mathrm{kW}$, and is the maximum load observed after the High or Critical signal periods.

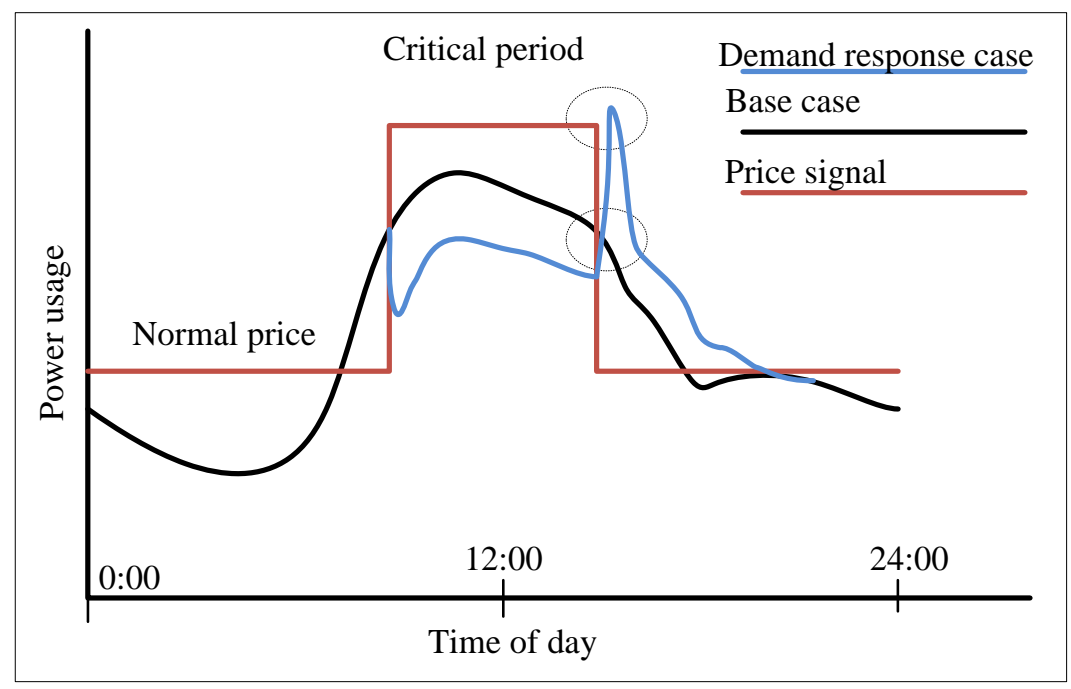

Figure B-4: Calculation of the peak demand after a Critical period.

\section{Daily peak demand}

The purpose of this metric is to study the change in the daily peak power. Peak demand is used to study future capacity building requirements. It is important to size system equipment optimally to account for this peak demand value. Oversized equipment can result in unnecessary capacity cost investment and under-utilization of the equipment. Undersized equipment can result in reduction of system reliability. Utilities use the greatest daily peak demand value to balance their economic and reliability objectives. Figure B-5 shows an example of the time frame (within the dotted box) that is used for calculating this value. The peak values to be determined are represented in the figure by the dotted circles. The value is reported in $\mathrm{kW}$, and is the maximum load observed during the 24-hour period of the simulation. 


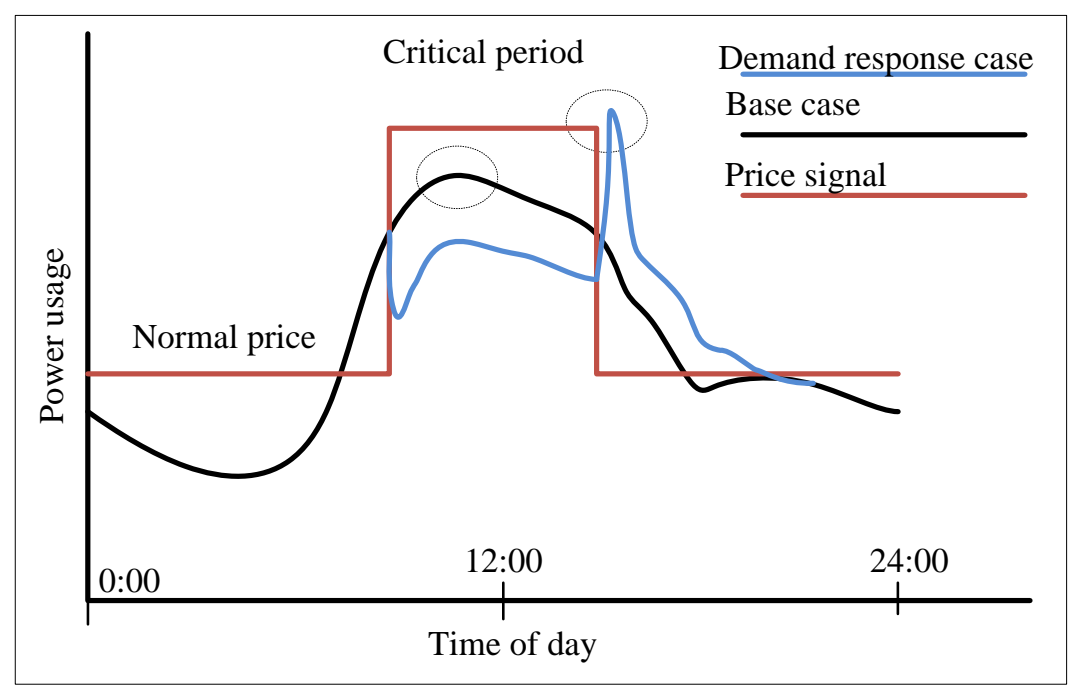

Figure B-5: Calculation of the daily peak demand. 


\section{Appendix C: ZIP and HVAC Load Models}

\section{ZIP Models}

ZIP models are two-state models: energized and de-energized. When energized, there is only a single operational state and the energy consumption can be determined using $(\mathrm{C}-1)$ for real power, (C-2) for reactive power, and (C-3) as a constraint [7].

$$
\begin{aligned}
& P_{i}=\left[\frac{\left|V_{a}^{2}\right|}{\left|V_{n}^{2}\right|} \cdot\left|S_{n}\right| \cdot Z_{\%} \cdot \cos \left(Z_{\theta}\right)+\frac{\left|V_{a}\right|}{\left|V_{n}\right|} \cdot\left|S_{n}\right| \cdot I_{\%} \cdot \cos \left(I_{\theta}\right)+\left|S_{n}\right| \cdot P_{\%} \cdot \cos \left(P_{\theta}\right)\right] \\
& Q_{i}=\left[\frac{\left|V_{a}^{2}\right|}{\left|V_{n}^{2}\right|} \cdot\left|S_{n}\right| \cdot Z_{\%} \cdot \sin \left(Z_{\theta}\right)+\frac{\left|V_{a}\right|}{\left|V_{n}\right|} \cdot\left|S_{n}\right| \cdot I_{\%} \cdot \sin \left(I_{\theta}\right)+\left|S_{n}\right| \cdot P_{\%} \cdot \sin \left(P_{\theta}\right)\right] \\
& 100=Z_{\%}+I_{\%}+P_{\%}
\end{aligned}
$$

$\begin{array}{cl}\text { where: } & \\ P_{i}: & \text { real power consumption of the } \mathrm{i}^{\text {th }} \text { load } \\ Q_{i}: & \text { reactive power consumption of the } \mathrm{i}^{\text {th }} \text { load } \\ V_{a}: & \text { actual terminal voltage } \\ V n: & \text { nominal terminal voltage } \\ S_{n}: & \text { apparent Power consumption at nominal voltage } \\ Z_{\%}: & \text { percent of load that is constant impedance } \\ I_{\%}: & \text { percent of load that is constant current } \\ P_{\%}: & \text { percent of load that is constant power } \\ Z_{\theta}: & \text { phase angle of constant impedance component } \\ I_{\theta}: & \text { phase angle of constant current component } \\ P_{\theta}: & \text { phase angle of constant power component }\end{array}$

In a time-variant load representation, the coefficients of the ZIP model, $V_{\mathrm{n}}, S_{\mathrm{n}}, Z \%, I \%, P \%$, $Z_{\theta}, I_{\theta}$, and $P_{\theta}$, remain constant, but the power consumption, $P_{i}$ and $Q_{i}$, of the $i^{\text {th }}$ load varies with the actual terminal voltage, $V_{a}$. The ZIP model is similar to the polynomial representation used in many commercial software packages. In the polynomial representation of the ZIP load, the constant coefficient is equivalent to $P \%$, the linear coefficient is equivalent to $I \%$, and the quadratic coefficient is equivalent to Z\%. The ZIP model only varies the power consumption as a function of actual terminal voltage, $V_{a}$.

In $(\mathrm{C}-1)$ and $(\mathrm{C}-2)$, there are 6 constants that define the voltage-dependent behavior of the ZIP load: $Z_{\%}, I_{\%}, P_{\%}, Z_{\theta}, I_{\theta}$, and $P_{\theta}$. Because the actual value of the distribution feeder voltage 
continually changes, it is critical to understand how the energy consumption of end use loads will vary. Specifically, what are the six constants that accurately reflect various end use loads? For loads such as a heating element, it is clear that the load is $100 \% \mathrm{Z}$, but for more complicated loads, such as a liquid crystal display (LCD) or compact florescent light (CFL), the proper ratios are not as apparent.

As part of the 2010 DOE report on Conservation Voltage Reduction (CVR), a number of laboratory tests were conducted to determine the six constants for various end use loads [10]. Figure $\mathrm{C}-1$ is an example of the laboratory testing that was conducted on a $13 \mathrm{~W}$ compact florescent light bulb.
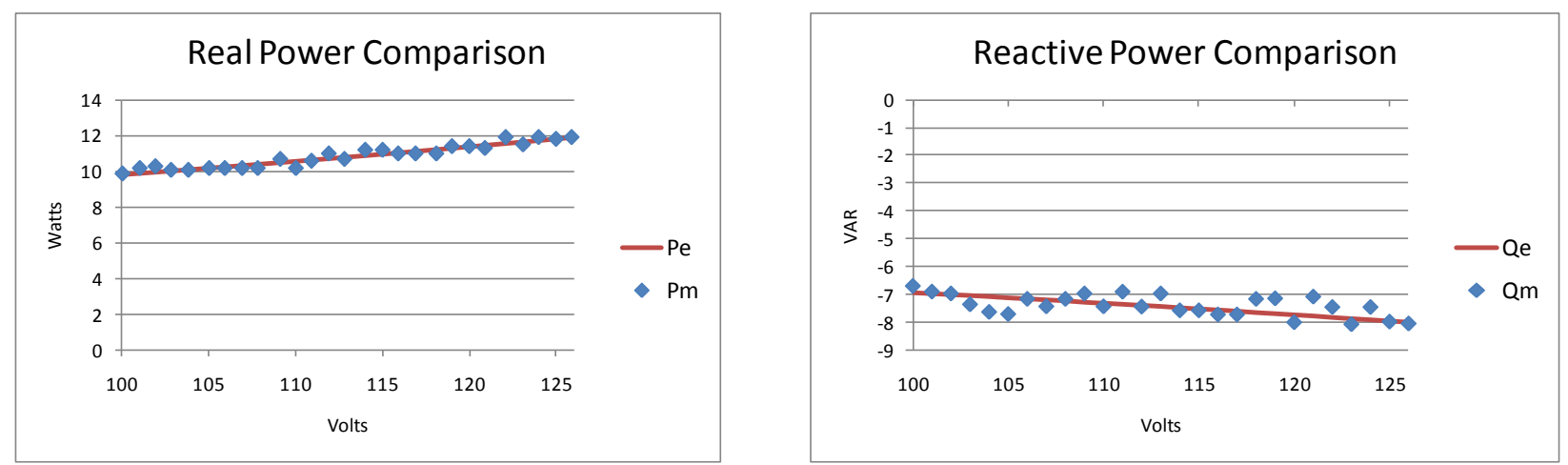

Figure C-1: Voltage-dependent energy consumption of 13W CFL.

In traditional distribution analysis, ZIP models are generally not developed for every individual load; instead models are developed for load classes such as residential, commercial, and industrial. Every load within a given load class then uses the same ZIP values, with the exception of the apparent power consumption at nominal voltage, $S_{n}$. The value of $S_{n}$ for each load may change at 1-hour intervals to generate a daily load profile at the feeder level. The use of similar ZIP values for each load class, which only change at 1-hour intervals, is not able to represent coincidental load peaks that occur at the distribution level, especially due to exogenous signals that may modify the natural behavior of the load.

\section{Heating, Ventilation, and Air Conditioning Model}

When the energy consumption of an end-use load is a function of variables other than terminal voltage, the use of a ZIP model is no longer adequate. This is true of any load with an external control system or an internal control loop. To illustrate this issue, the air conditioning system of a single family residence is examined while in the cooling mode. As with the ZIP model, an air conditioning system is a two-state model (ON or OFF), but only has a single operational state. 
Because a cooling system operates to maintain internal air temperature within a band, parameters such as near term history of operation, time of year, outside air temperature, building construction, and terminal voltage will impact the instantaneous power consumption, as well as the energy consumption. To examine these issues, a physical model of the cooling system and the structure of the building is constructed using an equivalent thermal parameter (ETP) model [2]. Because the ETP model has been shown to be an accurate representation of residential and small commercial building instantaneous power draw, as well as energy consumption, it will be used for the formulation of the physical model.

Figure C-2 is a diagram showing the heat flow for the ETP model of a single family residence, i.e., a house. While the heating/cooling system can be one of any numerous types, for the purposes of this paper, it is assumed that the system is a heat pump in the cooling mode. In addition to the heat removal of the heat pump while cooling and the heat gain through the building exterior, there are two additional significant flows of heat within a house: incident solar radiation and internal gains from waste heat generated by end-use loads. These sources and sinks of heat constitute the total heat energy exchange in the house. This flow of heat is then divided between the air in the house and the mass of the house, i.e., walls and furniture. A portion of the incident solar energy shining through a window will heat the interior air of the house, while the remaining incident energy will be absorbed by the walls, floors, and furniture. A similar division occurs with the waste heat from end-use loads. The internal air temperature of the house is thermally coupled to the internal mass temperature, and the internal air temperature is then thermally coupled to the outside air temperature through the thermal envelope of the house.

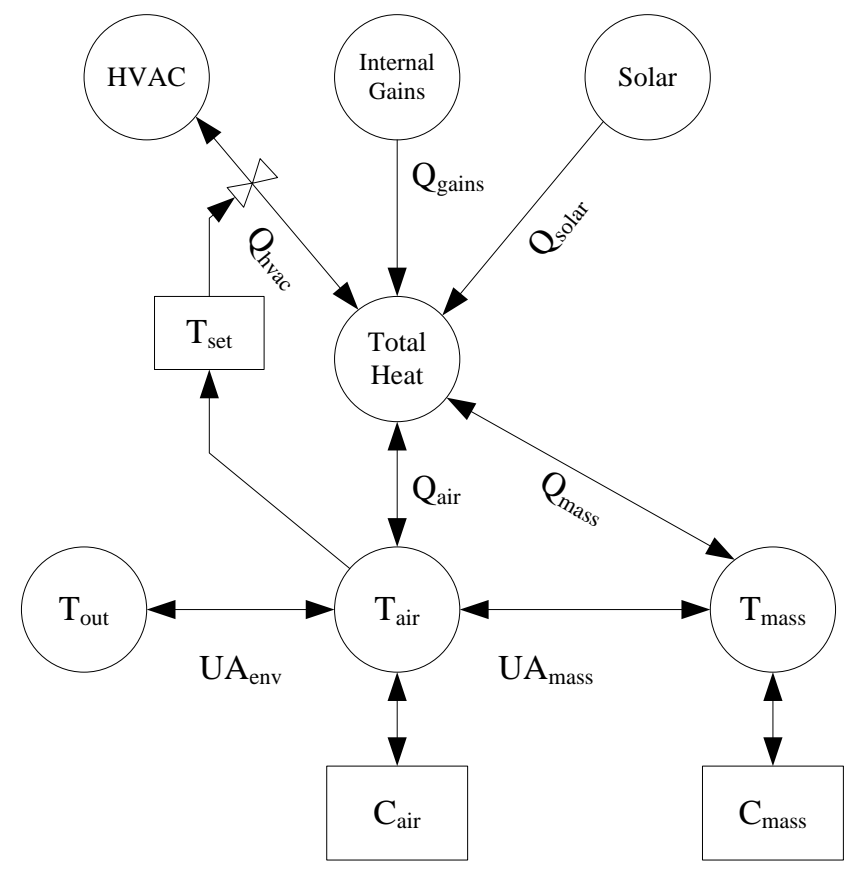

Figure C-2: The ETP mode of a residential heating/cooling system. 
where,

$C_{\text {air }}: \quad$ air heat capacity $\left(\mathrm{Btu} /{ }^{\circ} \mathrm{F}\right)$

$C_{\text {mass }}: \quad$ mass heat capacity $\left(\mathrm{Btu} /{ }^{\circ} \mathrm{F}\right)$

$U A_{\text {env }}: \quad$ external gain $/$ heat loss coefficient $\left(\mathrm{Btu} /{ }^{\circ} \mathrm{F}-\mathrm{h}\right)$

$U A_{\text {mass }}: \quad$ internal gain $/$ heat loss coefficient $\left(\mathrm{Btu} /{ }^{\circ} \mathrm{F}-\mathrm{h}\right)$

$T_{\text {out }}$ : $\quad$ air temperature outside the house $\left({ }^{\circ} \mathrm{F}\right)$

$T_{\text {air }}: \quad$ air temperature inside the house $\left({ }^{\circ} \mathrm{F}\right)$

$T_{\text {mass }}: \quad \quad$ mass temperature inside the house $\left({ }^{\circ} \mathrm{F}\right)$

$T_{\text {set }}: \quad$ temperature setpoints of HVAC system $\left({ }^{\circ} \mathrm{F}\right)$

$Q_{\text {air }}: \quad$ heat rate to house air (Btu/h)

$Q_{\text {gains }}: \quad \quad$ heat rate from appliance waste heat $(\mathrm{Btu} / \mathrm{h})$,

$Q_{\text {hvac }}: \quad$ heat rate from HVAC system (Btu/h),

$Q_{\text {mass }}: \quad$ heat rate to house mass $(\mathrm{Btu} / \mathrm{h})$, and

$Q_{\text {solar }}: \quad$ heat rate from solar gains $(\mathrm{Btu} / \mathrm{h})$.

Equation (C-4) is the second order differential equation that describes the heat flows shown in Figure C-2 [2]. Its solution determines the time-varying temperature of the house, both air and mass, given the thermal inputs. With the inside air temperature, $T_{a i r}$, known, the thermal behavior of the heat pump system in response to the defined thermostatic setpoint, $T_{\text {set }}$, can be determined.

$a \frac{d^{2} T_{a i r}}{d t^{2}}+b \frac{d T_{a i r}}{d t}+c T_{a i r}=d$

where,

$$
\begin{aligned}
& a=\frac{C_{\text {mass }} \cdot C_{\text {air }}}{U A_{\text {mass }}} \\
& b=\frac{C_{\text {mass }} \cdot\left(U A_{\text {env }}+U A_{\text {mass }}\right)}{U A_{\text {mass }}}+C_{\text {air }} \\
& c=U A_{\text {env }} \\
& d=Q_{\text {mass }}+Q_{\text {air }}+\left(U A_{\text {env }} \cdot T_{\text {out }}\right)
\end{aligned}
$$

With the temperature of the house known from (C-4) and the occupant-controlled setpoint fixed, the operation of the cooling system can be determined. Based on these values, the cooling system will operate long enough to remove the heat necessary to maintain the inside air temperature, $T_{\text {air }}$, within the desired range. The electrical input energy to the motor, $S_{\text {comp-motor }}$, necessary to provide the thermal heat energy is a function of two elements: the heat flow through the cooling unit, $Q_{h v a c}$, and the electrical losses of the compressor motor, $S_{\text {losses }}$, as shown in (C5) [2]. 


$$
S_{\text {comp-motor }}=\left[Q_{\text {hvac }}\left(T_{\text {out }}, V_{T}, C O P\right)+S_{\text {losses }}\left(V_{T}\right)\right]
$$

The coefficient of performance (COP) is a scalar value that relates the cooling rate of the heat pump unit to the mechanical power delivered by the compressor as a function of temperature and operation time. A higher value of COP indicates less electrical power is necessary to remove a given amount of heat from the air. $V_{T}$ is the terminal voltage of the system compressor motor. Additionally, it should be noted that $Q_{h v a c}$ is expressed in terms of British thermal units (Btu) consistent with the conventions of the heating/cooling industry in the United States and the derivation of the ETP model of [2], while $S_{\text {losses }}$ is expressed in SI units. As a result, the two terms of (C-5) must be converted using the conversion of $1.0 \mathrm{Btu} / \mathrm{h}=0.2931 \mathrm{~W}$.

Because both of the elements of (C-5) are voltage-dependent, changes in line voltage will cause a change in power consumption. The cooling system's heat removal rate, $Q_{\text {hvac }}$, can be solved using heat transfer equations based on the available mechanical torque of the compressor [2]. When (C-5) is implemented in a time series simulation, the result is a model that determines the energy consumption, both real and reactive, of the cooling system as a function of the outside air temperature, the inside air temperature, equipment parameters, terminal voltage, and occupant-controlled setpoint.

Unlike ZIP models that apply the same values to each load in a given load class, physical models are specific to each individual load. The values of physical models vary on a 1-second or 1-minute basis to capture the true time-variant nature of the end-use load. This physical model has examined a heat pump in the cooling mode, which is one of multiple operational states. Because of the design of heat pumps, their energy consumption varies according to their current operational state. To properly capture the energy consumption it is necessary to construct a multi-state load model.

A multi-state, time-variant load model uses more than one state to describe the energy consumption of an end-use load. Each state is governed either by a ZIP model and/or a physical model, with transitions between states determined by either internal state transition rules or external signals. For example, a typical heat pump has four normal operating states: State 1 (off), State 2 (cooling), State 3 (heating-normal), and State 4 (heating-emergency). State 2 operates as described in the previous section, and State 3 follows a similar description but with different values that represent the change in the heating cycle, i.e., heat is added instead of removed. State 4 operates as State 3, except that the COP is 1.0 and the load is a ZIP model. There are other abnormal states, such as "stalled compressor motor" or "low refrigerant charge", but they will not be examined in this paper. Additionally, there are numerous heat pump types and many differing thermostatic controllers that are commercially available, but this paper will discuss a "typical" design. Because a heat pump has two heat-flow configurations, the value of $T_{\text {set }}$ must be split into a heating setpoint, $T_{\text {low }}$, and a cooling setpoint, $T_{\text {high }}$. These setpoints determine the 
mode of operation of the heat pump system at any given time: off, cooling, heating-normal, or heating-emergency, as shown in Figure C-3.

For a simple single state simulation, the heat pump system would be operating to either heat or cool the house, as discussed in the previous section. For a time series simulation, the multistate model captures the transitions between states. While a heat pump system may not transition through all operational states in a single day, it is likely that it will transition through more than one state in any given day. For example, on a mild autumn night, the heat pump may operate to heat the house, then as the sun heats the house during the day, it may be necessary to switch to cooling.

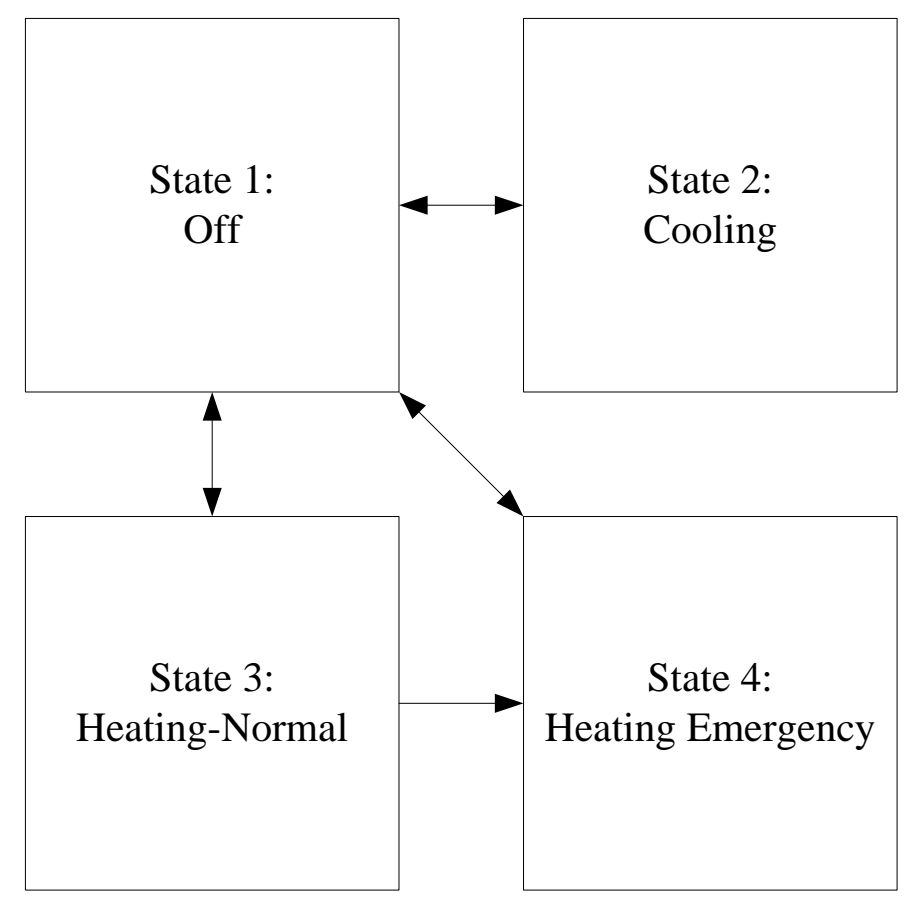

Figure C-3: Multi-state load model.

To be in States 2, 3, or 4, the heat pump unit must be turned "on" with defined setpoints, both occupant-controlled and internal. The occupant-controlled setpoints are $T_{\text {high }}$ and $T_{\text {low }}$. If the internal air temperature $T_{\text {air }}$ rises above $T_{\text {high }}$ plus a dead band, $D B_{h i g h}$, then the heat pump will start cooling. If $T_{\text {air }}$ decreases below $T_{\text {low }}$ minus a dead band, $D B_{\text {low }}$ then the heat pump will start heating normally. If $T_{\text {out }}$ decreases to a temperature, $T_{\text {aux }}$, where the heat pump efficiency becomes too low to effectively heat the home, the system will start heating in the emergency state using resistive heating elements. In addition to the internal control parameters of $T_{\text {aux }}$, the $D B_{\text {low }}$ and $D B_{\text {high }}$ are internal parameters that are not occupant-controlled, but are included to prevent the heat pump from cycling excessively. Table $\mathrm{C}-1$ gives the logic for the allowable state transitions shown in Figure C-3. 
Table C-1: Heat pump state transition logic.

\begin{tabular}{|c|c|c|}
\hline From State & To State & Transition Rule \\
\hline 1 & 2 & $T_{\text {air }}>\left(T_{\text {high }}+D B_{\text {high }}\right)$ \\
\hline 1 & 3 & $T_{\text {air }}<\left(T_{\text {low }}-D B_{\text {low }}\right)$ \\
\hline 1 & 4 & $\begin{array}{c}T_{\text {air }}<\left(T_{\text {low }}-D B_{\text {low }}\right) \text { and } \\
T_{\text {out }}<T_{\text {aux }}\end{array}$ \\
\hline 2 & 1 & $T_{\text {air }}<\left(T_{\text {high }}-D B_{\text {high }}\right)$ \\
\hline 3 & 1 & $T_{\text {air }}>\left(T_{\text {low }}+D B_{\text {low }}\right)$ \\
\hline 3 & 4 & $T_{\text {out }}<T_{\text {aux }}$ \\
\hline 4 & 1 & $T_{\text {air }}>\left(T_{\text {low }}+D B_{\text {low }}\right)$ \\
\hline
\end{tabular}

Each of the four discrete states of operation has a different set of characteristics that determine the instantaneous power consumption. In State 1, there is no power draw because the system is off. In State 2 and State 3, there is an electric fan motor plus a compressor motor. Similar to State 3, State 4 provides heating with an associated electric fan for ventilation but with the difference that heating is provided by resistive heating elements and not a heat pump. The instantaneous power draw of the four states shown in Figure C-3 is given by (C-6)-(C-9).

State 1: Off

$$
S_{H V A C}=0
$$

State 2: Cooling

$$
S_{\text {HVAC }}=S_{\text {fan-motor }}+S_{\text {comp-motor }}
$$

State 3: Heating-Normal

$$
S_{H V A C}=S_{\text {fan-motor }}+S_{\text {comp-motor }}
$$

State 4: Heating-Emergency

$$
S_{H V A C}=S_{\text {fan-motor }}+\frac{V_{T}^{2}}{R_{\text {elements }}}
$$


where,

$S_{\text {fan-motor }}: \quad$ apparent power of ventilation fan motor (VA)

$S_{\text {comp-motor }}: \quad$ apparent power of compressor motor (VA)

$V_{T}$ : terminal voltage of the heat pump unit $(\mathrm{V})$

$R_{\text {elements }}: \quad$ resistance of the heating coil elements $(\Omega)$

While the power consumption for State 2 and State 3, given by (C-7) and (C-8) respectively appear to be the same, there are different internal models for $Q_{h v a c}$, particularly with respect to the COPs. With the instantaneous power draw determined by (C-6)-(C-9), the time necessary to heat or cool the house to within the occupant-controlled setpoints is determined by the solution to $(\mathrm{C}-4)$. The result is that variations in temperature, voltage, and efficiency are translated into a variable duty cycle of the heat pump. This information can then be used to determine the instantaneous power demand and the energy consumption of the heat pump over time. 


\section{Appendix D: Appliance Demand Calibration}

The ELCAP (End-Use Load and Consumer Assessment Program Residential Base Study) documents what are referred to as "load shapes" for different residential end-use appliances ("loads") from multiple years through the late 1980s [9]. These load shapes indicate the usage patterns for different appliances during the course of an average day. The usage patterns are specified by a list of average power levels $(\mathrm{kW})$ by time of day (e.g., hourly) and optionally, by day of a week and/or season of the year. The ELCAP load shapes were derived from intervalmetered, end-use data, where the measured load during each metered time interval is averaged over a year or over a season to estimate the average load during that interval. For example, Figure D-1 shows the ELCAP dryer annual, summer, and winter load shapes. In this case, the average energy consumed during each hour of the day is computed by averaging the metered load during a particular hour annually, or over the winter months, or summer months; and is specified as $\mathrm{kWh}$.

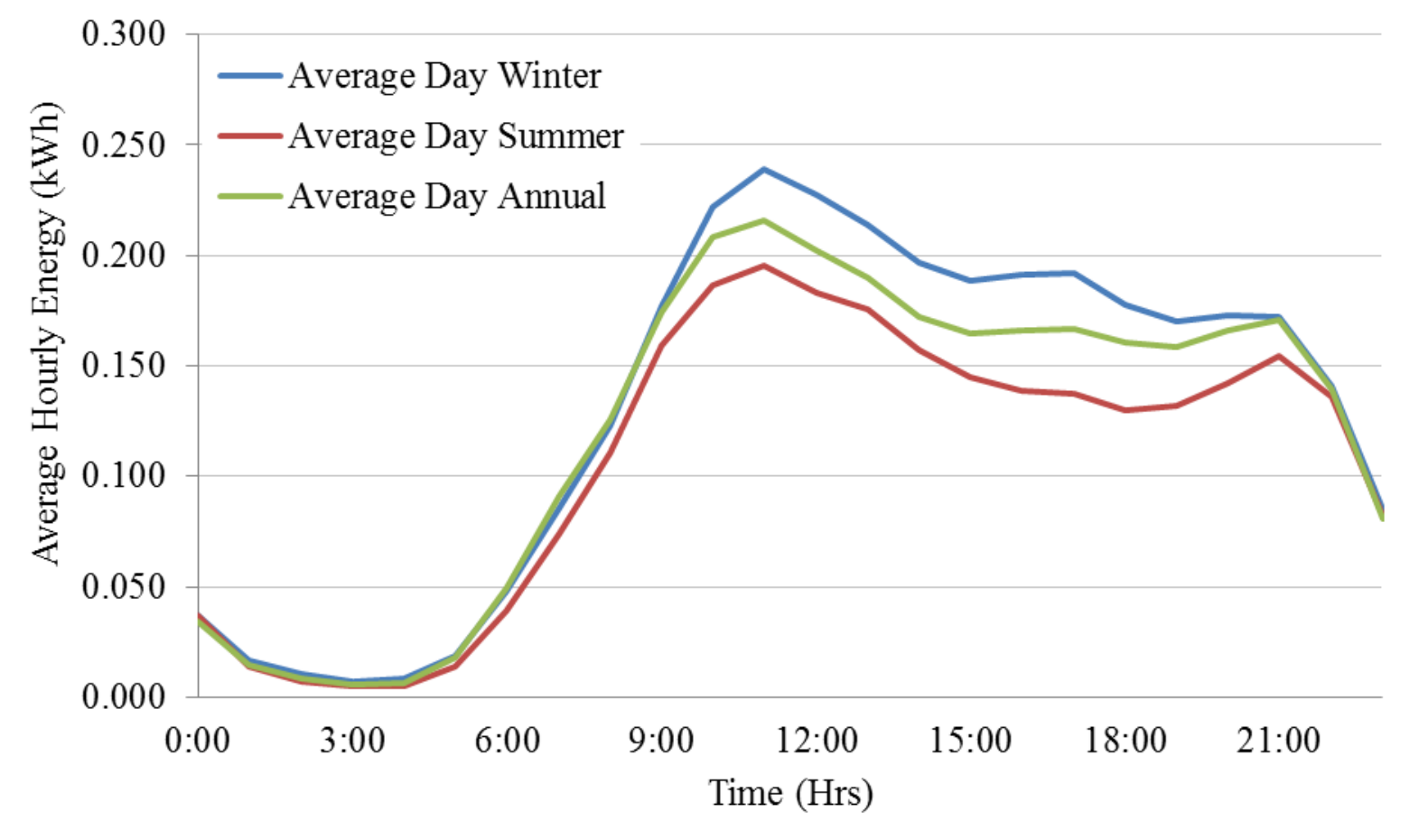

Figure D-1: ELCAP dryer load shape.

For this project, given the absence of any other recent data, the ELCAP load shapes are used to estimate the usage pattern of different appliances at different times during the course of an average day to study the impact of their aggregate behavior on the power grid using the GridLAB-D smart grid simulation software platform. GridLAB-D is an agent based system in which each appliance's response is independent of all the other appliances in a population of appliances. Hence, in order to get a population of appliances to respond as per a given load shape 
collectively, it is required to model the collective or aggregate response of a given number of appliances of a particular type to match the corresponding ELCAP load shape.

It should be emphasized that it is not each individual appliance of a particular brand or model, but rather, the collective response of an arbitrarily large population of such appliances that follow the appliance's ELCAP load shape. An appliance like a dryer for example, uses a defined amount of energy per cycle as determined by its manufacturer rating. The key modeling challenge that arises then is to 'fit' a curve representing the average aggregate load of all the appliances of a particular type, so as to match the appliance's ELCAP load shape.

The approach used in this analysis is to model every appliance such that the model has embedded within it, the knowledge of the collective appliance load shape, so that the model when simulated, can interact with GridLAB-D in a manner such that from a GridLAB-D perspective, the collective load of an arbitrary number of appliances of a particular type as a function of time matches the corresponding appliance's ELCAP load shape. The details of our approach are presented below and are based on the more general approach discussed in [25].

The model presented here is applicable for simulating appliances whose operation is characterized by 'random-pulses' such as clothes washers, clothes dryers, and dishwashers; these will be referred to as pulsed-load appliances. In other words, each cycle of operation involves a certain power draw $(\mathrm{kW})$ from the power grid over the duration from start to finish. Furthermore, the rate of appliance usage or demand, i.e., the average number of cycles per day is stochastic around some average value (to mimic the fact that in real life, demand for the usage of an appliance is driven by appliance user's behavior).

Given an arbitrary number of appliances, $N$, whose operation is characterized by random pulses, let $D_{i}, i=1,2,3, \ldots, N$ denote the demand in cycles per day of appliance $i$. Note that depending on the value of $D_{i}$, a given appliance could turn on more than once or not at all during a given day's simulation of that appliance.

For each appliance $i$, and each simulation time step $k_{T}, k=1,2,3, \ldots$, where $T$ is the simulation sampling interval, the variable queue $i(k)$ can be defined as

$$
\begin{aligned}
& \text { queue }_{i}(k)=\text { queue }_{i}(k-1)+D_{i} *\left(E_{k} / E_{\text {tot }}\right) \\
& \text { queue }_{i}(0)=\text { queue }_{\text {io }}
\end{aligned}
$$

where $E_{k}$ denotes the energy consumed by the appliance over the $k^{\text {th }}$ time step as specified by the ELCAP data (integral of an ELCAP curve such as the one shown in Figure D-1 between $(k-1)_{T}$ and $k_{T}$ ), and $E_{\text {tot }}$ denotes the total energy consumed by the appliance over the course of a day as specified by ELCAP. The ratio $E_{k} / E_{\text {tot }}$ gives a measure of the percentage of daily appliance consumption over the $k^{\text {th }}$ time step, and a plot of $E_{k} / E_{t o t}$ as a function of kT gives the normalized 
ELCAP appliance load shape. The difference equation (D-1) is initialized to a random number $q_{i 0}$ for each $i$ chosen from an exponential distribution with parameter $\lambda$. The rationale for this choice for the $q_{i 0}$ (including the precise value of $\lambda$ ) is presented later.

Note that there is an interesting physical interpretation of queue $i(k)$. Basically, each appliance $i$ is placed in its 'queue' denoted by queue $(k)$, and awaiting its turn to be turned on. And after each simulation time step of duration $T$, queue $_{i}(k)$ is incremented by an amount that is proportional to its daily demand. In other words, each appliance's "queue" is being built up or accumulated. And the rate at which the 'queue' is accumulated depends on the normalized load shape $E_{k} / E_{t o t}$. Thus, a higher value of $E_{k} / E_{t o t}$ would result in a higher rate at which an appliance's "queue" is accumulated, and the following logic is utilized to determine when to turn on a particular appliance

If for some $k=k^{*}$, queue $_{i}\left(k^{*}\right)>\delta$ for some threshold $\delta>0$, appliance $i$ is turned on And once turned on, its 'queue' is re-set as

$$
\text { queиe }_{i}\left(k^{*}+1\right)=\text { queue }_{i}\left(k^{*}\right)-\delta
$$

and accumulated again in accordance with (D-1) to be turned on again at some later time.

Intuitively, it is clear that the probability that a given appliance $i$ is turned on depends on its daily demand $D_{i}$, and the value of the normalized appliance load shape $E_{k} / E_{t o t}$ at any given time $k_{T}$. The higher these quantities are the higher is the probability of the given appliance turning on. Also, as the aggregate number of appliances $N$ goes up, the number of times a given appliance is likely to be turned on is lower.

To complete the model description, a realistic demand $D_{i}$ for each appliance needs to be specified for use in (D-1). If it were possible, the most obvious and straightforward choice for each appliance's daily average demand $D_{i}$ would be the daily average demand for that appliance as estimated by the ELCAP data. But this is not possible for the following reason: the ELCAP data specified as $\mathrm{kWh} / \mathrm{h}$ estimates the average energy consumed by an appliance during each hour of a day, while the daily demand $D_{i}$ in (D-1) is specified as the average number of appliance cycles/day. To circumvent this problem, two constants, $\mu$ and $\sigma$, are chosen to model each $D_{i}$ as

$$
D_{i}=\mu+\sigma * \operatorname{rand}_{i}, i=1,2,3 \ldots
$$

where $\operatorname{rand}_{i}, i=1,2,3, \ldots$, is a random number drawn from a standard normal distribution of zero mean and stand deviation 1. How $\mu$ and $\sigma$ are chosen is explained below, but, as explained earlier, each $D_{i}$ is modeled as a random number around some average value to account for the difference in demand arising from each appliance user's behavior.

The constants $\mu$ and $\sigma$ are determined as follows. In this methodology, this step is referred to as "appliance model calibration", and takes place "off-line", i.e., prior to actually simulating the appliances in GridLAB-D. First, let $E_{E L C A P}$ denote the average energy consumed per day as per 
ELCAP data by an appliance over a certain time period $T_{E L C A P}$. Note that $T_{E L C A P}$ could cover a month, or a season, or a year; long enough to capture day-to-day and weekday-to-weekend variations. For example, for the month of January, the ELCAP data gives a dryer average daily energy consumption of $2.42 \mathrm{kWh}$ /day. Over the time period $T_{E L C A P}$, compute the mean, $\mu^{*}$, and standard deviation, $\sigma^{*}$, of the normalized ELCAP data.

For the given number of appliances (pulsed-loads) $N$, the usage (turning on) of each appliance is simulated based on (D-1) and (D-2) with $\mu=\mu^{*}$ and $\sigma=\sigma^{*}$. Let the simulation time period be denoted by $T_{\text {sim }}$, where $T_{\text {sim }}$ is at least one day, starting at midnight. Typically, in the simulations presented, $T_{\text {sim }}$ was chosen to be at least one week per season to get a large data set, and to cover both weekdays and weekends and both winter and summer. Once turned on, how long each appliance is simulated to run is based on the energy consumed per cycle (e.g., for GE Appliances' driers, the energy per cycle in normal mode of operation is $2.2 \mathrm{kWh}$ ).

At the end of the simulation time period $T_{\text {sim }}$, the net energy consumed by all of the appliances is tabulated. Again, note that some appliances may run more than once, and some may not run at all. Also, it could be the case that towards the end of the time period $T_{\text {sim }}$, some appliances that were turned on, may not have completed their cycle. Finally, the net energy consumed divided by $\left(N * T_{\text {sim }}\right)$ gives the average energy consumed per appliance per day, say $E_{\text {simulated_average. If }}\left|E_{\text {simulated_average }}-E_{E L C A P}\right|<\varepsilon$ for some small tolerance $\varepsilon>0$, then the final values of $\mu$ and $\sigma$ are $\mu^{*}$ and $\sigma^{*}$ respectively and appliance model calibration is complete. If however, $\left|E_{\text {simulated_average }}-E_{E L C A P}\right|<\varepsilon$, then $\mu^{*}$ and $\sigma^{*}$ are incremented or decremented (this is determined through trial and error), and the simulation re-run, until the convergence criterion in is achieved. The final converged values of $\mu^{*}$ and $\sigma^{*}$ are then used in (D-2), and combined with (D-1), the appliances are simulated in GridLAB-D to reproduce the ELCAP load shapes.

It should be noted, however, that the daily or annual energy consumption values denoted by the ELCAP load shapes are 30 years out-of-date. Standards for appliance energy consumption have been driven towards more efficient units. So, where information was available from the EIA database [17], GE Appliances, or other standard sources, $E_{E L C A P}$ was replaced with a more up-to-date value.

Trial and error experience indicates that efficacy of the above algorithm in forcing the aggregate behavior of a large population of 'pulsed-loads' (dryers, clothes washers, and dish washers) to follow a given ELCAP load shape depends crucially on the initial condition $q_{i 0}$ specified in (D-1). Recall that each $q_{i 0}, i=1,2,3, \ldots, N$, is a random number chosen from an exponential distribution with parameter $\lambda$. This was determined through trial and error, and after experimenting with different choices, it was heuristically found that the best choice (in the sense of reproducing an ELCAP load shape through the above algorithm) for each $q_{i 0}$ is a random number chosen from an exponential distribution with parameter $\lambda$. Furthermore, for $N=646 \mathrm{GE}$ dryers, the optimal choice for $\lambda$ turned out to be $\lambda=1.5$. With this choice, it was found that through the above algorithm, $\mu^{*}$ and $\sigma^{*}$ converged to $\mu^{*}=8.5$ and $\sigma^{*}=1.5$ respectively, the average load from 646 GE smart dryers running in normal mode is shown in Figure D-2, which 
closely matches the ELCAP load shape shown in Figure D-1. Notice that the simulated average energy consumption of the dryer for each hour matches the load "shape" from ELCAP, but consumes less energy than that of the ELCAP load shapes. Again, this reflects the fact that standards for appliance have dictated reduced energy consumption since the ELCAP load studies.

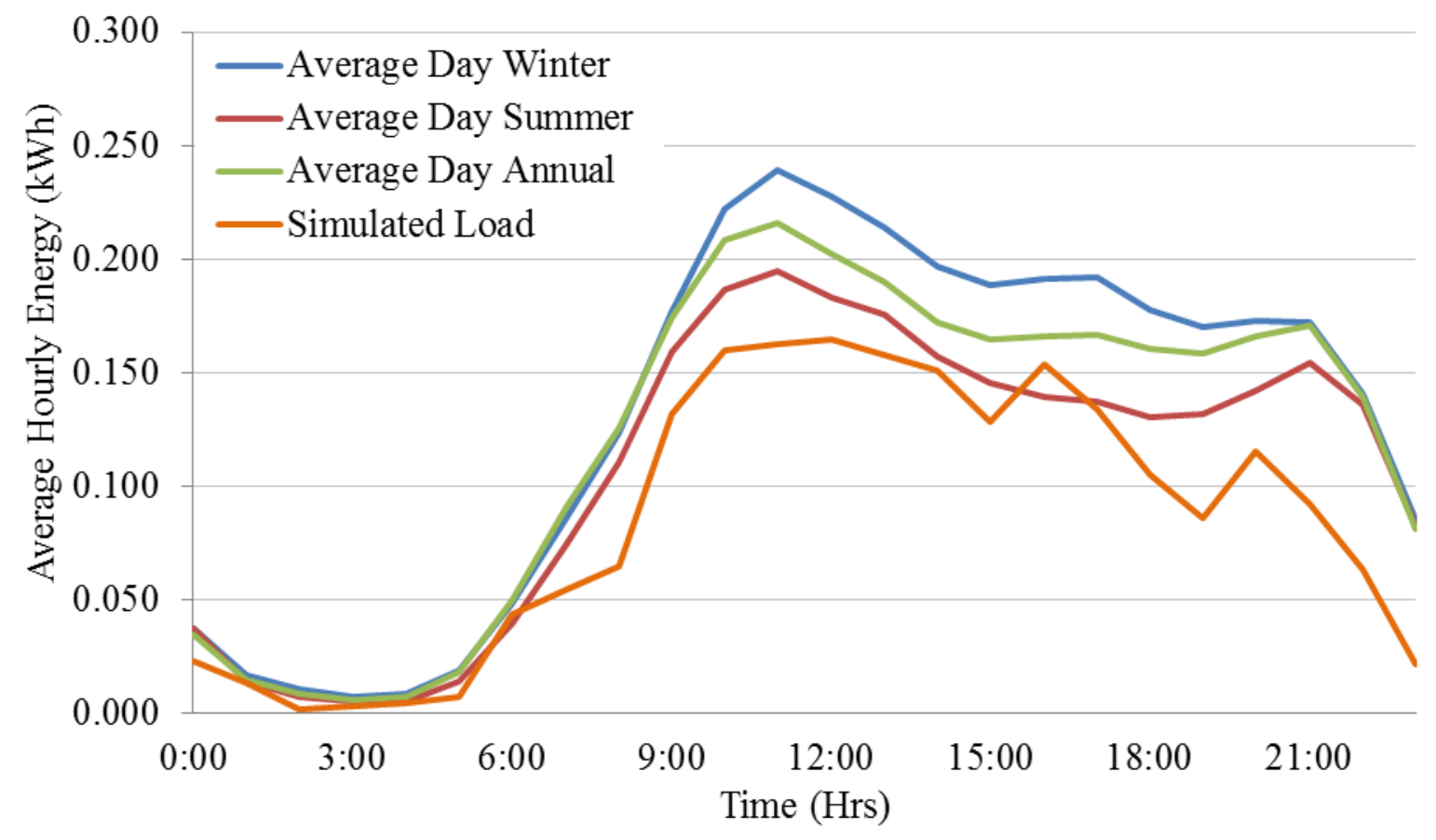

Figure D-2: ELCAP dryer load shape versus simulated load of $646 \mathrm{GE}$ dryers. 
PNNL-21358

\section{Distribution}

No. of

\section{Copies}

1 Dan Ton

U.S. Department of Energy 1000 Independence Avenue, SW

Washington, DC 20585

1 Charles Smith

GE Appliances and Light

Address

City, State and ZIP Code

1 William Burke

GE Appliances and Light

Address

City, State and ZIP Code
No. of

\section{Copies}

8 Local Distribution

Pacific Northwest National Laboratory

GB Parker

K6-05

$\mathrm{CH}$ Imhoff

K9-69

DA King

K2-12

RG Pratt

K1-85

JC Fuller

K1-85

B Vyakaranam

K1-85

N Prakash Kumar

K1-85

SM Leistritz

K6-05 





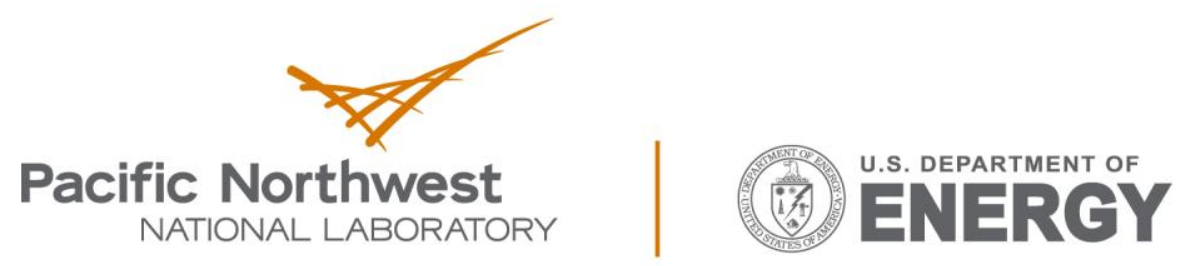

Proudly Operated by Battelle Since 1965

902 Battelle Boulevard

P.O. Box 999

Richland, WA 99352

1-888-375-PNNL (7665)

www.pnnl.gov 